Florida International University

FIU Digital Commons

\title{
A Geochemical Study of Crustal Plutonic Rocks from the Southern Mariana Trench Forearc: Relationship to Volcanic Rocks Erupted during Subduction Initiation
}

Julie A. Johnson

Florida International University, jjohn013@fiu.edu

DOI: $10.25148 /$ etd.FI14040840

Follow this and additional works at: https:// digitalcommons.fiu.edu/etd

Part of the Geochemistry Commons, Geology Commons, Tectonics and Structure Commons, and the Volcanology Commons

\section{Recommended Citation}

Johnson, Julie A., "A Geochemical Study of Crustal Plutonic Rocks from the Southern Mariana Trench Forearc: Relationship to Volcanic Rocks Erupted during Subduction Initiation" (2014). FIU Electronic Theses and Dissertations. 1249.

https://digitalcommons.fiu.edu/etd/1249 


\section{FLORIDA INTERNATIONAL UNIVERSITY \\ Miami, Florida}

\section{A GEOCHEMICAL STUDY OF CRUSTAL PLUTONIC ROCKS FROM THE SOUTHERN MARIANA TRENCH FOREARC: RELATIONSHIP TO VOLCANIC ROCKS ERUPTED DURING SUBDUCTION INITIATION}

A dissertation submitted in partial fulfillment of the requirements for the degree of DOCTOR OF PHILOSOPHY in GEOSCIENCES by

Julie Ann Johnson 
To: Dean Kenneth Furton

College of Arts and Sciences

This dissertation, written by Julie Ann Johnson, and entitled A Geochemical Study of Crustal Plutonic Rocks from the Southern Mariana Trench Forearc: Relationship to Volcanic Rocks Erupted during Subduction Initiation, having been approved in respect to style and intellectual content, is referred to you for judgment.

We have read this dissertation and recommend that it be approved.

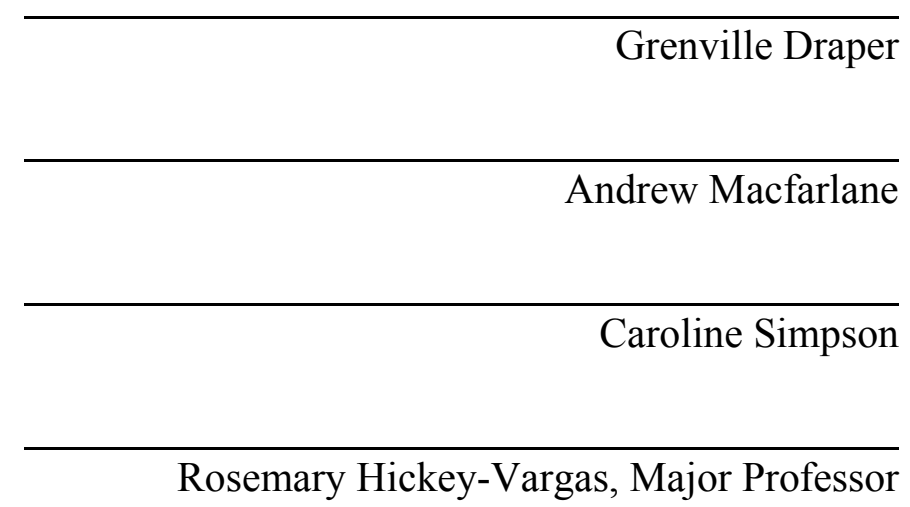

Date of Defense: March 26, 2014

The dissertation of Julie Ann Johnson is approved.

Dean Kenneth Furton College of Arts and Sciences

Dean Lakshmi N. Reddi

University Graduate School

Florida International University, 2014 


\section{DEDICATION}

To my parents, Lori and Tom, and my sisters, Kim and Katie, for all your love and unconditional support. 


\section{ACKNOWLEDGMENTS}

I would like to express my heartfelt thanks to my advisor and mentor, Dr. Rosemary Hickey-Vargas, who guided, motivated, and inspired me all these years; my committee members for their revisions, suggestions and tolerance of my penchant for waiting until the eleventh hour; the NSF grant that funded most of the data analyses and three semesters of an assistantship and tuition; Dr. Patty Fryer for graciously hosting me at her house in Hawai'i while she assisted me in choosing the samples for this study from hundreds of five gallon buckets, and her invaluable advice and knowledge during this project; travel grants from the Ocean Leadership to Bremen, Germany for the INVEST workshop and from the Graduate Professional Student Committee to conferences; NSF/JAMSTEC for the opportunity to participate in the R/V YK08-08 research cruise to the southern Mariana forearc; Tom Beasley for his assistance in analyses on the SEM and EPMA in FCAEM; Diane Pirie for being the go-to person for keeping the lab spaces running smoothly and always helping me get essential lab materials; Cary Machado, Gail Excel and Sabrina Delgado for guiding me through the labyrinth of university bureaucracy; Dr. Vincent Salters and Afi Sachi-Kocher for their assistance and use of the facilities at the National High Magnetic Field Laboratory in Tallahassee, FL.

I am grateful for the assistance of the undergraduates who assisted in sample processing and/or modal analyses: Adriana Sofia, Tara Verdia, Daniel Gonzalez and Lilian Garcia; my classmates and my labmates for their help and brainstorming in our classes and in our trace element and isotopic analyses. I want to thank Kevin Chau, Bret Stodolka, Sven Holbik, and Dr. Adriana Potra for their insights and years of support and encouragement. 


\author{
ABSTRACT OF THE DISSERTATION \\ A GEOCHEMICAL STUDY OF CRUSTAL PLUTONIC ROCKS FROM THE \\ SOUTHERN MARIANA TRENCH FOREARC: RELATIONSHIP TO VOLCANIC \\ ROCKS ERUPTED DURING SUBDUCTION INITIATION \\ by
}

Julie Ann Johnson

Florida International University, 2014

Miami, Florida

Professor Rosemary Hickey-Vargas, Major Professor

Two suites of intermediate-felsic plutonic rocks were recovered by dredges RD63 and RD64 (R/V KK81-06-26) from the northern wall of the Mariana trench near Guam, which is located in the southern part of the Izu-Bonin-Mariana (IBM) island arc system. The locations of the dredges are significant as the area contains volcanic rocks (forearc basalts and boninites) that have been pivotal in explaining processes that occur when one lithospheric plate initially begins to subduct beneath another. The plutonic rocks have been classified based on petrologic and geochemical analyses, which provides insight to their origin and evolution in context of the surrounding Mariana trench.

Based on whole rock geochemistry, these rocks $\left(\mathrm{SiO}_{2}: 49-78 \mathrm{wt} \%\right)$ have island arc trace element signatures $(\mathrm{Ba}, \mathrm{Sr}, \mathrm{Rb}$ enrichment, $\mathrm{Nb}$-Ta negative anomalies, $\mathrm{U} / \mathrm{Th}$ enrichment), consistent with the adjacent IBM volcanics. Depletion of rare earth elements (REEs) relative to primitive mantle and excess $\mathrm{Zr}$ and $\mathrm{Hf}$ compared to the middle REEs indicate that the source of the plutonic rocks is similar to boninites and transitional boninites. Early IBM volcanic rocks define isotopic fields $(\mathrm{Sr}, \mathrm{Pb}, \mathrm{Nd}$ and 
Hf-isotopes) that represent different aspects of the subduction process (e.g., sediment influence, mantle provenance). The southern Mariana plutonic rocks overlap these fields, but show a clear distinction between RD63 and RD64. Modeling of the REEs, Zr and Hf shows that the plutonic suites formed via melting of boninite crust or by crystallization from a boninite-like magma rather than other sources that are found in the IBM system.

The data presented support the hypothesis that the plutonic rocks from RD63 and RD64 are products of subduction initiation and are likely pieces of middle crust in the forearc exposed at the surface by faulting and serpentine mudvolcanoes. Their existence shows that intermediate-felsic crust may form very early in the history of an intra-oceanic island arc system. Plutonic rocks with similar formation histories may exist in obducted suprasubduction zone ophiolites and would be evidence that felsic-intermediate forearc plutonics are eventually accreted to the continents. 


\section{TABLE OF CONTENTS}

CHAPTER

PAGE

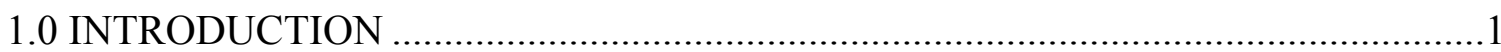

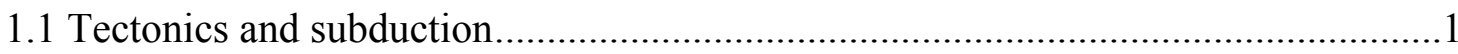

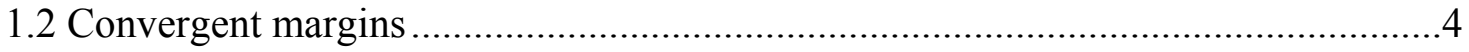

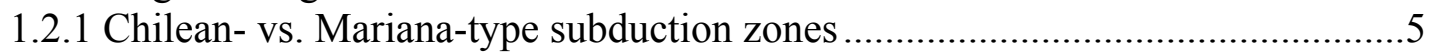

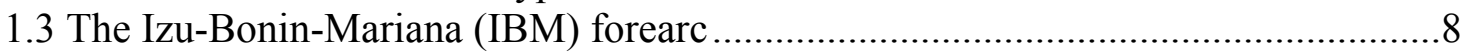

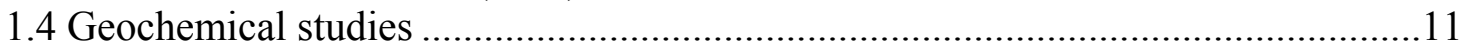

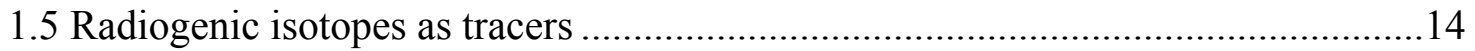

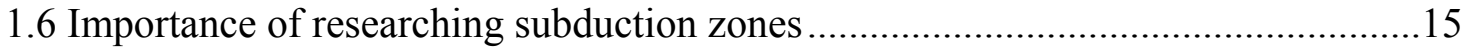

1.7 Outline of dissertation objectives and summary ...................................................16

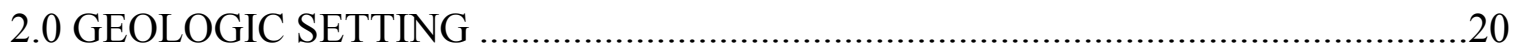

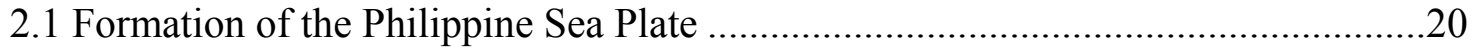

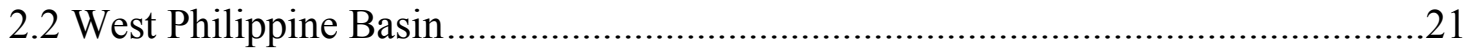

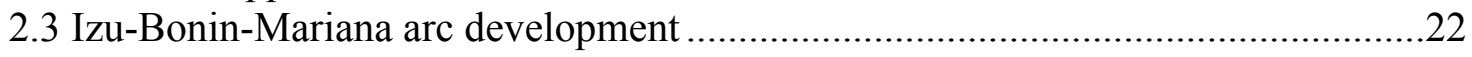

2.3.1 The forearc (protoarc) ……………......................................................22

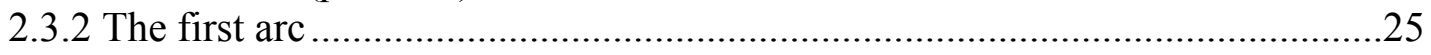

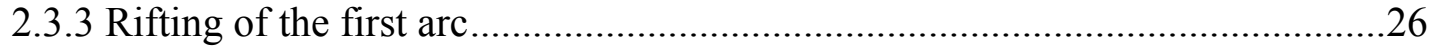

2.3.4 West Mariana Ridge and Mariana Trough......................................................26

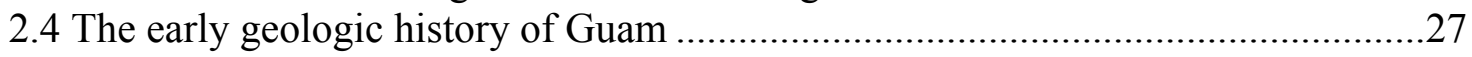

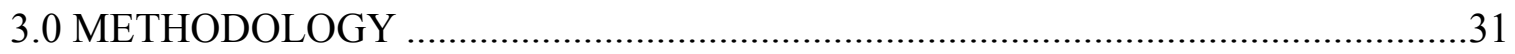

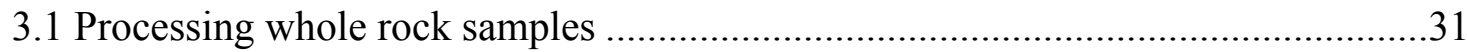

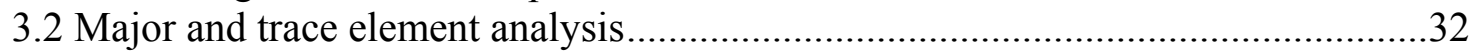

3.2.1 Select trace element analysis at FIU .............................................................33

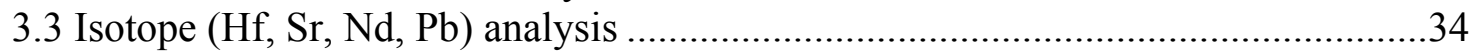

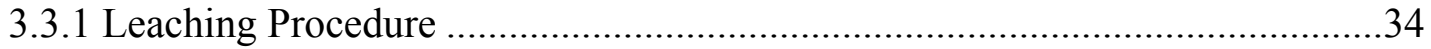

3.3.2 National High Magnetic Field Laboratory: clean lab procedures.......................35

3.3.2.1 Dissolution and $\mathrm{Pb}, \mathrm{Nd}, \mathrm{Hf}, \mathrm{Sr}$ column separation ......................................35

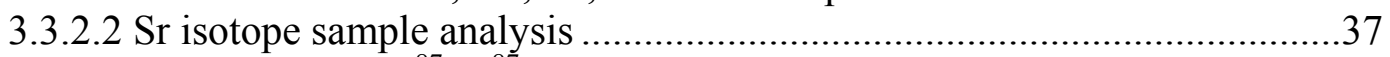

3.3.2.3 Measurement of ${ }^{87} \mathrm{Sr} /{ }^{87} \mathrm{Rb}$ in samples before analysis...............................37

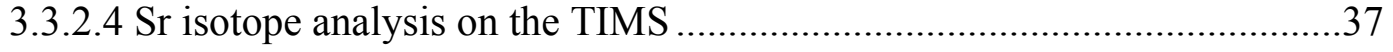

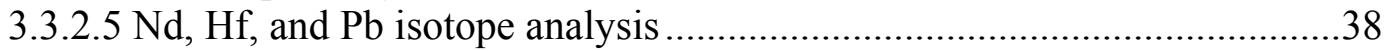

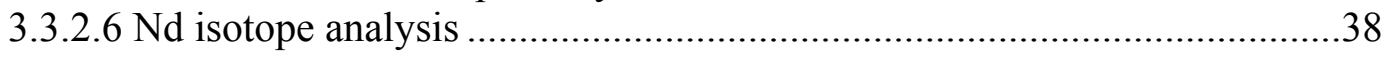

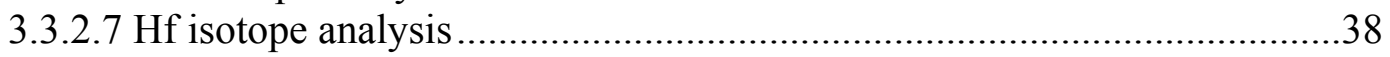

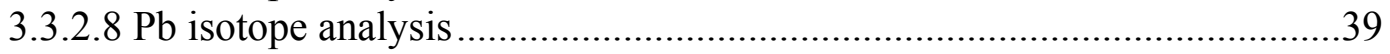

4.0 ANALYSES AND CHARACTERIZATION OF DREDGE RD63 AND RD64 .......40

4.1 Results of geochemical analyses and petrography ..................................................40

4.1.1 Normative, modal and textural petrologic review of RD63 and RD64

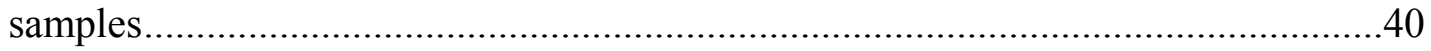

4.1.2 Mineral chemistry of RD63 and RD64 ........................................................44 


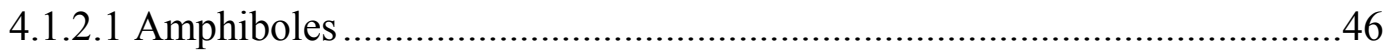

4.1.2.1.1 Interpretation of amphiboles in the (RD63-J07) gabbro ......................46

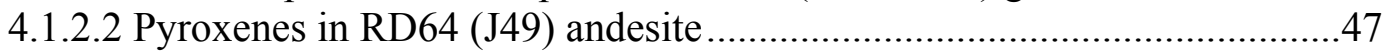

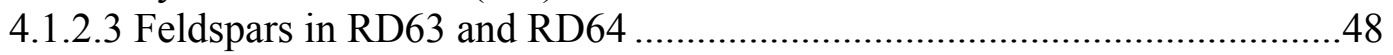

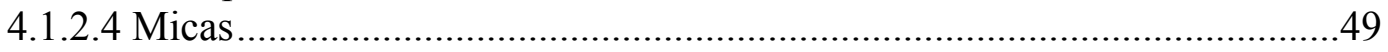

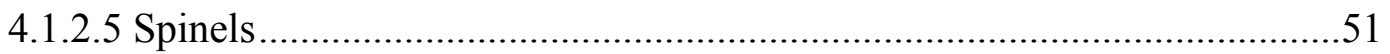

4.1.2.6 Mineralogic and petrologic summary ………......................................52

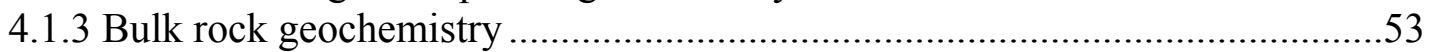

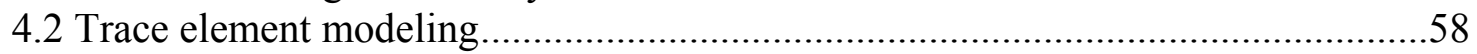

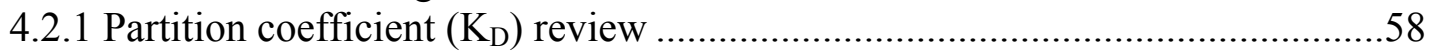

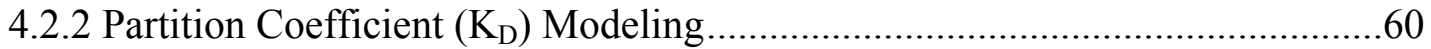

4.2.2.1 Equilibrium melting and crystallization................................................62

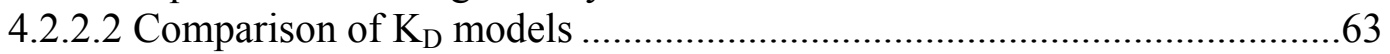

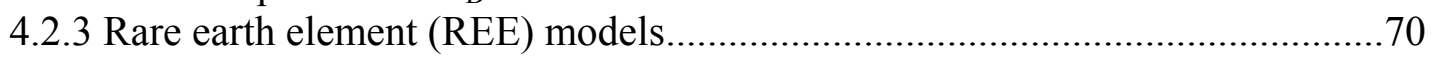

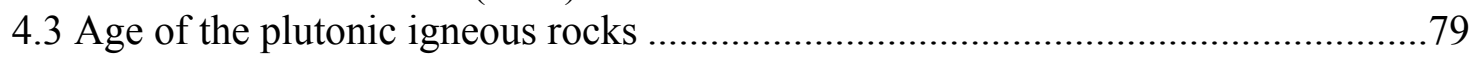

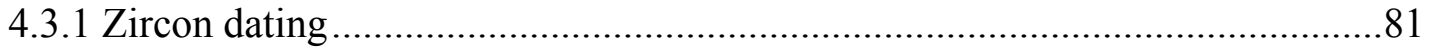

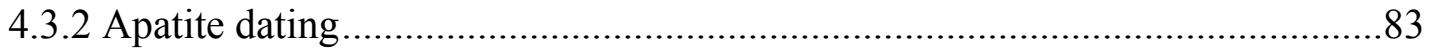

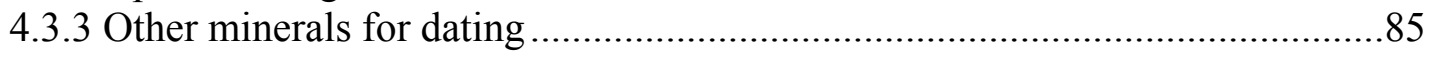

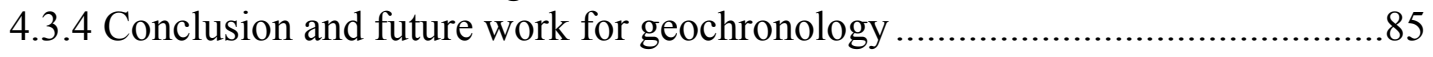

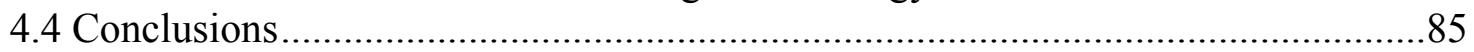

5.0 GEOCHEMICAL AND ISOTOPIC STUDY OF A PLUTONIC SUITE AND RELATED EARLY VOLCANIC SEQUENCES IN THE SOUTHERN MARIANA

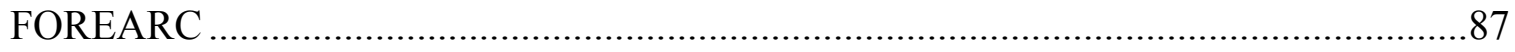

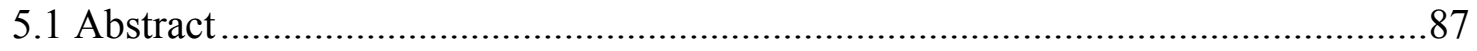

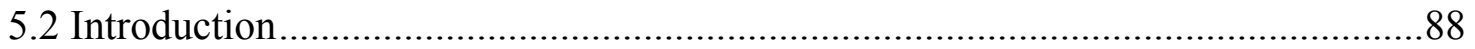

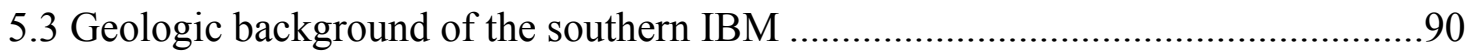

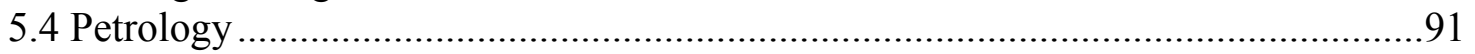

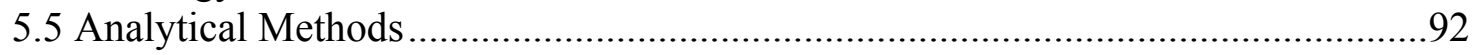

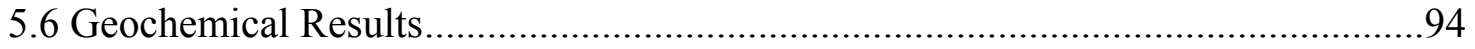

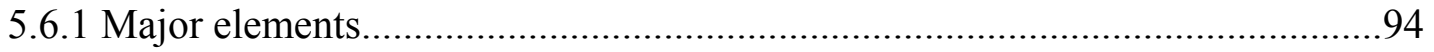

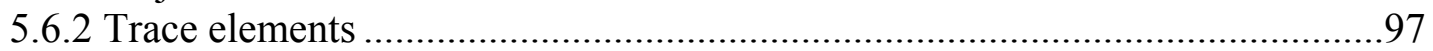

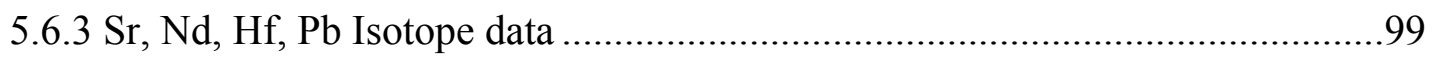

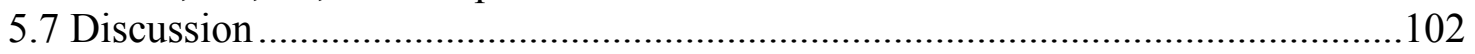

5.7.1 Origin of dredged suites and relationship to volcanic suites ..........................102

5.7.2 Boninite differentiation to form the plutonic suites........................................105

5.7.3 Comparison with other IBM-related plutonic suites and the mid-crustal

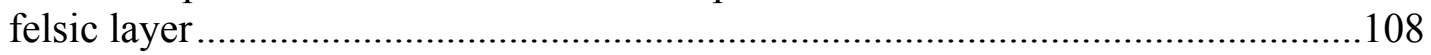

5.7.4 Geologic and petrogenetic synthesis........................................................111

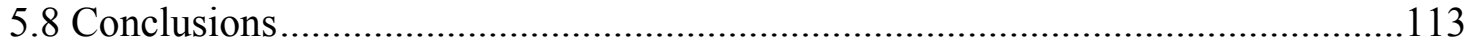

6.0 SUPRA-SUBDUCTION ZONE (SSZ) OPHIOLITES AND THE MARIANA FOREARC: PLUTONIC SECTIONS IN THE CONTEXT OF SUBDUCTION

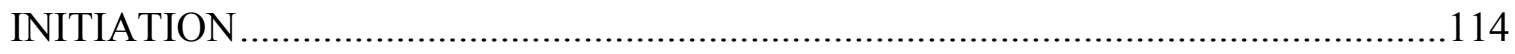

6.1 Introduction to supra-subduction zone ophiolites...............................................114 


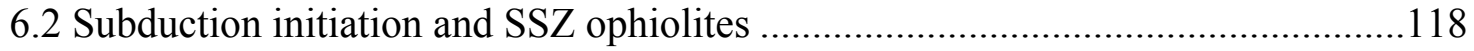

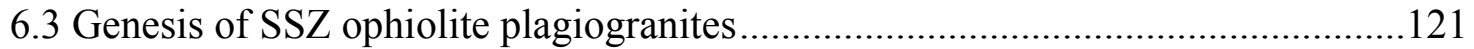

6.4 Geochemical and petrologic comparisons of IBM forearc and ophiolites ............122

6.5 Analogies between plutonic rocks in SSZ ophiolites and the RD63 Mariana

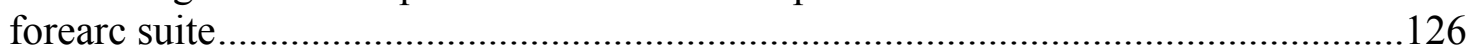

6.6 Relationship between SSZ ophiolites, the RD63 suite and felsic to intermediate composition of continental crust .................................................... 130

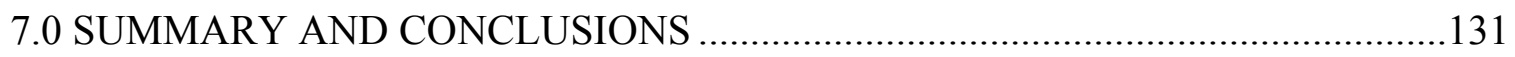

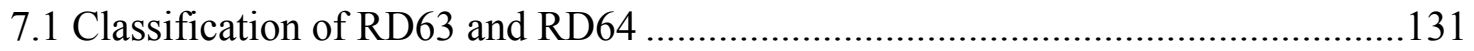

7.2 Origin and evolution of dredge suites RD63 and RD64 ...................................132

7.2.1 Summary of plutonic origin and evolution conclusions ..............................134

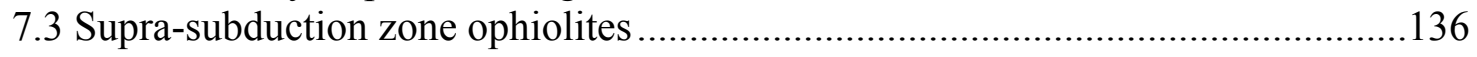

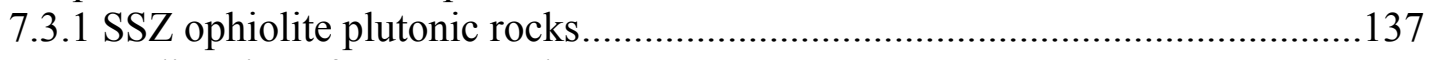

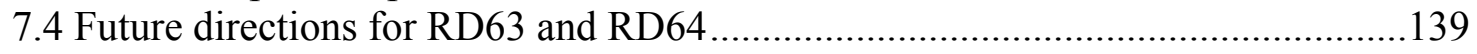

LIST OF REFERENCES.................................................. 141

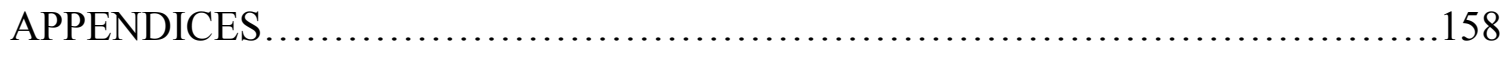

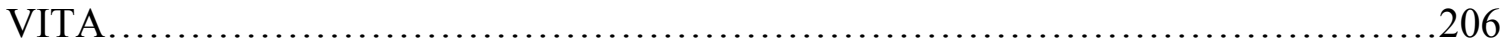




\section{LIST OF TABLES}

TABLE

PAGE

Table 1 . Modal analysis by point counting

Table 2. Mineral partition coefficients $\left(\mathrm{K}_{\mathrm{D}} \mathrm{s}\right)$ used for calculating bulk D in hypothetical minerals assemblages in an equilibrium system with basaltic melts (except apatite and sphene)

Table 3. REE and HFSE concentrations ( $\mathrm{ppm}$ ) used for calculating bulk partition coefficients in equilibrium melting and equilibrium crystallization. Significant digits are consistent with reported values in each reference. MORB (N-MORB average) [Hofmann, 1988]; FAB (1092-20) [Reagan et al., 2010]; IAT (GUM 8094) [Reagan et al., 2008]; Boninite: (Chichijima 32108) [Reagan et al., 2010]; Transitional Boninite (458-32-2) [Reagan et al., 2010]; Tonalite: This study (RD63J43).

Table 4. Calculated bulk partition coefficients for partial melts and fractional crystallization by liquid fraction (F) and source-tonalite systems [B-T (boninitetonalite), I-T (IAT-tonalite), F-T (FAB- tonalite), M-T (MORB- tonalite)]. This table lists select values shown in Figure 4.9 for quantitative comparison between partial melting and fractional crystallization.

Table 5. Values of calculated bulk partition coefficients for three different hypothetical residual mineral assemblages that are expected to be produced due to equilibrium melting/crystallization.

Table 6. $\mathrm{K}_{\mathrm{D}} \mathrm{s}$ from calculations of batch melting and fractional crystallization (for $\mathrm{F}=0.3$ ) that are shown graphically in Figure 4.9. Values are presented here for comparison to the bulk Ds calculated above (Table 5) for various mineral assemblages..... 


\section{LIST OF FIGURES}

FIGURE

PAGE

Figure 1.1. Location map of the Izu-Bonin-Mariana (IBM) arc system. Inset showing locations of RD63 and RD64 collected by dredge during the 1981 cruise R/V Kana Keoki (KK) 81-06-26 by University of Hawai'i.

Figure 1.2. Interacting lithospheric plates without the formation of an accretionary complex at the trench (Mariana-type subduction). The subduction zone is shown in more detail than the spreading ridge (mid-ocean ridge) and transform fault. Diagram shows how terms used in the introduction relate to plate interactions. 4

Figure 1.3. Chilean- and Mariana-type subduction zones (from Stern [2002]). The shaded orange area represents an example of the width of the plate-coupled zone. In comparison, the strongly coupled Chilean-type subduction zone has a wider plate-coupled zone than the weakly coupled Mariana-type. Back-arc spreading also occurs in the Mariana-type subduction zone, due to the extensional regime in the overriding plate.

Figure 1.4. The variety of plate configurations that have been considered for subduction initiation, from Stern [2004b]. One main difference between induced and spontaneous subduction initiation is that in the induced model, a subduction regime exists prior to the new subduction, while in the spontaneous model, there is no prior subduction activity until a segment of lithosphere begins to sink.

Figure 2.1. Early configurations of the Pacific Plate, West Philippine Basin and early IBM volcanism (slightly modified from Hall et al. [1995]). Their model is based on the hypothesis that the WPB formed as a backarc basin that was rotating 50-40Ma during subduction initiation. Rotation began again at 25Ma to its current configuration. The shaded red area is approximately the location of southern Mariana forearc rocks. The diagonal shaded areas represent lithospheric plate that likely existed during this time but has been subducted since then.

Figure 2.2. IBM formation history (modified after Stern et al. [2003]). Note the Pacific slab sinking at subduction initiation (A) causing asthenospheric upwelling and forearc volcanism.

Figure 2.3. Geologic map and stratigraphic columns for southern Guam (altered from Siegrist and Reagan [2008])

Figure 4.1. IUGS classification and nomenclature of plutonic rocks in RD63 and RD64. Quartz-alkali feldspar-plagioclase (QAP) diagram for plutonic rocks. Fine grained rocks from RD64 (Group 1) are not included on diagram because they are volcanic or hypabyssal rocks. Fields are based on Streckeisen [1974]. 
Figure 4.2. Classification of amphiboles from Leake et al. [1997]. Diagram parameters: $\mathrm{Ca}_{\mathrm{B}} \geq 1.50 ;(\mathrm{Na}+\mathrm{K})_{\mathrm{A}}<0.50 ; \mathrm{Ca}_{\mathrm{A}}<0.5$

Figure 4.3. Pyroxene ternary showing EPMA data from sample RD64-J49 .48

Figure 4.4. Feldspar ternary diagram showing EPMA data for four samples described above.

Figure 4.5. An content (\%) of plagioclase grains plotted according to $\mathrm{SiO}_{2}(\mathrm{wt} \%)$. Points show difference in composition between core and rim measurements, except for the andesite in which the grains were finer and had no discernible compositional variation. Data were collected by EPMA.

Figure 4.6. TAS diagram (total alkali versus silica), classification and nomenclature for volcanic rocks. RD63 (blue diamonds) and RD64 (red squares) plotted.

Figure 4.7. Trace element patterns (spidergrams) for RD63 and RD64 samples grouped by lithology. RD63-J15 could be included in Group 5 because $(\mathrm{Ta} / \mathrm{La})_{\mathrm{N}}<1$ but because the analysis of Ta is sometimes not as accurate as $\mathrm{La}$, the positive $\mathrm{Eu}$ anomaly of J15 groups it with Group 6 that also have other positive Eu anomalies

Figure 4.8. Comparison of $K_{D}$ values in REEs and HFSEs of igneous minerals for melt compositions: (A) Basalt: cpx and amphibole [Hart and Dunn, 1993], lo-Ca pyx [McKenzie and O'Nions, 1991], opx [Green et al., 2000], apatite [Paster et al., 1974]. (B) Andesite: lo-Ca pyx, cpx, amphibole [Bacon and Druitt, 1988], apatite [Fujimaki, 1986]. (C) Dacite: lo-Ca pyx [Nagasawa and Schnetzler, 1971], amphibole [Sisson, 1994], apatite [Fujimaki, 1986]. (D) Rhyolite: cpx [Bacon and Druitt, 1988], lo-Ca pyx [Sisson, 1991], amphibole min and max [Sisson, 1994].

Figure 4.9. Calculated bulk partition coefficients vs. F (\% liquid). Select trace elements were plotted for each of the sources used in the calculations. Elements that plot above unity preferentially partition into the residual solid; elements that preferentially get taken into the bulk liquid during melting will have D values less than one.

Figure 4.10. RD63 - REE behavior during four different equilibrium melting/crystallization scenarios: FAB, MORB, IAT, and boninite sources listed in Table 3. Mineral abbreviations: ol (olivine), fsp (plagioclase feldspar), opx (orthopyroxene), cpx (clinopyroxene), amph (amphibole), magn (magnetite).

Figure 4.11. RD63 - REE behavior during four different fractional crystallization scenarios: FAB, MORB, IAT, and boninite sources listed in Table 3. Mineral abbreviations: ol (olivine), fsp (plagioclase feldspar), opx (orthopyroxene), cpx (clinopyroxene), amph (amphibole), magn (magnetite). 
Figure 4.12. RD64 - REE behavior during four different fractional crystallization scenarios: FAB, MORB, IAT, and boninite sources listed in Table 3. Mineral abbreviations: ol (olivine), fsp (plagioclase feldspar), opx (orthopyroxene), cpx (clinopyroxene), amph (amphibole), magn (magnetite).

Figure 4.13. RD64 - REE behavior during four different equilibrium melting/crystallization scenarios: FAB, MORB, IAT, and boninite sources listed in Table 3. Mineral abbreviations: ol (olivine), fsp (plagioclase feldspar), opx (orthopyroxene), cpx (clinopyroxene), amph (amphibole), magn (magnetite).

Figure 4.14. RD64 - REE behavior during fractional crystallization and equilibrium melting of transitional boninite (Table 3 ) .78

Figure 4.15. Example of a second step of equilibrium melting where the initial composition is a RD63 diorite $\left(\mathrm{C}_{\mathrm{i}}^{\mathrm{o}}\right)$. Each graph shows the results if different mineral assemblages were melted (i.e., changing bulk D varies the outcome of the models): a) amphibolite (100\% hornblende), b) typical assemblage of a diorite, c) same assemblage as (b) but with a trace amount of sphene $(0.5 \%)$, d) similar assemblage as (b) but with 5\% modal apatite. Mineral abbreviations: hb (hornblende), plag (plagioclase feldspar), opx (orthopyroxene), cpx (clinopyroxene), amph (amphibole), sph (sphene).

Figure 4.16. Examples of hypothetical melting of an intermediate FAB differentiate as a comparison to the melting of a boninite differentiate (Figure 4.10). Source composition is the result of fractional crystallization of $\mathrm{FAB}$ to $\mathrm{F}=0.40$ (see Figure 4.11). Mineral abbreviations: plag (plagioclase feldspar), opx (orthopyroxene), cpx (clinopyroxene), amph (amphibole), magn (magnetite).

Figure 5.1. Major element data plotted vs. $\mathrm{SiO}_{2} \mathrm{wt} \%$. Data points are rocks from RD63 and RD64 (red triangles and squares, this work), FABs (orange circles: Reagan et al. [2010]) and boninite differentiates (blue and yellow square symbols) such as andesites, dacites and rhyolites from Chichijima [Kuroda et al., 1988; Taylor et al., 1994] and bronzite andesites from DSDP Site 458 and 786 [Pearce et al., 1999]. The blue field is boninites from Guam, the southern Mariana forearc and Chichijima (Bon) [Hickey-Vargas and Reagan, 1987; Pearce et al., 1999; Reagan et al., 2010; Taylor et al., 1994]. The red field is gabbro through tonalite from the Tanzawa Plutonic Complex (TPC) in Honshu, Japan [Kawate and Arima, 1998]. The orange field is gabbro through tonalite from the Komahashi-Daini Seamount (KDS) in the northern Kyushu-Palau Ridge [Haraguchi et al., 2003]. The green field is for non-boninite related rhyolites from Saipan [Reagan et al., 2008] and from Quaternary northern IBM volcanic centers [Tamura et al., 2009] (Non-bon diff' $\mathrm{t}$ ). $\mathrm{FeO}_{\mathrm{T}}$ is total $\mathrm{Fe}$. The orthopyroxene (OPX) data is from boninites analyzed by Bloomer and Hawkins [1987] and the arrows are an approximate fractionation trajectory. 
Figure 5.2. Primitive mantle normalized rare earth elements (REE) and other trace elements. In the RD63 diagram, the red lines represent gabbro, diorite, quartz diorite and tonalite from RD63. The gabbro and tonalite have lowest REE abundances and positive $\mathrm{Eu}$ anomalies, whereas diorite and quartz diorite have higher REE abundances and either negative or no Eu anomaly. In the RD64 diagram, the red lines represent a gabbro, quartz diorite, diorite and tonalite. The orange line represents a bronzite andesite from RD64 as a comparison to a bronzite andesite from Site 458 (458 24-1wr) [Reagan et al., 2010] which is a purple line on both diagrams. Shaded fields in both diagrams are FABs (green), boninites (blue), differentiated boninites (darker blue in RD63). FABs are from DSDP Site 458 and 459 and Mariana forearc submersible dive sites [Reagan et al., 2010] and a representative FAB (1097-3) is shown by a dashed black line.. Boninites are from Chichijima, Guam, DSDP Site 458 and ODP Site 786, and dredges and dives from the southern Mariana forearc [Hickey-Vargas and Reagan, 1987; Pearce et al., 1999; Reagan et al., 2010; Taylor et al., 1994]. Boninite differentiates (andesites, dacites, rhyolites) are from Chichijima [Taylor et al., 1994]. Elements with an asterisk $(*)$ indicate that they were not reported or analyzed and therefore are an average of the adjacent elements. The boninite differentiates from Chichijima in Taylor et al. [1994] did not include Th or Nb values and were omitted in the darker blue field. REEs were normalized based on the primitive mantle value of Sun and McDonough [1989].

Figure 5.3. Variation of $\mathrm{Zr} / \mathrm{Sm}$ ratios in $\mathrm{RD} 63$ and $\mathrm{RD} 64$ plutonic suites compared with other volcanic and plutonic suites from the early IBM, and the relationship of $\mathrm{Zr} / \mathrm{Sm}$ to Sm abundances. FABs (forearc basalts) are from Reagan et al. [2010]; Saipan rhyolites are from Reagan et al. [2008]; boninites are from Chichijima [Taylor et al., 1994] and the southern Mariana forearc [Reagan et al., 2010]. The black dashed line represents the $\mathrm{Zr} / \mathrm{Sm}$ composition of primitive mantle reported by Sun and McDonough [1989]. Abbreviations of lithologies are as follows: ton $=$ tonalite; $\mathrm{q}$ dior $=$ quartz diorite; dior $=$ diorite.

Figure 5.4. Trace elements (REEs and HFSEs) ppm vs. $\mathrm{SiO}_{2}$ (wt\%). REE: La, Sm, $\mathrm{Nd}, \mathrm{Yb}$ and HFSE: $\mathrm{Zr}, \mathrm{Hf}, \mathrm{Nb}$ and $\mathrm{Th}$ plotted versus $\mathrm{SiO}_{2}$ to compare how the trace elements behave as differentiation occurs in intermediate and felsic rocks. Rocks from RD63 and RD64 (this study) are compared with Quaternary dacites and rhyolites from the northern IBM [Tamura et al., 2009], Saipan rhyolites [Reagan et al., 2008]; and plutonic rocks from the Komahashi-Daini Seamount tonalites [Haraguchi et al., 2003]. The dashed line through the data represents a rough boundary between the RD63 and RD64 and other intermediate and felsic rocks.

Figure 5.5. Initial isotopic compositions of rocks from RD63 and RD64 compared with other igneous rocks from the southern Mariana arc. An age of $50 \mathrm{Ma}$ was assumed for the RD63 and RD64 dredge samples, similar to that of the dated boninite volcanic rocks. The other rocks on the plots were corrected using their ages inferred from radiometric dating. Data sources for these plots are the same as 
previous figures. The MORB field in (a) was compiled from the literature.

Sediment compositions for the Pacific Plate in the vicinity of the IBM arc are represented by average volcaniclastic sediments (V) and clay (CL) from Pearce et al. [1999] and Elliott et al. [1997]. NHRL in b) and d) is the Northern Hemisphere Reference Line from Hart [1984], and the Indian-Pacific boundary in c) is from Pearce et al. [1999].

Figure 5.6. Quantitative trace element modeling of various sources (boninite and FAB: Reagan et al. [2010] and diorite: this study) showing the resultant REE, Zr, and $\mathrm{Hf}$ abundances compared with intermediate and felsic plutonic samples from RD63. The REE signature is inherited from boninite during melting and crystallization, a signature unlike FAB. The high $\mathrm{Zr}-\mathrm{Hf}$ anomaly found in high silica tonalites can be achieved by either crystallization or partial melting, including amphibole and trace sphene. Partition coefficients used in the model are from the GERM website (EarthRef.org).

Figure 6.1. Typical oceanic seafloor ophiolite sequence. Lherzolite (fertile mantle), Harzburgite (depleted mantle). SSZ ophiolite sequences are similar to mid-ocean ridge (MOR)-type ophiolites, and all layers may not be present (or in this order) after obduction. In the case of MOR ophiolites, the gabbro and plagiogranite layers may be a result of melting and differentiation at the ridge, but in SSZ they may either be part of the subduction initiation sequence or form later after true subduction begins.

Figure 6.2. Generalized schematic cross section of the opening and closing of the Tethys Sea, in the context of the initiation of subduction and the formation and obduction of a non-specific forearc/boninite crust (shaded red). Drawn based on widely accepted literature regarding the timeline of the breakup of Pangaea. Note: The opening of the north Atlantic ocean in the early Cenozoic rifted Laurasia, forming Laurentia (not shown) and Eurasia (the latter is depicted the last panel).

Figure 6.3. Major element diagrams showing trends of SSZ ophiolite plutonics with fields of Tethyan ophiolite lavas (Evros [Bonev and Stampfli, 2009], Troodos [Dilek and Furnes, 2009; Flower and Levine, 1987], Pindos [Saccani and Photiades, 2004], Semail (Oman) [Alabaster et al., 1982; Ishikawa et al., 2002; Rollinson, 2009], Kizildag [Dilek and Thy, 2009]), Karmoy ophiolite (Norway) [Pedersen and Hertogen, 1990] and the Papuan ultramafic belt (PUB) [Jaques and Chappell, 1980]. RD63 plutonics are from southern Mariana forearc (this study).....

Figure 6.4. Multielement plot of data from Kizildag ophiolite [Dilek and Thy, 2009; Dilek and Furnes, 2009]. Values for Pr are an average of Ce and Nd. Zr was measured by XRF and in some cases, Hf was not provided so it was estimated from $\mathrm{Zr}$ concentrations. The blue field is gabbroic samples, both isotropic and dikes. The light red field is basaltic pillows and dikes. 
Figure 6.5. Multielement plot of Semail (Oman) ophiolite plutonic rocks [Alabaster et al., 1982; Rollinson, 2009]. Green and blue fields are from Rajmi, red field represents rocks from J Fayyad (fields include tonalite, trondhjemites, diorites and gabbros). The remaining samples plotted are from Hamaliya, Wadi Salahai, the Mahad complex and a locality referred to as the Alley. The boninite data is from Lippard et al [1986] and was interpreted by Dilek and Furnes [2009] (trace elements measured by ICP-MS, except Zr which was measured by XRF).

Figure 6.6. Evros ophiolite, Greece. Bonev and Stampfli [2008; 2009] concluded the plagiogranites have tholeiite affinities and the gabbros have some boninite affinity. Red dotted lines are tonalites from the Mariana forearc RD63 (J40 and J45), and the dotted black line is a boninite from the Mariana forearc (974-R6; Reagan et al [2010])

Figure 7.1. Volcanism at subduction initiation leading to FABs, boninites and boninite-like plutonic rocks. The melts formed during 48-40Ma, eventually cooled and solidified forming gabbro cumulates, diorites, quartz diorites and tonalites. Some areas of these melts maintain enough heat to remelt or differentiate further and produce tonalites with granophyric textures and $\mathrm{SiO}_{2}>78 \mathrm{wt} \%$. 


\subsection{INTRODUCTION}

This dissertation focuses on the magma and plutonic rocks that originated during the initiation of subduction between the Pacific and Philippine Sea lithospheric plates at about $50 \mathrm{Ma}$. It explores the relationship of the plutonic rocks to volcanic sequences that formed in adjacent areas, using petrologic and geochemical techniques. The plutonic rocks studied are from two dredges (RD63 and RD64) in the southern Mariana forearc in the Philippine Sea plate, adjacent to the Pacific plate as shown in a location map in Figure 1.1. The dredges were recovered from the seafloor surface by the 1981 cruise of the University of Hawai'i R/V Kana Keoki at a depth of 8150-7420 meters (RD63) and at 7390-7195 meters (RD64). Dredge RD63 was taken from a serpentine mud volcano and RD64 was taken $74 \mathrm{~km}$ to the southwest from a fault scarp. The bulk of the volume of both dredge hauls consisted of serpentinized peridotitic rock, mainly harzburgite. About $10 \%$ of the dredge hauls consisted of the plutonic samples used in this study, ranging from mafic to felsic in both RD63 and RD64, in addition to some hypabyssal rocks of intermediate composition at RD64.

\subsection{Tectonics and subduction}

The earth's outermost layer, the lithosphere, is 50-200 km thick, composed of rigid rocks and is broken into different pieces, called lithospheric plates. The lithosphere is underlain by the asthenosphere which has variable thickness, but may extend hundreds of kilometers into the Earth. The asthenosphere is more ductile and structurally weaker than the lithosphere and these properties allow the lithospheric plates to move with 


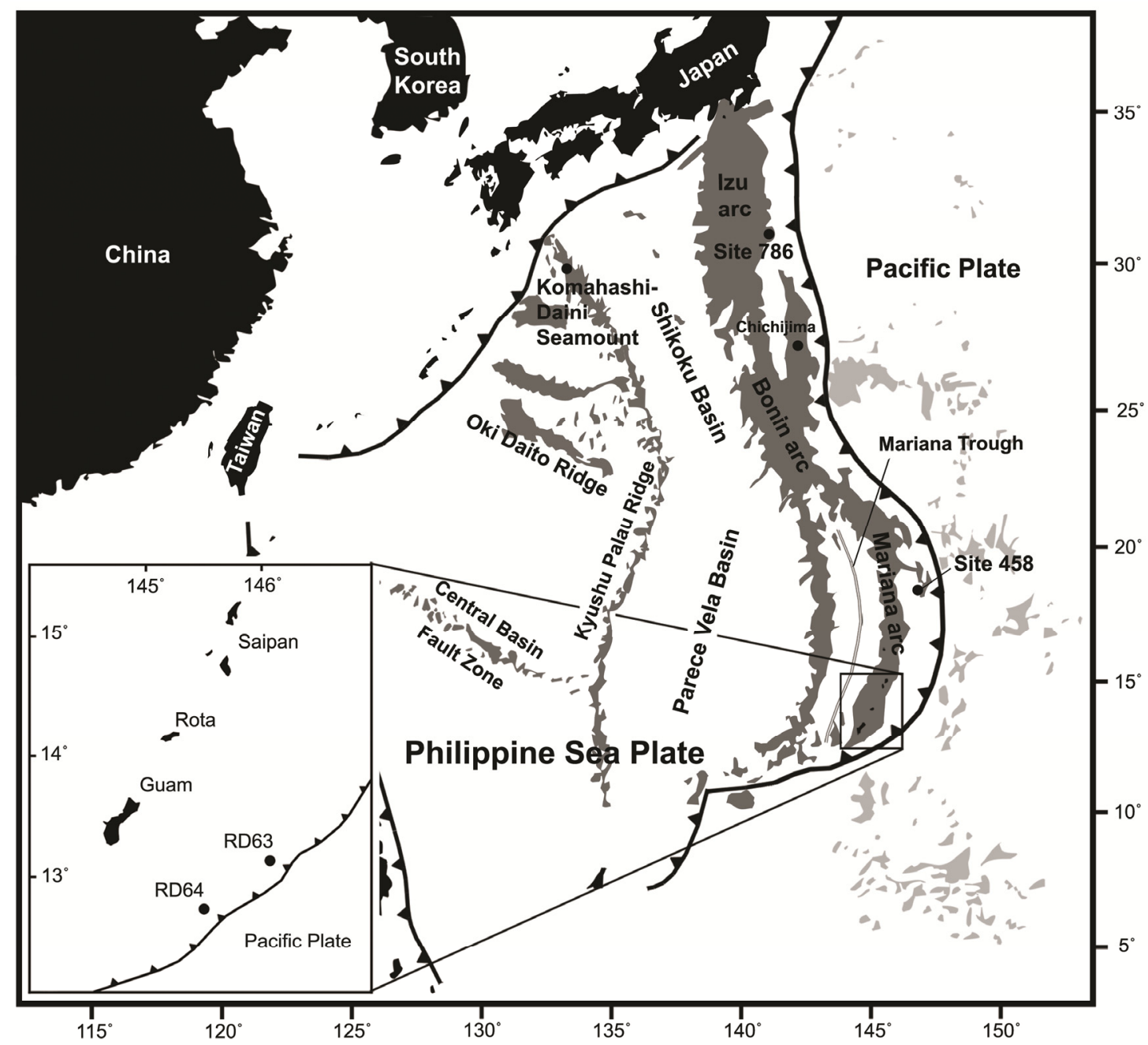

Figure 1.1. Location map of the Izu-Bonin-Mariana (IBM) arc system. Inset showing locations of RD63 and RD64 collected by dredge during the 1981 cruise R/V Kana Keoki (KK) 81-06-26 by University of Hawai'i.

respect to each other at the surface. The plates move by complex processes involving dynamics between the asthenosphere, the lithosphere, and the adjacent tectonic plates. The motion of each individual plate determines the type of stress that develops at its boundaries. Plates that move away from each other create an extensional environment. These plate margins are termed divergent and the extension axis, or spreading ridge, 
occurs mainly underwater where new lithosphere is produced from mantle that upwells from underneath, melts and crystallizes as lavas, dikes or plutons. Lithospheric plates that move toward each other become deformed in some way and when compressional forces dominate, the plate boundary is called convergent. Convergence of plates leads to crust entering a subduction zone, and may ultimately lead to orogenesis (mountain building) at the plate boundary if both plates are sufficiently buoyant. Plates that slide past each other, neither convergent nor divergent, are called strike-slip or transform. Transform boundaries are generally found in oceanic lithosphere, but may also be found in continental lithosphere, e.g., the San Andreas Fault.

This study focuses on rocks that were recovered from the boundary of the Pacific plate and the Philippine Sea plate (PSP), which at present-day is a convergent margin (Figure 1.1). Subduction is currently ongoing and the related processes are responsible for the formation of the rocks found there and for recycling lithospheric plates into deeper levels of the Earth. The primary driving force that moves the plates is a pulling force that drags a plate into the trenches and subsequently the asthenosphere, called slab-pull (Figure 1.2). A minor force acting on the moving plates occurs near the topographic high of mid-ocean ridges where new oceanic crust is generated by upwelling mantle. A gravitational force acts on the elevated lithosphere near the ridge, moving it down the sloped asthenosphere, effectively pushing the two juxtaposed plates away from each other (called ridge-push). 


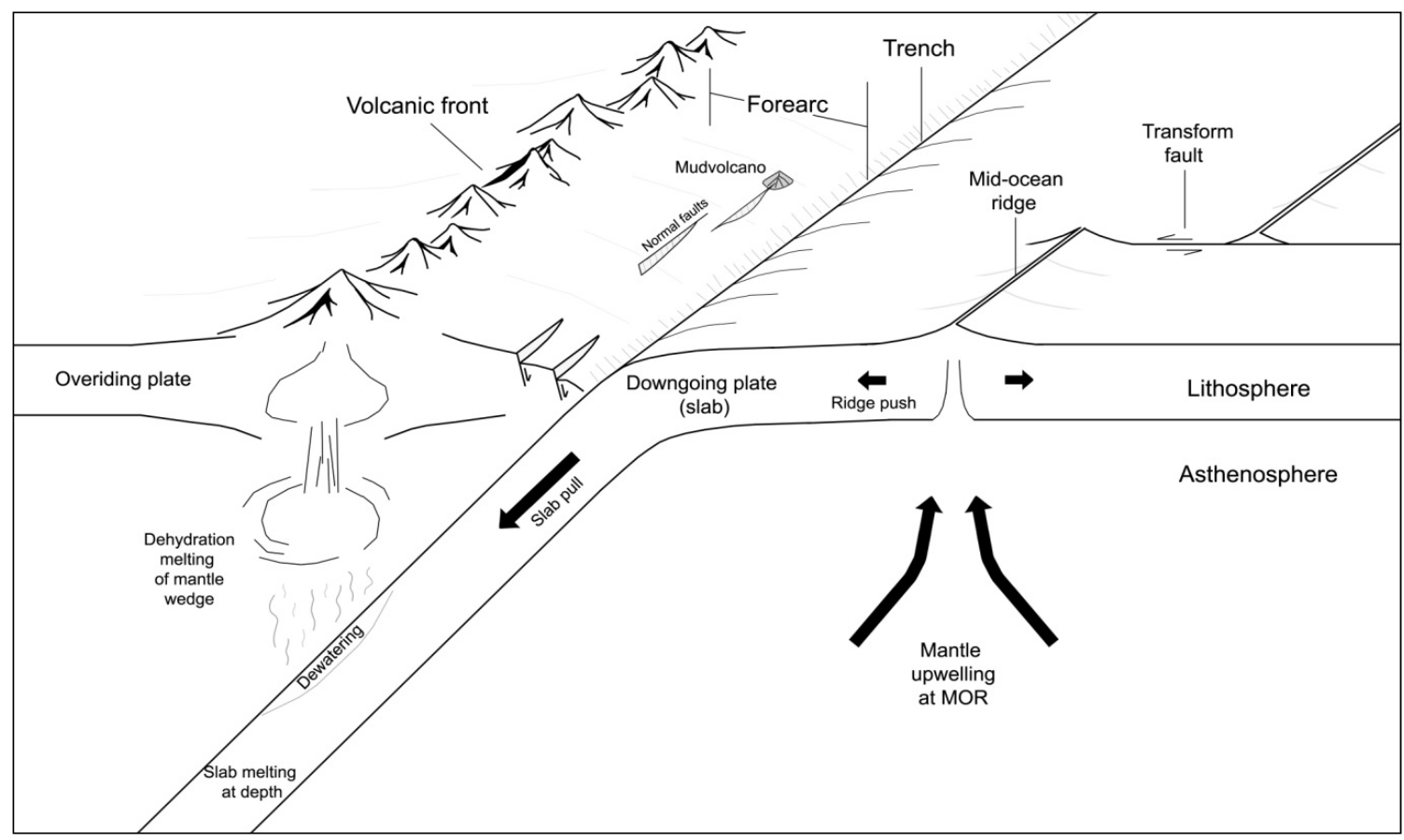

Figure 1.2. Interacting lithospheric plates without the formation of an accretionary complex at the trench (Mariana-type subduction). The subduction zone is shown in more detail than the spreading ridge (mid-ocean ridge) and transform fault. Diagram shows how terms used in the introduction relate to plate interactions.

\subsection{Convergent margins}

Convergent margins are one type of lithospheric plate boundary found on the earth. The density of the mantle lithosphere is an important factor at convergent margins and the sinking of this lithosphere is what drives the dynamics of subduction, creating a force great enough to move the entire plate (slab pull). Subduction can occur between continental lithosphere and oceanic lithosphere (an Andean-type margin) or between two plates with juxtaposed oceanic lithosphere (an intraoceanic-type margin). If continental crust on the downgoing plate arrives at the trench, it jams the subduction zone and eventually there is cessation of subduction, but through complex convergence and thrust 
systems a large mountain belt may form [O'Brien, 2001]. This is referred to as a Himalayan-type margin.

The Pacific plate and the Philippine Sea plate represent an intraoceanic subduction system. Each plate is oceanic lithosphere, but the western edge of the Pacific plate is the oldest ocean crust on earth $(167.4 \pm 3.4 \mathrm{Ma}$; [Koppers et al., 2003]). The Philippine Sea plate was initially formed by ocean spreading at $\sim 49 \mathrm{Ma}$ and is thus much younger and more buoyant than the Pacific plate. Moreover, newer crust formed by active subduction makes the PSP even more buoyant relative to the Pacific plate.

\subsubsection{Chilean- vs. Mariana-type subduction zones}

There are two end-members of subduction zones classified by the dipping angle of the subducting plate relative to the earth surface and strain regime: Chilean and Mariana (Figure 1.3). The downgoing plate in the Chilean-type subduction zone has a shallow angle in part due to the young age and relatively warm temperature of the lithosphere, which makes it more difficult for the plate to sink into the warm asthenosphere. Conversely, the Mariana-type subduction zone involves a plate that is much older, thus colder and denser which allows it to sink more readily into the asthenosphere and to deeper depths; this makes a much steeper angle of subduction. The dip angle of the subducting plate also affects the distance to the volcanic arc from the trench and thus the width of forearc. A shallower angle of subduction (Chilean-type) means that dehydration melting of the overriding mantle occurs further from the trench (Figure 1.2), thus the volcanic front is further from the trench as well, which makes the forearc longer and often a forearc basin develops where kilometers of eroded continental sediment or ocean sediments settle. Conversely, the steep dip of the downgoing plate in a 
Mariana-type subduction zone means dehydration of the overriding plate occurs much closer to the trench axis, hence the volcanic front is closer to the trench and the width of the forearc is shorter and may not develop a forearc basin at all. The Izu-Bonin-Mariana (IBM) arc does not have a forearc basin, which is one reason the lithospheric rocks are exposed rather than being covered in thick layers of sediment.
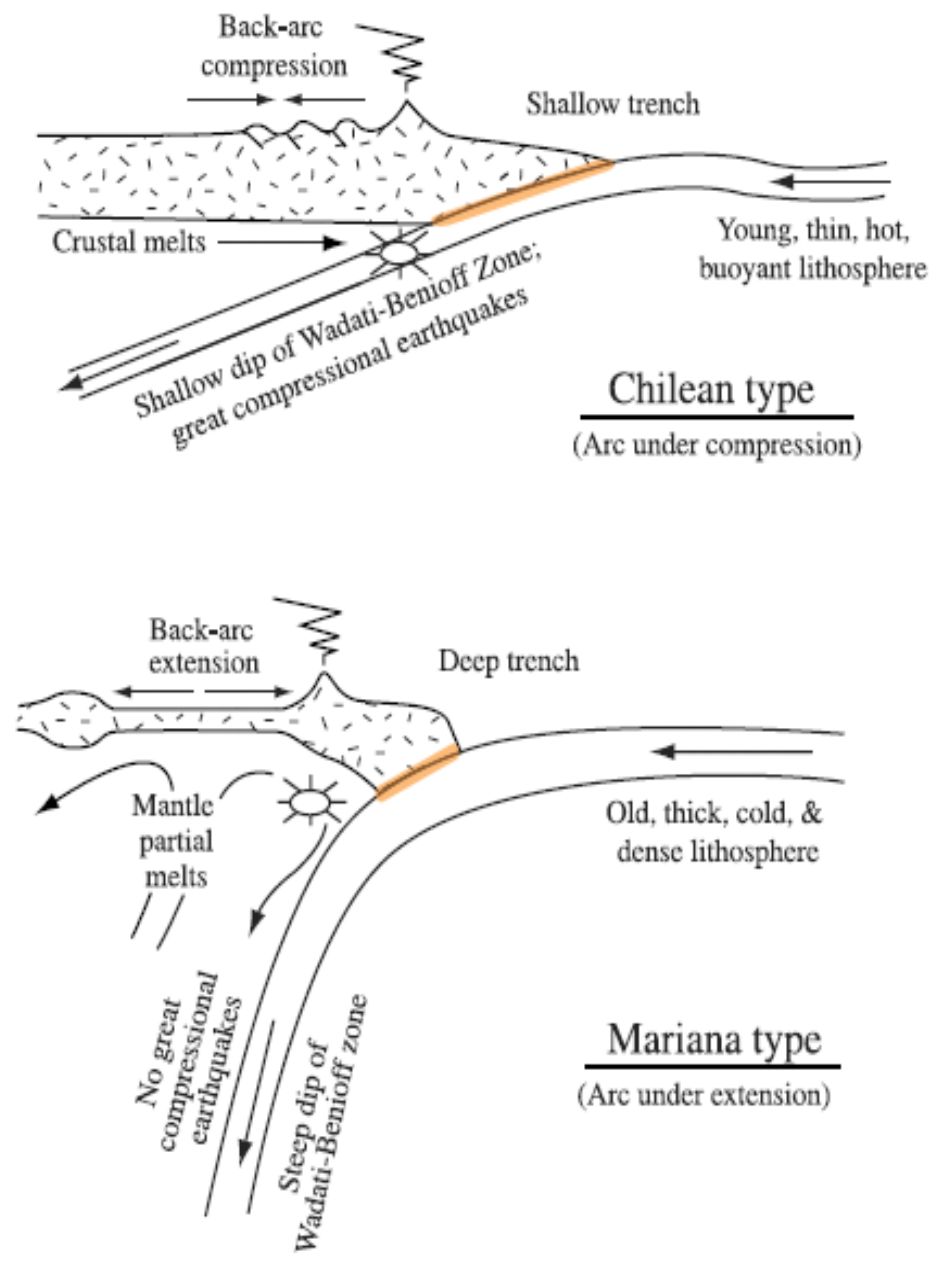

Figure 1.3. Chilean- and Mariana-type subduction zones (from Stern [2002]). The shaded orange area represents an example of the width of the plate-coupled zone. In comparison, the strongly coupled Chilean-type subduction zone has a wider platecoupled zone than the weakly coupled Mariana-type. Back-arc spreading also occurs in the Mariana-type subduction zone, due to the extensional regime in the overriding plate. 
The type of arc also indirectly influences the strain that is present throughout the arc system. Jarrard [1986] found that the strain class in the overriding plate primarily depends on the age of the subducting plate and the absolute motion of the overriding plate. The two end members of the strain classes were strongly extensional (Mariana arc) and strongly compressional (Chilean arc) [Stern, 2002; Uyeda and Kanamori, 1979] shown in Figure 1.3. In addition to the age and absolute motion of the plates, the width of the plate-coupling zone is hypothesized to have an effect on seismic coupling, as well as a large effect on trench depth [Gvirtzman and Stern, 2004]. The terms are differentiated by Gvirtzman and Stern [2004] to mean that plate-coupling is "the resistance of the plates to detach vertically..." while seismic coupling is "...the resistance for two plates to slide past each other." And they postulate that the two "must be related because both deal with lithosphere-lithosphere contact along the subduction interface."

In the Chilean-type arc, the plate-coupling zone is generally wide (see Figure 1.3) due, in part, to the shallow angle of subduction which also leads to a shallower trench. It is strongly coupled and under compression, which makes it associated with some of the more severe earthquakes around the world, such as the 8.8 and 8.2 magnitude earthquakes offshore of Chile in February 2010 and April 2014, and the 9.0 magnitude earthquake offshore of Japan in March 2011.

The narrower the plate-coupling zone is, the weaker the slab will be attached allowing it to hang and exert a "down-pulling" force on the upper plate (also enabling a steep dip) [Gvirtzman and Stern, 2004]. This creates a steeper and deeper trench in the Mariana-type arc, e.g., the deepest ocean floor on earth: the Challengers Deep. It seems to follow that the down-pulling force will affect a roll back system, such as is present in 
the Mariana trench and causing the normal faulting in the forearc [Fryer et al., 2003]. By general definition, the Mariana-type arc is a loosely coupled system, although plate coupling and seismic coupling do vary along the length of the IBM system [Gvirtzman and Stern, 2004; Scholz and Campos, 1995].

Accretionary prisms can form at the toe of the trench in a weakly coupled system. Sediments from the downgoing plate are scraped off and accumulate on the overlying plate. The sediment layers form a wedge or prism shape and have complex internal structures. The accretionary prism usually covers most of the forearc. Even though the Mariana arc is loosely coupled, there is no accretionary complex and this may be due to the weak vertical "plate-coupling" described above. But this force may also be a factor in the roll back at the Mariana trench, which contributes to the exposure of the plutonic rocks in this study that otherwise would be found at greater depths in the mid-crust of the forearc.

\subsection{The Izu-Bonin-Mariana (IBM) forearc}

There have been several hypotheses about how the forearc of an island arc forms. It is widely believed that the forearc of the Izu-Bonin-Mariana arc (crust between the volcanic front and the trench; Figure 1.2) represents crust formed during the initiation processes of subduction [Karig, 1974; Meijer, 1980; Umino, 1985] (see section 2.3.1 for details on how this crust formed during subduction initiation).

One simple model for subduction initiation in the IBM is that it occurred at a zone of weakness between two mid-ocean ridge basalt (MORB) oceanic plates, likely a transform fault [Hilde et al., 1977; Uyeda and Ben-Avraham, 1972]. The denser plate 
would move beneath the other and the subsequent overriding plate would develop arc volcanism. In this case, the crust that lay between the volcano and the trench was considered "forearc" though originally a part of the overriding plate before subduction. According to this hypothesis, the forearc would have the same geochemical characteristics as the original plate on which the new arc was formed. This is a spontaneous type of initiation that resembles the transform collapse diagram in Figure 1.4 except the model would not include forearc spreading. A second model suggests that the present-day IBM subduction zone is a result of an older subduction zone which rotated into place [Klein and Kobayashi, 1980; Ogawa and Naka, 1984]. This model does not actually deal with subduction initiation, it merely hypothesizes that the IBM is an older subduction zone. However, rocks from the area of study and the rest of the IBM system are approximately $45 \mathrm{Ma}$ or younger, and not significantly older, thus the first general model is preferred.

This study is built on the concept that the first stage of developing the IBM forearc occurred by spontaneous transform fault collapse (Figure 1.4) that created an extensional environment that allowed asthenospheric upwelling between the two adjacent plates. The high heat flux and exposure to hydrous fluids led to shallow melting of the depleted upper mantle, which produced forearc basalts and boninitic volcanism (see Figure 2.2). The first studies to propose this kind of spontaneous subduction for the IBM arc were Natland and Tarney [1981] and Hawkins et al. [1984], and later Stern and Bloomer [1992] further developed the concept. Stern [2004b] describes spontaneous subduction in detail (his diagram illustrating the different mechanisms, as Figure 1.4). He also describes another mechanism for new subduction: induced nucleation. Induced 


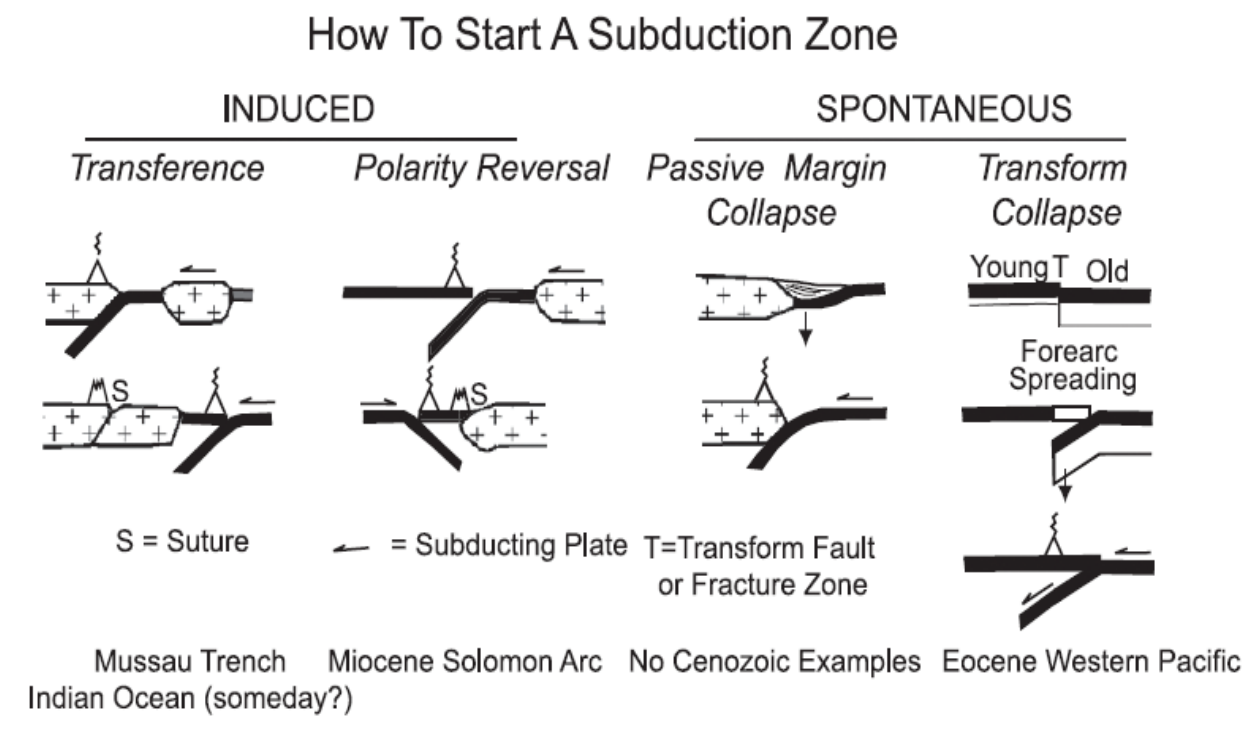

Figure 1.4. The variety of plate configurations that have been considered for subduction initiation, from Stern [2004b]. One main difference between "induced" and "spontaneous" subduction initiation is that in the "induced" model, a subduction regime exists prior to the new subduction, while in the "spontaneous" model, there is no prior subduction activity until a segment of lithosphere begins to sink.

nucleation for a new subduction zone is a result of buoyant crust jamming the previous trench, but convergence continues and relocates the trench (i.e., the transference or polarity reversal models). Spontaneous subduction is a response to the gravitational instability between two lithospheric plates so that one plate sinks relative to the other (e.g., the IBM). Presently, the idea of how subduction started in the IBM is fairly well established as the collapse of transform fault sections, and geodynamic modeling has been done to test this hypothesis (e.g., Hall et al. [2003] and Leng and Gurnis [2011]). They found that after only $100 \mathrm{~km}$ of convergence, a new subduction system can be selfsustaining, i.e., the negative buoyancy of the downgoing slab is stronger than all resistive forces. 
The IBM forearc is exposed across the entire arc primarily by erosive processes. It is difficult to determine how much of the forearc crust is removed by tectonic erosion because there may have been two contributing methods: stripping crust off the base of the forearc (basal erosion) and slumping material into the trench (frontal erosion). Basal erosion occurs because normal faults in the downgoing plate near and under the forearc act as a rough surface, scraping off pieces of the base of the overriding forearc as the plate descends into the mantle. Evidence for frontal erosion is seen primarily at the toe of the forearc where observations of disturbed topography are evident, often where seamounts have been subducted. Frontal erosion is also expected because of normal faulting in the forearc itself that is evident via seismic survey profiles as well as detailed bathymetry of the forearc.

Because the forearc is exposed, in situ crust representing the volcanic and plutonic sequences that were formed during subduction initiation gives scientists a rare opportunity to study a wide range of the processes that were occurring at that time. It is also a helpful tool for understanding supra-subduction ophiolites that, by definition, have been uplifted and experienced many stages of deformation during the obduction process.

\subsection{Geochemical studies}

In addition to using observations of the physical properties of rocks, it is possible to dissolve a sample into its basic chemical constituents and analyze the elements. Major (and minor) elements are defined as making up more than $\sim 0.1 \%$ of the rock (elements less than $\sim 0.1 \%$ are considered trace elements). The concentrations of major elements change in predictable trends, known as liquid lines of descent, when certain minerals 
crystallize from a melt while it cools. For example, olivine crystallizing from a melt will progressively decrease the $\mathrm{Mg}$ and $\mathrm{Fe}$ in the residual magma in the form of $\mathrm{MgO}, \mathrm{FeO}$ and $\mathrm{Fe}_{2} \mathrm{O}_{3}$ (the major oxides). Major elements may be plotted against other major elements to show differentiation trends. A common major element oxide, $\mathrm{SiO}_{2}$, is used for comparison because the silica content of a rock is directly related to the fractionation of silicate rocks, especially in cogenetic suites. For example, basalts are classified with an $\mathrm{SiO}_{2}$ range up to $52 \mathrm{wt} \%$; andesites are $52-58 \mathrm{wt} \%$, dacites are $58-69 \mathrm{wt} \%$ and rhyolites, the most silicic volcanic rocks, are $69 \mathrm{wt} \%$ or greater. The $\mathrm{SiO}_{2} \mathrm{wt} \%$ is a useful analyte because silica content increases with increasing fractionation of a magma body and is reflected in plutonic as well as volcanic rocks.

Trace and rare earth (of the lanthanide series) elements are present in very small amounts and as such, we use very precise and sensitive instruments to measure their concentrations. Trace elements can be plotted in a similar manner as the major elements, though the implications of the trends depend on which trace elements (or ratios of elements) are plotted. Many X-Y trace element plots use incompatible elements, defined as elements that prefer to stay in the melt rather than partition into a solid crystal and have partition coefficients less than 1 . In comparison, elements that fractionate into a solid crystal preferentially over the liquid, such as during typical primitive mantle melting, are considered compatible elements (e.g., $\mathrm{Ni}, \mathrm{Cr}, \mathrm{V}, \mathrm{Co}$ and other transition metals) and have a partition coefficient greater than 1. Because of their partitioning preferences, compatible elements tend to accumulate in the mantle and incompatible elements (Rb, Ba, Sr, U, La, etc.) will accumulate in the crust, especially continental crust [Rollinson, 1993]. Incompatible elements are often used in X-Y plots (discriminant 
or covariant plots) in conjunction with elements that are more incompatible to classify the rocks with other geochemically similar rocks or to show deviations from typical differentiation patterns. For example, as $\mathrm{SiO}_{2}$ increases the element $\mathrm{Y}$ fractionates into the solid at a more or less consistent rate. But when this element, Y (ppm), is plotted against $\mathrm{Sr} / \mathrm{Y}$, a seawater influence (either into the melt or as an alteration effect) will be apparent as values of $\mathrm{Sr} / \mathrm{Y}$ will be high relative to $\mathrm{Y}$. If there is no significant $\mathrm{Sr}$ input, the fractionation of $\mathrm{Y}$ would show as a horizontal line.

A different kind of trace element diagram, a multi-element diagram, plots a suite of trace (usually minor and rare earth) elements on the x-axis and their concentrations normalized to a characterized source (e.g., chondrite, primitive mantle, MORB) for many different samples. These specific kinds of multi-element diagrams are often called "spider diagrams" because the line patterns on the diagram can vary greatly along the yaxis, and perhaps have the appearance of spider legs! These are useful to geochemists because certain patterns in element enrichment or depletion become evident relative to the normalized values. For example, some samples may become predictably enriched in certain fluid mobile elements if they formed in an environment that might introduce fluids to the rocks. This would be the case in subduction zone related rocks, where fluids from the downgoing plate are released during dehydration and can thus be "seen" in the spidergram patterns as enrichments in $\mathrm{Sr}, \mathrm{Pb}, \mathrm{Ba}, \mathrm{Rb}$ or $\mathrm{U}$, especially in comparison with less mobile elements $(\mathrm{Nb}, \mathrm{Th})$. The ratios of these elements (e.g., U/Th) will vary depending on the ratios in the fluid source, thus fluid sources can be traced in this way. Non-mobile elements, like rare earth elements (REEs) and high field strength elements (HFSEs), are used as petrogenetic indicators to determine the source of melt: ocean island 
basalts (OIBs) will have different REE and HFSE ratios than mid-ocean ridge basalts (MORBs). Similar comparisons are employed in island arc settings to differentiate between forearc basalts (FABs), boninites, island arc tholeiites (IATs), back-arc basin basalts (BABBs) and related plutonics, which all have different melting and crystallization histories.

\subsection{Radiogenic isotopes as tracers}

Radiogenic isotopes can be used for dating purposes and also for tracer studies. Dating methods are based on the idea that radioactive isotopes decay at a constant rate from the parent (starting isotope) to the radiogenic daughter (variants of the parent through radioactive decay). The abundances of radiogenic isotopes (often expressed as a ratio) in rock suites or minerals can be used to find the age of crystallization in a magma body or lava flow, metamorphism, weathering, remelting, reheating or any other process that affects the temperature and/or pressure of rocks.

In this study, radiogenic isotope ratios are used as tracers for the sources of magmas and rocks formed by subduction processes. Tracer studies use the difference in ratios between the radiogenic daughters and stable isotopes of the same element (e.g., ${ }^{207} \mathrm{~Pb} /{ }^{206} \mathrm{~Pb},{ }^{144} \mathrm{Nd} /{ }^{143} \mathrm{Nd},{ }^{87} \mathrm{Sr} /{ }^{86} \mathrm{Sr},{ }^{176} \mathrm{Hf} /{ }^{177} \mathrm{Hf}$, etc.). These ratios vary in different earth materials as the result of the abundance of the radioactive parent in a particular source material or reservoir and the time that has passed since homogenization of isotopes through melting or metamorphism.

The parent-daughter isotope systems from RD63 and RD64 are Lu-Hf, Sm-Nd, $\mathrm{Rb}-\mathrm{Sr}, \mathrm{U}-\mathrm{Pb}$, and Th-Pb. These pairs have different geochemical behavior. Lu-Hf [a 
REE and a HFSE] and Sm-Nd (REEs) are very immobile and make effective petrogenetic indicators, especially when paired with other isotopic systems ( $\mathrm{Rb}-\mathrm{Sr}, \mathrm{U}-\mathrm{Pb}$ and $\mathrm{Th}-\mathrm{Pb}$ ) which provide insight into sediment sources and also, when used together, upper mantle provenance.

\subsection{Importance of researching subduction zones}

The most significant, potentially devastating, large magnitude earthquakes occur in the seismogenic zones of subduction margins. These earthquakes and other seismic events (e.g., slumping, minor fault slips) can cause equally devastating tsunamis. Most volcanic eruptions on the earth that disrupt lives are located at convergent margins and are directly related to subduction. In a more beneficial point of view, many of the world's economically viable ore deposits exist because of the unique chemical reactions that occur at subduction zones. In order to understand the mechanics and processes that cause earthquakes, tsunamis, volcanic eruptions and ore deposition, the inner workings of subduction zones must first be understood. Furthermore, the process of subducting lithospheric plates into the asthenosphere is what drives the entire tectonic system on the earth.

The IBM arc is considered to be an excellent location to study subduction zone processes as the history of the PSP is fairly well understood and the geochemical fluxes of the arc are simpler than other convergent margins; arc magmatism in continental crust usually has crustal contamination from mixing that occurs while magma rises through the thick continental crust; sediment input in the IBM is also easier to estimate than other 
arcs because all the sediment is subducted and there is little to no accretion on the forearc.

1.7 Outline of dissertation objectives and summary

Suites of felsic to intermediate composition plutonic rocks are rarely recovered from expeditions of the seafloor. The objectives of this study are to classify the two plutonic suites that were recovered by seafloor dredging in the southern Mariana forearc, and to compare them to other volcanic and plutonic rocks in the IBM system. In this way, the origin and evolution of the plutonic rocks might be ascertained. It is also of interest to postulate how these plutonics were exposed on the surface of the seafloor, because seismic models that include these types of plutonics (as interpretations of changes in p-wave velocities) show them existing at depth in the crust.

The forearc in the IBM system has been likened to an in situ example of presentday supra-subduction zone ophiolites [Cameron et al., 1979; Dilek and Thy, 2009; Dilek and Furnes, 2009; Dobretsov and Kepezhinscas, 1981; Stern et al., 2012] and indeed, there is overwhelming petrologic, chemical and structural data that support this theory. Therefore, an objective of this study is to examine SSZ ophiolites that have clear links to forearc development (i.e., the presence of boninites, boninite dikes and normal faults) to see if published data include plutonic rocks and if any of them were perhaps boninite-like and thus linked to subduction initiation. The purpose of this comparison was part of a hypothesis that plutonics may form in the earliest stages of island arc development which may have an impact on how scientists think about the formation and accretion of felsicintermediate continental crust composition. 
This dissertation presents geochemical data that supports the hypothesis that initial subduction began with voluminous FAB eruptions followed by transitional and boninitic lavas [Reagan et al., 2010] with associated crystal accumulation, high level differentiation and perhaps partial melting of boninite crust leading to the plutonic rocks under study. The lack of radiometric age dating of the intermediate-felsic plutonics is not a hindrance to the aforementioned conclusion because the only time at which a heat source sufficient to cause melting and support differentiating magma chambers in the forearc was present was during early subduction; mantle upwelling in the forearc ceased $\sim 10 \mathrm{Myr}$ after subduction initiation. These intermediate-felsic plutonic rocks very closely resemble the other felsic rocks in the island arc except for their source signatures. Given the variety of volcanism across the arc, it can be reasoned that the southern Mariana suites may be mineralogically similar to other plutonics in the IBM but have a different petrogenetic history. There appears to be scarcely any other analogous regions on earth with similar boninite-like plutonic suites and similar theories for petrogenesis, e.g., suprasubduction zone (SSZ) ophiolites in the Mediterranean are well-known to be analogous to early subduction forearcs (like the IBM) in their volcanic sequences, but little research has been done on the plagiogranites and tonalites that outcrop there. Those felsic plutons are rarely boninite-related, if any geochemical data is reported on them at all.

The rest of the dissertation is in the following layout:

Chapter 2 introduces the geologic history of the Izu-Bonin-Mariana arc system: the various stages of magmatism and rifting that led to the present-day configuration of the arc. An emphasis on the early stages of formation in the southern Mariana arc is given by an examination of the lava sequences studied on Guam (specifically boninites, 
transitional boninites and normal arc tholeiites), but also includes a brief description of more recent eruptions and sedimentary deposition.

Chapter 3 gives a detailed account of the preparation and analysis procedures that ultimately produced the quantitative results presented in this document.

Chapter 4 is the compilation of the data gathered for the dredges RD63 and RD64, including the petrography, modal analysis and rare earth element modeling, and explains how this information was interpreted and incorporated into the petrogenesis model which explains how the plutonics may have formed as a result of processes during subduction initiation. The REE modeling makes a case for multi-stage differentiation or differentiation and a second partial melting step to achieve geochemical patterns seen in the high level intrusives.

Chapter 5 is a manuscript that, at the time of this dissertation, has been accepted for publication by the online journal "Geochemistry, Geophysics, Geosystems" (also known as "G cubed"). The focus of the manuscript is on the geochemical and isotopic data acquired for dredges RD63 and RD64 (felsic, intermediate and gabbroic plutonic rocks) from the Mariana forearc as a comparison to other rocks in the forearc: volcanics most of which have been classified as extrusives formed during the initiation of subduction (FABs, boninites and transitional boninites). Trace elements confirm arc signatures and REE patterns are boninite-like. Isotopic ratios overlap other early volcanics. The mechanism for mid-crust exposure is puzzling and exposure of both dredges could be related to normal faulting common in forearc environments. The coauthors of this manuscript are the major advisor, two experts in the field of 
geochemistry and the IBM arc system, and an expert in isotope systems and they provided invaluable and insightful comments prior to submission.

Chapter 6 is an overview of supra-subduction zone (SSZ) ophiolites in regard to the occurrence of subduction initiation volcanics (boninites) and the possibility of related plutonics.

Chapter 7 is the conclusions that have been drawn as a result of the research done during the course of this project, and a summary of ideas for the future direction of work. 


\subsection{GEOLOGIC SETTING}

2.1 Formation of the Philippine Sea Plate

The Philippine Sea Plate (PSP) is made up of several different basins and ridges that formed in the late Paleocene to early Eocene [Watts et al., 1977] and continues to evolve in the present. The Izu-Bonin-Mariana (IBM) arc history has been extensively studied using information collected by numerous Ocean Drilling Program (ODP), Deep Sea Drilling Program (DSDP), International Ocean Discovery Program (IODP), Japan Agency for Marine-Earth Science and Technology (JAMSTEC) drilling and dredging expeditions, and in situ collection by manned and un-manned submersibles throughout the PSP. The present-day arc system (Figure 1.1) is made up of (from east to west) the forearc, the currently active arc, a currently rifting back-arc basin (the Mariana Trough), two long connected extinct rift basins (the Shikoku and Parece Vela Basin), and a ridge that represents the rifted edge of the first active arc (the Kyushu-Palau Ridge). Early comprehensive histories of formation leading to the present-day configuration of the arc were compiled by Karig [1974], Meijer et al. [1983], Scott et al. [1980] and others. Ages of the arc magmatism and rifting events were determined by radiometric and paleontological dating of rocks from the PSP, the Mariana forearc, Guam and other Mariana and Bonin islands [Cosca et al., 1998; Hussong et al., 1981; Kroenke et al., 1980; Meijer et al., 1983; Tracey et al., 1964]. The discovery of boninites as the oldest lavas associated with IBM volcanism (before the discovery of older forearc basalts) and concurrent explanations of their petrogenesis was key to forming the model of how subduction initiation between the PSP and the Pacific Plate began [Hawkins et al., 1984; Natland and Tarney, 1981; Stern and Bloomer, 1992]. 


\subsection{West Philippine Basin}

The present-day IBM magmatic axis is approximately $2800 \mathrm{~km}$ long and extends from Honshu, Japan to south of Guam, USA where the Pacific Plate is subducting beneath the PSP. Before volcanism for the IBM system even began, active seafloor spreading starting $\sim 55 \mathrm{Ma}$ [Hilde and Lee, 1984] along the present-day Central Basin Ridge created what is now called the West Philippine Basin (WPB; the combined lithosphere of the WPB and the IBM arc is called the PSP). Some have suggested that the WPB was a fragment of ocean floor and mid-ocean ridge that was trapped by the onset of IBM arc subduction (e.g., Jolivet et al. [1989], Uyeda and Ben-Avraham [1972]) but others argue that the WPB is a backarc basin that formed in a subduction setting during plate rotation and a subsequent change in motion of the Pacific Plate [Deschamps and Lallemand, 2003; Hall, 2002; Hall et al., 1995]. The Daito and Oki-Daito ridge are remnant arcs in the northern PSP and are parallel to the Central Basin ridge, which seems to support the latter theory (Figure 2.1). Furthermore, the plate rotation and the change in motion of the Pacific Plate may have caused the new subduction beneath the WPB and the beginning of the IBM arc.

Some studies propose that the orientation of central basin spreading center (CBSC) of the WPB was parallel to the boundary of the Pacific plate [Honza and Fujioka, 2004] and prior to a shift in plate motion the Pacific plate and WPB/PSP were separated by a transform fault [Hall et al., 2003]. When subduction began, the Pacific plate was 100-90 Myr and the WPB was very young, 20-0Myr [Hilde and Lee, 1984; Shih, 1980]. The age difference aided the lithospheric collapse of the older Pacific plate and was probably critical in the initial sinking of the downgoing plate [Stern, 2004a; 
Stern and Bloomer, 1992]. The WPB was actively spreading for approximately $\sim 20 \mathrm{Myr}$ and continued spreading millions of years after the Pacific plate started subducting underneath it, but eventually the spreading ceased as mantle flow was cut off and the ridge is presently called the Central Basin Ridge (or Fault) [Hilde and Lee, 1984].

\subsection{Izu-Bonin-Mariana arc development}

\subsubsection{The forearc (protoarc)}

Subduction was initiated approximately at 51-50Ma [Bloomer et al., 1995; Reagan et al., 2010; Stern and Bloomer, 1992] and processes associated with initiation continued until 40Ma. At the start of subduction, the edge of the Pacific plate began to sink downwards relative to the PSP, thus creating an extensional environment between the two plates (Figure 2.2a). As the thick Pacific lithosphere sank, the asthenosphere upwelled at the boundary of the plates, causing extension at the edge of the "overlying" lithosphere. The extreme heat melted the oceanic lithosphere and erupted forearc basalts with little fluid input from the Pacific plate [Reagan et al., 2010]. After several million years, the mantle was very depleted and the Pacific lithosphere had sunk deeper (cooling the mantle slightly) and was beginning to release fluids from Pacific sediments. The fluids were incorporated into boninite melts which were erupted until $\sim 40 \mathrm{Ma}$ (see Figure 7.1). The FAB and boninite lavas formed in the spreading area are the present-day forearc lavas and have remained magmatically and tectonically unchanged since emplacement (with the exception of normal faulting).

The first lavas extruded in this forearc spreading 51-48Ma were most likely a product of mantle melting, thus they have MORB-like chemical signatures while still 

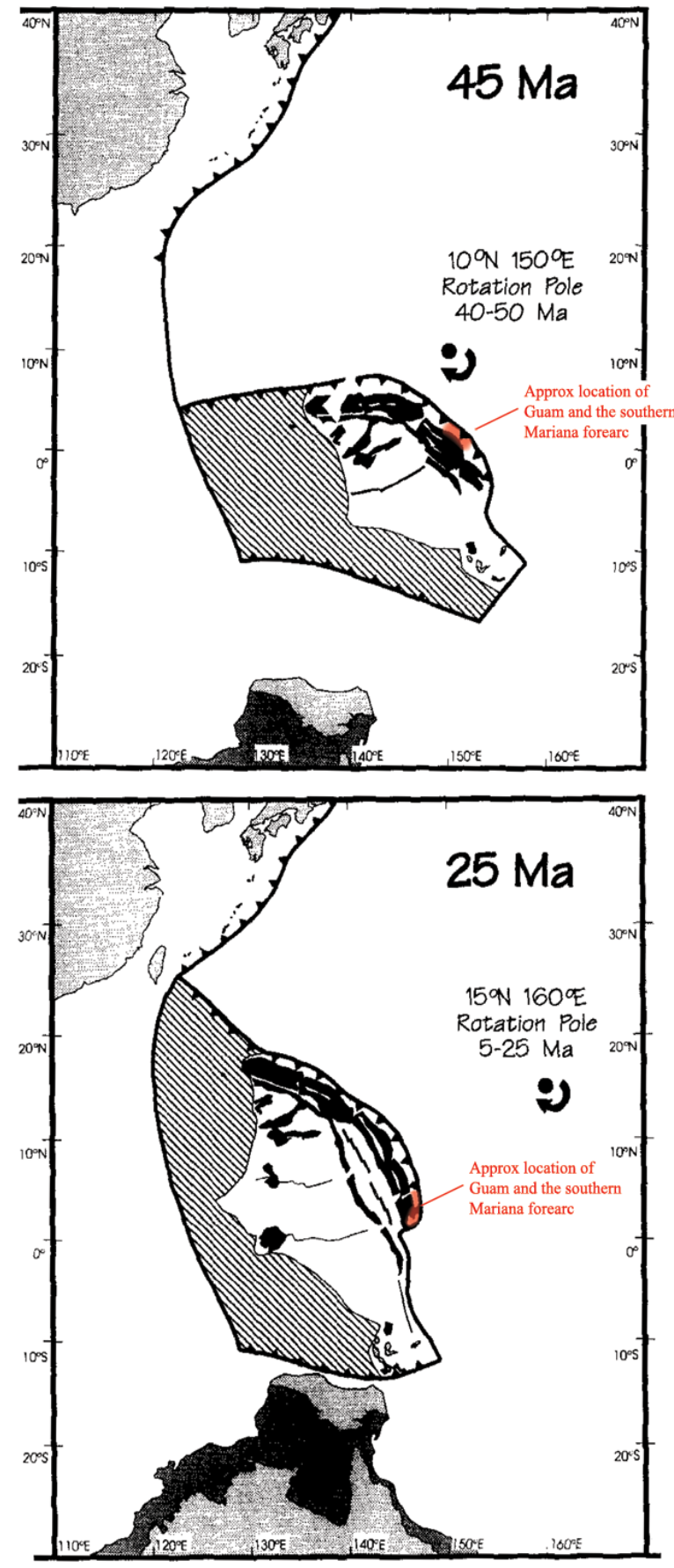

Figure 2.1. Early configurations of the Pacific Plate, West Philippine Basin and early IBM volcanism (slightly modified from Hall et al. [1995]). Their model is based on the hypothesis that the WPB formed as a backarc basin that was rotating 50-40Ma during subduction initiation. Rotation began again at $25 \mathrm{Ma}$ to its current configuration. The shaded red area is approximately the location of southern Mariana forearc rocks. The diagonal shaded areas represent lithospheric plate that likely existed during this time but has been subducted since then. 
A) Subduction Initiation (50-40 Ma) Forearc spreading

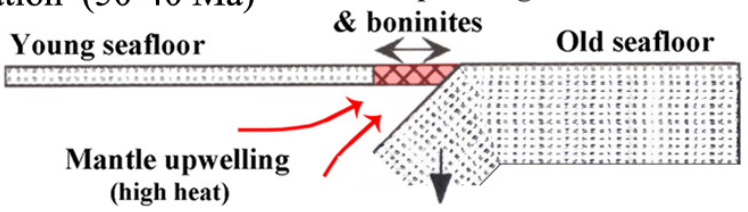

B) Early Arc; 1st Unrifted Arc (40-30 Ma) Forearc

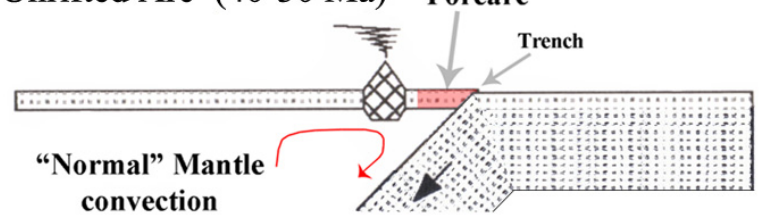

C) Shikoku-Parece Vela Back-Arc Basin (30-15 Ma)

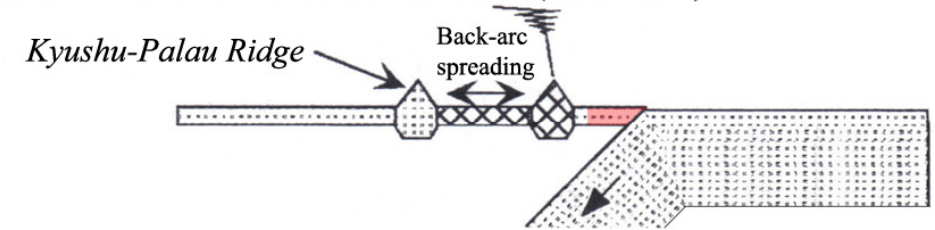

D) 2nd Unrifted Arc (15-7 Ma)

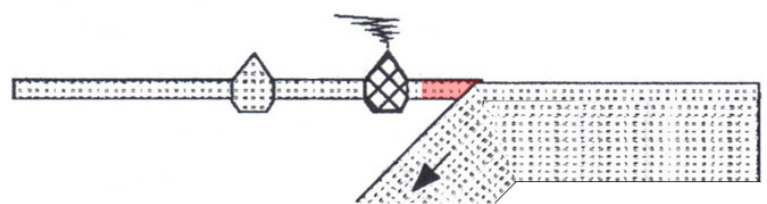

E) Mariana Trough Back-Arc Basin (7 Ma-present day)

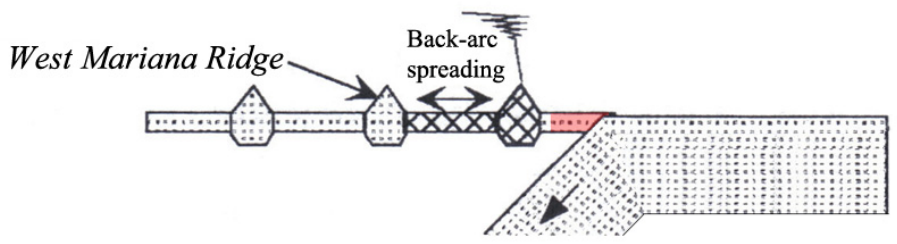

Figure 2.2. IBM formation history (modified after Stern et al. [2003]). Note the Pacific slab sinking at subduction initiation (A) causing asthenospheric upwelling and forearc volcanism.

having arc affinities (lower $\mathrm{Ti} / \mathrm{V}$ and $\mathrm{Yb} / \mathrm{V}$, and some highly fluid-mobile elements) [Reagan et al., 2010]. They are not simply ocean floor MORBs so the term "forearc basalt" (FAB) has been coined by Reagan et al. After FAB volcanism, the mantle was very depleted in REEs and HFSEs, and starting around 48Ma until $\sim 40 \mathrm{Ma}$ boninitic and transitional lavas were erupted. 
Boninites are generated by shallow hydrous melting of previously depleted mantle and require water input from the lithosphere of the Pacific plate and a high heat flux from the strongly upwelling upper mantle [Bénard and Ionov, 2012; Hickey-Vargas, 1989; Hickey-Vargas and Reagan, 1987; Hickey and Frey, 1982; Karig, 1974; Meijer, 1980; Natland and Tarney, 1981; Pearce et al., 1999; Reagan and Meijer, 1984]. As a result of the unique melting conditions and the source of the melt, boninites have high $\mathrm{Zr} / \mathrm{Sm}$, $\mathrm{La} / \mathrm{Sm}, \mathrm{MgO}(>9 \mathrm{wt} \%)$, compatible elements (e.g., $\mathrm{Ni}, \mathrm{Cr})$ and low $\mathrm{TiO}_{2}(<0.4 \mathrm{wt} \%)$. Transitional boninites erupted prior to true island arc tholeiites (IATs). These precursors to typical oceanic arc were erupted after forearc basalts and boninites (in some areas, transitional boninite lavas are interbedded with boninite lavas). Forearc basalts, boninites and transitional boninites underlie the first and second arc lavas (primarily IATs) [Bloomer et al., 1995; Pearce et al., 1999; Pearce et al., 1992]. An unpublished lithologic cross section of the southern Mariana forearc illustrates an example of the position and general thicknesses of the volcanic and plutonic layers, and can be viewed in the JAMSTEC YK08-08 cruise report (Ohara et al. [2008]).

\subsubsection{The first arc}

The edge of the Pacific plate continued sinking for $\sim 10$ Myr after which the sense of motion changed to a "true" subduction motion that can be thought of as a "conveyor belt" to the mantle. After $~ 7-8$ Myr of true subduction into the mantle, dewatering of the downgoing plate released fluids that aided melting of the overlying mantle wedge. This process created magma that rose through the lithosphere and began arc volcanism on the Philippine Sea plate. This configuration and related arc volcanism is considered the "first arc," which existed from 40-30Ma (Figure 2.2b). During the aforementioned time period 
the lavas produced were mainly tholeiitic basalts and andesites and some calc-alkaline lavas [Reagan and Meijer, 1984]. There is evidence of rhyolitic lavas being erupted primarily in the northern region of the IBM arc, near the Izu-Bonin islands [Straub, 2003; Tamura and Tatsumi, 2002; Taylor et al., 1994].

\subsubsection{Rifting of the first arc}

Extensional forces within the first arc were perpendicular to the trench and rifted apart the western edge of the first arc, creating a long backarc basin stretching northsouth. Rifting of the first arc began 30Ma and continued until 15Ma (Figure 2.2c). This rifting is known as back-arc spreading and it created the Shikoku and Parece Vela backarc basins which are bounded by the Kyushu-Palau ridge (KPR) on the west and the present-day arc on the east [Kobayashi et al., 1995; Taylor, 1992a].

The opening of the basins did not occur exactly simultaneously or at the same spreading rates (note the wider nature of the Parece-Vela basin compared to the narrower Shikoku basin, see Figure 1.1). Back-arc rifting of the Shikoku-Parece Vela basin ceased at approximately $15 \mathrm{Ma}$, but during this rifting, arc volcanism continued near the trench at what is considered the second arc, (Figure 2.2d) producing tholeiitic basalts and andesites and, to a lesser extent, dacites and rare rhyolites until 7Ma.

\subsubsection{West Mariana Ridge and Mariana Trough}

Starting at approximately $7 \mathrm{Ma}$ a second rifting event began in the second arc and is still actively rifting (Figure 2.2e). The rift basin is known as the Mariana Trough and the backarc spreading is only active from south of the Bonin islands $\left(\sim 21^{\circ} \mathrm{N}\right.$ latitude) to the southwest of Guam $\left(\sim 12.5^{\circ} \mathrm{N}\right.$ latitude). The Mariana Trough is bounded by the West Mariana Ridge on the west and the present-day IBM active volcanic arc on the east. 


\subsection{The early geologic history of Guam}

A close look was given to the geologic history of Guam because the island is the closest landmass to the dredge sites where the samples in this study were recovered. The geochemical and age similarity of the boninites on the island to boninites in the forearc gives good reason to compare the environments in which the rocks formed on Guam and in the forearc. A geologic map, stratigraphic sections and unit descriptions for southern Guam are shown in Figure 2.3, modified after Siegrist and Reagan [2008].

The oldest formations on Guam are volcanic sequences erupted during the latemiddle Eocene to middle Miocene. These early volcanic arc rocks were first comprehensively described by Tracey et al. [1964] and later revised by Meijer et al. [1983] and Reagan and Meijer [1984]. The volcanic sequence still recognized today was published by Reagan and Meijer [1984] and is as follows: the Facpi Formation (latemiddle Eocene to late Eocene), the Alutom Formation (late Eocene to early Oligocene), and the Umatac Formation (early Oligocene to middle Miocene). Detailed petrographic descriptions of these formations and others listed in this section can be found in Tracey et al. [1964].

The lower portion of the Facpi Formation consists of $60-70 \%$ pillow lavas from the boninite series [Meijer et al., 1983; Reagan and Meijer, 1984]. In the upper sections, there are breccias interbedded with pillow lavas, bedded tuff breccias and a few layers of sandstone, shales and hyaloclastites. The only occurrence of boninite lavas on Guam are in this formation (except one pillow flow on the northern part of the island, reported as part of the Alutom Formation by Reagan and Meijer [1984]). The boninites in the Facpi 
Formation are chemically analogous to the boninites in the southern Mariana forearc [Natland and Tarney, 1981].

The Alutom Formation paraconformably overlies the Facpi Formation and contains sandstone, shale, limestones and volcanic breccias. The upper section is mostly coarse breccias with a few layers of pillow lavas. Radiometric dating by Meijer et al. [1983] suggest that the upper section of the Alutom Formation was erupted over a two million year time period starting at 35Ma. The volcanics from this formation are chemically diverse, ranging from calc-alkaline rocks in central and southern Guam to arc tholeiites in central and northern Guam.

The Eocene to mid-Miocene volcanism (pillow lavas and breccias from Facpi and Alutom formations) most likely erupted from two volcanoes northwest and southwest of Guam but there are numerous basaltic to andesitic dikes that cut through the upper Facpi Formation, some of which may be feeders for the Alutom Formation [Reagan and Meijer, 1984]. Basaltic sills that cut through the Alutom Formation were K-Ar dated to have intruded $\sim 32 \mathrm{Ma}$ [Meijer et al., 1983], which corresponds to the rifting of the "first arc" (proto-KPR arc) [Sutter et al., 1980]. There was no volcanic activity on Guam from 32 to $13 \mathrm{Ma}$ [Tracey et al., 1964], which most likely also corresponds to the rifting. During this time, the Maemong Limestone (of the Alutom Formation) accumulated on Guam. Afterward volcanic activity produced pyroclastic flows, pillow lavas and breccias, all with interbedded limestones and calcareous sandstones. The pillow lavas (the Schroeder member) are found near Mount Schroeder in southern Guam.

Volcanic activity on Guam ended at 13.5-13Ma, and a series of limestone formations were deposited; the Bonyan, Alifan, Barrigaden, Janum, Mariana and Merizo 


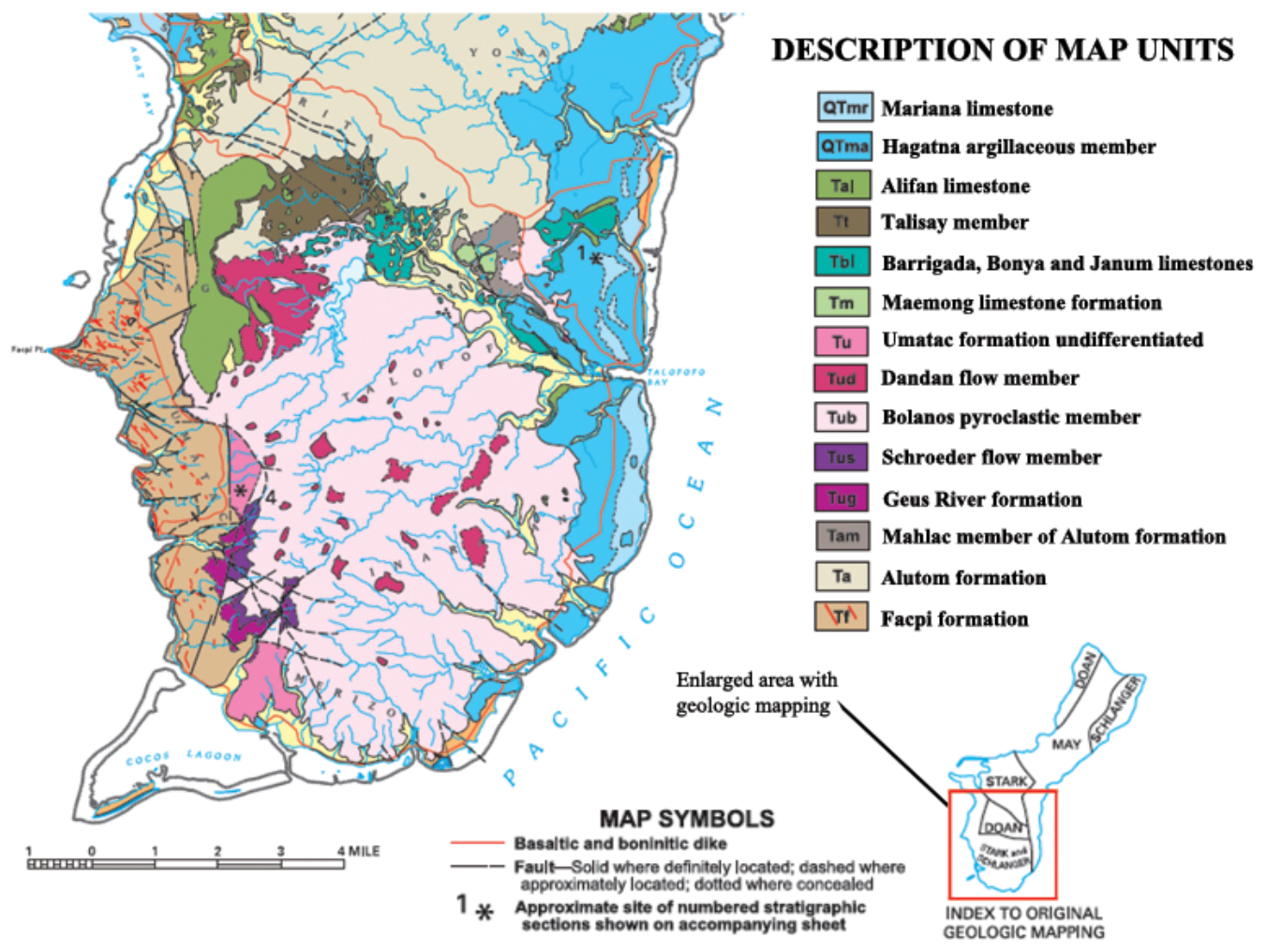

COMPOSITE STRATIGRAPHIC SECTIONS

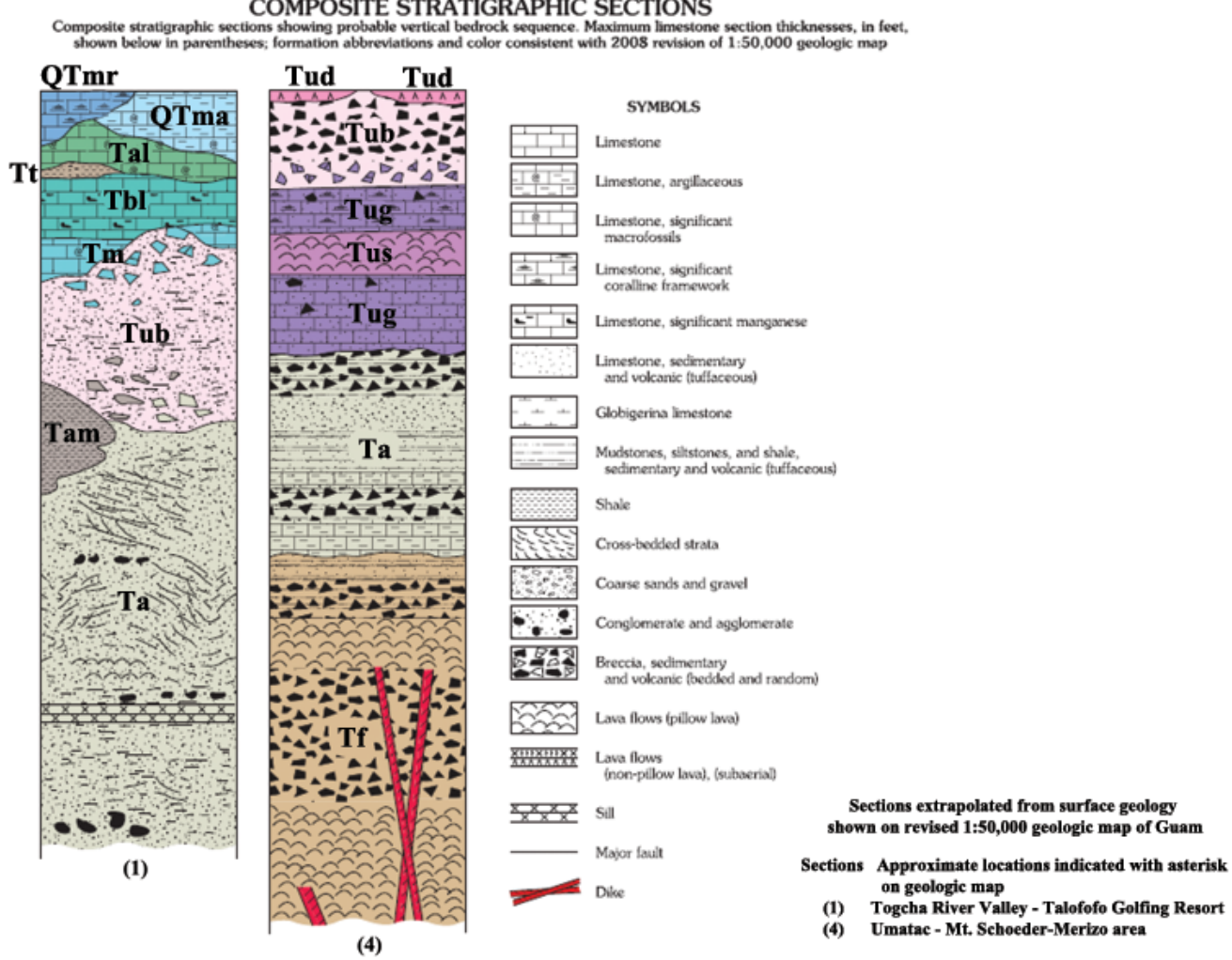

Figure 2.3. Geologic map and stratigraphic columns for southern Guam (altered from Siegrist and Reagan [2008]). 
limestones were deposited at shallow to intermediate depths with evidence of reefs and lagoons in several of them [Tracey et al., 1964]. The island of Guam experienced several episodes of submergence and uplift during the Pliocene and Pleistocene and has remained exposed since the late Pleistocene [Tracey et al., 1964]. The outcropping of the early volcanic sequences is a product of periodic, and later prolonged, aerial exposure to weathering and wave erosion at the coastal regions and in bays. 


\subsection{METHODOLOGY}

3.1 Processing whole rock samples

Whole rock samples were collected from a repository at University of Hawai'i at Mānoa in Honolulu, Hawai'i. Sixty of the most felsic and gabbroic rocks were chosen based on visual characteristics of the hand samples in two dredges (RD63 and RD64) recovered by the 1981 cruise by R/V Kana Keoki (University of Hawai’i). In many cases, small corners of the rocks were chipped to see the mineralogy under the manganese oxide coating. Many had been previously chipped, probably shortly after recovery, in order to obtain the lithology classifications for the dredge. These two dredges were chosen based on the initial reports of shipboard scientists (especially Dr. Patricia Fryer of University of Hawai'i). Approximately $1 / 2$ to $1 / 4$ of any sample taken for this study remains at the repository at University of Hawai'i.

Rocks were cut into slabs in the "Rock Prep Lab" at Florida International University using a water-cooled diamond bit MK 101 series Tile saw. Select slabs were chosen from 30 samples for thin and thick section preparation. Billets were cut with the water-cooled diamond bit Hillquist saw. Then all cut sides of the billets were abraded with 80 mesh silicon carbide sand paper with DI (deionized) water to remove metallic saw marks and then the sanded billets were placed in an ultrasonic bath for 10 minutes in DI water. Billets were sent for thin and thick section preparation at a commercial lab. Petrographic descriptions and modal analyses are given in Chapter 4 and the Appendix. 


\subsection{Major and trace element analysis}

Samples were chosen for major and trace element analysis so that the full range of lithologies at both sites is represented. Slabs were chosen to cut smaller billets (approximately 10 grams) for making rock powder for major and trace element geochemical analyses. These billets were cut so that alteration rinds were excluded and major fractures were avoided; minor fractures were also avoided as much as possible. These billets were placed in an ultrasonic bath for 10 minutes and then air dried for at least 12 hours. The dry billets were crushed in a Sr-free laboratory using a SPEX 4200 Jaw Crusher with alumina jaws and the fragments $(<1 \mathrm{~cm})$ were collected in a snap-cap plastic bottle. The Jaw Crusher was cleaned between samples with a long handle brush, vacuum and air pressure hose to prevent cross-sample contamination. Then, each sample was crushed further in a SPEX Mixer/Mill using an alumina vessel and milling balls. These bottled powders are currently stored on the bottom shelf of a fixed cabinet in PC340. Additional powdering was performed as needed for geochemical major and trace element analysis by Washington State University GeoAnalytical Lab in Pullman, Washington.

Major and trace elements were analyzed at GeoAnalytical Lab by ICP-MS and XRF. The ThermoARL XRF measured the major elements. The Agilent 7700 ICP-MS was used to measure most of the trace elements (and all the rare earth elements (REEs) in the lanthanide series).

GeoAnalytical Lab used a combination fusion-dissolution method to decompose refractory mineral phases that are otherwise difficult to digest completely in open-beaker dissolutions. The procedure begins with a low-dilution fusion with di-Lithium 
tetraborate, after which the bead is crushed. The bead powder is then subjected to a mixed acid digestion $\left(\mathrm{HNO}_{3}-\mathrm{HF}-\mathrm{HClO}_{4}\right)$ in a savillex beaker. Additional acid steps and dry downs are needed to ensure complete dissolution of the sample and these steps are available from the lab by request. The final diluted $\mathrm{HNO}_{3}-\mathrm{H}_{2} \mathrm{O}_{2}-\mathrm{HF}$ solution is the trace element solution (the HF removes the last traces of silica and the flux as gaseous fluorides so the remaining solution is clear and can be analyzed on the ICP-MS).

The solution was diluted $(5 \mathrm{x}, 10 \mathrm{x}$, or 20x) by the auto-sampler at the time of introduction to the nebulizer. Instrumental drift was corrected using $\mathrm{Ru}$, In, and Re as internal standards. Internal standardization for the REEs was done using techniques by Doherty (1989) and involve a linear interpolation between In and Re that compensates for mass-dependent differences in the rate and degree of instrumental drift. According to information from the technical notes on the WSU GeoAnalytical website, correction factors used to compensate for the remaining oxide interferences are estimated using two mixed-element solutions. The lab used three in-house rock standards which are analyzed multiple times interspersed within each batch of 18 unknowns. Concentrations, oxide and drift corrections are then calculated offline at GeoAnalytical Lab using an in-house spreadsheet.

\subsubsection{Select trace element analysis at FIU}

Unfused samples were prepared and processed at FIU clean labs and analyzed for trace elements at the Trace Evidence and Analysis Facility (TEAF) on FIU campus. These data acquired by these analyses were compared to the analyses of fused samples that were run at GeoAnalytical Lab (WSU, Washington). Details about the procedures, experimental data and conclusions are listed in the Appendix. 
3.3 Isotope ( $\mathrm{Hf}, \mathrm{Sr}, \mathrm{Nd}, \mathrm{Pb})$ analysis

\subsubsection{Leaching Procedure}

This procedure was modified from Mahoney [1987] and Weis and Frey [1991; 1996] who used leaching to prepare altered seafloor basalts for isotopic analysis. Petrographic and modal analysis of the sample suites in this study indicated that the rock powders were likely to contain a percentage of secondary alteration mineralogy sufficient to influence isotopic compositions, therefore more initial rock powder was weighed out and extra leaching steps were added and then dissolved as outlined in the steps below.

1. Approximately $0.8 \mathrm{~g}$ of rock powder was weighed into clean $15 \mathrm{~mL}$ savillex beakers. One gram of sample was weighed out for one sample with exceptionally high amounts of hydrous secondary mineralization (RD63-J07).

2. A total of $10 \mathrm{~mL}$ of $6 \mathrm{~N}$ "sub-boiled" $\mathrm{HCl}$ was added to the savillex beakers. In order to expose all the powder to the acid, a few mLs were added first and the beakers were tilted until the powder was not stuck to the bottom inside of the beaker. Then the beaker was filled.

3. The beakers were then capped tightly and wrapped completely in parafilm and placed in the ultrasonic bath for 20 minutes.

4. The beakers were removed from the ultrasonic bath, the parafilm was discarded and the beakers were left to settle for about 10 minutes so the larger particles would settle but the fine clays were still suspended.

5. The supernatant solution was decanted and discarded.

6. Steps 2 through 5 were repeated seven times until the supernatant solution was clear and colorless or pale yellow. Some of the samples did not lighten very 
much after seven steps and lost a significant volume, but a few became completely clear in only five leaching steps.

7. After ultrasonicating with acid, steps 2 through 5 were repeated three times using "quartz water" instead of $\mathrm{HCl}$ for all samples to eliminate the excess $\mathrm{HCl}$ and various salts that may have formed during the leaching.

8. The leached rock powder was dried on a hot plate at $100^{\circ} \mathrm{C}$ overnight.

9. The dried powder was then weighed and recorded after it was cooled.

\subsubsection{National High Magnetic Field Laboratory: clean lab procedures}

The following methodology is a summary of the full procedure for the dissolution of powdered rock samples and column separation for isotope analysis. These methods were developed by faculty and staff at the National High Magnetic Field Laboratory (NHMFL) in Tallahassee, FL unless otherwise noted. The full procedure is listed in the Appendix. All savillex beakers from FIU for these analyses were prepared based on the steps described in the Appendix.

\subsubsection{Dissolution and $\mathrm{Pb}, \mathrm{Nd}, \mathrm{Hf}, \mathrm{Sr}$ column separation}

Sample powders were shipped to Tallahassee where the sample digestion and column separation was performed in the clean lab at NHMFL. First, 200mg of powder was digested with concentrated $\mathrm{HF}, \mathrm{HNO}_{3}, \mathrm{HCl}$ and $\mathrm{HBr}$ with repeated dissolution and drydown steps until the samples were completed dissolved. The final sample was in a $10 \mathrm{~mL}$ solution of QD water, $\mathrm{HNO}_{3}$ and $\mathrm{HBr}$. The sample was run through the $\mathrm{Pb}$ columns and the $\mathrm{Pb}$ fraction was collected, dried down and stored, and when ready for analysis on the Neptune MC-ICP-MS, $200 \mu \mathrm{L}$ of $2 \% \mathrm{HNO}_{3}$ was added to pick up the sample. 
The $\mathrm{Sr}$, Hf, $\mathrm{Nd}$ was collected during $\mathrm{Pb}$ column separation, and this fraction was converted for the $\mathrm{Hf}$ columns using $6 \mathrm{~N}$ and then $3 \mathrm{~N} \mathrm{HCl}$ and dried down completely. The Hf column technique is based on Münker et al. [2001]. Before loading the Sr, Hf, $\mathrm{Nd}$ fraction in the column, $4.25 \mathrm{~mL} 3 \mathrm{~N} \mathrm{HCl}$ and $0.251 \mathrm{M}$ ascorbic acid (to reduce the $\mathrm{Fe}$ in the solution for decreased compatibility with the Fe in the column resin) was added for a total solution of $\sim 5 \mathrm{~mL}$. This solution was run through the Hf columns and the Hf was collected, dried down and stored with $1-2 \mathrm{~mL}$ of diluted $\mathrm{HNO}_{3}$ until ready to analyze on the Neptune MC-ICP-MS.

The Sr and REEs were collected, dried down, then converted for the cation columns using repeated dissolutions and drydowns with $\mathrm{HCl}, \mathrm{HNO}_{3}$ and $\mathrm{HClO}_{4}$. The sample was loaded into the first of the cation columns in a $2.5 \mathrm{~N} \mathrm{HCl}$ solution to collect the $\mathrm{Sr}$ fraction, which was then dried down overnight. After drying the sample, $\mathrm{HClO}_{4}$ and $\mathrm{HNO}_{3}$ were added in separate steps and the sample was dried after each step. The final sample was left dry in a capped beaker until ready to be loaded onto a filament for analysis on the TIMS.

The REEs were collected from the first cation column using $6 \mathrm{~N} \mathrm{HCl}$ and were then also dried down overnight. Then the fraction was picked up with $0.25 \mathrm{~N} \mathrm{HCl}$ for the second cation column separation (to collect the $\mathrm{Nd}$ ). The solution was run through the column and the $\mathrm{Nd}$ was collected, and dried overnight. After drying the sample, $\mathrm{HClO}_{4}$ and concentrated $\mathrm{HNO}_{3}$ were added in separate steps and the sample was dried after each step. The final sample was left dry in a capped beaker until ready to be run on the Neptune MC-ICP-MS. 


\subsubsection{2 $\mathrm{Sr}$ isotope sample analysis}

The Sr isotopes were analyzed on a Thermo Scientific Finnigan MAT TIMS (thermal ionization mass spectrometer) series 262. Dried Sr samples from the columns were loaded onto degassed $\mathrm{W}$ filaments (see Appendix for details).

\subsubsection{Measurement of ${ }^{87} \mathrm{Sr} /{ }^{87} \mathrm{Rb}$ in samples before analysis}

Before running a sample on the TIMS it is important to do a quantitative estimate of ${ }^{87} \mathrm{Rb}$ to ensure it will not interfere with the ${ }^{87} \mathrm{Sr}$ during analysis. This is done by reading the counts of ${ }^{85} \mathrm{Rb}$ with the ICM (ion counter multiplier) SEM (secondary electron multiplier) on the TIMS. A ratio of $2.6: 1\left({ }^{87} \mathrm{Rb}:{ }^{85} \mathrm{Rb}\right)$ is used to approximate ${ }^{87} \mathrm{Rb}$ in the sample. Then the counts of ${ }^{87} \mathrm{Sr}$ are read from the TIMS. If the ratio of ${ }^{87} \mathrm{Sr}:{ }^{87} \mathrm{Rb}$ is greater than 10,000 then the sample can be run without further steps, but if the ratio is less than 10,000 (as was the case with most samples from KK810626) then the sample must be "flashed" (i.e., quickly increasing current across the filament) until that ratio is near or above 10,000. "Flashing" the sample results in some loss of Sr but the concentrations were high enough in the samples that it could be flashed multiple times without burning off the sample.

\subsubsection{4 $\mathrm{Sr}$ isotope analysis on the TIMS}

The Sr isotope samples were loaded on tungsten filaments and run on a Finnigan MAT TIMS, series 262. Most 2-sigma values were less than 0.00009 and the measured sample values were corrected using repeated analysis of the $\mathrm{E} \& \mathrm{~A}$ standard $(87 \mathrm{Sr} / 86 \mathrm{Sr}=$ 0.70808) which was bracketed among the samples. 


\subsubsection{Nd, $\mathrm{Hf}$, and $\mathrm{Pb}$ isotope analysis}

These element isotope ratios were measured on the Thermo Electron Corporation Finnigan Neptune MC ICP-MS (multi-collector inductively coupled plasma mass spectrometer). The Neptune did not have an autosampler, so the sample tube was moved between centrifuge tubes manually. The Apex "Element 2" nebulizer and spray chamber apparatus introduced the solution to the plasma at a rate of approximately $60 \mu \mathrm{L} / \mathrm{min}$. In each isotope run a dip and wash solution of $2 \% \mathrm{HNO}_{3}$ was used to clean the autosampler.

\subsubsection{6 $\mathrm{Nd}$ isotope analysis}

The Spex solution that monitored drift was $150 \mathrm{ppb} \mathrm{Nd}$ in $2 \% \mathrm{HNO}_{3}$. Samples were loaded in $100 \mu \mathrm{L}$ of $2 \% \mathrm{HNO}_{3}$ so that approximately $150 \mathrm{ppb} \mathrm{Nd}$ of each sample was run through the instrument. The synthetic LaJolla standard with ${ }^{143} \mathrm{Nd} /{ }^{144} \mathrm{Nd}=0.511850$ was run three times at the beginning and end of the analysis and once every four samples during analysis. The average value for the LaJolla standard was ${ }^{143} \mathrm{Nd} /{ }^{144} \mathrm{Nd}=0.511800$ and the one-sigma values were 0.000003 or less. The one-sigma values of ${ }^{143} \mathrm{Nd} /{ }^{144} \mathrm{Nd}$ for all samples analyzed were 0.000007 or less. The normalizing ratio used was ${ }^{146} \mathrm{Nd} /{ }^{144} \mathrm{Nd}=0.7219$.

\subsubsection{Hf isotope analysis}

The Spex solution used to monitor drift was $150 \mathrm{ppb} \mathrm{Hf}$ in $2 \% \mathrm{HNO}_{3}+0.02 \mathrm{~N} \mathrm{HF}$. Samples were loaded in $100 \mu \mathrm{L}$ of $2 \% \mathrm{HNO} 3+0.02 \mathrm{HF}$ so that approximately $150 \mathrm{ppb} \mathrm{Hf}$ of each sample was run through the instrument. The JMC475 standard with ${ }^{178} \mathrm{Hf} /{ }^{176} \mathrm{Hf}=$ 0.28216 was run three times at the beginning and end of the analysis and once every four samples during analysis. The average value for the JMC475 standard was ${ }^{178} \mathrm{Hf} /{ }^{176} \mathrm{Hf}=$ 0.282142 and the one-sigma values were 0.000005 or less. The one-sigma values of 
${ }^{178} \mathrm{Hf} /{ }^{176} \mathrm{Hf}$ for all samples analyzed were 0.000009 or less (except for sample RD63-J15, whose one-sigma $=0.000044)$. The normalizing ratio used was ${ }^{178} \mathrm{Hf} /{ }^{176} \mathrm{Hf}=0.7325$.

\subsubsection{8 $\mathrm{Pb}$ isotope analysis}

The Spex solution was $150 \mathrm{ppb} \mathrm{Pb}$ in $2 \% \mathrm{HNO}_{3}$ with an internal correction added to it (40 $\mu \mathrm{L}$ of a $100 \mathrm{ppb} \mathrm{Tl}$ solution). Samples were loaded in $500 \mu \mathrm{L}$ of $2 \% \mathrm{HNO}_{3}$ so that approximately $40 \mathrm{ng} \mathrm{Pb}+4 \mathrm{ng} \mathrm{Tl}$ in each sample was run through the instrument. The NSB 981 standard $\left({ }^{206} \mathrm{~Pb} /{ }^{204} \mathrm{~Pb}=16.9356 ;{ }^{207} \mathrm{~Pb} /{ }^{204} \mathrm{~Pb}=15.4891 ;{ }^{208} \mathrm{~Pb} /{ }^{204} \mathrm{~Pb}=\right.$ 36.7006) was run three times at the beginning and twice at the end of the analysis and twice every four samples during analysis. The average values for the NSB 981 standard was ${ }^{206} \mathrm{~Pb} /{ }^{204} \mathrm{~Pb}=16.9292,{ }^{207} \mathrm{~Pb} /{ }^{204} \mathrm{~Pb}=15.4820$, and ${ }^{208} \mathrm{~Pb} /{ }^{204} \mathrm{~Pb}=36.6691$ and the onesigma values were 0.0009 or less. The one-sigma values of ${ }^{206} \mathrm{~Pb} /{ }^{204} \mathrm{~Pb}$ and ${ }^{207} \mathrm{~Pb} /{ }^{204} \mathrm{~Pb}$ were 0.0009 or less and ${ }^{208} \mathrm{~Pb} /{ }^{204} \mathrm{~Pb}$ was 0.0016 or less for all samples analyzed. The mass fractionation correction ratio used was ${ }^{203} \mathrm{Tl} /{ }^{205} \mathrm{Tl}=0.418922$. 


\subsection{ANALYSES AND CHARACTERIZATION OF DREDGE RD63 AND RD64}

This chapter details the mineralogic, petrologic and geochemical characteristics of the rocks from the 1981 University of Hawai'i research cruise KK81-06-26 dredges RD63 and RD64. The general outline of this chapter is as follows: 1) details of the mineralogic and petrologic classifications, and geochemical, isotopic results with some interpretations of the magmatic environment during formation and subsequent alteration

of the samples, 2) a demonstration of how rare earth element modeling for RD63 plutonic rocks gives insight to the differentiation or partial melting steps required to form highly differentiated plutonic rocks in the Mariana forearc, 3) a brief discussion of geochronological methods used for dating igneous rocks, and 4) an overview of the conclusions for the data in this chapter.

4.1 Results of geochemical analyses and petrography

4.1.1 Normative, modal and textural petrologic review of RD63 and RD64 samples

The bulk rock chemical analysis of an igneous rock (see Chapter 5 and section 4.1.3) can be used to recalculate the data into a general mineral composition of the rock assuming common minerals are forming in an equilibrated, ideal system. This is a classic CIPW recalculation (named after the authors that first proposed the classification: Cross, Iddings, Pirsson, and Washington) and it is useful in simple comparisons to other igneous rocks. After the recalculation into mineral weight or volume percent, the quartz $(\mathrm{Q})$, alkali (A) feldspar and plagioclase (P) feldspar values can be summed, normalized and plotted on a QAP ternary diagram (Figure 4.1) developed by Streckeisen [1974], Maitre et al. [1989] and Le Bas and Streckeisen [1991] and adopted by the IUGS (International Union of Geological Sciences). 
A program from Union College developed by Hollocher was used in this study to determine the normative mineralogy ("norms") for RD63 and RD64 rocks; the program was closely based on the CIPW calculations in Johannsen [1931] but slightly different in that the program calculates feldspar and pyroxene norms as percentages of the solid solution end members (plagioclase-orthoclase and diopside-hypersthene), while the classic CIPW calculation lists each mineral separately. This difference is only a slight simplification but does not affect the accuracy of the normative calculation.

A modal analysis of a thin section is a method used to estimate the percent of different types of minerals present volumetrically in a rock in a relatively quick yet accurate way without bias. Generally, a setup called a point counter is attached to the stage of an optical microscope and the user affixes the slide to the device. Then the slide may be moved in an " $\mathrm{x}$ " and "y" direction using two dials. Every turn of one of the dials moves the slide a uniform distance either in the $\mathrm{x}$ or $\mathrm{y}$ direction and the user identifies the mineral in the crosshairs of the microscope and keeps record of the count; in this manner, an unbiased tally is generated for the slide. The counts are converted to percent based on the total number of points for the slide.

In this study, two different geology undergraduates were employed to perform the point counting of thirteen representative slides, recording at least 200 points for each slide. When possible, the probable primary mineral was counted rather than the remineralization (e.g., if a point landed on sericite or clay, it would be counted as feldspar if it was clear that was the primary mineral). Ferromagnesian minerals were grouped 


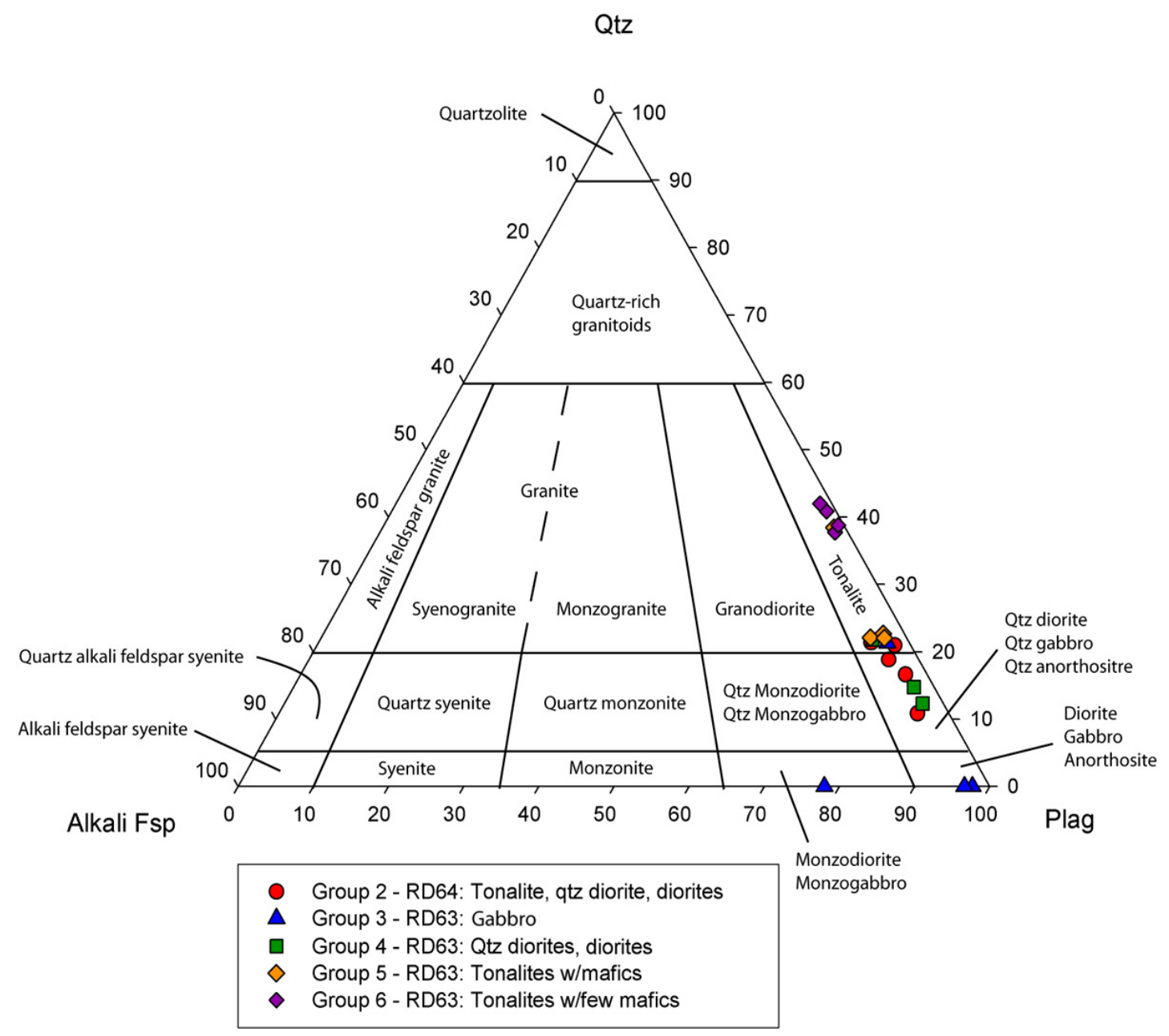

Figure 4.1. IUGS classification and nomenclature of plutonic rocks in RD63 and RD64. Quartz-alkali feldspar-plagioclase (QAP) diagram for plutonic rocks. Fine grained rocks from RD64 (Group 1) are not included on diagram because they are volcanic or hypabyssal rocks. Fields are based on Streckeisen [1974].

together as an estimation for mafic minerals (e.g., orthopyroxene, clinopyroxene, amphiboles, chlorite). One or two slides of each lithology were analyzed for modes as supplemental information to normative lithology calculations.

Furthermore, as a comparison to the petrographic modal analyses by point counting, the same slides were photographed using a Nikon digital camera mounted to a 
Leica microscope. The image analysis of the slides was done using Adobe Creative Suite Photoshop software, but the analysis could not be done automatically with this software because of the visual similarity between quartz, feldspar, orthopyroxenes and other minerals with low birefringence (i.e., color and contrast cannot be used to isolate the mineral phases) so minerals were outlined manually and an area percentage was calculated. The image analysis shows fairly good correlation to the point counting in about half the slides. The other slides have a difference up to $30 \mathrm{wt} \%$ between the point counting and manual image analysis, usually within the quartz and feldspar phases and in samples where the feldspar is anhedral.

Descriptions for thin sections analyzed in this study are included in the Appendices. Textural observations in the thin section descriptions can provide evidence for the formational environment of the samples. The following is a summary of the major and notable observational trends in the thin sections from RD63 and RD64. Gabbros have the largest grain sizes up to $5 \mathrm{~mm}$. Diorites, quartz diorites and tonalites $\left(\mathrm{SiO}_{2} 56-78 \mathrm{wt} \%\right)$ have smaller grain sizes mostly between 0.5 to $2 \mathrm{~mm}$, but grain sizes vary within each sample (e.g., plagioclase as small as 160 microns). The grain sizes for tonalites with $\mathrm{SiO}_{2}>78 \mathrm{wt} \%$ are difficult to measure because of their granophyric texture, but the same approximate grain sizes $(0.5-2 \mathrm{~mm})$ were measured from subhedral grains. Feldspar zoning varies across samples but almost all feldspar grains have some extent of gradational extinction. Some samples exhibit albite twinning in the feldspar (e.g., quartz diorite RD63-J29) but most do not. Most samples show at least thin growth rims around feldspar cores, but in other samples the feldspars have vastly different zoning patterns within the same crystal. Granophyric texture is found only in the most silicic tonalites 
and with the use of EPMA (Electron Probe Micro-Analysis) it is known that the feldspar composition does not vary between portions of the tonalite with and without the granophyric texture (An3-8).

Sericitization of plagioclase feldspar in the gabbros makes it impossible to see any potential zoning and the primary ferromagnesian minerals (pyroxenes and amphiboles, likely) have various degrees of intergrowth of fine-grained micas and in some cases amphibole rims. There is a lesser degree of plagioclase alteration in most other samples, and a few samples (e.g. RD63-J23, RD63-J32) having fresh looking euhedral plagioclase grains. Secondary mineralogy in other samples is evidenced by chlorite intergrowth between quartz and feldspar grains, within which is interspersed magnetite.

\subsubsection{Mineral chemistry of RD63 and RD64}

Studying the chemistry of individual minerals rather than the bulk chemistry of a sample can provide insights into the magmatic conditions at the time of crystal growth and also any subsequent changes in magma chamber dynamics during crystallization history. Electron Microprobe Analyzer (EPMA) observations in back scatter electron (BSE) mode can visually reveal alteration and heterogeneities within minerals and give quantitative results of those alterations, heterogeneities and in some cases secondary mineralization. In this section, the EPMA results are summarized and their significance elucidated in regard to this study. EPMA analyses were performed during the spring of 2010 to help characterize the igneous minerals in four representative thin sections. The EPMA mineral data are listed in the Appendix with the backscatter images that correspond to the probe spots. 
Table 1. Modal analysis by point counting

\begin{tabular}{|c|c|c|c|c|c|c|c|c|c|c|c|}
\hline & & & \multicolumn{9}{|c|}{ Modes $^{+}$} \\
\hline Lithology* & Sample & $\begin{array}{l}\mathrm{SiO}_{2} \\
\mathrm{wt} \% \\
\end{array}$ & Quartz & $\begin{array}{l}\text { Plagio- } \\
\text { clase }\end{array}$ & $\begin{array}{c}\text { Ferro- } \\
\text { magnesian }\end{array}$ & Oxides & $\begin{array}{l}\text { Serp } \\
\text { pyx }\end{array}$ & $\begin{array}{l}\text { Grano- } \\
\text { phyre }\end{array}$ & $\begin{array}{l}\text { Pheno- } \\
\text { crysts }\end{array}$ & Skip & Total \\
\hline Gabbro & RD63-J07 & 49.3 & 0.0 & 55.9 & 42.4 & 0.0 & -- & -- & -- & 1.8 & 100 \\
\hline Tonalite & RD63-J15 & 73.6 & 40.9 & 44.3 & 7.6 & 5.5 & -- & -- & -- & 1.7 & 100 \\
\hline Quartz diorite & RD63-J23 & 63.2 & 39.8 & 27.7 & 31.8 & 0.5 & -- & -- & -- & 0.2 & 100 \\
\hline Tonalite & RD63-J28 & 74.2 & 38.4 & 54.1 & 5.2 & 2.2 & -- & -- & -- & 0.0 & 100 \\
\hline Diorite & RD63-J29 & 58.2 & 32.9 & 27.2 & 35.7 & 2.2 & -- & -- & -- & 2.0 & 100 \\
\hline Tonalite & RD63-J32 & 64.1 & 30.9 & 38.6 & 30.2 & 0.4 & -- & -- & -- & 0.0 & 100 \\
\hline $\mathrm{QD}^{1} /$ Tonalite & RD63-J34 & 61.5 & 24.0 & 51.1 & 21.4 & 3.4 & -- & -- & -- & 0.0 & 100 \\
\hline Gabbro & RD63-J35 & 48.8 & 0.0 & 71.4 & 26.9 & 0.8 & -- & -- & -- & 0.8 & 100 \\
\hline Tonalite & RD63-J40 & 76.9 & 28.9 & 41.4 & 4.6 & 1.5 & -- & 23.6 & -- & 0.0 & 100 \\
\hline Bronzite andesite & RD64-J49 & 57.3 & 6.0 & 47.8 & 43.3 & 0.8 & -- & -- & 1.5 & 0.5 & 100 \\
\hline Quartz diorite & RD64-J55 & 60.0 & 28.7 & 37.6 & 28.8 & 3.3 & -- & -- & -- & 1.5 & 100 \\
\hline Altered "diorite" & RD64-J63 & 57.5 & 0.0 & 28.0 & 44.0 & 1.7 & 25.1 & -- & -- & 1.1 & 100 \\
\hline Tonalite & RD64-J65 & 68.2 & 40.3 & 24.4 & 33.7 & 0.7 & -- & -- & -- & 0.9 & 100 \\
\hline
\end{tabular}

*Lithology determined by normative mineralogy.

${ }^{+}$Modes given in percent of thin section area.

${ }^{++}$Granophyre is a texture where the feldspar and quartz ratio is approximately $1: 1$.

The skipped column represents the percentage of points that were skipped due to the point landing on the boundary of two grains or a fracture or vein. ${ }^{1} \mathrm{QD}=$ quartz diorite 


\subsubsection{Amphiboles}

The four polished thick sections are from a medium to fine grained mafic rock with phenocrysts (RD64-J49), a coarse grained diorite (RD63-J07), a tonalite with 8\% mafics (RD63-J15), and a tonalite with less than 5\% mafics (RD63-J40). J49 is from dredge 64, and the other three (J07, J15, and J40) are from dredge 63.

The mafic minerals analyzed in J07 have high Fe (10.5-13.5 wt\%), Mg (15.7-17.3 $\mathrm{wt} \%)$, and $\mathrm{Ca}(11.1-12.8 \mathrm{wt} \%)$. Under optical microscope, they have relict cleavage and grain shapes that would indicate a pyroxene. However, the internal structure shows fine intergrowths which EPMA analyses confirm as amphibole. The amphibole classification used was from Leake et al. [1997] and the recalculation method was in Appendix 2 by Schumacher, J.C. Figure 4.2 shows the classification chart of six points from one grain in J07. Data are shown for formula recalculations of all ferric iron or all ferrous iron in the structural formula, as both are plausible outcomes for the given EPMA analyses.

\subsection{Interpretation of amphiboles in the (RD63-J07) gabbro}

Most of the mafic minerals in J07 gabbro optically appear to have once been pyroxenes but the chemistry indicates that they have been converted to amphiboles, which typically occurs by hydration reactions. The amphiboles are actinolite, with possible magnesiohornblende and tremolite occurring in minor amounts. The occurrence of secondary amphibole replacement of pyroxene in a gabbro is evidence of moderate temperature hydrothermal alteration $\left(450-600^{\circ} \mathrm{C}\right.$, hornfels facies) which is consistent with a spreading ridge environment. 


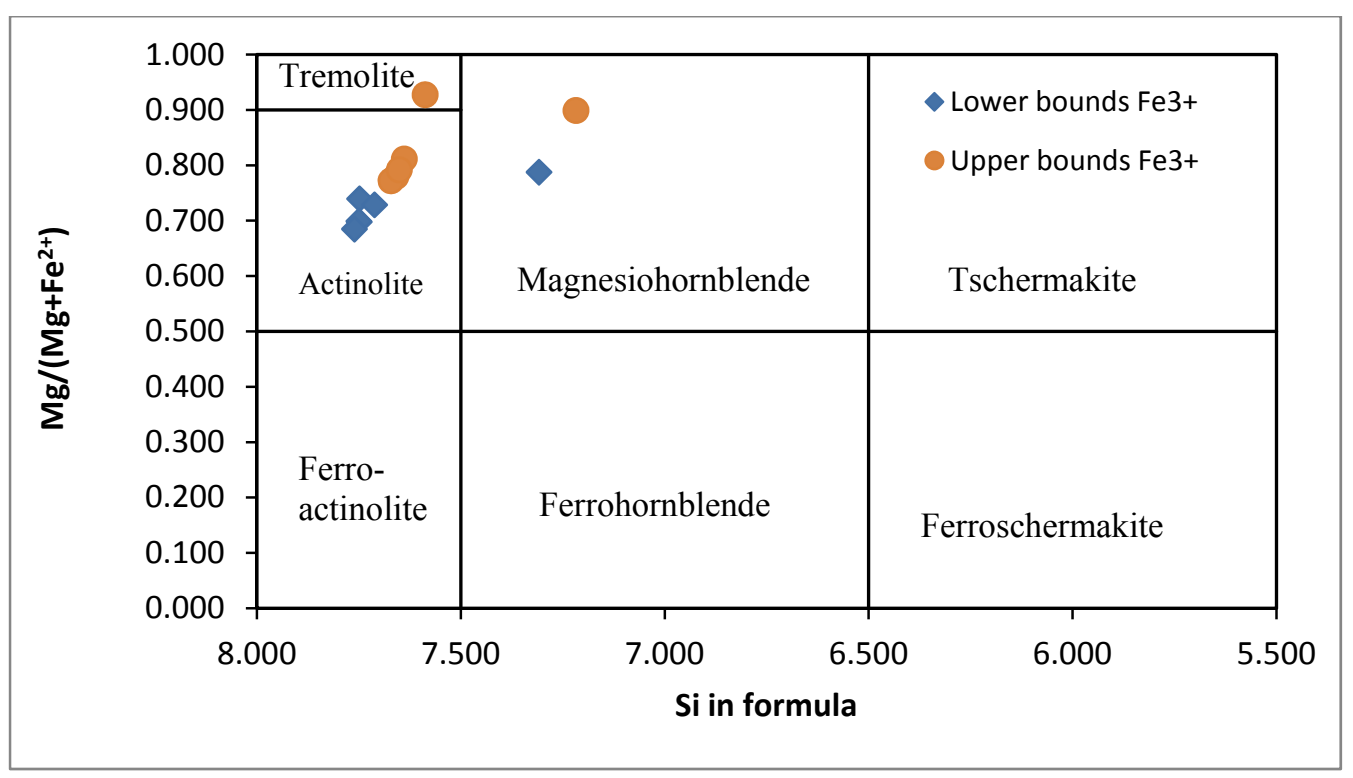

Figure 4.2. Classification of amphiboles from Leake et al. [1997]. Diagram parameters: $\mathrm{Ca}_{\mathrm{B}} \geq 1.50 ;(\mathrm{Na}+\mathrm{K})_{\mathrm{A}}<0.50 ; \mathrm{Ca}_{\mathrm{A}}<0.5$

\subsubsection{Pyroxenes in RD64 (J49) andesite}

Mafic minerals analyzed in $\mathrm{J} 49$ have high $\mathrm{FeO}_{\mathrm{T}}(5.0-15.6 \mathrm{wt} \%), \mathrm{MgO}(11.0-$ $19.6 \mathrm{wt} \%)$ and $\mathrm{CaO}(17.7-23.4 \mathrm{wt} \%)$ which are indicative of pyroxenes. The chemical compositions obtained by EPMA analyses were recalculated in terms of Wo:En:Fs and plotted in Figure 4.3. The Ca range is above the miscibility gap of pyroxenes and all the mineral data fall in the clinopyroxene field, specifically in the range of diopside and augite. Two fields of compositions appear on the ternary. All pyroxene grains in sample J49 that are plotted on Figure 4.3 are consistently the same approximate size throughout the thin section. 


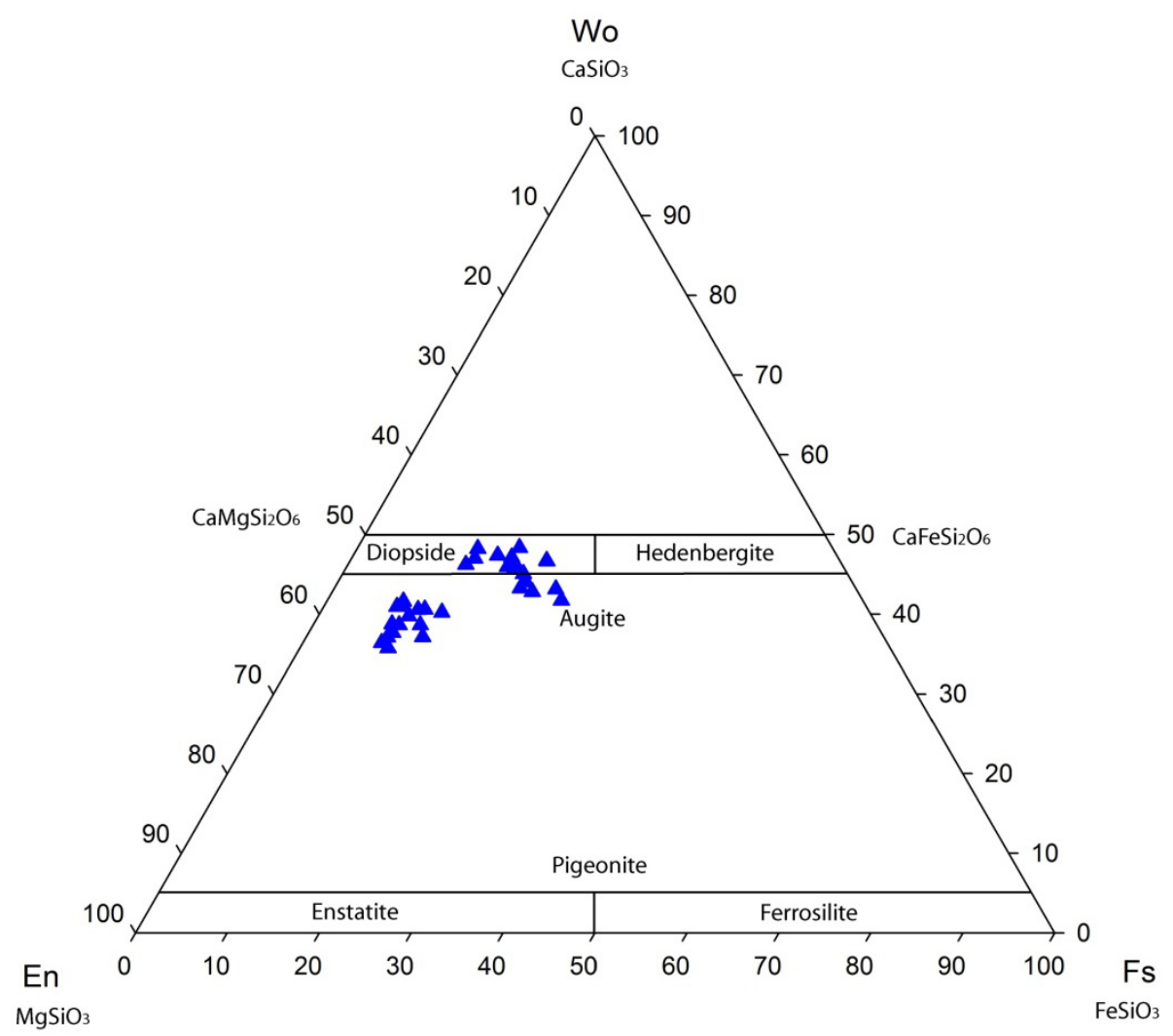

Figure 4.3. Pyroxene ternary showing EPMA data from sample RD64-J49.

The groundmass in the andesite from RD64 (J49) has mafic minerals that are mostly clinopyroxenes: diopside and augite. The phenocrysts are magnesian orthopyroxenes (i.e., enstatite, also considered bronzite because of the abundant chromite accessory minerals). Analyses of mafic minerals should be performed in other thin sections from RD63 and RD64 in order to establish a clearer picture of the environment in which these rocks were formed and altered.

\subsubsection{Feldspars in RD63 and RD64}

Chemical compositions for feldspar grains were recalculated in terms of An:Ab:Or. All the values recalculated lie within the plagioclase solid solution in each of 
the four thin sections probed. Figure 4.4 is the feldspar ternary on which the feldspar compositions are plotted. Sample RD63-J40 (tonalite) has the most sodic plagioclase, falling in the albite region An0-10; RD63-J15 (tonalite) contains a large range of plagioclase between An20-70; RD64-J49 (bronzite andesite) contains plagioclase with compositions that are more clustered between An75-90; RD63-J07 (gabbro) has the most calcic plagioclase but also covers a large range An50-97. As expected, the An content of the feldspars decreases with increasing $\mathrm{SiO}_{2}$ of the whole rock (Figure 4.5).

Crystals were observed in thin section under cross polarized light with growth or reaction rims of varying widths. Several probe spots were chosen in the core, in the rim and in between to determine the chemical zoning pattern of the plagioclase grains. The grains are normally zoned, as illustrated in Figure 4.5. In all samples, the freshest cores of the plagioclase are higher in $\mathrm{Ca}$ than the rims, which become more sodic. The grains in these four samples do not appear to have oscillatory chemical zoning when viewed with backscatter electron imaging in the EPMA.

\subsubsection{Micas}

In addition to the data gathered across the albite-anorthoclase solid solution, six data points were taken within the grain boundaries of feldspar that initially appeared to have alkali feldspar compositions ( $\mathrm{K}_{2} \mathrm{O}$ values between 8.3 and $\left.10.0 \mathrm{wt} \%\right)$. However, silica values for these spots are only $48.0-51.0 \mathrm{wt} \%$ which is too low to meet the structural requirements of the orthoclase-albite solid solution $\left(\mathrm{SiO}_{2}\right.$ between 64.8 and $68.7 \mathrm{wt} \%)$. Moreover, alumina contents are between 35.2 and $36.1 \mathrm{wt} \%$ which is too high for the same solid solution (structurally limited $\mathrm{Al}_{2} \mathrm{O}_{3}$ of $18.3-19.4 \mathrm{wt} \%$ ). 


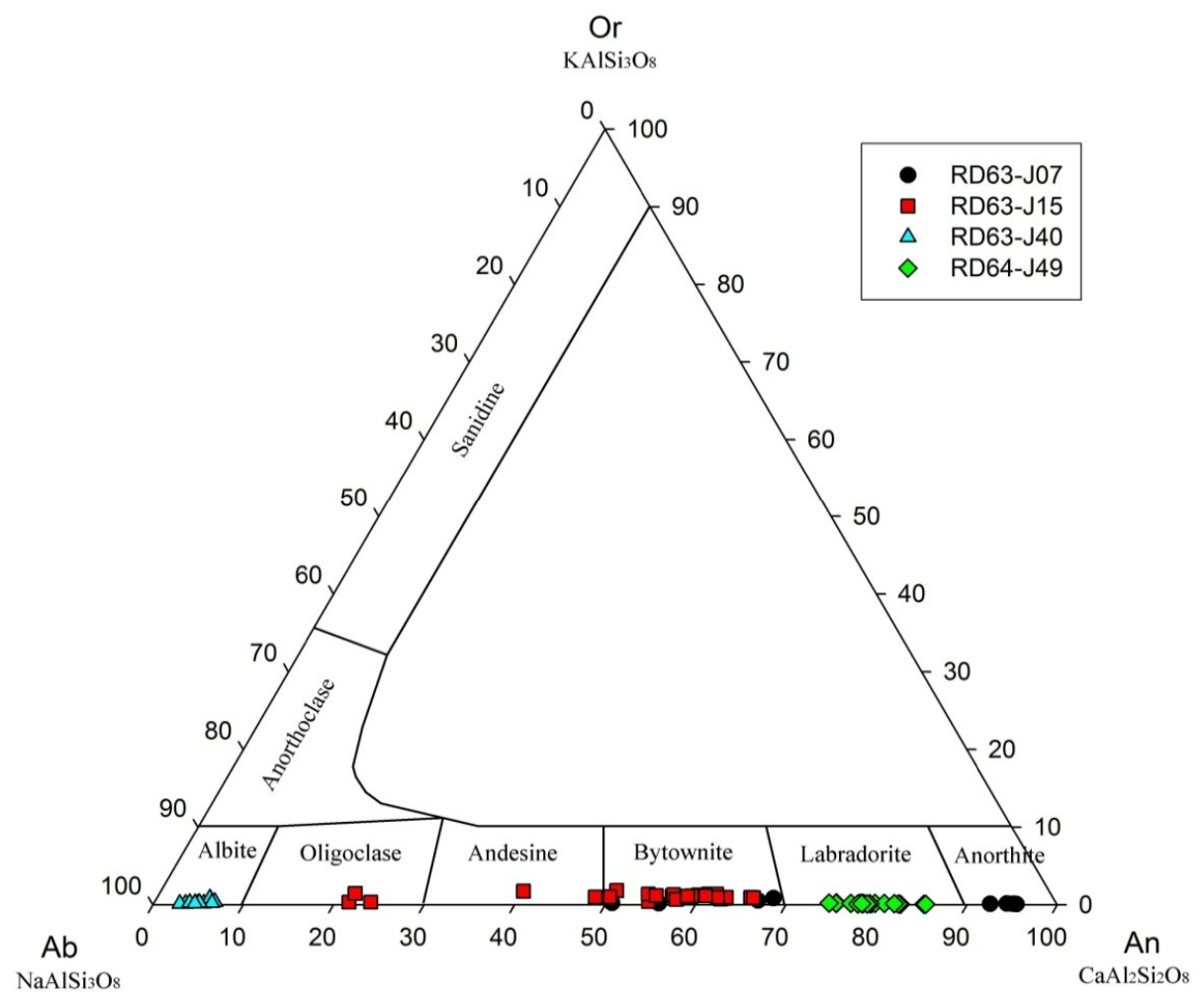

Figure 4.4. Feldspar ternary diagram showing EPMA data for four samples described above

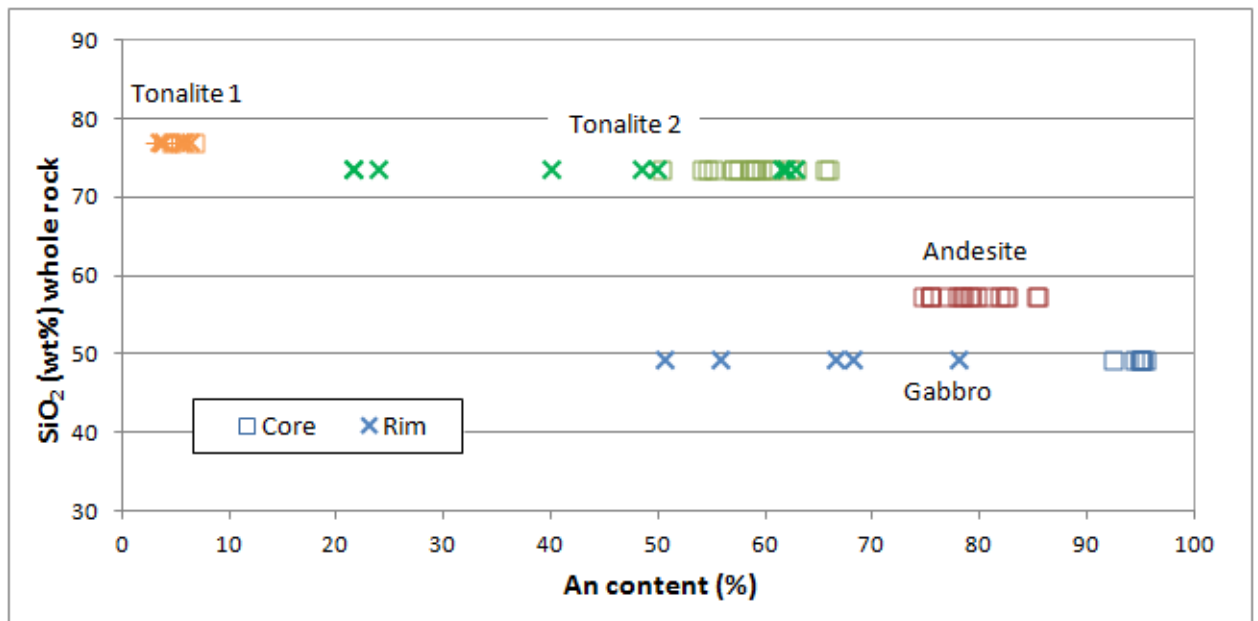

Figure 4.5. An content (\%) of plagioclase grains plotted according to $\mathrm{SiO}_{2}$ (wt\%). Points show difference in composition between core and rim measurements, except for the andesite in which the grains were finer and had no discernible compositional variation. Data were collected by EPMA. 
Therefore, recalculations of the oxide data were done for micaceous minerals. It is likely that these probe spots within the feldspar are hydrothermal "sericite" which commonly forms during alteration of feldspar grains.

\subsubsection{Spinels}

EPMA was used to determine the composition of iron oxide minerals in samples from $\mathrm{RD} 63$ and $\mathrm{RD} 64 . \mathrm{FeO}_{\mathrm{T}}$ was recalculated using charge balances to yield $\mathrm{Fe}^{2+}$ and $\mathrm{Fe}^{3+}$ values ( $\mathrm{FeO}$ and $\mathrm{Fe}_{2} \mathrm{O}_{3}$, respectively). The oxide minerals in $\mathrm{RD} 63$ are very $\mathrm{FeO}_{\mathrm{T}^{-}}$ rich (94-99 wt\%). The minerals also contain a maximum of $0.1 \mathrm{wt} \% \mathrm{MgO}, 0.5 \mathrm{wt} \%$ $\mathrm{CaO}, 0.6 \mathrm{wt} \% \mathrm{SiO}_{2}, 2.8 \mathrm{wt} \% \mathrm{TiO}_{2}, 0.2 \mathrm{wt} \% \mathrm{Al}_{2} \mathrm{O}_{3}, 1.5 \mathrm{wt} \% \mathrm{~V}_{2} \mathrm{O}_{3}$ and $3.8 \mathrm{wt} \% \mathrm{Cr}_{2} \mathrm{O}_{3}$. Given the concentrations of these elemental oxides, the chemical formula for the magnetites may be written as $\mathrm{Fe}^{3+}\left(\mathrm{Fe}^{2+}, \mathrm{Fe}^{3+}\right)_{2} \mathrm{O}_{4}$. The oxide minerals in $\mathrm{RD} 64$ primarily have $\mathrm{Cr}_{2} \mathrm{O}_{3}: 50-55 \mathrm{wt} \%, \mathrm{Al}_{2} \mathrm{O}_{3}: 11-11.8 \mathrm{wt} \%, \mathrm{MgO}: 11-13.8 \mathrm{wt} \%$, and $\mathrm{FeO}_{\mathrm{T}}: 19-25 \mathrm{wt} \%$, giving a general chemical formula for chromite: $\left(\mathrm{Mg}^{2+}, \mathrm{Fe}^{2+}\right)\left(\mathrm{Cr}^{3+}, \mathrm{Al}^{3+}\right)_{2} \mathrm{O}_{4}$.

Concentrations of $\mathrm{FeO}, \mathrm{Fe}_{2} \mathrm{O}_{3}$ and $\mathrm{TiO}_{2}$ were normalized and plotted on a ternary to determine classification. The Fe-oxides from RD63 plot near the magnetite field with varying degrees of oxidation; Fe-oxides in RD64 plot on the more reduced end of the magnetite field.

Accessory minerals in all four samples were analyzed with EDS only. Most of these minerals were clays, sulfides and carbonates less than 50 microns and were usually found in veins and fractures. One apatite grain (100 microns) was observed in the gabbro RD63-J07. 


\subsubsection{Mineralogic and petrologic summary}

RD63 and RD64 intrusives are classified as gabbros, diorites, quartz diorites and tonalites. The samples are K-deficient (except for one anomalous sample with extensive sericite alteration of plagioclase) and as such, they plot along the quartz-plagioclase leg of the QAPF diamond. Modal analyses reinforce the CIPW classifications and major mineral contents, which include plagioclase feldspar, orthopyroxene, clinopyroxene and magnetite. The intermediate-felsic plutonic rocks have hydrous chlorite-albite-actinolite assemblages indicating they have undergone low pressure greenschist facies, lowmoderate temperature hornfels facies metamorphism after crystallization, which is consistent with hydrothermal circulation $\left(<450-500^{\circ} \mathrm{C}\right)$ through the plutonic layers of a spreading center environment.

Further evidence of more complex magma processes are growth rims in plagioclase feldspar present in almost every sample. This feldspar texture occurs when one or more new batches of magma are introduced in the interstices during crystallization, therefore each growth band could have a different composition (but in this case, the "new" batch of magma seems to have had the same composition as the previous based on EPMA analyses). Corona textures are common around the pyroxenes and relicts, which is consistent with low grade metamorphism or metasomatism causing the crystal to become unstable and react with the surrounding material, which may have been interstitial melt, fluid or adjacent minerals. Granophyric textures in several of the RD63 tonalite samples are indicative of quartz and feldspar crystallizing simultaneously, such as when a silicate melt is at the eutectic point or when a silicic liquid is undercooled [Fenn, 1986; Lentz and Fowler, 1992; London et al., 1989; Lowenstern et al., 1997]. 
This is often the case in plutons at shallow depths during late stage crystallization, or in the first phase of melting of a mafic rock. The scenarios that cause these mineral compositions and textures are easily explained in the context of conditions existing in the Mariana forearc during subduction initiation.

4.1.3 Bulk rock geochemistry

Major, trace and isotopic ratios were measured for the bulk rock. The table containing all the geochemical data for rocks analyzed from RD63 and RD64 are listed in the Appendix. The major elements $\left(\mathrm{MgO}, \mathrm{CaO}\right.$, and $\left.\mathrm{FeO}_{\mathrm{T}}\right)$ change with increasing silica content and follow typical volcanic and plutonic differentiation trends. Potassium and titanium contents are unusually and consistently low even for felsic rocks $\left(\mathrm{K}_{2} \mathrm{O}<0.63 \mathrm{wt} \% ; \mathrm{TiO}_{2}<0.39 \mathrm{wt} \%\right)$. Samples are plotted on a total alkali versus silica (TAS) diagram as a comparison of RD63 and RD64 rocks to the IUGS classification of volcanic rocks (Figure 4.6). Plotting plutonic rocks on this diagram only shows the relationship to their volcanic chemical equivalents, i.e., the plutonic rocks are subalkaline like those of island arc tholeiites, boninites and many other extrusives found in arc settings (in the IBM and in other locations).

Trace element patterns were categorized into groups based on differences in rare earth element (REE) contents relative to primitive mantle $(\mathrm{PM}),(\mathrm{La} / \mathrm{Sm})_{\mathrm{N}}$, high field strength element (HFSE) anomalies, Eu anomalies, Nb-Ta anomalies (Figure 4.7). Fluid mobile elements are listed on the left side of the $\mathrm{x}$-axis and though there is some variability, the overall normalized abundances are uniform, e.g., $(\mathrm{U} / \mathrm{Th})_{\mathrm{N}}$ and $(\mathrm{U} / \mathrm{Pb})_{\mathrm{N}}$ values are greater than 2, except the $(\mathrm{U} / \mathrm{Pb})_{\mathrm{N}}$ of gabbros where the ratios are lower than other lithologies. 


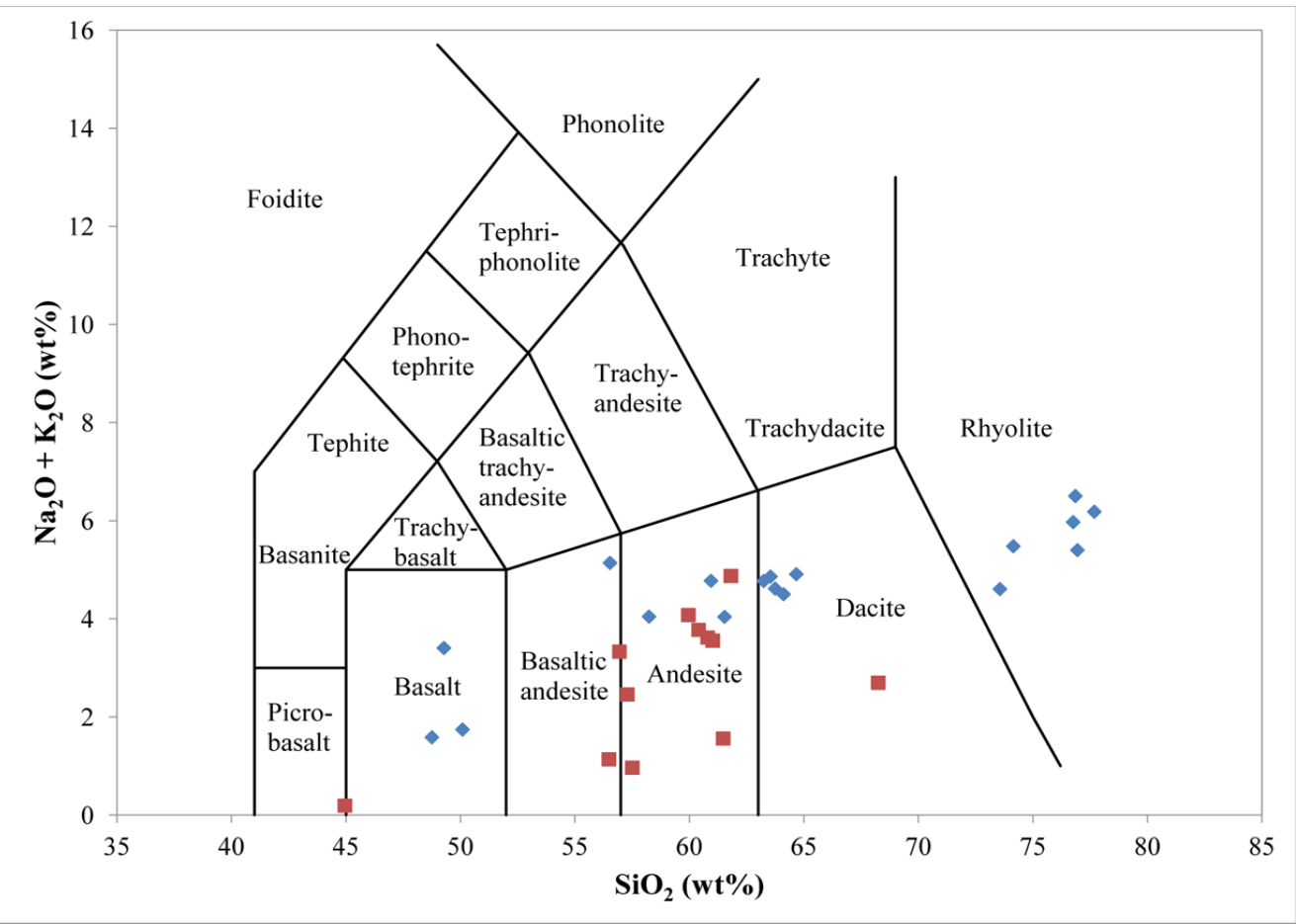

Figure 4.6. TAS diagram (total alkali versus silica), classification and nomenclature for volcanic rocks. RD63 (blue diamonds) and RD64 (red squares) plotted.

The most pronounced characteristics of the RD63 rocks are the high HFSE/REE ratios, specifically $\mathrm{Zr} / \mathrm{Sm}$, and the $(\mathrm{Nb} / \mathrm{Th})_{\mathrm{N}}<1$ (or negative $\mathrm{Nb}-\mathrm{Ta}$ negative anomaly). Also, because of their immobility, the pattern of REEs can be indicative of the melt source of the plutonic rocks. Interestingly, the "group 6" tonalites have $(\mathrm{La} / \mathrm{Ta})_{\mathrm{N}}<1$, except for RD63-J15 which could be considered a chemical intermediate between group 5 and group 6; the texture of the sample is like that of group 5 tonalites, but it has a slight positive Eu anomaly, similar to sample RD63-J28 with a slight negative Eu anomaly. The $(\mathrm{La} / \mathrm{Ta})_{\mathrm{N}}$ is unusual for arc rocks that typically have negative $\mathrm{Nb}-\mathrm{Ta}$ anomalies compared to Th and La but can perhaps be explained because the analytical sensitivity of Ta is much less than $\mathrm{Nb}$, and also some metasomatic process or remineralization could slightly alter the abundance of Ta relative to $\mathrm{Nb}$ or La. The $\mathrm{Zr} / \mathrm{Sm}$ in the most felsic 

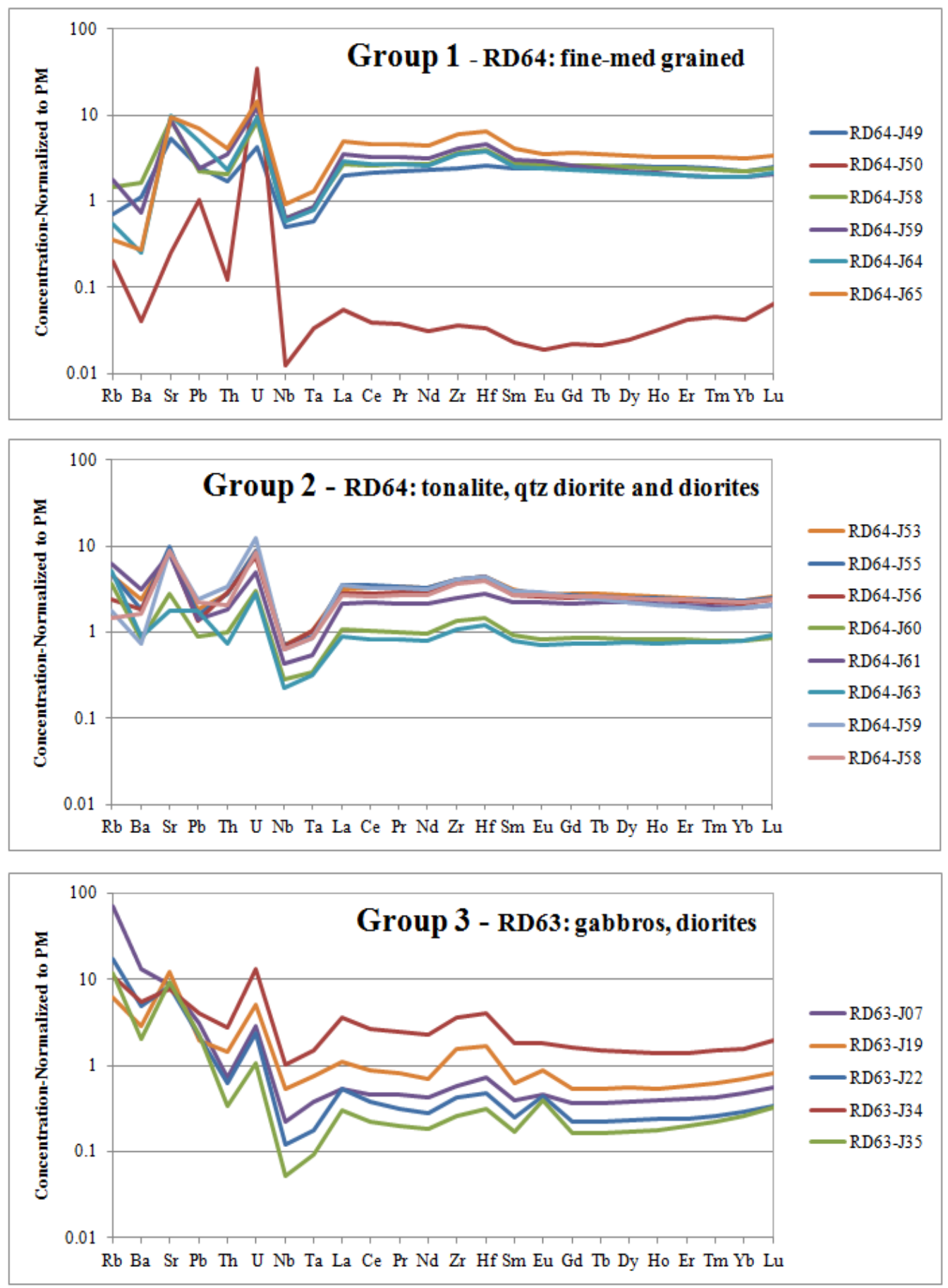

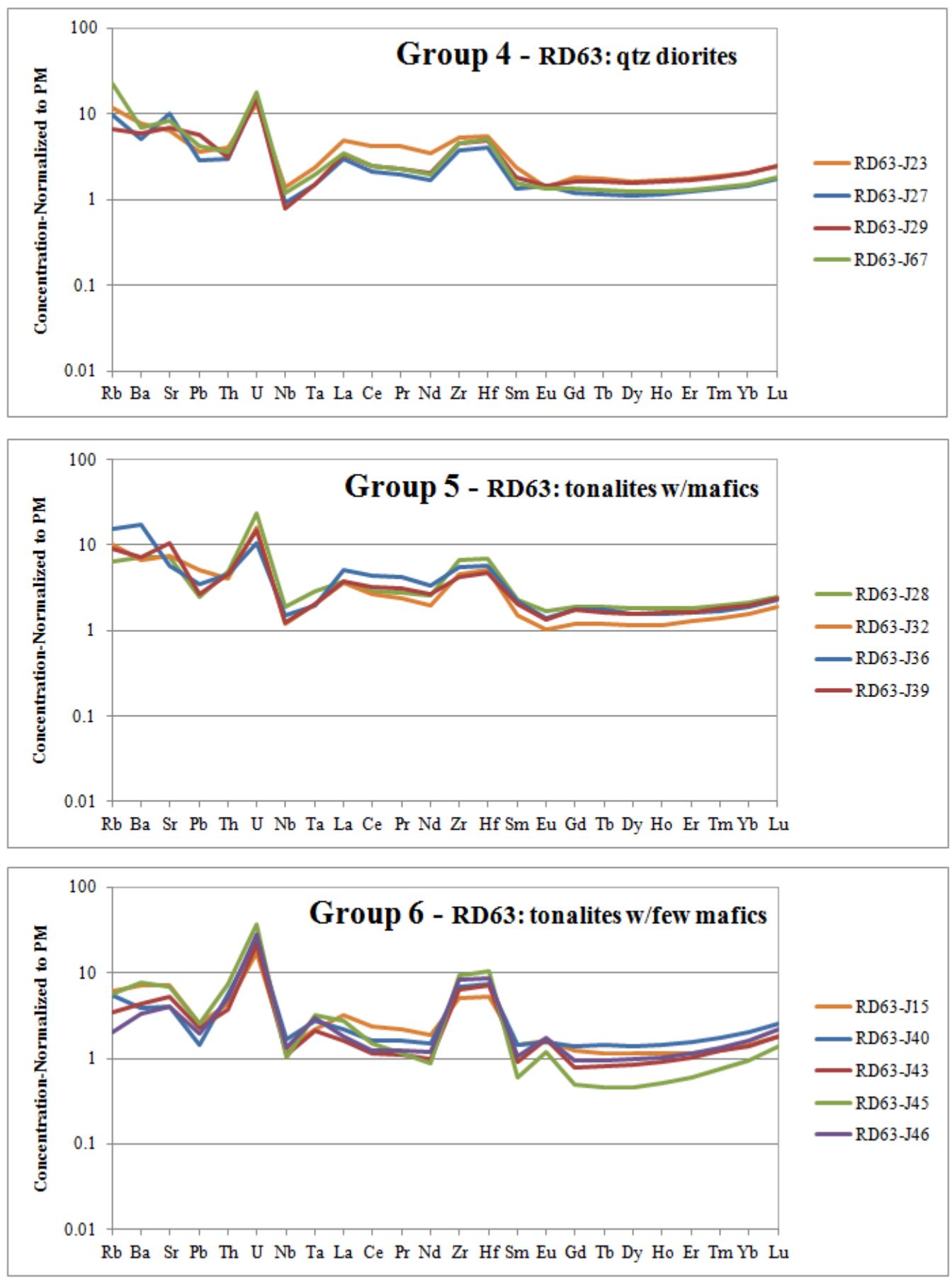

Figure 4.7. Trace element patterns (spidergrams) for RD63 and RD64 samples grouped by lithology. RD63-J15 could be included in Group 5 because $(\mathrm{Ta} / \mathrm{La})_{\mathrm{N}}<1$ but because the analysis of Ta is sometimes not as accurate as La, the positive Eu anomaly of J15 groups it with Group 6 that also have other positive Eu anomalies. 
group 6 samples is quite high (120-400) and in general the abundances of the REEs seem to decrease with increasing $\mathrm{SiO}_{2}$ (while the abundance of $\mathrm{Zr}$ and $\mathrm{Hf}$ does not change much). LREEs in RD63 are more enriched than the HREEs which may suggest a particular mineral that, in a fractional crystallization scenario, takes up LREEs and excludes the HREEs.

Trace element characteristics of RD64 include flatter REE patterns (e.g., $(\mathrm{La} / \mathrm{Yb})_{\mathrm{N}}$ $\sim 1)$ and smaller, if any, $\mathrm{Zr}-\mathrm{Hf}$ positive anomalies $(\mathrm{Zr} / \mathrm{Sm} \sim 30-40)$. Patterns like these are more typical of transitional boninites and arc tholeiites in the IBM (except the latter tend not to have Hf-Zr anomalies). The fine grained sample (RD64-J49) is a bronzite andesite, which has been found elsewhere in the IBM forearc with boninite affinity. The rocks with intermediate grain sizes (e.g., hypabyssal) have $\mathrm{SiO}_{2}$ of $56-61 \mathrm{wt} \%$ which may be congruous with differentiates of transitional boninites. The enrichment of fluid mobile trace elements $(\mathrm{Rb}, \mathrm{Ba}, \mathrm{U}, \mathrm{Sr})$ in both dredges is consistent with signatures inherited in subduction settings by fluids released by the downgoing plate.

Isotopic data are in the Appendix and are discussed at length in Chapter 5. One major conclusion that can be made on the basis of the isotopic data is that each suite may have a common parental magma and source because their isotope ratios do not vary with major or trace element trends that reflect differentiation or melting processes. Isotopic data also suggest that the parental magma and source for RD64 is distinct from RD63, since isotope ratios differ slightly. Based on this finding, I interpreted the variation of major and trace element features within each suite in terms of differentiation and/or partial melting from a single parental magma or source (section 4.2.3). I also find that the isotopic characteristics of the suites are similar to those of boninites from the IBM 
system. This provides constraints on the parental magma and partial melting sources used in the trace element modeling (section 4.2), as well as the interpretation of the age of the suites (section 4.3).

\subsection{Trace element modeling}

We can explore the sources of trace and rare earth element concentrations in the plutonic rocks by modeling their behavior during the partial melting or crystallization of rocks with various compositions. Modeling in this chapter refers to the use of Microsoft Excel spreadsheets for performing repetitive calculations with variables and equations listed below (e.g., $\mathrm{K}_{\mathrm{D} i}, \mathrm{D}_{i}$, Rayleigh Fractional crystallization and equilibrium modal melting equations). An example of the spreadsheet is shown in the Appendix.

\subsubsection{Partition coefficient $\left(\mathrm{K}_{\mathrm{D}}\right)$ review}

In igneous geochemistry, a partition coefficient is the ratio of concentrations of an element in two different phases, i.e., a magmatic melt (liquid) and a mineral crystal (solid) that are at equilibrium. The general equation of the concentration of a chemical component between a solid phase and a liquid phase is defined as:

$$
K_{D i}=\frac{C_{\text {element } i}^{\text {mineral }}}{C_{\text {element } i}^{\text {melt }}}
$$

Where, $\quad C$ : concentration of element $i$ in mineral or melt, as specified $\mathrm{K}_{\mathrm{D} i}$ : Nernst partition coefficient

In geochemistry, equation [1] quantifies the degree to which an element will mobilize from one phase to another. If the value of the partition coefficient is one, then the element partitions equally between liquid and solid phases; a value less than one 
means the element partitions more strongly into the liquid, whereas a value greater than one means the element partitions more strongly into the solid. Mineral partition coefficients $\left(\mathrm{K}_{\mathrm{D}}\right)$ are unique, dependent on temperature, pressure, oxygen fugacity, melt composition and water present in the melt.

It is important to understand how $\mathrm{K}_{\mathrm{D}} \mathrm{S}$ behave during equilibrium melting and crystallization because depending on the element concentrations in a rock, the $\mathrm{K}_{\mathrm{D}} \mathrm{s}$ can set constraints on the formation history, such as extent of melting.

Mineral-melt partition coefficients for REEs and select HFSEs (Zr and Hf) were tabulated from the Geochemical Earth Reference Model (GERM) partition coefficient database, part of the larger online database of Earth Science data and models (http://www.earthref.org). The minerals included in this review are common constituents of igneous rocks (clinopyroxene, orthopyroxene, amphibole, plagioclase, and an accessory mineral, apatite) whose partition coefficients vary widely based on melt composition. A review of the $\mathrm{K}_{\mathrm{D}} \mathrm{S}$ was performed as a thorough and systematic approach to understand how $\mathrm{K}_{\mathrm{D}}$ values in the GERM database vary by mineral, author, method of analysis and melt composition (Figure 4.8). The results of the review ultimately led to the suites of $K_{D S}$ chosen (Table 2) for the rare earth element (REE) modeling.

It was determined that within a single mineral-melt system reported in GERM, the quantitative variation of $K_{D}$ values was not significant. The $K_{D} S$ chosen for the REE forward modeling were from sources that were published in the last 20 years, were from both experimental and phenocryst-matrix studies with elemental abundance measurements by SIMS, and had the most complete set of $\mathrm{K}_{\mathrm{DS}}$ for REEs with $\mathrm{Zr}$ and Hf. 
Table 2. Mineral partition coefficients $\left(\mathrm{K}_{\mathrm{D}} \mathrm{s}\right)$ used for calculating bulk D in hypothetical minerals assemblages in an equilibrium system with basaltic melts (except apatite and sphene)

\begin{tabular}{|r|c|c|c|c|c|c|}
\hline & $L a$ & $S m$ & $D y$ & $Y b$ & $Z r$ & $H f$ \\
\hline Olivine & $0.0080^{*}$ & $0.0049^{*}$ & $0.0095^{*}$ & $0.0468^{*}$ & $0.0047^{*}$ & $0.0038^{*}$ \\
\hline Cpx & $0.0515^{+}$ & $0.462^{+}$ & $0.711^{+}$ & $0.633^{+}$ & $0.195^{+}$ & $0.223^{+}$ \\
\hline Opx & $0.0008^{\wedge}$ & $0.0150^{\wedge}$ & $0.0770^{\wedge}$ & 0.22 & $0.032^{\wedge}$ & $0.06^{\wedge}$ \\
\hline Plagioclase & $0.0348^{*}$ & $0.0132^{*}$ & $0.0112^{*}$ & $0.0155^{*}$ & $0.0094^{*}$ & $0.0092^{*}$ \\
\hline Amphibole & $0.17^{\wedge}$ & $0.76^{\wedge}$ & $0.78^{\wedge}$ & $0.59^{\wedge}$ & $0.35^{\dagger \dagger}$ & $0.5^{\dagger \dagger \dagger}$ \\
\hline Apatite & $8.6^{\ddagger}$ & $14.6^{\ddagger}$ & $34.8^{\ddagger}$ & $15.4^{\ddagger}$ & $0.636^{\ddagger}$ & $0.73^{\ddagger}$ \\
\hline Sphene & $46^{++}$ & $204^{++}$ & $206^{++}$ & $104^{++}$ & -- & $10.1^{++}$ \\
\hline
\end{tabular}

*Fujimaki et al. [1984]; ${ }^{+}$Hauri et al. [1994]; 'Green et al. [2000]; ${ }^{++}$Luhr and Carmichael [1980]; ${ }^{\dagger}$ Sisson, T.W. [1994]; ${ }^{\dagger \dagger}$ Dostal et al. [1983]; ${ }^{\dagger}$ Fujimaki, H. [1986].

These qualifications were met for all mineral-melt compositions used for the REE modeling, shown in Figure 4.8.

\subsubsection{Partition Coefficient $\left(\mathrm{K}_{\mathrm{D}}\right)$ Modeling}

After studying the trace and rare earth element (REE) geochemical data, the hypothesis was formed that the precursor of the RD63 samples has a boninitic composition. Simple modeling was done with bulk partition coefficients to compare the effects of melting/crystallizing from different sources in order to test the aforementioned hypothesis. In a forearc environment, there are several ways in which melting and crystallization occur in the crust. The two modes of petrogenesis for the boninite-like tonalites considered here are: 1) equilibrium (batch) partial melting of a source rock in which small degrees of melt have a felsic composition, and then crystallize to form tonalite, and 2) equilibrium crystallization in which the liquids that remain after high 

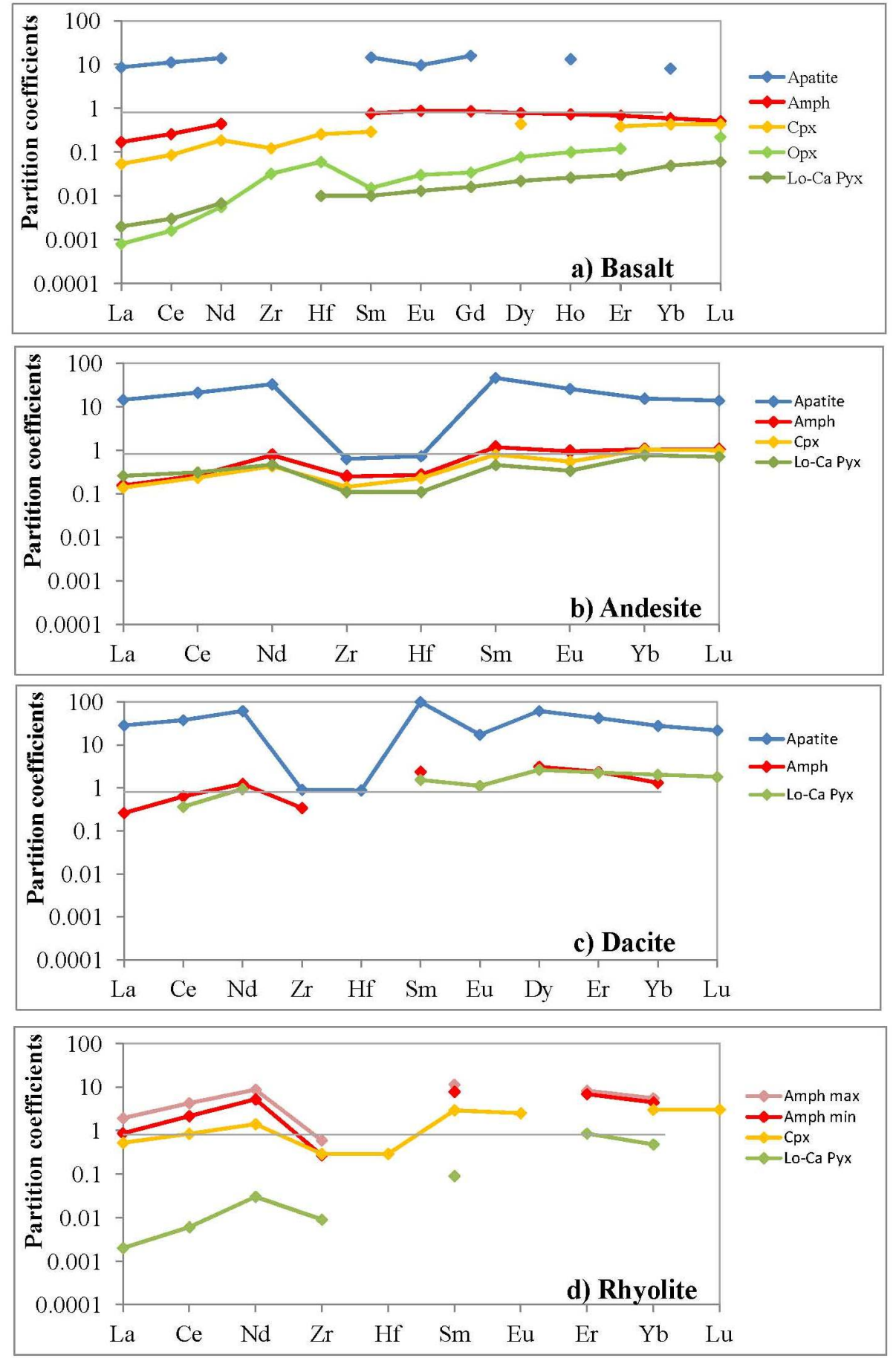

Figure 4.8. Comparison of $\mathrm{K}_{\mathrm{D}}$ values in REEs and HFSEs of igneous minerals for melt compositions: (A) Basalt: cpx and amphibole [Hart and Dunn, 1993], lo-Ca pyx [McKenzie and O'Nions, 1991], opx [Green et al., 2000], apatite [Paster et al., 1974]. (B) Andesite: lo-Ca pyx, cpx, amphibole [Bacon and Druitt, 1988], apatite [Fujimaki, 1986]. (C) Dacite: lo-Ca pyx [Nagasawa and Schnetzler, 1971], amphibole [Sisson, 1994], apatite [Fujimaki, 1986]. (D) Rhyolite: cpx [Bacon and Druitt, 1988], lo-Ca pyx [Sisson, 1991], amphibole min and max [Sisson, 1994]. 
extents of crystal extraction solidify to form tonalite. It is also important to consider the different source compositions that might be found in the forearc, which might melt or crystallize into felsic to intermediate intrusive rock suites. Possible sources considered here include mid-ocean ridge basalt (MORB), island arc tholeiite-basalt (IAT), fore-arc basalt (FAB) and boninite. Each of these sources has a distinct composition which is well documented in literature, therefore representative samples of each type were selected (Table 3) to use in the modeling calculations.

\subsubsection{Equilibrium melting and crystallization}

The process of equilibrium melting involves incremental melting of a solid mass and assumes that the melted portion remains in chemical equilibrium with the remaining (residual) solid until that liquid is removed. Melting of the source may occur until the entire mass is liquid. Equilibrium crystallization is the opposite process, in which a parental liquid crystallizes mineral phases that remain in chemical equilibrium with the residual liquid until the entire liquid body is solid.

Bulk partition coefficients (bulk D) are a weighted average of the individual components in a solid mass (i.e., whole rock), and because mineral assemblages vary between rock samples, it is often important to evaluate the bulk partition coefficient of the sample in terms of the minerals present,

$$
\mathrm{D}_{i}=\mathrm{X}_{1} \mathrm{~K}_{D i}^{\min 1}+\mathrm{X}_{2} \mathrm{~K}_{D i}^{\min 2}+\mathrm{X}_{3} \mathrm{~K}_{D i}^{\min 3} \ldots
$$

Where, $\quad \mathrm{D}_{i}$ : bulk partition coefficient for element $i$ in the rock $\mathrm{X}_{1}$ : modal proportion of mineral 1 in the rock

$\mathrm{K}_{D i}^{\min 1}$ : Nernst partition coefficient of element $i$ in mineral 1 
To estimate chemical changes during equilibrium modal melting, initial compositions were selected to represent the possible sources to be melted. The selected melt composition used in the calculation is a representative tonalite from this study (see Table 1 for all compositions). The bulk partition coefficient (D) between source and melt was calculated from the following equation:

$$
\frac{C_{l}}{C_{o}}=\frac{1}{D+F(1-D)}
$$

Where, $\quad \mathrm{C}_{1}$ : concentration of element in liquid

$\mathrm{C}_{\mathrm{o}}$ : concentration of element in the unmelted solid source

D: bulk partition coefficient of residual solid during melting

F: fraction of melt

This equation (from Shaw [1970]) assumes modal melting of the source, i.e., each mineral contributes to the melt in the same proportion as its modal abundance in the unmelted source. The results of the bulk partition coefficient calculations are shown in Figure 4.9 as a function of the melt fraction (shown as \% liquid).

\subsubsection{Comparison of $\mathrm{K}_{\mathrm{D}}$ models}

Small degrees of partial melting (0-40\%) of mafic material produce felsic liquids with high $\mathrm{SiO}_{2}$ composition (60 $\mathrm{wt} \%$ or more); the same applies to crystallization $(60 \%$ or more) of a magma body [Annen et al., 2006; Foden and Green, 1992; Müntener et al., 2001]. It is possible that the tonalites $\left(>60 \mathrm{wt} \% \mathrm{SiO}_{2}\right)$ in this study were produced by either scenario, or by a combination of crystallization and reheating within a magma "mush." The amount of liquid present for tonalites of this composition to form is constrained by the $\mathrm{Hf}$ and $\mathrm{Zr}$ trend on the graphs in Figure 4.9 and this result is fairly 
Table 3. REE and HFSE concentrations (ppm) used for calculating bulk partition coefficients in equilibrium melting and equilibrium crystallization. Significant digits are consistent with reported values in each reference. MORB (N-MORB average) [Hofmann, 1988]; FAB (1092-20) [Reagan et al., 2010]; IAT (GUM 80-94) [Reagan et al., 2008]; Boninite: (Chichijima 32108) [Reagan et al., 2010]; Transitional Boninite (458-32-2) [Reagan et al., 2010]; Tonalite: This study (RD63-J43)

\begin{tabular}{|c|c|c|c|c|c|c|}
\hline Elements & $\begin{array}{c}\text { MORB } \\
\text { Values }\end{array}$ & $\begin{array}{c}\text { IAT } \\
\text { Values }\end{array}$ & $\begin{array}{c}\text { FAB } \\
\text { Values }\end{array}$ & $\begin{array}{c}\text { Boninite } \\
\text { Values }\end{array}$ & $\begin{array}{c}\text { Trans Bon } \\
\text { Values }\end{array}$ & $\begin{array}{c}\text { Tonalite } \\
\text { Values }\end{array}$ \\
\hline $\mathrm{La}$ & 3.895 & 1.38 & 2.20 & 1.32 & 0.93 & 1.10 \\
\hline $\mathrm{Ce}$ & 12.001 & 3.8 & 5.61 & 3.23 & 2.31 & 2.02 \\
\hline $\mathrm{Pr}$ & 2.074 & 0.68 & 0.94 & 0.42 & 0.38 & 0.30 \\
\hline $\mathrm{Nd}$ & 11.179 & 3.54 & 5.43 & 2.01 & 1.91 & 1.36 \\
\hline $\mathrm{Sm}$ & 3.752 & 1.21 & 2.14 & 0.57 & 0.65 & 0.41 \\
\hline $\mathrm{Eu}$ & 1.335 & 0.47 & 0.76 & 0.21 & 0.25 & 0.29 \\
\hline $\mathrm{Gd}$ & 5.077 & 1.73 & 3.11 & 0.67 & 0.95 & 0.47 \\
\hline $\mathrm{Tb}$ & 0.885 & 0.32 & 0.62 & 0.13 & 0.17 & 0.09 \\
\hline $\mathrm{Dy}$ & 6.304 & 2.08 & 4.44 & 0.83 & 1.15 & 0.61 \\
\hline $\mathrm{Ho}$ & 1.342 & 0.47 & 1.00 & 0.18 & 0.27 & 0.15 \\
\hline $\mathrm{Er}$ & 4.143 & 1.37 & 3.08 & 0.56 & 0.77 & 0.49 \\
\hline $\mathrm{Tm}$ & 0.621 & -- & 0.48 & 0.09 & -- & 0.09 \\
\hline $\mathrm{Yb}$ & 3.900 & 1.48 & 3.15 & 0.64 & 0.81 & 0.69 \\
\hline $\mathrm{Lu}$ & 0.589 & 0.25 & 0.48 & 0.09 & 0.13 & 0.14 \\
\hline $\mathrm{Hf}$ & 2.974 & 0.88 & 1.55 & 0.81 & 0.81 & 2.21 \\
\hline $\mathrm{Zr}$ & 104.24 & 28.2 & 57.3 & 32.2 & 30.3 & 73 \\
\hline
\end{tabular}

consistent regardless of the source composition. The concentrations of $\mathrm{Zr}$ and $\mathrm{Hf}$ are defined and limited by the source and the tonalite, so where the lines "disappear" marks the value of $\mathrm{F}$ at which there is no longer any $\mathrm{Zr}$ or $\mathrm{Hf}$ left in the system to partition (i.e., the $\mathrm{K}_{\mathrm{D}}$ would theoretically be zero, meaning the elements are entirely in the liquid phase at any fraction above $\mathrm{F}=0.35-0.40$ ). It is the maximum possible amount of liquid allowable to produce the measured enrichment of $\mathrm{Zr}$ and $\mathrm{Hf}$ in the tonalites, which is consistent with experimental studies of producing silicic melts [Annen et al., 2006]. Considering this limitation of $\mathrm{Zr}-\mathrm{Hf}$ enrichment in the melt fraction (F), it is fairly 
straightforward to make a comparison of the four likely source compositions and determine their plausibility for producing the REE patterns found in the high silica tonalites in the forearc.

Even assuming a bulk D value as high as 5 (which is only possible if the mineral assemblage has upwards of $10 \%$ modal accessory minerals, e.g., sphene, apatite, see Table 5d), it is impossible for MORB and FAB sources and melt fractions higher than 35$40 \%$ to produce RD63 tonalites. It is necessary to consider the mineral assemblages of the sources because each $K_{D}$ for a specific mineral-melt system will affect the bulk D. The different sets of mineral assemblages (that might constitute reasonable magma chamber residue) to calculate hypothetical bulk partition coefficients of the assemblages (or hypothetical "rocks") are shown in Table 5. A brief numerical comparison of bulk Ds in Table 4 and Table 5 helps determine the likelihood of a particular source producing a tonalite with a REE composition from RD63. Table 2 lists the mineral-melt $K_{D}$ values used in this examination. The melt compositions are mafic, usually tholeiitic basalt, except for apatite and sphene where the most "mafic" composition in the GERM data base was andesitic.

Four mineral assemblages that are typical residue due to melting or crystallization were chosen for the purpose of calculating bulk partition coefficients (see equation [2]): a typical gabbro, amphibole-gabbro, amphibolite and a hypothetical composition for a "gabbro" (the latter is extremely unlikely to occur due to natural processes; of the "accessory" minerals, only amphibole is often present in large ( $>5 \%)$ modal quantities. Results in Table 5 give the expected bulk Ds if equilibrium melting occurs until a tonalite composition is reached. The calculations done for the gabbro and amphibole-gabbro 

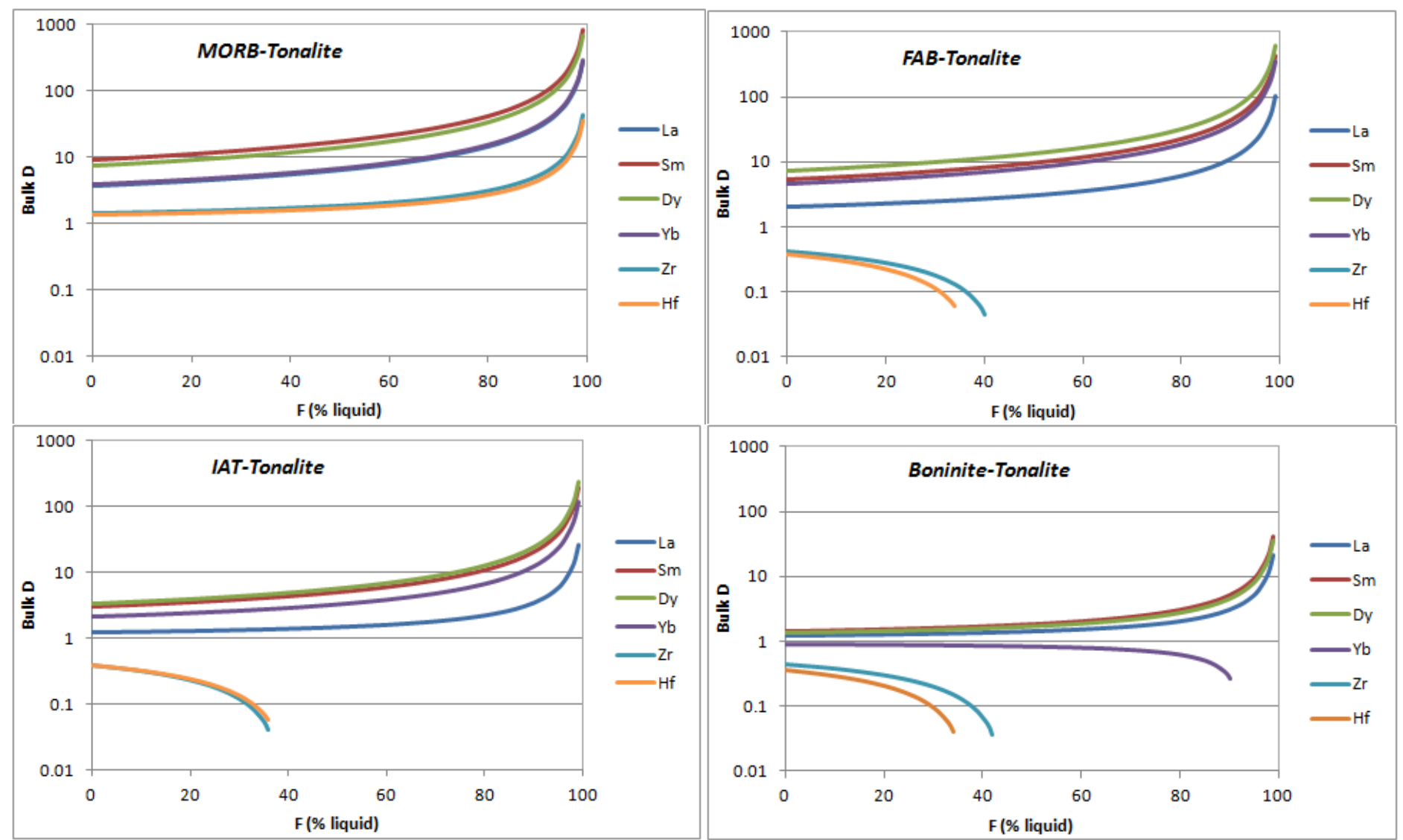

Figure 4.9. Calculated bulk partition coefficients vs. F (\% liquid). Select trace elements were plotted for each of the sources used in the calculations. Elements that plot above unity preferentially partition into the residual solid; elements that preferentially get taken into the bulk liquid during melting will have D values less than one. 
Table 4. Calculated bulk partition coefficients for partial melts and fractional crystallization by liquid fraction (F) and sourcetonalite systems [B-T (boninite-tonalite), I-T (IAT-tonalite), F-T (FAB- tonalite), M-T (MORB- tonalite)]. This table lists select values shown in Figure 4.9 for quantitative comparison between partial melting and fractional crystallization.

\section{Partial Melt}

\begin{tabular}{|c|c|c|c|c|}
\hline Element & \multicolumn{4}{|c|}{ La } \\
\hline Source & B-T & I-T & F-T & M-T \\
\hline $\mathbf{F = 0 . 0 0 1}$ & 1.20 & 1.25 & 2.00 & 3.75 \\
\hline $\mathbf{F}=\mathbf{0 . 2}$ & 1.25 & 1.32 & 2.25 & 4.44 \\
\hline $\mathbf{F}=\mathbf{0 . 3}$ & 1.28 & 1.36 & 2.43 & 4.93 \\
\hline $\mathbf{F}=\mathbf{0 . 4}$ & 1.33 & 1.42 & 2.66 & 5.58 \\
\hline $\mathbf{F}=\mathbf{0 . 9}$ & 2.99 & 3.53 & 10.98 & 28.50 \\
\hline
\end{tabular}

\begin{tabular}{|c|c|c|c|}
\hline \multicolumn{4}{|c|}{ Nd } \\
\hline B-T & I-T & F-T & M-T \\
\hline 1.48 & 2.60 & 3.99 & 6.84 \\
\hline 1.60 & 3.00 & 4.74 & 8.30 \\
\hline 1.68 & 3.29 & 5.28 & 9.34 \\
\hline 1.80 & 3.67 & 5.99 & 10.74 \\
\hline 5.79 & 17.04 & 30.94 & 59.41 \\
\hline
\end{tabular}

\begin{tabular}{|c|c|c|c|}
\hline \multicolumn{4}{|c|}{ Sm } \\
\hline B-T & I-T & F-T & M-T \\
\hline 1.40 & 2.98 & 5.27 & 9.23 \\
\hline 1.50 & 3.47 & 6.33 & 11.29 \\
\hline 1.58 & 3.83 & 7.10 & 12.76 \\
\hline 1.67 & 4.30 & 8.11 & 14.72 \\
\hline 5.03 & 20.78 & 43.67 & 83.34 \\
\hline
\end{tabular}

\begin{tabular}{|c|c|c|c|}
\hline \multicolumn{4}{|c|}{ Dy } \\
\hline B-T & I-T & F-T & M-T \\
\hline 1.35 & 3.39 & 7.23 & 7.65 \\
\hline 1.44 & 3.98 & 8.79 & 9.31 \\
\hline 1.50 & 4.41 & 9.90 & 10.50 \\
\hline 1.59 & 4.98 & 11.38 & 12.09 \\
\hline 4.51 & 24.86 & 63.28 & 67.52 \\
\hline
\end{tabular}

\section{Fractional Crystallization}

\begin{tabular}{|c|c|c|c|c|}
\hline Element & \multicolumn{4}{|c|}{ La } \\
\hline Source & B-T & I-T & F-T & M-T \\
\hline $\mathbf{F = 0 . 0 0 1}$ & 1.03 & 1.03 & 1.10 & 1.19 \\
\hline $\mathbf{F = 0 . 2}$ & 1.11 & 1.14 & 1.43 & 1.82 \\
\hline $\mathbf{F}=\mathbf{0 . 3}$ & 1.15 & 1.19 & 1.57 & 2.10 \\
\hline $\mathbf{F = 0 . 4}$ & 1.20 & 1.25 & 1.76 & 2.44 \\
\hline $\mathbf{F = 0 . 9}$ & 2.72 & 3.14 & 7.57 & 13.55 \\
\hline
\end{tabular}

\begin{tabular}{|c|c|c|c|}
\hline \multicolumn{4}{|c|}{ Nd } \\
\hline B-T & I-T & F-T & M-T \\
\hline 1.06 & 1.14 & 1.20 & 1.28 \\
\hline 1.24 & 1.59 & 1.86 & 2.19 \\
\hline 1.32 & 1.79 & 2.15 & 2.60 \\
\hline 1.43 & 2.04 & 2.51 & 3.10 \\
\hline 4.71 & 10.08 & 14.14 & 19.25 \\
\hline
\end{tabular}

\begin{tabular}{|c|c|c|c|}
\hline \multicolumn{4}{|c|}{ Dy } \\
\hline B-T & I-T & F-T & M-T \\
\hline 1.04 & 1.18 & 1.29 & 1.29 \\
\hline 1.19 & 1.76 & 2.23 & 2.26 \\
\hline 1.25 & 2.01 & 2.64 & 2.69 \\
\hline 1.33 & 2.33 & 3.16 & 3.22 \\
\hline 3.86 & 12.58 & 19.77 & 20.31 \\
\hline
\end{tabular}


(Table 4 con't)

Partial Melt
\begin{tabular}{|c|c|c|c|c|}
\hline Element & \multicolumn{4}{|c|}{ Yb } \\
\hline Source & B-T & I-T & F-T & M-T \\
\hline F= $\mathbf{0 . 0 0 1}$ & 0.93 & 2.14 & 4.56 & 3.94 \\
\hline F= $=\mathbf{0 . 2}$ & 0.91 & 2.43 & 5.45 & 4.68 \\
\hline $\mathbf{F}=\mathbf{0 . 3}$ & 0.90 & 2.63 & 6.09 & 5.20 \\
\hline $\mathbf{F}=\mathbf{0 . 4}$ & 0.88 & 2.91 & 6.94 & 5.90 \\
\hline $\mathbf{F}=\mathbf{0 . 9}$ & 0.27 & 12.44 & 36.63 & 30.40 \\
\hline
\end{tabular}

\begin{tabular}{|c|c|c|c|}
\hline \multicolumn{4}{|c|}{$\mathbf{Z r}$} \\
\hline B-T & I-T & F-T & M-T \\
\hline 0.44 & 0.39 & 0.43 & 1.43 \\
\hline 0.30 & 0.23 & 0.28 & 1.54 \\
\hline 0.20 & 0.12 & 0.18 & 1.61 \\
\hline 0.07 & -0.02 & 0.04 & 1.72 \\
\hline-4.58 & -5.13 & -4.73 & 5.30 \\
\hline
\end{tabular}

\begin{tabular}{|c|c|c|c|}
\hline \multicolumn{4}{|c|}{ Hf } \\
\hline B-T & I-T & F-T & M-T \\
\hline 0.37 & 0.40 & 0.38 & 1.34 \\
\hline 0.21 & 0.25 & 0.22 & 1.43 \\
\hline 0.09 & 0.14 & 0.11 & 1.49 \\
\hline-0.06 & 0.00 & -0.03 & 1.57 \\
\hline-5.34 & -5.02 & -5.20 & 4.45 \\
\hline
\end{tabular}

\section{Fractional Crystallization}

\begin{tabular}{|c|c|c|c|c|}
\hline Element & \multicolumn{4}{|c|}{ Yb } \\
\hline Source & B-T & I-T & F-T & M-T \\
\hline $\mathbf{F = 0 . 0 0 1}$ & 0.99 & 1.11 & 1.22 & 1.20 \\
\hline $\mathbf{F = 0 . 2}$ & 0.95 & 1.47 & 1.94 & 1.85 \\
\hline $\mathbf{F = 0 . 3}$ & 0.94 & 1.63 & 2.26 & 2.14 \\
\hline $\mathbf{F = 0 . 4}$ & 0.92 & 1.83 & 2.66 & 2.50 \\
\hline $\mathbf{F = 0 . 9}$ & 0.28 & 8.24 & 15.41 & 14.01 \\
\hline
\end{tabular}

\begin{tabular}{|c|c|c|c|}
\hline \multicolumn{4}{|c|}{$\mathbf{Z r}$} \\
\hline B-T & I-T & F-T & M-T \\
\hline 0.88 & 0.86 & 0.88 & 1.05 \\
\hline 0.49 & 0.41 & 0.47 & 1.22 \\
\hline 0.32 & 0.21 & 0.29 & 1.30 \\
\hline 0.11 & -0.04 & 0.07 & 1.39 \\
\hline-6.76 & -8.02 & -7.09 & 4.39 \\
\hline
\end{tabular}

\begin{tabular}{|c|c|c|c|}
\hline \multicolumn{4}{|c|}{ Hf } \\
\hline B-T & I-T & F-T & M-T \\
\hline 0.85 & 0.87 & 0.86 & 1.04 \\
\hline 0.38 & 0.43 & 0.40 & 1.18 \\
\hline 0.17 & 0.23 & 0.20 & 1.25 \\
\hline-0.10 & -0.01 & -0.06 & 1.32 \\
\hline-8.53 & -7.75 & -8.19 & 3.81 \\
\hline
\end{tabular}


produce small bulk $\mathrm{D}$ values, less than 2 , and the amphibolite values are also relatively low though the Sm and Dy are a bit higher, which is expected for amphiboles. When the bulk D values for the different residual mineral assemblages in Table 5 are compared to the graphical source-tonalite modeling in Figure 4.9, some general patterns are observed. The typical anhydrous gabbro assemblage produces the lowest bulk D values, consistent with the boninite-tonalite model. The other modeled results produced bulk D values that were high, which is consistent with the higher abundances of REEs (especially HREEs). For all the modeled results shown in the upper ranges of the bulk $\mathrm{D}$ values belong to $\mathrm{Sm}$ and Dy which are end members of the MREEs and suggest the MREEs prefer the residue mineral phase. This preference is accentuated in the MORB, FAB and IAT models.

The fractional crystallization scenario produces consistently lower bulk Ds at $\mathrm{F}=0.3$ compared to equilibrium melting but are still greater than one, except for $\mathrm{Zr}$ and $\mathrm{Hf}$ which are higher than the melting scenario (and are less than one). These smaller values are closer to the bulk Ds calculated for the gabbro residues; however, none of the sourcetonalite model calculations are a great match which could be due to the complexities of melting and/or fractionation, including extraction of melt fractions, other disequilibria conditions and melting/crystallization in multiple increments. The boninite-tonalite model, both in batch melting and fractional crystallization, are closest to the bulk Ds of the gabbros (except for the unreasonably high values of the hypothetical gabbro). More importantly, when looking at any of the four sources, the smallest bulk Ds are in the system with a boninite-like source and a final REE composition of the RD63 tonalites. The next section focuses on REE modeling using the $K_{D} S$ and conclusions in this section. 
Table 5. Values of calculated bulk partition coefficients for three different hypothetical residual mineral assemblages that are expected to be produced due to equilibrium melting/crystallization.

\begin{tabular}{|c|c|c|c|c|c|c|c|}
\hline a) Anhydrous Gabbro & & $\mathrm{La}$ & $\mathrm{Sm}$ & Dy & $\mathrm{Yb}$ & $\mathrm{Zr}$ & Hf \\
\hline \multirow{2}{*}{$\begin{array}{ll}10 \% & \text { ol } \\
45 \% & \mathrm{cpx} \\
45 \% & \text { fsp }\end{array}$} & $\begin{array}{c}\text { Calc } \\
D:\end{array}$ & 0.37 & 1.36 & 0.59 & 1.40 & 0.22 & 0.14 \\
\hline & & & & & & & \\
\hline
\end{tabular}

\begin{tabular}{|c|c|c|c|c|c|c|c|}
\hline b) Amph-Gabbro & & $\mathrm{La}$ & $\mathrm{Sm}$ & Dy & $\mathrm{Yb}$ & $\mathrm{Zr}$ & Hf \\
\hline \multirow{2}{*}{$\begin{array}{ll}20 \% & \text { amph } \\
40 \% & \text { cpx } \\
40 \% & \text { fsp }\end{array}$} & $\begin{array}{c}\text { Calc } \\
D:\end{array}$ & 0.40 & 1.67 & 1.14 & 1.60 & 0.30 & 0.23 \\
\hline & & & & & & & \\
\hline
\end{tabular}

\begin{tabular}{|c|c|c|c|c|c|c|c|}
\hline c) Amphibolite & & $\mathrm{La}$ & $\mathrm{Sm}$ & Dy & $\mathrm{Yb}$ & $\mathrm{Zr}$ & Hf \\
\hline $100 \%$ amph & $\begin{array}{c}\text { Calc } \\
D:\end{array}$ & 0.36 & 2.30 & 3.08 & 1.80 & 0.50 & 0.52 \\
\hline
\end{tabular}

\begin{tabular}{|c|c|c|c|c|c|c|c|}
\hline d) Hypothetical Gabbro & & $\mathrm{La}$ & $\mathrm{Sm}$ & Dy & $\mathrm{Yb}$ & $\mathrm{Zr}$ & Hf \\
\hline $25 \% \quad$ ol & $\begin{array}{c}\text { Calc } \\
\text { D: }\end{array}$ & 3.96 & 15.90 & 13.69 & 7.38 & 0.20 & 0.63 \\
\hline $\begin{aligned} 25 \% & \text { cpx } \\
40 \% & \text { fsp } \\
5 \% & \text { apatite } \\
5 \% & \text { sphene }\end{aligned}$ & & & & & & & \\
\hline
\end{tabular}

\subsubsection{Rare earth element (REE) models}

Simple incompatible trace element models were developed in spreadsheets using the information above as an additional examination for the probable source of the rocks and to graphically present the behaviors of REEs and HFSEs during fractional crystallization and batch melting. The results depict the expected pattern of enrichment or depletion in trace elements for the various fractions of melt during melting and 
Table 6. $\mathrm{K}_{\mathrm{D}}$ f from calculations of batch melting and fractional crystallization (for $\mathrm{F}=0.3$ ) that are shown graphically in Figure 4.9. Values are presented here for comparison to the bulk Ds calculated above (Table 5) for various mineral assemblages.

Equilibrium Melt

\begin{tabular}{|c|c|c|c|c|c|c|c|}
\hline Source & La & Nd & Sm & Dy & Yb & Zr & Hf \\
\hline Boninite & 1.28 & 1.68 & 1.58 & 1.50 & 0.90 & 0.20 & 0.09 \\
\hline IAT & 1.36 & 3.29 & 3.83 & 4.41 & 2.63 & 0.12 & 0.14 \\
\hline FAB & 2.43 & 5.28 & 7.10 & 9.90 & 6.09 & 0.18 & 0.11 \\
\hline MORB & 4.93 & 9.34 & 12.76 & 10.50 & 5.20 & 1.61 & 1.49 \\
\hline
\end{tabular}

Fractional Crystallization

\begin{tabular}{|c|c|c|c|c|c|c|c|}
\hline Source & La & Nd & Sm & Dy & Yb & Zr & Hf \\
\hline Boninite & 1.15 & 1.32 & 1.28 & 1.25 & 0.94 & 0.32 & 0.17 \\
\hline IAT & 1.19 & 1.79 & 1.91 & 2.01 & 1.63 & 0.21 & 0.23 \\
\hline FAB & 1.57 & 2.15 & 2.38 & 2.64 & 2.26 & 0.29 & 0.20 \\
\hline MORB & 2.10 & 2.60 & 2.85 & 2.69 & 2.14 & 1.30 & 1.25 \\
\hline
\end{tabular}

fractionation from the same four sources discussed above (boninite, FAB, MORB, IAT), as well as an example of melting of an intermediate RD63 diorite.

Fractional crystallization is the process where mineral phases crystallize from a liquid magma chamber, and the first fraction that crystallizes $(\mathrm{F} \rightarrow 0)$ partitions the highest relative concentration of compatible elements. As more of the magma crystallizes, the relative concentration in the solid portion decreases. In contrast, equilibrium (or batch) melting occurs when a small fraction of melt is produced from a solid source and the most incompatible elements (i.e., REEs and HFSEs) partition into the liquid. The liquid stays in equilibrium with the solid until a time when a "batch" can be separated and extracted from the system.

The equation for equilibrium melting/crystallization of a solid from an initial liquid composition is described above in equation 3 (section 4.2.2.1), and was used to calculate the bulk D values (Figure 4.9) and to calculate REE concentrations ( 
Figure 4.10). The equation for fractional crystallization of a solid from an initial liquid composition is:

$$
\frac{C_{l}}{C_{o}}=F^{(D-1)}
$$

where, $\quad \mathrm{C}_{1}$ : concentration of element in crystallized phases

$\mathrm{C}_{\mathrm{o}}$ : concentration of element in primary magma

D: bulk partition coefficient of residual solid during melting

F: fraction of melt

The equation (from Gast [1968]) is used to calculate the bulk REE composition of the mineral phases crystallizing from a magma body with four different compositions ( Figure 4.11) as a comparison with REE composition during equilibrium melting. The same set of $K_{D} S$ were used in both models. The relative abundances of REEs are much higher at small $\mathrm{F}$ in fractional crystallization compared to equilibrium melting and it appears that the MREEs (particularly $\mathrm{Nd}$ ) are preferentially extracted into the melt during the initial stages of equilibrium melting.

In both batch melting and fractional crystallization models, even with assumptions to simplify the systems, it is observed that the pattern of REEs is inherited from the source. The starting compositions with reasonable mineral assemblages of FAB, MORB and IAT do not produce U-shaped REE patterns, although at small values of $\mathrm{F}$, there is an accentuation of $\mathrm{Zr}-\mathrm{Hf}$ anomalies because $\mathrm{K}_{\mathrm{D}}$ values of $\mathrm{Nd}$, Sm and Dy are larger than $\mathrm{La}$ or $\mathrm{Yb}$.

As a first step of melting and crystallization, Figure 4.10 and

Figure 4.11 show that diorites, quartz diorites and some tonalites in RD63 can be modeled as the outcome of $\mathrm{F}<0.40$, which is consistent with the $\mathrm{K}_{\mathrm{D}} \mathrm{S}$ calculated above in 
Figure 4.9. Gabbros of RD63 have the same low abundance as the boninites. RD64 samples are plotted in the same manner as RD63 (see Figure 4.12 and Figure 4.13), but all samples from RD64 (except for the bronzite andesite) can be modeled as intermediate products of melt/crystallization of a source that is transitional between boninite and island arc tholeiite (or "transitional boninite"), shown in Figure 4.14. A few diorites in this dredge (56-58wt\% $\left.\mathrm{SiO}_{2}\right)$ have been partially serpentinized ("altered diorites") and these samples are more depleted in trace element concentrations, close to primitive mantle values.

An additional step of melting or crystallization is required to produce the large $\mathrm{Zr} / \mathrm{Sm}$ in the high silica tonalites of RD63. The starting composition in the second step model is a diorite from RD63 that could be formed from the first stage of melting/crystallization. The mineral assemblages were varied in the second step primarily to examine the effects that amphibole and accessory minerals have on the model results (Figure 4.15). While it is unlikely that a large modal amount of sphene, apatite or other accessory mineral is present in a residue, only a very small amount needs to be present for the large Zr-Hf anomalies to form in the high silica tonalites, i.e. RD63J46 (especially at low fractions of melt). In the case of RD63, as with boninites, the amount of Ti is very low and the oxide minerals are magnetites, making sphene even more unlikely to exist in a melt that produced tonalites. Apatite however was observed under EPMA backscatter imaging (see EPMA Appendix) and there is some $\mathrm{P}_{2} \mathrm{O}_{5}(0.02$ $0.06 \mathrm{wt} \%$ ) in the bulk rock analyses but not enough to produce 5\% apatite. Perhaps a 

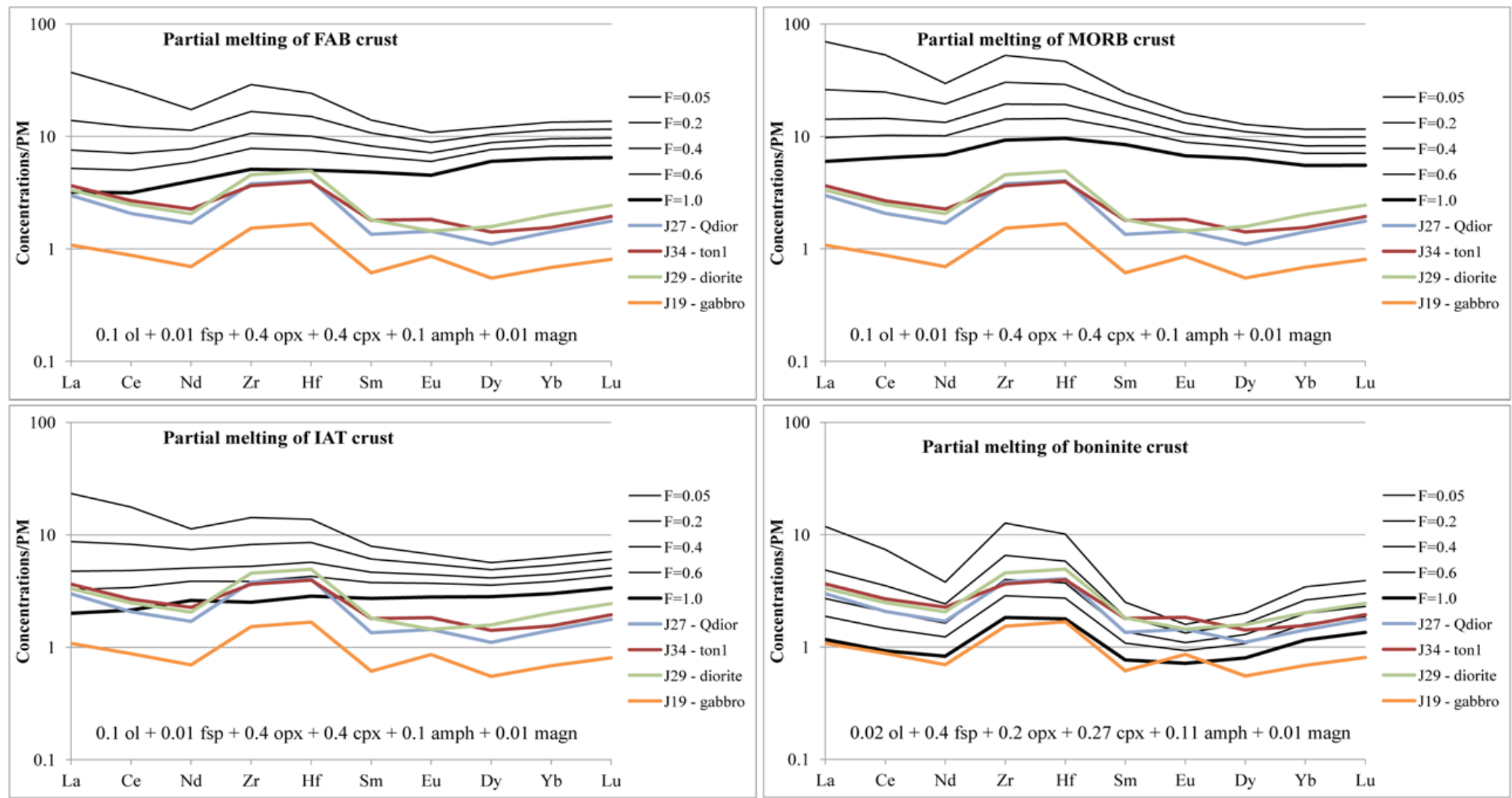

Figure 4.10. RD63 - REE behavior during four different equilibrium melting/crystallization scenarios: FAB, MORB, IAT, and boninite sources listed in Table 3. Mineral abbreviations: ol (olivine), fsp (plagioclase feldspar), opx (orthopyroxene), cpx (clinopyroxene), amph (amphibole), magn (magnetite). 

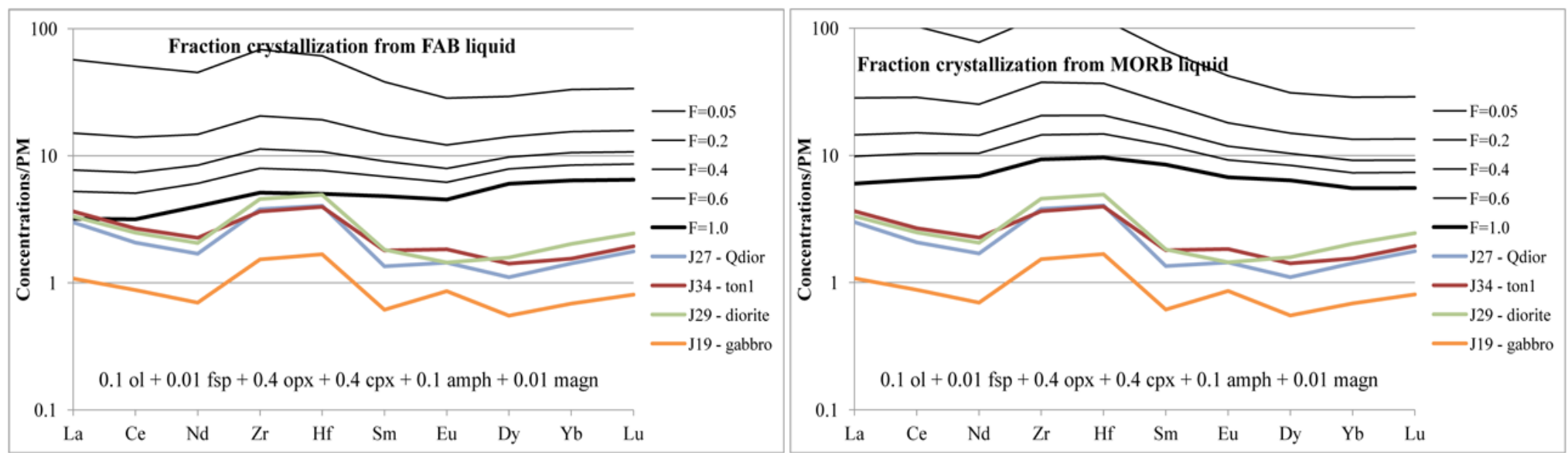

$0.1 \mathrm{ol}+0.01 \mathrm{fsp}+0.4 \mathrm{opx}+0.4 \mathrm{cpx}+0.1 \mathrm{amph}+0.01 \mathrm{magn}$

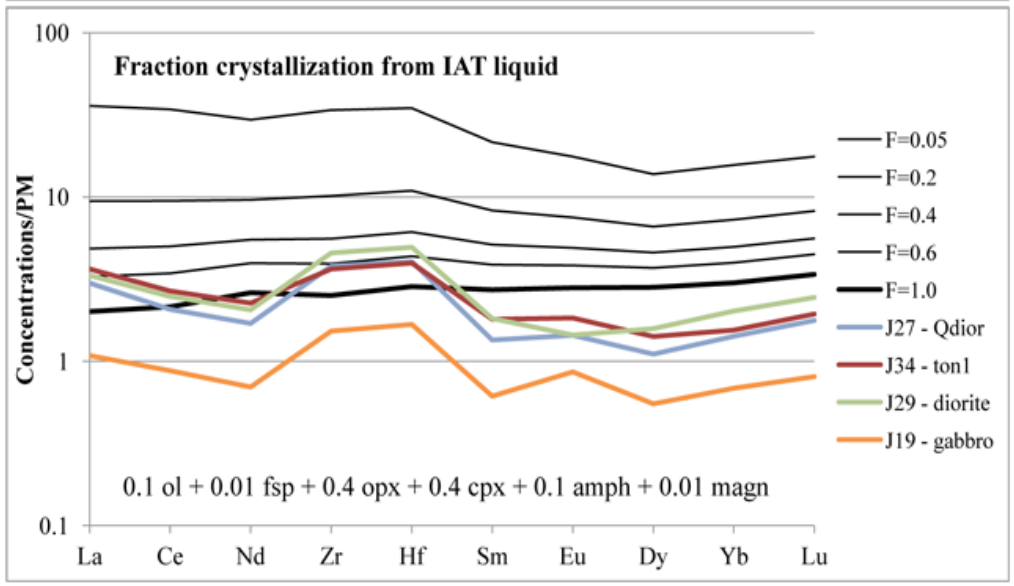

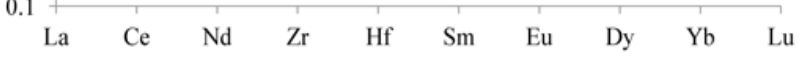

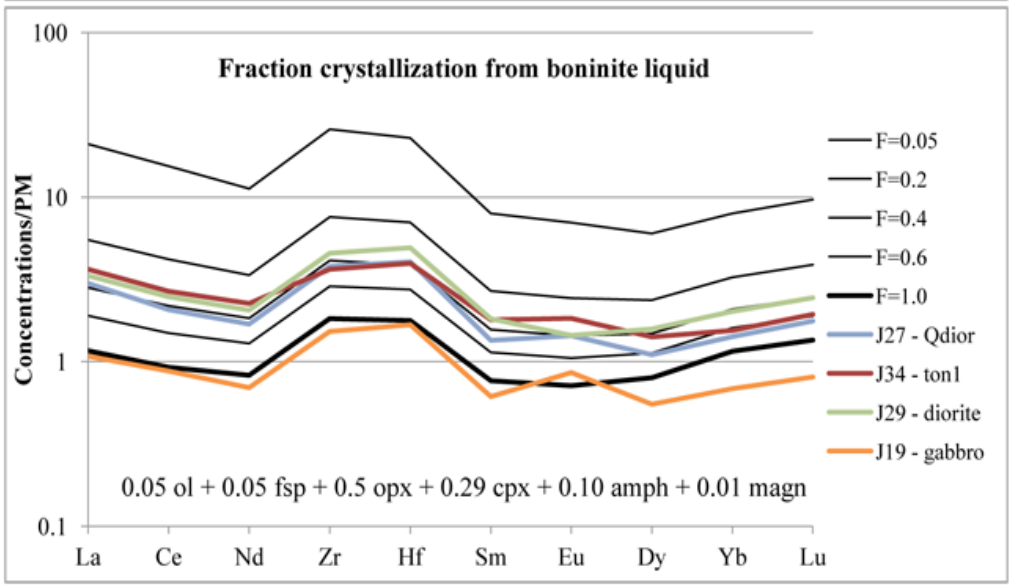

Figure 4.11. RD63 - REE behavior during four different fractional crystallization scenarios: FAB, MORB, IAT, and boninite sources listed in Table 3. Mineral abbreviations: ol (olivine), fsp (plagioclase feldspar), opx (orthopyroxene), cpx (clinopyroxene), amph (amphibole), magn (magnetite). 
combination of apatite or monazite and another mineral (even minute amounts of allanite, cerite, bastnäsite, etc. can strongly partition LREEs) may be responsible for the extreme patterns in the high silica tonalites.

A quasi U-shaped REE pattern and a Zr-Hf anomaly can be created or slightly exaggerated in any source via batch melting if $>0.2 \%$ apatite (or trace sphene) is included in the mineral assemblage for $\mathrm{F}<0.15$. But it is only with a boninite source that this pattern is retained regardless of accessory mineral (or amphibole) content or F value. Furthermore, the fractions at $\mathrm{F}<0.15$ with the anomaly or $\mathrm{U}$-shaped patterns have REE

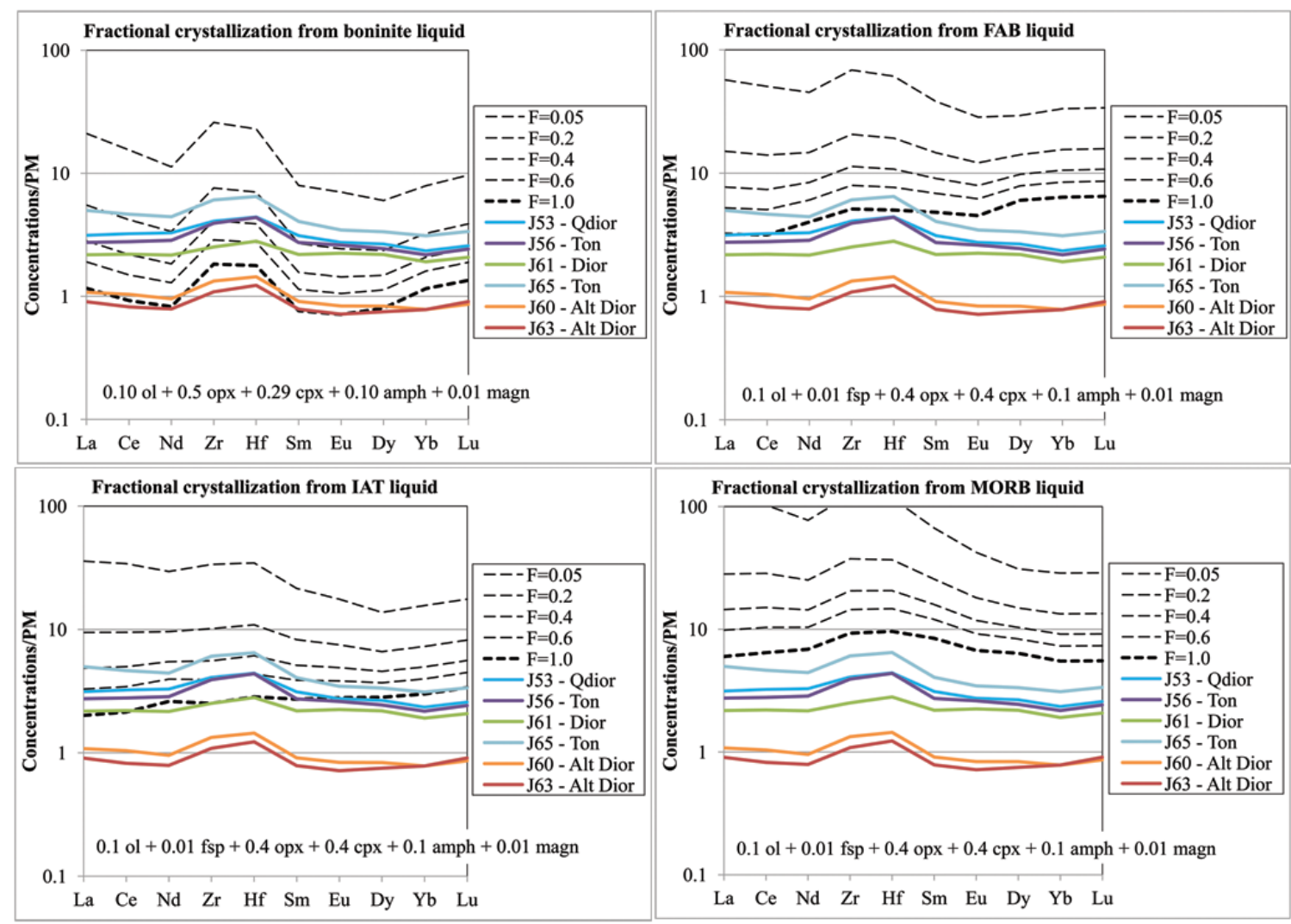

Figure 4.12. RD64 - REE behavior during four different fractional crystallization scenarios: FAB, MORB, IAT, and boninite sources listed in Table 3. Mineral abbreviations: ol (olivine), fsp (plagioclase feldspar), opx (orthopyroxene), cpx (clinopyroxene), amph (amphibole), magn (magnetite). 
These models support the hypothesis that rocks from RD63 are boninite differentiates and RD64 are transitional boninite differentiates, and they could not have formed by crystallization or melting of another source in the forearc. Gabbros, diorites, quartz diorites, and even some tonalites can be explained by either equilibrium melting or fractional crystallization. Moreover, a second step of equilibrium melting can even explain the most silicic plutonic rocks with the large $\mathrm{Zr}-\mathrm{Hf}$ anomalies.
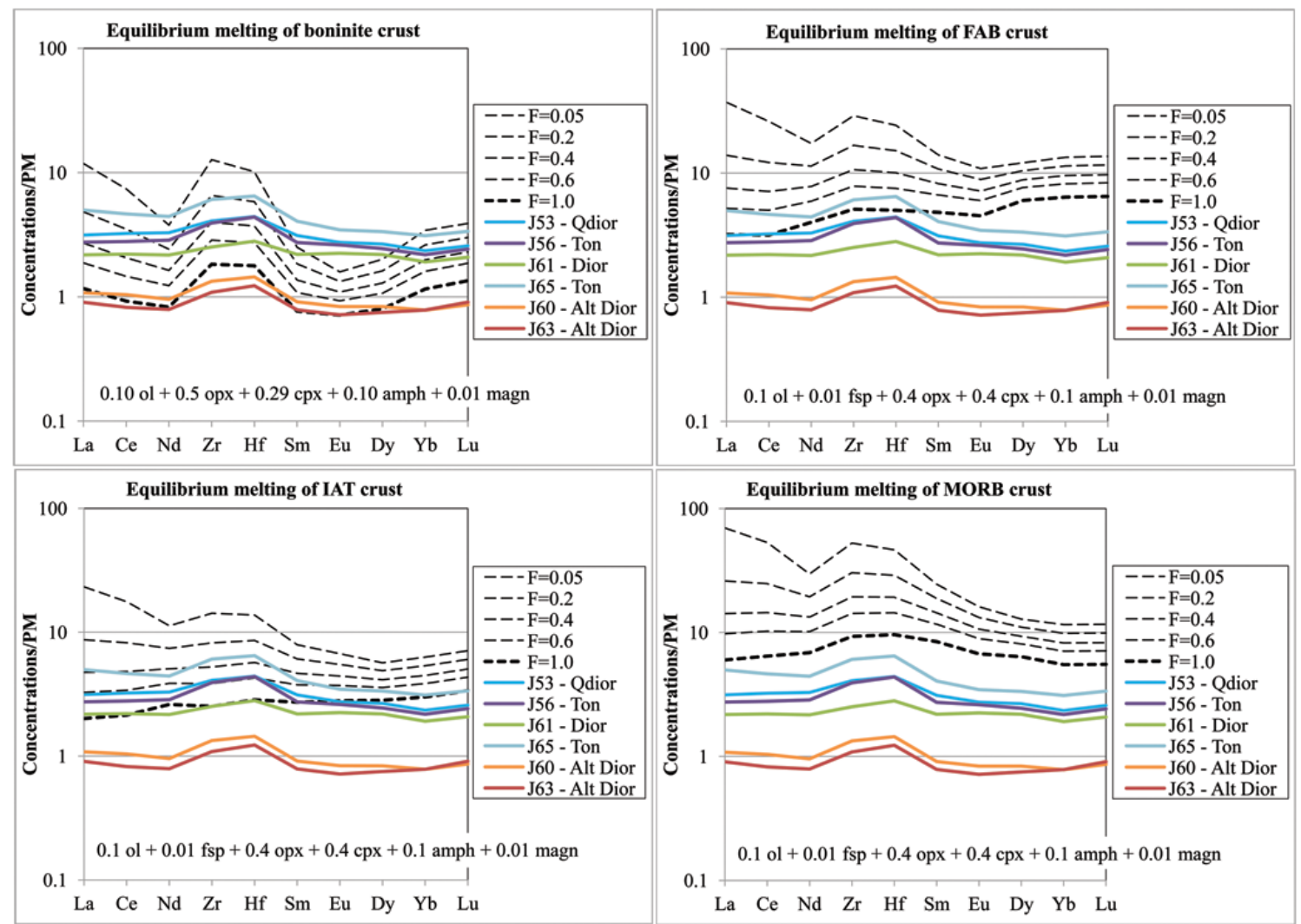

Figure 4.13. RD64 - REE behavior during four different equilibrium melting/crystallization scenarios: FAB, MORB, IAT, and boninite sources listed in Table 3. Mineral abbreviations: ol (olivine), fsp (plagioclase feldspar), opx (orthopyroxene), cpx (clinopyroxene), amph (amphibole), magn (magnetite). 

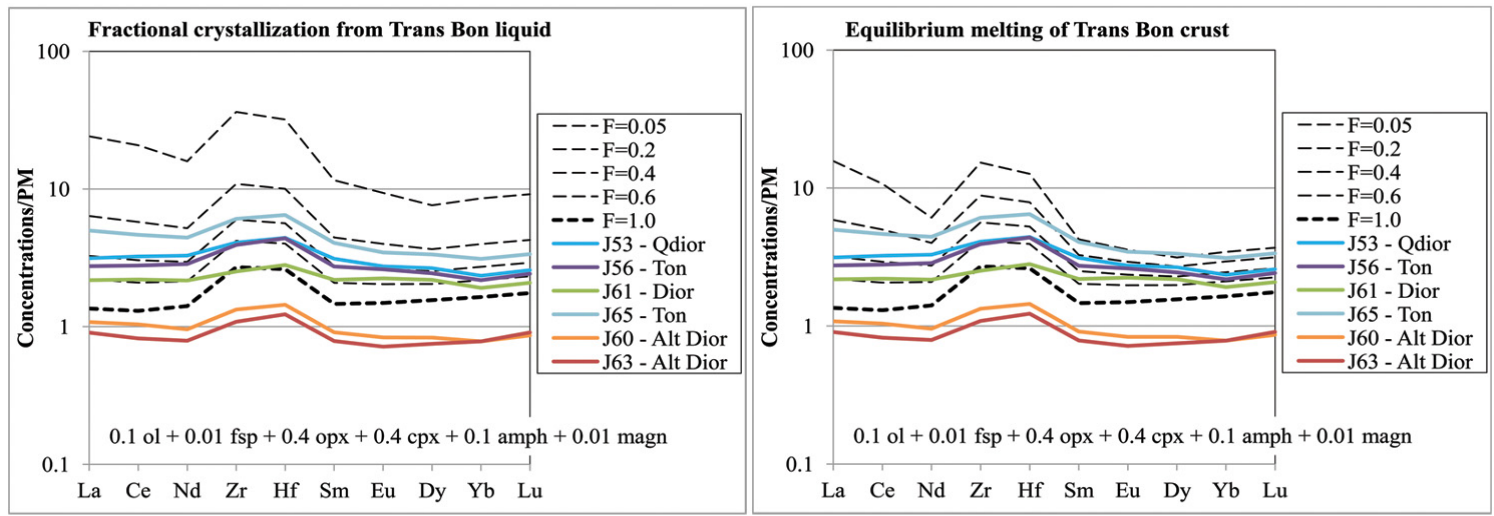

Figure 4.14. RD64 - REE behavior during fractional crystallization and equilibrium melting of transitional boninite (Table 3 )
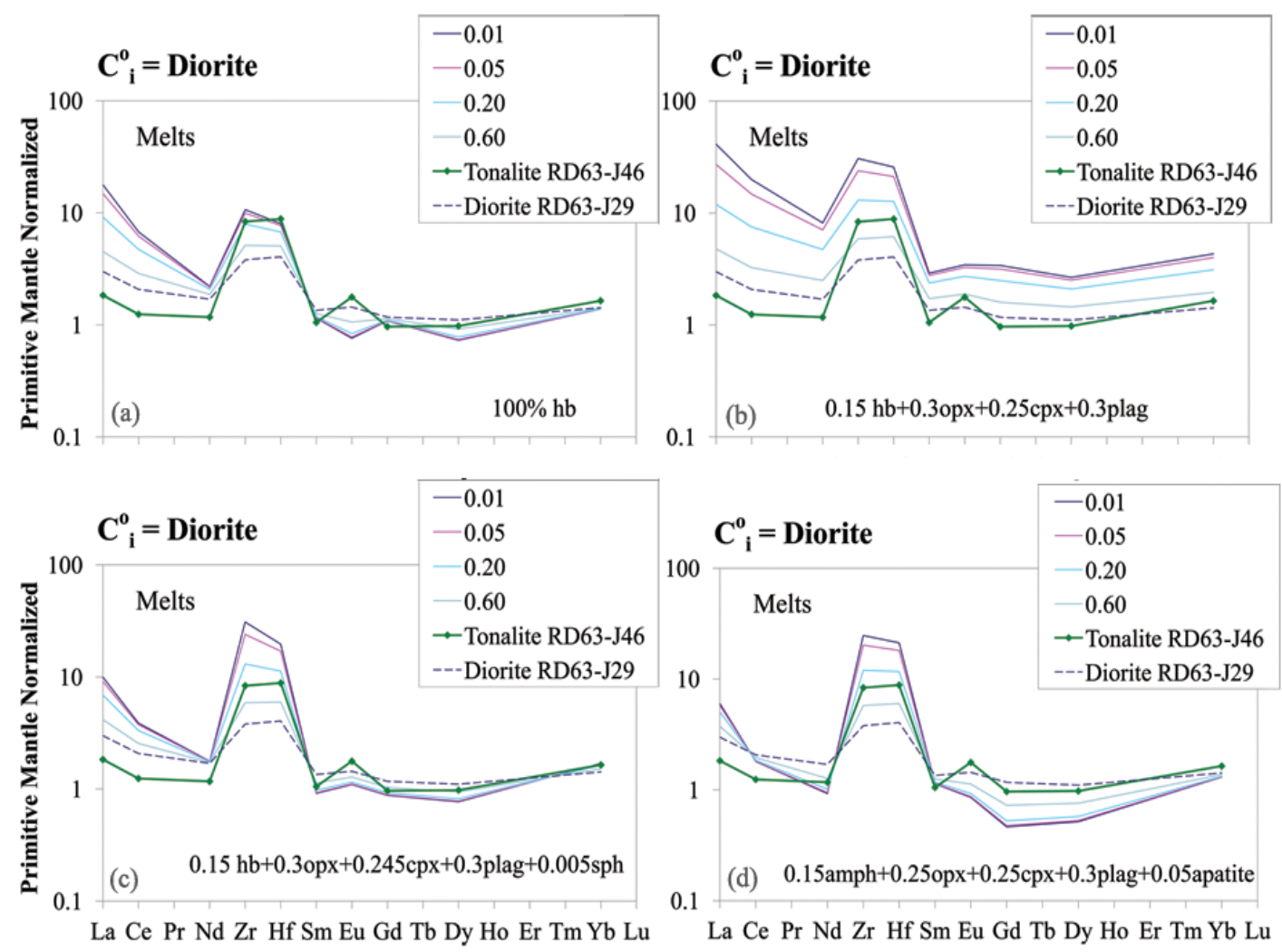

Figure 4.15. Example of a second step of equilibrium melting where the initial composition is a RD63 diorite $\left(\mathrm{C}^{\mathrm{o}} \mathrm{i}\right)$. Each graph shows the results if different mineral assemblages were melted (i.e., changing bulk D varies the outcome of the models): a) amphibolite (100\% hornblende), b) typical assemblage of a diorite, c) same assemblage as (b) but with a trace amount of sphene $(0.5 \%)$, d) similar assemblage as (b) but with $5 \%$ modal apatite. Mineral abbreviations: hb (hornblende), plag (plagioclase feldspar), opx (orthopyroxene), cpx (clinopyroxene), amph (amphibole), sph (sphene). 


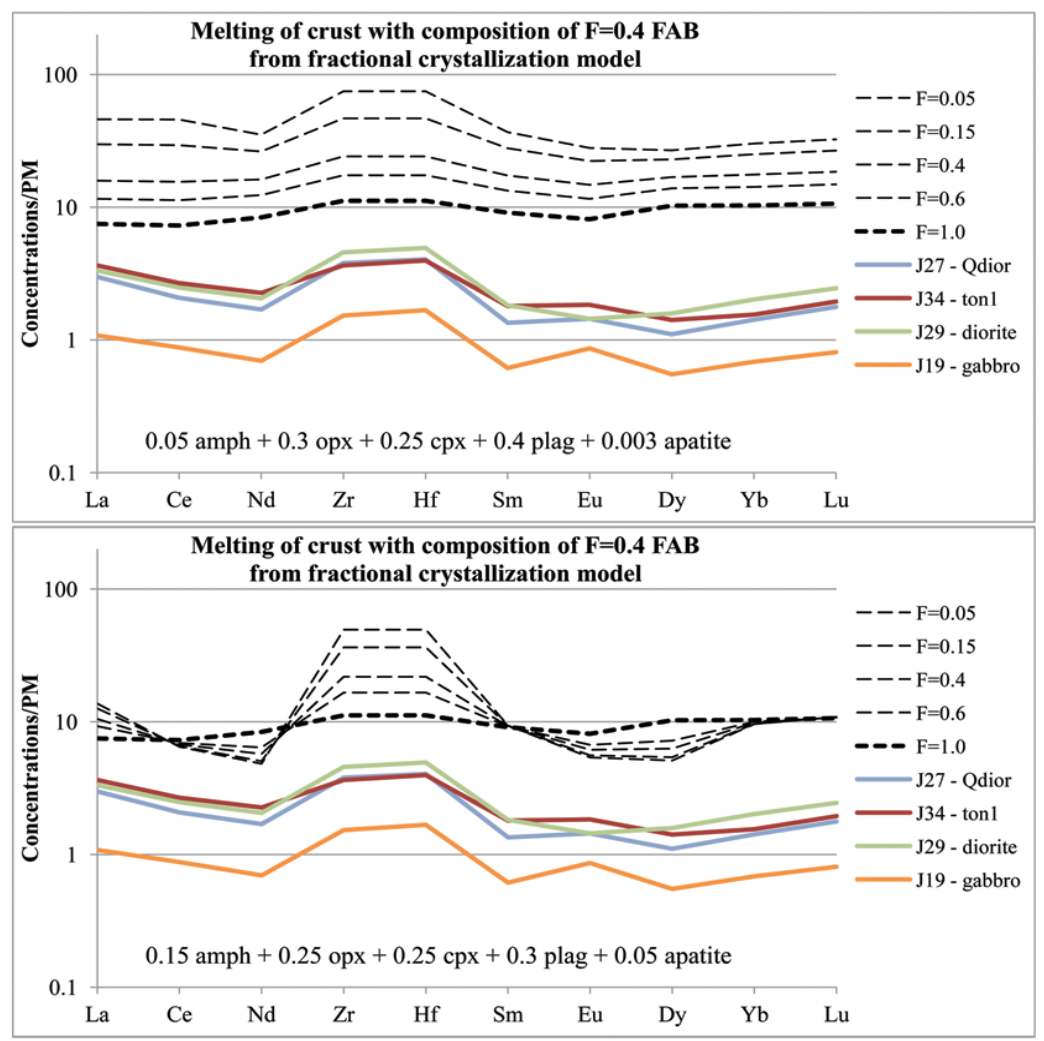

Figure 4.16. Examples of hypothetical melting of an intermediate FAB differentiate as a comparison to the melting of a boninite differentiate (

Figure 4.10). Source composition is the result of fractional crystallization of FAB to $\mathrm{F}=0.40$ (see

Figure 4.11). Mineral abbreviations: plag (plagioclase feldspar), opx (orthopyroxene), cpx (clinopyroxene), amph (amphibole), magn (magnetite).

\subsection{Age of the plutonic igneous rocks}

The forearc crust contains sequences of volcanic rocks that represent the earliest arc volcanism in the intra-oceanic Izu-Bonin-Mariana (IBM) system. Forearc basalts and boninitic lavas erupted 50-40Ma and are thought to be products of subduction initiation between the Pacific Plate and the Philippine Sea Plate. The emplacement of these early volcanic rocks is fairly well characterized as eruptions resulting from shallow, hydrous melting of the upper mantle by a high heat flux introduced by mantle upwelling [Bloomer and Hawkins, 1987; Hall et al., 2003; Hickey and Frey, 1982; Meijer, 1980; Stern and 
Bloomer, 1992; Taylor et al., 1994]. However, the suite of felsic, intermediate and mafic plutonic rocks in this study were recovered from the forearc during R/V cruise KK81-0626 (RD63 and RD64) and are geochemically and isotopically similar to the early volcanic sequences. As yet forearc plutonic rocks have not been incorporated into the discussion of early IBM arc formation or subduction initiation. It is, therefore, beneficial to obtain radiometric ages of the volcanic sequences and related plutonic rocks in order to fully understand the specific sequence of events and processes that occur to create forearc crust, and thus better understand the processes during subduction initiation, prior to normal arc volcanism.

The first studies of early IBM arc formation suggested that early volcanism coincided with the change in motion of the Pacific Plate at 43Ma [Clague and Dalrymple, 1987]. The estimates of early arc volcanism were based on paleontological and K-Ar dating of exposures on the arc islands and oceanic drill cores [Cloud et al., 1956; Ellis, 1981; Fryer et al., 1990; Hanzawa, 1947; Kaneoka et al., 1970; Kling, 1981; Meijer et al., 1983; Tracey et al., 1964; Umino, 1985]. However, later studies found evidence of volcanism occurring before the change of motion, as early as 50-48Ma [Ishizuka et al., 2006; Reagan et al., 2008; Seno and Maruyama, 1984; Taylor, 1992b] and more recent studies of the Emperor Seamount Bend put the change in motion of the Pacific Plate close to 50Ma [Sharp and Clague, 2006]. The volcanic rocks that represent the earliest eruptive events are found at almost every depth sampled on the inner trench wall. Samples of plutonic rocks in the IBM system are rarer and their stratigraphic occurrences are not still well constrained or understood. Obtaining accurate crystallization ages of the volcanic and plutonic sequences in the upper, middle and lower crustal sections is 
important to establish the sequence of magma intrusion, differentiation, melt extraction and perhaps magma stalling during subduction initiation.

Turbidites, volcanic and plutonic rocks in an oceanic setting have often been dated using K-Ar, Ar-Ar, and U-Th-Pb radiogenic systems [Gill et al., 1994; Hochstaedter et al., 1990; Ishizuka et al., 1998; Ishizuka et al., 2006; Mitchell et al., 1992; Taylor and Mitchell, 1992]. A less common method for dating oceanic rocks is $\mathrm{Rb}-\mathrm{Sr}$ due to the relative high fluid mobility of both elements. Whole rock dating can be done but, especially in oceanic environments, is prone to large uncertainties in the obtained ages, regardless of the radiogenic system that is used. Dating mineral separates is another option for determining crystallization age of igneous rocks, but certain minerals are preferable to others depending on the mineralogy of the rock and extent of weathering. The mineral used also dictates the radiogenic system used to obtain an age; moreover not all single mineral separates can be used to obtain the age of crystallization for the rock. Some isotope systems require the use of more than one type of mineral to obtain an estimate of crystallization, but this method becomes less reliable if weathering has occurred. Some refractory minerals can be used to obtain a crystallization age without the need to analyze other minerals because they are considerably resistant to weathering and partition coefficients are high for the radiogenic elements (i.e., $\mathrm{Pb}, \mathrm{U}, \mathrm{Th}$, $\mathrm{Nd}, \mathrm{Hf}$, etc. do not mobilize after crystallization of refractory minerals). The rest of this section outlines dating methods considered for this study.

\subsubsection{Zircon dating}

Dating zircon minerals is regarded as the most desirable method for determining crystallization age of plutonic rocks because of its high closure temperatures, $>900^{\circ} \mathrm{C}$, in 
the U-Pb system [Cherniak and Watson, 2000; Lee et al., 1997]. The resilience of zircons and their ability to withstand thermal alteration are reasons they were first considered as datable minerals for this study; all of the samples exhibit some extent of low-grade alteration. Many granitic magma temperatures are in the range of $750-850^{\circ} \mathrm{C}$ or less, thus inherited (older) zircons are often found in granites and a wide range of metamorphic rocks, which can make analyzing for crystallization ages dangerous in magmatic regimes that experience a large extent of crust-magma mixing. Typically this occurs in areas with thick overriding crust, as in continental arcs; intra-oceanic island arcs have thinner crust and do not usually experience much crustal influence in the generation of magma.

The appeal of $\mathrm{U}-\mathrm{Pb}$ dating is the ability to use a number of high precision instruments, namely SHRIMP (sensitive high resolution ion microprobe), LA-ICPMS (laser ablation-inductively coupled plasma mass spectrometer), and TIMS (thermal ionizing mass spectrometer). Detailed investigation with the optical microscope, SEM (Scanning Electron Microscope) and EPMA (Electron Microprobe Analyzer) led to the conclusion that any zircons that were present in the rocks were too small for radiometric dating. Accurate readings on the SHRIMP or LA-ICPMS require that the grains being analyzed must be significantly larger than the spot size of the electron beam. Most laboratories recommend that the polished surface of the grain be at least twice as large as the smallest beam size. SHRIMP or SIMS has one of the smallest beam sizes $(10 \mu \mathrm{m})$ of the instruments that have precision high enough to record $\mathrm{U}-\mathrm{Th}-\mathrm{Pb}$ concentrations for dating. If a SHRIMP was used to date a zircon crystal, the polished surface of the grain would have to be at least $20 \mu \mathrm{m}$ in diameter. In this study, the largest zircon grains that 
were observed in thin or thick section are $10 \mu \mathrm{m}$ or less. Recently, a single zircon that is $25 \mu \mathrm{m}$ has been confirmed in a sample and should be sent for dating.

\subsubsection{Apatite dating}

Dating apatite minerals was also considered for the suite of rocks in KK81-06-26, dredges 63 and 64. Apatite is a fairly common U- and Th-bearing accessory mineral in igneous and metamorphic rocks. Observed grain sizes of apatites in thin and thick sections are much larger (up to $100 \mu \mathrm{m}$ ) than any zircon, but there are far fewer apatite minerals in thin section, sometimes none. The U-Pb system in apatite has a closure temperature of $450-550^{\circ} \mathrm{C}$ [Chamberlain and Bowring, 2000; Schoene and Bowring, 2007], which is high enough to resist low to moderate grade metamorphism or metasomatism, however higher closure temperatures of a mineral are better for preventing the exchange of elements with the melt or fluids. The closure temperature range of apatite is below the typical crystallization temperature of granitic melts (750$850^{\circ} \mathrm{C}$ ) so apatite is not as ideal as zircon for obtaining the crystallization age of an igneous source. Another limitation for using apatites in $\mathrm{U}-\mathrm{Th}-\mathrm{Pb}$ dating is that they commonly have low concentrations of $\mathrm{U}$, $\mathrm{Th}$ and $\mathrm{Pb}$ and often need common $\mathrm{Pb}$ correction due to its $\mathrm{Ca}$ content and ability to substitute a large amount of initial $\mathrm{Pb}$ into its crystal structure.

The LA-ICPMS causes laser-induced fractionation of the U-Th-Pb system in apatites, so to analyze apatite on the LA-ICPMS a "matrix-matched" apatite standard is required for external calibration; this standard would ideally have high $U$, Th and radiogenic $\mathrm{Pb}$ concentrations, no common $\mathrm{Pb}$ and have precise $\mathrm{U}-\mathrm{Th}$ and $\mathrm{Th}-\mathrm{Pb}$ ages repeatedly analyzed by TIMS or SHRIMP. In a study by Chew et al. [2011], apatite 
standards of known crystallization ages were analyzed by LA-ICPMS in an attempt to show the U-Th-Pb system as a reliable apatite chronometer. They found reasonable agreement between the ages obtained by zircon Concordia diagrams with the LA-ICPMS and TIMS.

Other studies have been marginally successful in developing methods to analyze in-situ apatite grains with SHRIMP [Kennedy and Dante, 1997; Sano et al., 1999] and are non-destructive, unlike IDTIMS (Isotope Dilution TIMS) methodology. Sano et al. [1999] reported relatively precise ages of apatite grains using the SHRIMP. In this case, the age of the apatites were obtained using the isochron method rather than Concordia diagrams (such as those used for zircons) because apatite exhibits a low ratio of radiogenic to common $\mathrm{Pb}$. The ages from the SHRIMP were compared to the ages of apatites analyzed by IDTIMS and were reasonably similar. The SHRIMP, however, experiences some of the same limitations as the LA-ICPMS when analyzing apatites in that there are no universal matrix-matched standards, apatite often has low $\mathrm{U}$ concentrations and the correction for common $\mathrm{Pb}$ is difficult. But the non-destructive nature of in-situ SHRIMP measurement is an important consideration when dealing with rare samples or in cases where the grains may need further analysis to assess alteration effects.

Advances are being made with apatite on both LA-ICPMS and SHRIMP so that in the near future it may be possible to obtain precise radiometric ages for the suite of plutonic rocks from the southern Mariana Trench. 


\subsubsection{Other minerals for dating}

Other minerals that are commonly considered for radiogenic dating are feldspars, hornblende, monazite, allanite, perovskite, sphene, biotite, and muscovite. These minerals were not chosen in this study because they were either not observed or they exhibited obvious signs of weathering, alteration and/or secondary mineralization under optical microscopy.

\subsubsection{Conclusion and future work for geochronology}

Although it is apparent that radiometric dating would be useful in determining a model of crystallization emplacement for this suite of plutonic rocks, there is merit in the geochemical and isotopic data alone. The source of the plutonic rocks has been determined with some certainty based on the already gathered data, and the conclusion that the plutonic rocks from RD63 have a boninite source is noteworthy and unique on its own without radiometric ages. Moreover, given the sea water alteration effects and secondary mineralization of the rocks, it is concluded that $\mathrm{U}-\mathrm{Pb}$ dating would be the only reliable dating method. Zircons and apatites, which could be dated, are either too small for analysis or not present in the sample. Furthermore the in-situ analysis methods for U$\mathrm{Pb}$ dating of apatites are still being developed.

\subsection{Conclusions}

The mineralogic, petrologic and geochemical evidence suggest that the plutonic rocks from RD63 were crystallized from a magma source related to the boninites in the southern Mariana forearc. Many studies have implied through dating volcanic rocks and modeling mechanical and thermal properties of a rollback environment with a sinking 
slab that the forearc maintained a heat source for approximately $10 \mathrm{Myr}$ [Cosca et al., 1998; Hall et al., 2003; Ishizuka et al., 2011; Meijer et al., 1983; Reagan et al., 2008] that probably kept the lower crust capable of regularly reheating a magma mush so that some crustal plutonic rocks were locally remelted and recrystallized. The relocation of asthenospheric convection in conjunction with subsequent "conveyor belt" subduction allowed the forearc to cool, caused relocation of the volcanic arc and simultaneously thickened the forearc crust as the last stages of magma solidified. It was during this transitional phase that a shift from boninite to tholeiitic volcanism occurred and likely when the RD64 rocks were differentiated.

In this chapter, the data from RD63 and RD64 give several important conclusions: 1) both dredges have arc signatures but are geochemically distinct from each other, 2) the rocks within each dredge are likely petrogenetically related, 3) because of their location, it is likely that they formed during the initiation of subduction: the only time when magmatism occurred in the forearc, 4) the trace element concentrations in RD63 plutonic rocks can only have been inherited from a boninite source, either through melting or crystallization, and the most felsic samples were the result of second stage of melting and crystallization of an intermediate source with specific accessory minerals (e.g., apatite), and 5) trace element concentrations in RD64 rocks seem to be inherited from a source that was transitional between boninite and island arc tholeiite and thus may be slightly younger than RD63 rocks, but still within a time frame of subduction initiation. 


\subsection{GEOCHEMICAL AND ISOTOPIC STUDY OF A PLUTONIC SUITE AND}

\section{RELATED EARLY VOLCANIC SEQUENCES IN THE SOUTHERN MARIANA}

\section{FOREARC}

Authors: Johnson, J.A.; Hickey-Vargas, R.; Fryer, P.; Salters, V.J.; Reagan, M.K.

Submitted to: Geochemistry, Geophysics, Geosystems (accepted Jan 20, 2014)

\subsection{Abstract}

The forearc of the southern Mariana arc preserves igneous suites formed during the initiation of subduction between the Pacific and Philippine Sea plates about $50 \mathrm{Ma}$ ago. We have studied rare suites of gabbroic to tonalitic plutonic rocks dredged from two locations in the Mariana forearc by University of Hawai'i cruise KK81-06-26.

Comparison of the chemical and isotopic $(\mathrm{Sr}, \mathrm{Nd}, \mathrm{Pb}, \mathrm{Hf})$ characteristics of these rocks with well-studied volcanic rocks from the forearc reveals that the plutonic rocks from dredge RD63 and RD64 are chemically related to boninites erupted at $48-43 \mathrm{Ma}$. This is the first report of boninite-like plutonic rocks in the southern Mariana trench. These suites have trace element characteristics consistent with island arc settings (U/Th: 0.581.44, Nb/La: $0.18-0.79)$ and other features uniquely connected with boninites: $\mathrm{TiO}_{2}<$ $0.15 \mathrm{wt} \%$ and $\mathrm{Zr} / \mathrm{Sm}>25 . \mathrm{RD} 63$ plutonic rocks resemble nearby boninite volcanics and were likely derived from differentiated boninite magma with $58 \% \mathrm{SiO}_{2}$, forming gabbro by crystal accumulation, diorite and quartz diorite by crystallization, and tonalite by crystallization and/or partial melting. The RD64 suite (gabbro through tonalite) may have had a more depleted magma source and formed by accumulation and crystallization only. Although the physical dimensions of the plutonic body are unknown, the 
relationship with boninites indicates that felsic intrusives can form during early stages of island arc development. Such rocks could form part of mid-crustal low velocity layers detected in arc crust by seismic studies. Tonalites similar to those studied here are also found in some ophiolites.

\subsection{Introduction}

The volcanic history of the southern Izu-Bonin-Mariana (IBM) arc system (Figure 1.1), starting with subduction initiation, has been relatively well characterized based on rocks recovered from dredge and submersible dive sampling and deep ocean drilling conducted by DSDP, ODP, IODP, JAMSTEC and other U.S. NSF funded cruises. Volcanic rocks in the Mariana forearc, including the forearc islands (e.g., Guam, Saipan, Rota) have been studied and described by Bloomer [1983], Bloomer and Hawkins [1987], Hickey-Vargas [1989], Hickey-Vargas and Reagan [1987], Hickey and Frey [1982], Meijer [1980], Natland and Tarney [1981], Ohara et al. [2008] Pearce et al. [1992], Reagan and Meijer [1984], Reagan et al. [2008; 2013; 2010]. According to Reagan et al. [2010], the early volcanic sequence subsequent to subduction initiation was: 1) FABs or fore-arc basalts; then 2) boninites; then 3) volcanic rocks of typical island arc tholeiitic and calc-alkaline characteristics, as plate subsidence transitioned to true subduction [Stern, 2004a; Stern and Bloomer, 1992]. Based primarily on K-Ar and Ar-Ar (and more recently $\mathrm{U}-\mathrm{Pb}$ ) radiogenic dating, the earliest volcanic activity in the IBM began 48-52 Ma [Cosca et al., 1998; Ishizuka et al., 2011; Ishizuka et al., 2006; Meijer et al., 1983; Reagan et al., 2013] which approximately coincides with the proposed change in motion of the Pacific plate [Clague and Dalrymple, 1987; Sharp and Clague, 2006]. Thus, the 
early arc volcanic sequence in the IBM forearc records the process of subduction initiation and onset of arc magmatism [Stern, 2004a; Stern and Bloomer, 1992].

In contrast to studies of volcanic rocks, few geochemical studies of the rare plutonic samples from this area have been conducted. Since the late 1970s, dredging of the trench wall in this region has yielded mafic to felsic plutonic rocks with poorly understood relationships to the volcanic rocks [Bloomer, 1983; Bloomer and Hawkins, 1987]. Intermediate and felsic plutonic rocks have also been recovered in other areas of the arc system, for example in the northern Kyushu Palau Ridge [Haraguchi et al., 2003]. Such rocks may be representative of the middle crustal layer that has been inferred for much of the Izu-Bonin-Mariana arc crust from seismic p-wave velocity studies [Hacker et al., 2003; Suyehiro et al., 1996; Takahashi et al., 1998; Takahashi et al., 2008].

In this paper we report and interpret geochemical data for plutonic rocks from two dredge sites on the inner Mariana Trench slope near Guam (Figure 1.1). These were recovered by the 1981 cruise of the University of Hawai'i R/V Kana Keoki, at site RD63, at a depth of 8150-7420 meters, and RD64 at 7390-7195 meters (Figure 1.1). Dredge RD63 was taken from a serpentine mud volcano and RD64 was taken $74 \mathrm{~km}$ to the southwest from a fault scarp. The bulk of the volume of both dredge hauls consisted of serpentinized peridotitic rock, mainly harzburgite. About $10 \%$ of the dredge hauls consisted of the plutonic samples used in this study, ranging from mafic to felsic in both RD63 and RD64, in addition to some hypabyssal rocks of intermediate composition at RD64. Data are interpreted in the context of the well-understood volcanic sequences. 


\subsection{Geologic background of the southern IBM}

Figure 1.1 shows a location map of the IBM system and an inset of the southern Mariana forearc with the locations of dredges RD63 and RD64. Reagan et al. [2013] include a sketch map of the southern Mariana forearc (in Figure 2) that shows the crustal succession in this area. Their figure also shows the location of a gabbro layer that is near the fault scarp from which RD64 is likely recovered, and includes the location of the serpentine mud volcano from which RD63 was recovered. FABs (or forearc basalts), were the first lavas to be erupted following the initiation of subduction of the Pacific plate beneath the Philippine Sea plate or its predecessor at 51-52Ma [Reagan et al., 2010]. An extensional regime is inferred for this early stage of plate subsidence and arc magmatism, with upwelling of asthenospheric mantle along fractures generated within the overriding plate lithosphere.

FABs have geochemical characteristics similar to depleted MORBs, but with varying extents of LIL (large ion lithophile) element enrichment caused by the addition of fluids from the subsiding Pacific lithosphere. Following FABs, boninites erupted in the same extensional environment. Boninites are generated by shallow hydrous melting of extremely depleted peridotite and require water from the subsiding lithosphere of the Pacific plate and high heat flux from the strongly upwelling upper mantle [Bénard and Ionov, 2012; Bloomer and Hawkins, 1987; Hickey-Vargas and Reagan, 1987; Hickey and Frey, 1982; Ishizuka et al., 2006; Meijer, 1980; Meijer et al., 1983; Natland and Tarney, 1981; Pearce et al., 1999; Reagan and Meijer, 1984]. These series are in the lower section of volcanic rocks in the forearc and constitute the IBM proto-arc [Bloomer et al., 1995; Pearce et al., 1999; Pearce et al., 1992]. The uppermost section of volcanic rocks 
in the forearc consists of "normal" tholeiitic and calc-alkaline volcanic rocks, marking the onset of true subduction and these are the volcanic products of the early IBM arc also called the first arc [Gill, 1981; Gill et al., 1994; Meijer et al., 1983]. A mid-crustal layer of gabbros through tonalites is inferred from rare dredge and submersible samples of plutonic rocks on the trench wall. The existence of such a layer, and its thickness beneath the arc, is consistent with seismic cross-sections of the northern and southern IBM [Suyehiro et al., 1996; Takahashi et al., 2008] which show a low p-wave velocity layer in the middle-crust. According to Suyehiro et al. [1996] and Takahashi et al. [2008] the low p-wave velocity layer is consistent with lithologies including gabbros, diorites, plagiogranites and tonalites based on density calculations.

\subsection{Petrology}

Igneous rock samples used for this study from KK81-06-26 dredge RD63 were 4 to $17 \mathrm{~cm}$ in size along the longest axis, and are categorized as tonalites, diorites, quartz diorites and quartz gabbros based on normative mineralogy and by plotting them on a QAPF diagram. Petrographic examination of the RD63 suite shows varying amounts of quartz, plagioclase feldspar, orthopyroxene, clinopyroxene, hornblende, phyllosilicates (mainly chlorite), and magnetite. The composition of the ferromagnesian minerals depends in part on the degree of low grade alteration of the sample. Some samples have retained some primary pyroxene and hornblende while other samples display replacement by secondary amphiboles and phyllosilicates. Almost all plagioclase show signs of sericitization, although $\mathrm{Ab}$ contents increase with bulk rock $\mathrm{SiO}_{2}$, consistent with igneous 
characteristics. Maximum grain sizes are $4.5 \mathrm{~mm}$ in gabbros, $1.8 \mathrm{~mm}$ in diorites and 1.1 $1.6 \mathrm{~mm}$ in tonalites.

Intrusive igneous rocks from KK81-06-26 dredge RD64 are mostly coarsegrained rocks: diorite, quartz diorite, and tonalite, with small amounts of diabase and bronzite andesite. Petrographic analyses show primarily quartz, plagioclase feldspar, orthopyroxene, clinopyroxene, hornblende, phyllosilicates (chlorite) and magnetite. The diabase and bronzite andesites contain chromite rather than magnetite. Grain sizes in RD64 rocks vary but are on the same scale as rocks from RD63, with the maximum grain sizes of $\sim 2 \mathrm{~mm}$ in plutonic rocks and 10-100 microns for minerals in the groundmass of the diabase and hypabyssal samples (phenocrysts in the bronzite andesites are 600 microns and the glomerocrysts are 2-3 $\mathrm{mm}$ in width). Zircons were observed in diorites, quartz diorites and tonalites on microprobe backscatter images but they were less than 10 microns and at this time could not be dated.

\subsection{Analytical Methods}

Bulk analyses for representative rocks from RD63 and RD64 are given in Tables included in the Appendix. Whole rock powders were prepared at Florida International University using an alumina ball-mill after cutting away alteration rinds and secondary veins and infilled fractures. Powders were sent to Washington State University (WSU) GeoAnalytical Lab in Pullman, WA for major and trace element analysis. Major elements were analyzed on a ThermoARL XRF with USGS BHVO-2 and two duplicate samples run to check analytical accuracy and precision [Table 1]. The WSU lab fused the sample powders into a low dilution Li-tetraborate bead for XRF analysis by methods 
described by [Johnson et al., 1999]. Trace elements were analyzed on an Agilent 7700 ICP-MS after fusion with di-lithium tetraborate, crushing, and dissolution with $\mathrm{HNO}_{3}$ $\mathrm{HF}-\mathrm{HClO}_{4}$. Instrument drift was corrected using $\mathrm{Ru}, \mathrm{In}$, and Re as internal standards. More detailed information about the standardization and correction factors can be found in the Technical Notes section of the WSU GeoAnalytical website.

Samples were chosen for $\mathrm{Sr}, \mathrm{Nd}, \mathrm{Hf}$ and $\mathrm{Pb}$ isotope analysis based on major and trace element results, and they are all plutonic rocks. Given the extent and kind of alteration of the samples, powders were leached with $6 \mathrm{~N} \mathrm{HCl}$ using a methodology based on [Mahoney, 1987; Weis and Frey, 1991; 1996] for ocean floor rocks. The leached powders were digested, processed and analyzed at the Geochemistry Division of the National High Magnetic Field Laboratory (NHMFL) at Florida State University, Tallahassee, FL, using techniques reported in Münker et al. [2001], isotope separations were performed based on accepted techniques [Hart and Brooks, 1977; Manhès et al., 1978; Richard et al., 1976; Zindler et al., 1979] and modified by staff at NHMFL and Salters [1994] and Salters et al. [2011]. Sr isotopes were loaded on tungsten filaments and run on a Finnigan MAT TIMS, series 262. The $2 \sigma$ values are reported in the Appendix and were corrected using repeated analysis of the E \& A standard $\left({ }^{87} \mathrm{Sr} /{ }^{86} \mathrm{Sr}=\right.$ 0.70808). $\mathrm{Nd}, \mathrm{Hf}$ and $\mathrm{Pb}$ isotopes were analyzed on a Finnigan Neptune MC-ICPMS and $1 \sigma$ sigma values are reported. The synthetic La Jolla standard $\left({ }^{143} \mathrm{Nd} /{ }^{144} \mathrm{Nd}=0.511850\right)$ was run with samples and the one-sigma values were 0.000003 . The JMC475 standard with ${ }^{178} \mathrm{Hf} /{ }^{176} \mathrm{Hf}=0.28216$ was run with samples and the one-sigma values were 0.000005 or less. $\varepsilon H f$ values are calculated using the CHUR value $(0.282772)$ established in Blichert-Toft and Albarède [1997] and is consistent with older literature. 
The $\mathrm{Pb}$ isotopes are corrected based on the accepted NBS-981 standard values $\left({ }^{206} \mathrm{~Pb} /{ }^{204} \mathrm{~Pb}=16.9356 ;{ }^{207} \mathrm{~Pb} /{ }^{204} \mathrm{~Pb}=15.4891 ;{ }^{208} \mathrm{~Pb} /{ }^{204} \mathrm{~Pb}=36.7006\right.$; Todt et al. [1996] $)$. A Tl spike was added to the samples for a $\mathrm{Pb} / \mathrm{Tl}$ of $\sim 6$ and a ${ }^{203} \mathrm{Tl} /{ }^{205} \mathrm{Tl}$ standard $(0.4188)$ was run with the samples as a correction for mass fractionation. Long-term averages of NBS-981 at NHMFL are ${ }^{206} \mathrm{~Pb} /{ }^{204} \mathrm{~Pb}=16.9294 \pm 136 \mathrm{ppm},{ }^{207} \mathrm{~Pb} /{ }^{204} \mathrm{~Pb}=15.4824 \pm 164$ ppm, and ${ }^{208} \mathrm{~Pb} /{ }^{204} \mathrm{~Pb}=36.6698 \pm 211 \mathrm{ppm}$ based on numerous replications.

\subsection{Geochemical Results}

Eighteen samples from RD63 and 11 samples from RD64 were analyzed for major and trace elements, and 12 representative samples were analyzed for $\mathrm{Sr}, \mathrm{Nd}, \mathrm{Hf}$ and $\mathrm{Pb}$ isotopes. Data from tables in Appendix 4 (page 184) are plotted in Figure 5.1 through Figure 5.6.

\subsubsection{Major elements}

The major element compositions of the dredge site plutonic suites are compared to those of igneous rocks from other locations in the IBM forearc and southern Japan (Figure 5.1). The RD63 plutonic suite has $\mathrm{SiO}_{2}$ of 49 to $78 \mathrm{wt} \%, \mathrm{MgO}$ between 1 and 13 wt $\%, \mathrm{Al}_{2} \mathrm{O}_{3} 13$ to $23 \mathrm{wt} \%, \mathrm{TiO}_{2}$ less than $0.3 \mathrm{wt} \%$, and $\mathrm{K}_{2} \mathrm{O}$ of 0.11 to $2.3 \mathrm{wt} \%$. The RD64 suite has $\mathrm{SiO}_{2}$ of 56 to $68 \mathrm{wt} \%, \mathrm{MgO}$ between 1 and $24 \mathrm{wt} \%, \mathrm{Al}_{2} \mathrm{O}_{3} 4$ and $17 \%$, $\mathrm{TiO}_{2}$ between 0.1 to $0.4 \mathrm{wt} \%, \mathrm{~K}_{2} \mathrm{O}$ of 0.01 to $0.53 \mathrm{wt} \%$.

One notable major element characteristic of the rocks from RD63 is their extremely low $\mathrm{TiO}_{2}$ contents (Figure 5.1d). RD64 rocks are slightly higher but still low compared with FABs, typical IBM arc lavas and MORBs [Hickey-Vargas, 1989; Ishizuka et al., 2006; Meijer, 1980; Sun and McDonough, 1989; Taylor et al., 1994]. Compared 

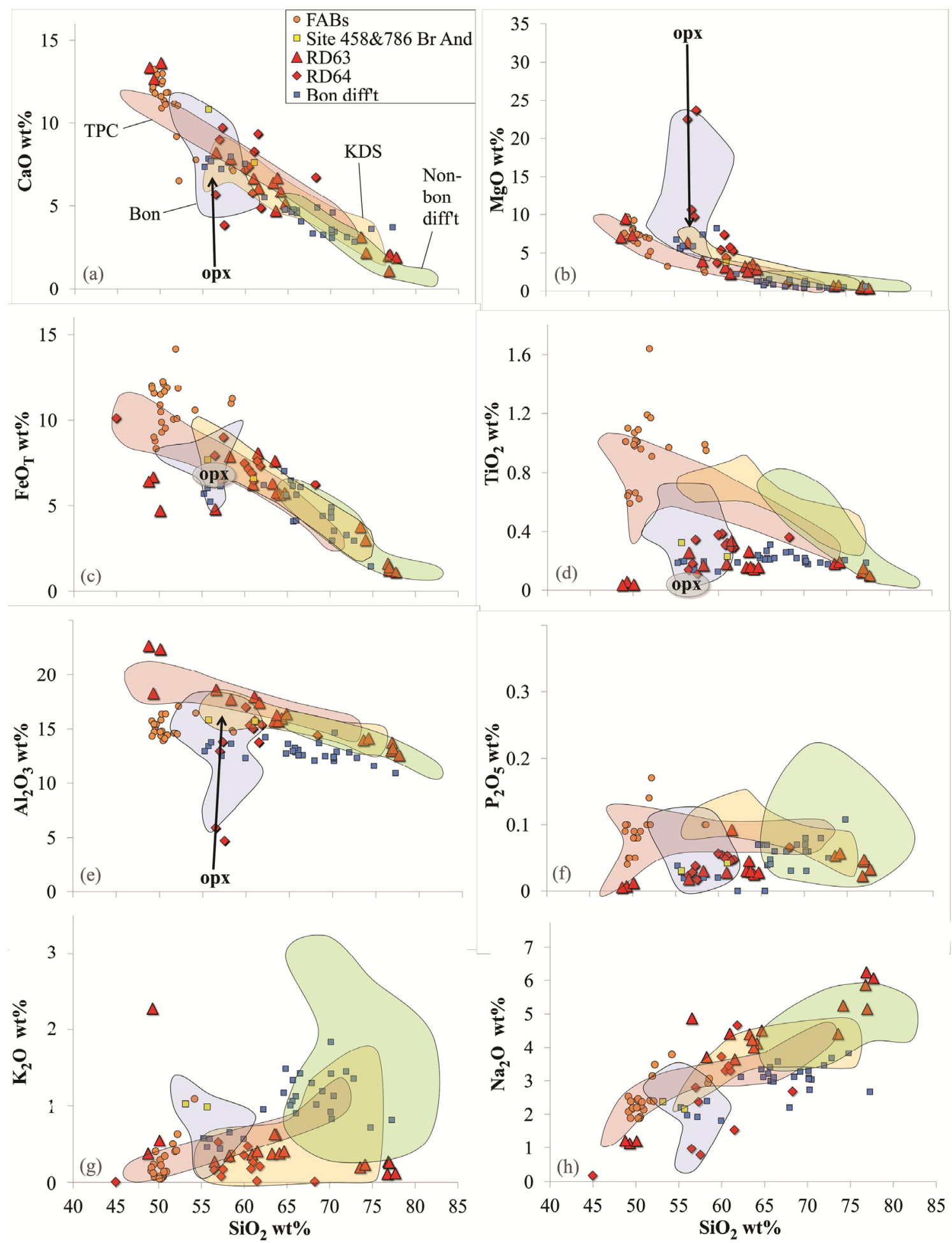

Figure 5.1. Major element data plotted vs. $\mathrm{SiO}_{2}$ wt \%. Data points are rocks from RD63 and RD64 (red triangles and squares, this work), FABs (orange circles: Reagan et al. [2010]) and boninite differentiates (blue and yellow square symbols) such as andesites, dacites and rhyolites from Chichijima [Kuroda et al., 1988; Taylor et al., 1994] and 
bronzite andesites from DSDP Site 458 and 786 [Pearce et al., 1999]. The blue field is boninites from Guam, the southern Mariana forearc and Chichijima ("Bon") [HickeyVargas and Reagan, 1987; Pearce et al., 1999; Reagan et al., 2010; Taylor et al., 1994]. The red field is gabbro through tonalite from the Tanzawa Plutonic Complex ("TPC") in Honshu, Japan [Kawate and Arima, 1998]. The orange field is gabbro through tonalite from the Komahashi-Daini Seamount ("KDS") in the northern Kyushu-Palau Ridge [Haraguchi et al., 2003]. The green field is for non-boninite related rhyolites from Saipan [Reagan et al., 2008] and from Quaternary northern IBM volcanic centers [Tamura et al., 2009] ("Non-bon diff't"). $\mathrm{FeO}_{\mathrm{T}}$ is total $\mathrm{Fe}$. The orthopyroxene (OPX) data is from boninites analyzed by Bloomer and Hawkins [1987] and the arrows are an approximate fractionation trajectory.

with other plutonic suites from the northern IBM (Komahashi Daini seamount on the Kyushu-Palau Ridge; Haraguchi et al. [2003]) and the Tanzawa Complex, Southern Honshu [Kawate and Arima, 1998], $\mathrm{RD} 63$ also has lower $\mathrm{TiO}_{2}$, but a similar range of $\mathrm{SiO}_{2}(\sim 49-78 \mathrm{wt} \%)$ and other major oxides. These low $\mathrm{TiO}_{2}$ contents link the dredge $\mathrm{RD} 63$ and $\mathrm{RD} 64$ rocks with boninites and boninite series rocks which have $\mathrm{SiO}_{2}$ of 52$60 \% \mathrm{SiO}_{2}$ and notably low $\mathrm{TiO}_{2}$ of 0.1 to $0.6 \%$ (Figure 5.1). The wide range of $\mathrm{SiO}_{2}$ contents in the RD63 suite is similar to that observed in differentiated boninite lavas. For example, boninite derived dacites from Chichijima reach $68 \% \mathrm{SiO}_{2}$ and rhyolites reach $78 \%$. On major element diagrams, the differentiated boninite lavas and RD63 plutonic rocks overlap, both having notably low $\mathrm{TiO}_{2}$ (Figure 5.1d), and differing only in that the plutonic suite has uniformly higher $\mathrm{Al}_{2} \mathrm{O}_{3}$ for a given $\mathrm{SiO}_{2}$ (Figure 5.1e). At high $\mathrm{SiO}_{2}$ (73-78\% $\mathrm{SiO}_{2}$ ) the $\mathrm{RD} 63$ also overlap in $\mathrm{TiO}_{2}$ with the range for non-boninite related early-IBM rhyolites from Saipan [Meijer, 1980; Meijer et al., 1983; Reagan et al., 2008] and Quaternary rhyolites from the northern IBM [Tamura et al., 2009]. 


\subsubsection{Trace elements}

Like most arc rocks, both suites exhibit a pronounced negative $\mathrm{Nb}$ anomaly (normalized $\mathrm{La} / \mathrm{Nb}=1.3-5.7$ for $\mathrm{RD} 63$ and 3.7-5.3 for RD64), and are enriched in $\mathrm{Th}$ relative to $\mathrm{Nb}(\mathrm{Th} / \mathrm{Nb}=2.6$ to 10.1$)$. The REE patterns of $\mathrm{RD} 63$ rocks (Figure 5.2) are enriched in both L(light)REE and H(heavy)REE (primitive mantle normalized La/Sm = 1.3-4.6 and $\mathrm{Yb} / \mathrm{Sm}=0.9-1.6$ ), resulting in a "U"-shaped REE pattern resembling that of boninites from the IBM. The dredge RD63 plutonic rocks exhibit both positive and negative Eu anomalies. Gabbros have a Eu/Eu* of 1.5-2.4, whereas diorites-quartz diorites have $\mathrm{Eu} / \mathrm{Eu}^{*}$ of $0.70-1.08$, and the tonalites have a large positive anomaly (up to 2.2). All dredge RD63 rocks exhibit a conspicuous positive $\mathrm{Hf}-\mathrm{Zr}$ anomaly relative to REE (Figure 5.2), which is a unique characteristic of boninites not found in other island arc rocks (e.g., Pearce et al. [1999]). The Hf-Zr anomaly becomes increasingly positive relative to middle $\mathrm{REE}$ as $\mathrm{SiO}_{2}$ content increases (Figure 5.2a and Figure 5.3). Dredge RD64 rocks have flat REE patterns and some but not all exhibit slight positive $\mathrm{Hf}$ and $\mathrm{Zr}$ anomalies relative to REE (Figure 5.2b). Interestingly, neither FABs nor the bronzite andesites from Site 458 on the Mariana forearc exhibit pronounced negative $\mathrm{Nb}$ anomalies or Th-enrichment (Figure 5.2), as do boninites and RD63 and RD64 rocks.

The behavior of REEs and $\mathrm{Zr}, \mathrm{Hf}, \mathrm{Nb}$ and $\mathrm{Th}$ is displayed in more detail in several other trace element plots. Overall, RD63 and RD64 rocks have systematically lower concentrations of REE, $\mathrm{Zr}, \mathrm{Hf}, \mathrm{Nb}$ and $\mathrm{Th}$ across their entire range of $55-78 \% \mathrm{SiO}_{2}$ compared with recent IBM silicic rocks and the plutonic suite from Komahashi-Daini Seamount, and this difference is most pronounced for middle (Nd, Sm) and heavy REE $(\mathrm{Yb})$. In all suites, incompatible trace element abundances increase with $\mathrm{SiO}_{2}$ up to about 

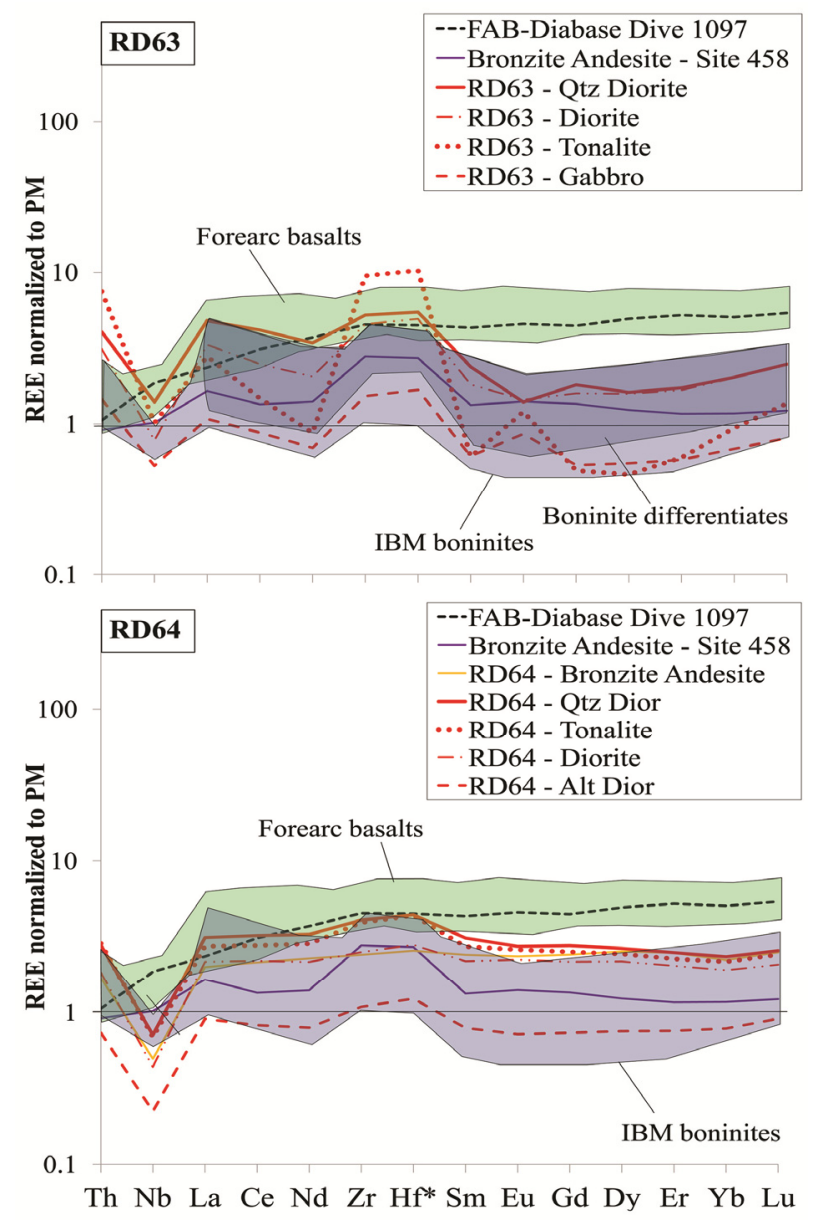

Figure 5.2. Primitive mantle normalized rare earth elements (REE) and other trace elements. In the RD63 diagram, the red lines represent gabbro, diorite, quartz diorite and tonalite from RD63. The gabbro and tonalite have lowest REE abundances and positive Eu anomalies, whereas diorite and quartz diorite have higher REE abundances and either negative or no Eu anomaly. In the RD64 diagram, the red lines represent a gabbro, quartz diorite, diorite and tonalite. The orange line represents a bronzite andesite from RD64 as a comparison to a bronzite andesite from Site 458 (458 24-1wr) [Reagan et al., 2010] which is a purple line on both diagrams. Shaded fields in both diagrams are FABs (green), boninites (blue), differentiated boninites (darker blue in RD63). FABs are from DSDP Site 458 and 459 and Mariana forearc submersible dive sites [Reagan et al., 2010] and a representative FAB (1097-3) is shown by a dashed black line.. Boninites are from Chichijima, Guam, DSDP Site 458 and ODP Site 786, and dredges and dives from the southern Mariana forearc [Hickey-Vargas and Reagan, 1987; Pearce et al., 1999; Reagan et al., 2010; Taylor et al., 1994]. Boninite differentiates (andesites, dacites, rhyolites) are from Chichijima [Taylor et al., 1994]. Elements with an asterisk $(*)$ indicate that they were not reported or analyzed and therefore are an average of the adjacent elements. The boninite differentiates from Chichijima in Taylor et al. [1994] did not include $\mathrm{Th}$ or $\mathrm{Nb}$ values and were omitted in the darker blue field. REEs were normalized based on the primitive mantle value of Sun and McDonough [1989]. 
decoupling of REE from $\mathrm{Zr}$ and $\mathrm{Hf}$ is evident here in the RD63 and RD64 plutonic suites 70\%. At that point, recent northern IBM silicic volcanic rocks and the Komahashi-Daini Seamount suite continue to increase for these eight elements, whereas abundances of REE in RD63 and RD64 decrease, mimicking the behavior of $\mathrm{TiO}_{2}$ (Figure 5.1). The (Figure 5.3). $\mathrm{Zr} / \mathrm{Sm}$ ratios in gabbros from $\mathrm{RD} 63$ and $\mathrm{RD} 64$, like those of boninites, are generally higher than those in FABs (average 25), normal arc basalts, MORBs and primitive mantle. $\mathrm{RD} 63$ diorites, quartz diorites and tonalites with less than $75 \% \mathrm{SiO}_{2}$ have even higher $\mathrm{Zr} / \mathrm{Sm}$ (average 58), whereas the most silicic tonalites, those having a granophyric texture, range from 71 to 394 . The diorites, quartz diorites and tonalites in $\mathrm{RD} 63$ have higher $\mathrm{Zr} / \mathrm{Sm}$ than any other rock (Figure 5.3) and the $\mathrm{Zr} / \mathrm{Sm}$ increases significantly in tonalites with $\mathrm{SiO}_{2}$ higher than $75 \mathrm{wt} \%$. This pattern of high $\mathrm{Zr} / \mathrm{Sm}$ in RD63 diorites, quartz diorites and tonalites coincides with depleted trace element contents for all RD63 samples (even compared to RD64 samples), and notably a pronounced decrease in Sm (and other REE) contents in granophyric tonalites with $\mathrm{SiO}_{2}>75 \mathrm{wt} \%$ (Figure 5.4). Diorites, quartz diorite and tonalite from RD64 do not show this trend, although $\mathrm{Zr} / \mathrm{Sm}$ ratios are generally higher than primitive mantle. 5.6.3 Sr, $\mathrm{Nd}, \mathrm{Hf}, \mathrm{Pb}$ Isotope data

On a plot of initial $\varepsilon_{\mathrm{Nd}}$ versus initial ${ }^{87} \mathrm{Sr} /{ }^{86} \mathrm{Sr}$ (Figure 5.5a) the RD63 and RD64 rocks lie within the field for IBM arc boninites at lower $\varepsilon_{\mathrm{Nd}}$ and generally higher ${ }^{87} \mathrm{Sr} /{ }^{86} \mathrm{Sr}$ than FABs or the early IBM arc lavas. RD64 rocks have systematically higher $\varepsilon_{\mathrm{Nd}}$ compared with RD63. Within each suite, there is no systematic change in $\mathrm{Sr}$ or $\mathrm{Nd}$ isotope ratios with bulk composition or normative lithology. On the plot of initial $\varepsilon_{\mathrm{Hf}}$ versus $\varepsilon_{\mathrm{Nd}}$ (Figure 5.5b), the RD63 and RD64 rocks also lie near the fields of IBM 


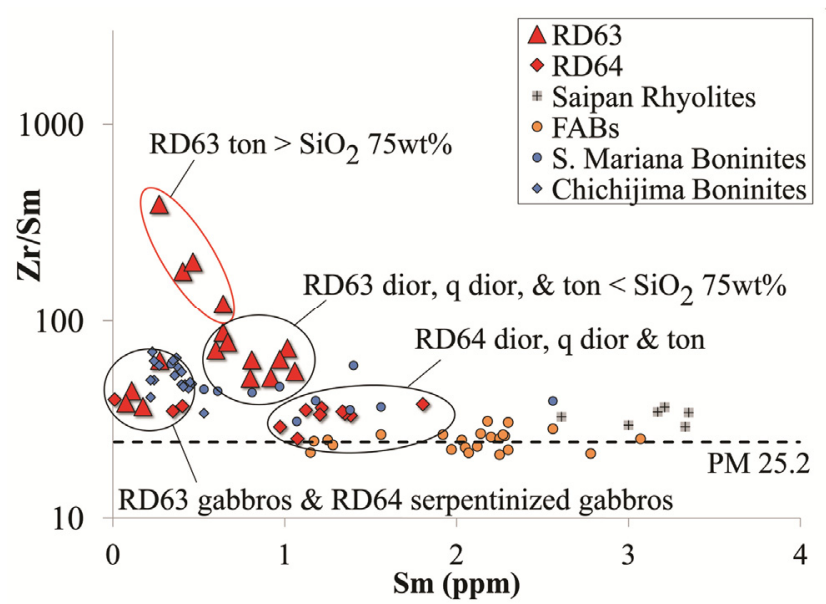

Figure 5.3. Variation of $\mathrm{Zr} / \mathrm{Sm}$ ratios in $\mathrm{RD} 63$ and $\mathrm{RD} 64$ plutonic suites compared with other volcanic and plutonic suites from the early IBM, and the relationship of $\mathrm{Zr} / \mathrm{Sm}$ to Sm abundances. FABs (forearc basalts) are from Reagan et al. [2010]; Saipan rhyolites are from Reagan et al. [2008]; boninites are from Chichijima [Taylor et al., 1994] and the southern Mariana forearc [Reagan et al., 2010]. The black dashed line represents the $\mathrm{Zr} / \mathrm{Sm}$ composition of primitive mantle reported by Sun and McDonough [1989]. Abbreviations of lithologies are as follows: ton $=$ tonalite; $\mathrm{q}$ dior $=$ quartz diorite; dior $=$ diorite.

boninites, distinct from the higher $\varepsilon_{\mathrm{Nd}}$ of FABs and the early IBM arc. $\varepsilon_{\mathrm{Hf}}$ values are generally lower in boninites and the RD63 and RD64 samples compared with FABs and early IBM arc lavas. Notably, however, nearly all FABs and early IBM rocks fall in the field of Indian MORB [Pearce et al., 1999]. On plots of initial Pb isotope ratios (Figure 5.5c and d), RD63 and RD64 rocks again lie with IBM arc boninites in a cluster from ${ }^{206} \mathrm{~Pb} /{ }^{204} \mathrm{~Pb}$ of $18.5-18.9$, and they overlap with the more radiogenic end of $\mathrm{FABs}$ and the early IBM arc. RD64 samples have slightly lower ${ }^{208} \mathrm{~Pb} /{ }^{204} \mathrm{~Pb}$ compared with RD63 (Figure 5.5d), and systematically lower ${ }^{207} \mathrm{~Pb} /{ }^{204} \mathrm{~Pb}$, which fall below the NHRL. Some RD63 samples have $\mathrm{Pb}$ isotopic compositions that are like boninites from Chichijima in 


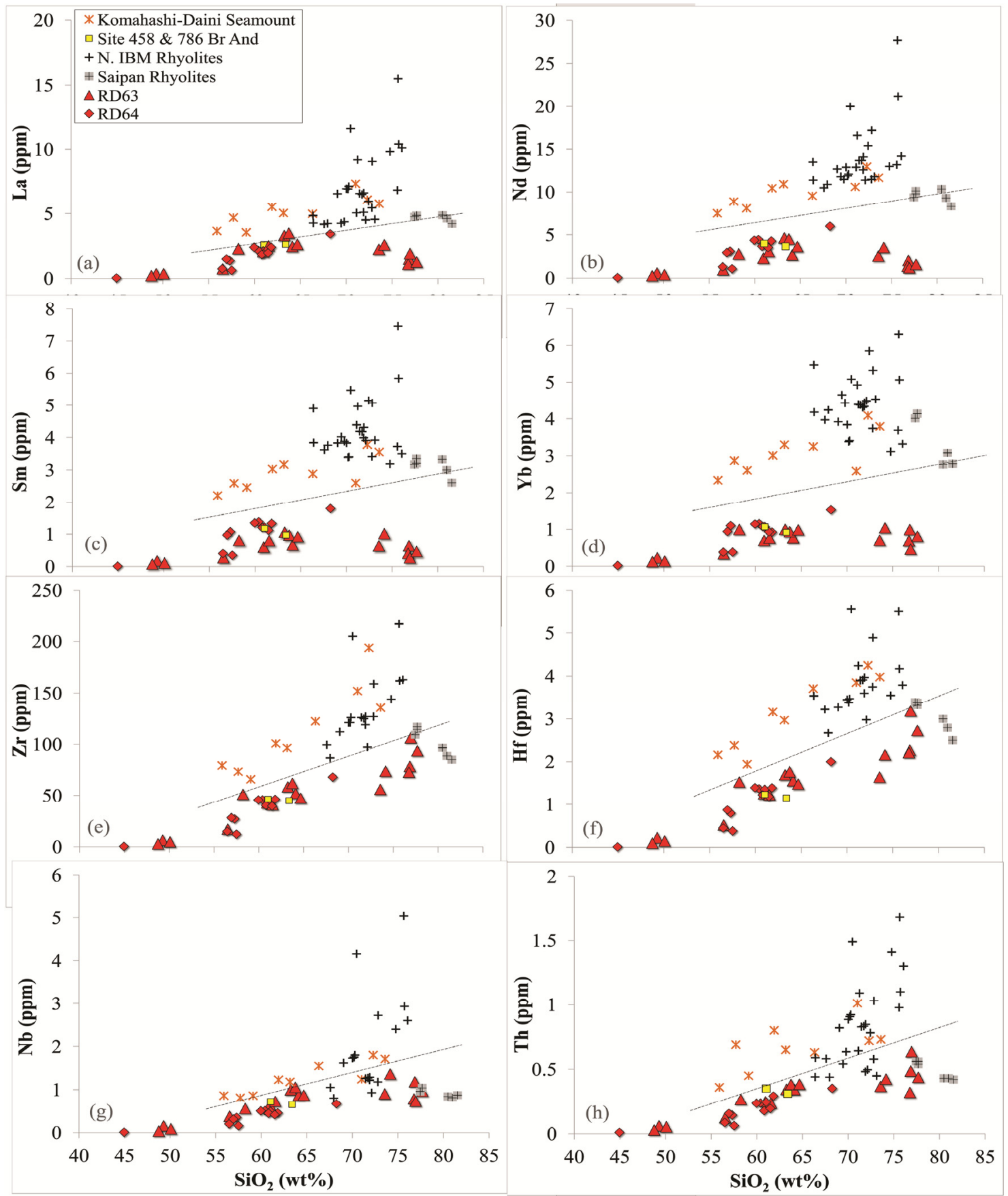

Figure 5.4. Trace elements (REEs and HFSEs) ppm vs. $\mathrm{SiO}_{2}(\mathrm{wt} \%)$. REE: $\mathrm{La}, \mathrm{Sm}, \mathrm{Nd}$, $\mathrm{Yb}$ and HFSE: $\mathrm{Zr}$, Hf, $\mathrm{Nb}$ and $\mathrm{Th}$ plotted versus $\mathrm{SiO}_{2}$ to compare how the trace elements behave as differentiation occurs in intermediate and felsic rocks. Rocks from RD63 and RD64 (this study) are compared with Quaternary dacites and rhyolites from the northern IBM [Tamura et al., 2009], Saipan rhyolites [Reagan et al., 2008]; and plutonic rocks from the Komahashi-Daini Seamount tonalites [Haraguchi et al., 2003]. The dashed line through the data represents a rough boundary between the RD63 and RD64 and other intermediate and felsic rocks. 
the northern IBM, which trend upward away from the NHRL, whereas others fall with boninites from ODP Site 786, Guam and the southern IBM which trend along the NHRL. Similar to $\mathrm{Sr}$, and $\mathrm{Nd}$ isotopes, there is no systematic change in $\mathrm{Hf}$ or $\mathrm{Pb}$ isotopes with bulk composition or normative lithology within each suite.

\subsection{Discussion}

5.7.1 Origin of dredged suites and relationship to volcanic suites

The recovery of plutonic rocks from the Mariana forearc, first reported by Bloomer [1983] and Bloomer and Hawkins [1987], is a puzzling discovery because it implies that deep layers of the arc crust are exposed on the inner Mariana Trench slope. The hypothesis that lavas from the IBM forearc likely represent the first volcanic products of subduction initiation, has led to many studies addressing the origin and age of those lavas through petrologic, geochemical and geochronological analyses [Bloomer, 1983; Fryer et al., 1990; Hawkins et al., 1984; Hickey-Vargas and Reagan, 1987;

Ishizuka et al., 1998; Ishizuka et al., 2006; Kaneoka et al., 1970; Meijer et al., 1983; Mitchell et al., 1992; Natland and Tarney, 1981; Pearce et al., 1999; Pearce et al., 1992; Reagan and Meijer, 1984; Stern and Bloomer, 1992; Taylor and Mitchell, 1992]. The synthesis of the volcanic stratigraphy, petrology and geochemistry [Reagan et al., 2008; Reagan et al., 2010], and recent efforts to fully sample the trench slope, provide a solid context for interpreting the origin of these nearby, rare plutonic rocks. Our geochemical data indicate that the plutonic rocks from dredges RD63 and RD64 are related to the infant arc volcanic sequence. The geochemical data, primarily the isotopic ratios, suggest 

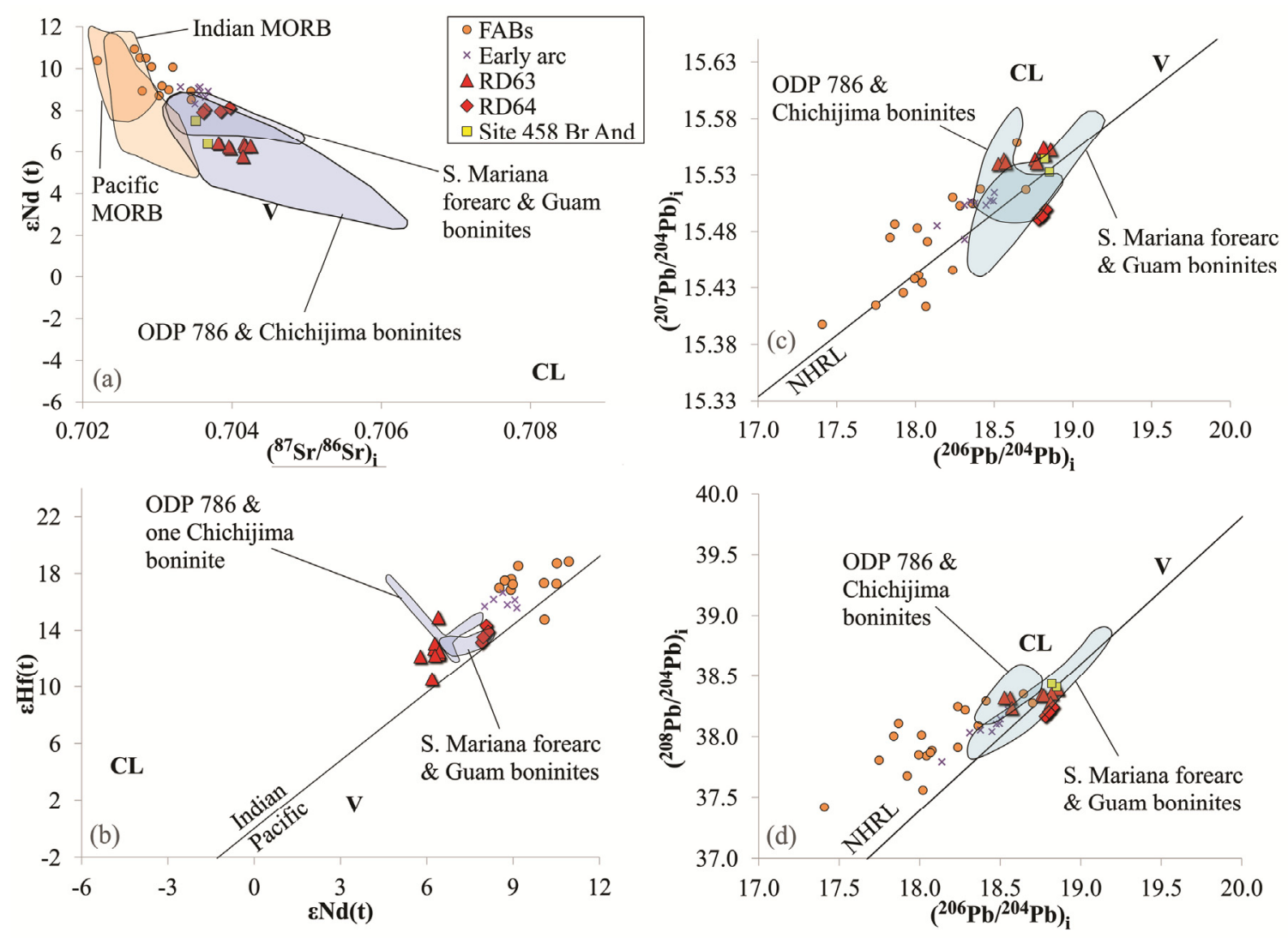

Figure 5.5. Initial isotopic compositions of rocks from RD63 and RD64 compared with other igneous rocks from the southern Mariana arc. An age of $50 \mathrm{Ma}$ was assumed for the RD63 and RD64 dredge samples, similar to that of the dated boninite volcanic rocks. The other rocks on the plots were corrected using their ages inferred from radiometric dating. Data sources for these plots are the same as previous figures. The MORB field in (a) was compiled from the literature. Sediment compositions for the Pacific Plate in the vicinity of the IBM arc are represented by average volcaniclastic sediments (V) and clay (CL) from Pearce et al. [1999] and Elliott et al. [1997]. NHRL in b) and d) is the Northern Hemisphere Reference Line from Hart [1984], and the Indian-Pacific "boundary" in c) is from Pearce et al. [1999].

that these dredges are distinct from each other even though they are from similar depths in the forearc. In addition, the uniform $\mathrm{Sr}, \mathrm{Nd}, \mathrm{Pb}$ and $\mathrm{Hf}$ isotopic composition of samples within each dredge suggests that the samples are genetically related to one another and can be interpreted in terms of crystallization and melting processes. 
Major and trace element evidence clearly shows that the RD63 plutonic suite is related to boninite and boninite-like rocks from the IBM forearc, including their characteristic low $\mathrm{TiO}_{2}$ content, U-shaped REE patterns and excess $\mathrm{Zr}$ and $\mathrm{Hf}$ compared with middle REEs. The $\mathrm{Sr}, \mathrm{Nd}, \mathrm{Hf}$ and $\mathrm{Pb}$ isotopic data are consistent with a boninite parent. Isotope ratios for the RD63 and RD64 plutonic suites have distinctly lower ${ }^{143} \mathrm{Nd} /{ }^{144} \mathrm{Nd}$ and higher ${ }^{206} \mathrm{~Pb} /{ }^{204} \mathrm{~Pb}$ than most FABs, low-K tholeiitic and calc-alkaline volcanic rocks from the early IBM arc, and all plot within fields for IBM arc boninites. Interestingly, plutonic rocks from RD63 have isotope ratios most similar to "bronzite andesite" boninite derivatives from DSDP Site 458 and boninites from Chichijima in the Izu-Bonin segment, rather than to boninite-like rocks sampled from Guam and the nearby upper trench. Compared to the latter boninites, ${ }^{143} \mathrm{Nd} /{ }^{144} \mathrm{Nd}$ and ${ }^{206} \mathrm{~Pb} /{ }^{204} \mathrm{~Pb}$ ratios are lower. These differences may reflect a difference in the sediment component in the boninite parent for the RD63 suite. Differences in ${ }^{206} \mathrm{~Pb} /{ }^{204} \mathrm{~Pb}$ ratios in IBM arc volcanic rocks have been widely attributed to sourcing of $\mathrm{Pb}$ from seamount-derived volcaniclastic sediment (V in Figure 5.5) versus a source from dominantly pelagic sediment (CL in Figure 5.5; Elliott et al. [1997]). Our interpretation is that the boninite parent magma of the RD63 suite incorporated more $\mathrm{Pb}$ and $\mathrm{Nd}$ from pelagic sediment, resulting in lower ${ }^{143} \mathrm{Nd} /{ }^{144} \mathrm{Nd}$, lower ${ }^{206} \mathrm{~Pb} /{ }^{204} \mathrm{~Pb}$ and higher ${ }^{207} \mathrm{~Pb} /{ }^{204} \mathrm{~Pb}$ and ${ }^{208} \mathrm{~Pb} /{ }^{204} \mathrm{~Pb}$ than boninites from the upper trench wall and Guam, and more similar to boninites from Chichijima. FABs have much less radiogenic $\mathrm{Pb}$ and $\mathrm{Sr}$ isotope ratios than boninites and related plutonic rocks everywhere within the early IBM, a feature which was interpreted by Reagan et al. [2010] to indicate there is little to no subduction influence in FABs compared with boninites. Boninites and the related RD63 and RD64 plutonic rocks also have 
unradiogenic $\mathrm{Nd}$ and $\mathrm{Hf}$ isotope ratios compared to $\mathrm{FABs}$ which may have been acquired from a distinct mantle source that was not incorporated into the FAB melts between 4852Ma [Reagan et al., 2010]. Alternatively, the depleted boninite source may have been affected by a small contribution from pelagic sediment at the early stages of subduction, resulting in lower ${ }^{143} \mathrm{Nd} /{ }^{144} \mathrm{Nd}$ (Figure 5.5).

Plutonic rocks from RD64 have ${ }^{143} \mathrm{Nd} /{ }^{144} \mathrm{Nd}$ in the uppermost range for IBM boninites, and overlap in ${ }^{87} \mathrm{Sr} /{ }^{86} \mathrm{Sr},{ }^{176} \mathrm{Hf} /{ }^{177} \mathrm{Hf}$ and ${ }^{206} \mathrm{~Pb} /{ }^{204} \mathrm{~Pb}$ with those from Guam and the nearby upper trench. ${ }^{207} \mathrm{~Pb} /{ }^{204} \mathrm{~Pb}$ and ${ }^{208} \mathrm{~Pb} /{ }^{204} \mathrm{~Pb}$ are slightly lower compared with those fields, and may reflect a slightly different composition for the seamount-derived volcaniclastic sediment end member (Figure 5.5) with lower ${ }^{207} \mathrm{~Pb} /{ }^{204} \mathrm{~Pb}$ and ${ }^{208} \mathrm{~Pb} /{ }^{204} \mathrm{~Pb}$ compared with those currently found on the Pacific Plate.

\subsubsection{Boninite differentiation to form the plutonic suites}

Potential differentiation pathways for boninite magma can be inferred from differentiated boninite volcanic suites [Hickey-Vargas, 1989; Ishizuka et al., 2006; Kuroda et al., 1988; Kushiro, 1981; Natland and Tarney, 1981; Taylor and Nesbitt, 1995; Taylor et al., 2003; Taylor et al., 1994; Umino, 1985] and observed boninite mineralogy. Major element trends (Figure 5.1) for boninite liquids are initially driven by crystallization of orthopyroxene, as shown by decreasing $\mathrm{MgO}$ and $\mathrm{FeO}_{\mathrm{T}}$, and increasing $\mathrm{Al}_{2} \mathrm{O}_{3}, \mathrm{CaO}$ and $\mathrm{TiO}_{2}$ at relatively constant $\mathrm{SiO}_{2}$ of $58 \%$. At this $\mathrm{SiO}_{2}$ content, trends approach the field for $\mathrm{RD} 63$ plutonic rocks at $16 \% \mathrm{Al}_{2} \mathrm{O}_{3}, 8 \% \mathrm{FeO}, 5 \% \mathrm{MgO}$ and $8 \%$ $\mathrm{CaO}$. These major element abundances are similar to those of boninite-derived bronzite andesites found at DSDP Site 458 and on Chichijima, which contain orthopyroxene and rare clinopyroxene phenocrysts, and plagioclase microlites. Our proposed crystallization 
scenario for the RD63 plutonic suite is: 1) crystallization of opx $+/-$ cpx from boninite magma, until plagioclase saturation is reached, followed by 2) accumulation of plagioclase and pyroxene to form rocks $<58 \% \mathrm{SiO}_{2}$ (Figure 5.1) and 3) plagioclase $+/-$ pyroxene crystallization for most of the trend $>58 \% \mathrm{SiO}_{2}$ (Figure 5.1).

The abundance of plagioclase in the RD63 plutonic suite contrasts with the typical characteristics of boninite volcanic rocks, where plagioclase is rarely an abundant mineral except at extreme $\mathrm{SiO}_{2}$ enrichment (i.e., perlitic dacite and rhyolite from Chichijima, Kuroda, et al., [1988]). Possibly, in the case of the RD63 plutonic rocks, the ascent of boninitic magma was stalled in the mid- to upper crust, allowing magma degassing and extended low-pressure crystallization, both of which favor plagioclase stability. Since there are no plutonic rocks coincident with the orthopyroxene crystallization part of the boninite trend, it is probable that a $\mathrm{MgO}$ poor, $\mathrm{Al}_{2} \mathrm{O}_{3}$ rich "bronzite andesite" precursor separated from the ascending boninite magmas and then underwent accumulation to form gabbro and differentiation to the extreme compositions represented by the tonalites. Gabbro cumulates have higher $\mathrm{Al}_{2} \mathrm{O}_{3}$ and positive $\mathrm{Eu}$ anomalies due to high modal amounts of plagioclase feldspar (Figure 5.2). Granophyric textures in four RD63 tonalite samples are indicative of quartz and feldspar crystallizing simultaneously, such as when a silicate melt is at the eutectic point or when a silicic liquid is undercooled [Fenn, 1986; Lentz and Fowler, 1992; London et al., 1989; Lowenstern et al., 1997]. This is often the case in plutons at shallow depths during late stage crystallization, or in the first phase of melting of a mafic rock, which in this case could be the previously emplaced boninite crust. Since we have no constraints on the size or original location of the suite, the 
plutonic rocks may have been small, heterogeneous pods or masses in the arc crust, or alternatively, kilometer-sized intrusions with gabbroic through tonalitic lithologies.

Rare earth element (REE) patterns of rocks from the plutonic suites from the southern Mariana Trench have the U-shaped pattern that is characteristic of boninites from the IBM arc, which has been attributed to partial melting of depleted mantle peridotite enriched in LREE by metasomatic fluids [Hickey-Vargas and Reagan, 1987; Hickey and Frey, 1982; Pearce et al., 1992; Reagan and Meijer, 1984]. Bronzite andesites from DSDP Site 458 and Chichijima, differentiates that are boninite-like, and all types of plutonic rocks from RD63 and RD64, with the exception of some gabbros, also have U-shaped patterns and they fall within these fields. The $\mathrm{Eu} / \mathrm{Eu}^{*}$ (i.e., the positive Eu anomaly) in the gabbroic cumulates supports plagioclase accumulation from a melt composition approximately similar to the DSDP Site 458 bronzite andesites. The unique REE patterns and elevated $\mathrm{Zr} / \mathrm{Sm}$ and $\mathrm{Hf} / \mathrm{Sm}$ of boninites are also found in diorites of the RD63 suite, confirming their origin from a boninite differentiate as described above. At this point in the crystallization sequence, none of the likely fractionating minerals, orthopyroxene, clinopyroxene, or plagioclase, can produce Ushaped REE patterns or elevated $\mathrm{Zr} / \mathrm{Sm}$ if not inherited from the parental magma.

The increased decoupling of the HFSEs from REEs with differentiation, particularly in high silica tonalites, appears to result from extraction of the REE rather than enrichment of $\mathrm{Zr}$ and Hf (Figure 5.4 and Figure 5.3). Detailed major and trace element modeling calculations for crystallization and partial melting of three possible magma or rock precursors: 1) boninite, 2) FAB and 3) diorite confirm that a differentiated boninite magma or boninite rock source is essential for the plutonic suite 
(Figure 5.6). Crystallization of an intermediate boninite magma is the most likely first step, and this produces gabbro, diorite and quartz diorite. In a second step leading to tonalite, both crystallization and partial melting are possible. For both crystallization and partial melting, hornblende, and in some cases an accessory mineral such as apatite or sphene, is required to account for the diminishing REE content and increasing $\mathrm{Zr} / \mathrm{Sm}$. The accessory mineral sphene was included in the trace element models (Figure 5.6) and it has been shown to have a somewhat large stability field at low to moderate P-T [Hunt and Kerrick, 1977]. Significantly, in all scenarios, a boninite precursor, magma or rock, is the only starting composition that results in HFSE/REE patterns similar to RD63 and RD64 plutonic rocks (Figure 5.6), confirming that the plutonic rocks have inherited this signature from boninites in this location.

5.7.3 Comparison with other IBM-related plutonic suites and the "mid-crustal" felsic layer

With the exception of $\mathrm{TiO}_{2}$, the intermediate to felsic plutonic rocks of $\mathrm{RD} 63$ and RD64 ( $\left.>60 \% \mathrm{SiO}_{2}\right)$ plot within the major oxide differentiation trends of other rare IBMrelated plutonic suites, i.e., rocks dredged from Komahashi-Daini Seamount on the Kyushu Palau Ridge and tonalites and gabbros found in the Tanzawa Plutonic Complex (TPC) in Honshu, Japan. $\mathrm{CaO}$ contents in the inner trench slope suites are slightly more scattered and some $\mathrm{MgO}$ contents are higher at the low $\mathrm{SiO}_{2}$ end. The tonalites from the Komahashi-Daini Seamount were dated at 38-37 Ma (K-Ar) and hypothesized to have formed by fractional crystallization from a low-K basaltic melt prior to the rifting of the early IBM arc [Haraguchi et al., 2003; Haraguchi et al., 2012; Shibata et al., 1977]. The TPC plutonic rocks have recently been dated using $\mathrm{U}-\mathrm{Pb}$ in zircon at 9-4 Ma, which 
indicates that the plutons are a result of syncollisional magmatism of the Honshu-TPC block with the northern IBM arc [Tani et al., 2012]. The complex is explained by partial melting of a hydrous calc-alkaline basaltic lower crust [Kawate and Arima, 1998; Tani et al., 2012]. Despite the differences in tectonomagmatic setting among these locations: 1) normal subduction zone magmatism (Kyushu Palau Ridge), 2) collision and lower crustal melting (Tanzawa) and 3) arc initiation (RD63 and RD64), the intermediate to felsic plutonic rocks have broadly similar major element and mineralogical characteristics and would be difficult to distinguish on this basis. Any or all of these types of plutonic suites could be incorporated into the mid-crustal low seismic velocity layer identified by Suyehiro et al. [1996] and Takahashi et al. [2008], although it is most likely that boninite derivatives form only a small proportion based on the abundance of boninite lavas. On the other hand, there are many petrologic similarities between the RD63 plutonic rocks and plutonic rocks found in some SSZ ophiolites, including rocks referred to as plagiogranites by Dilek and Thy [2006] and Rollinson [2009]. Several recent studies [Dilek and Thy, 2009; Dilek and Furnes, 2009; Stern et al., 2012; Whattam and Stern, 2011] have linked the occurrence of boninite in arc initiation suites to the concept that boninite-bearing SSZ ophiolites are preserved sections of forearc. Assuming our identification of the RD63 and RD64 plutonic suites as boninite derivatives is correct, the occurrence of plagiogranites with comparable major and trace element features in a SSZ ophiolite could confirm its formation in a forearc environment during the initiation of subduction even if boninites are not found. 

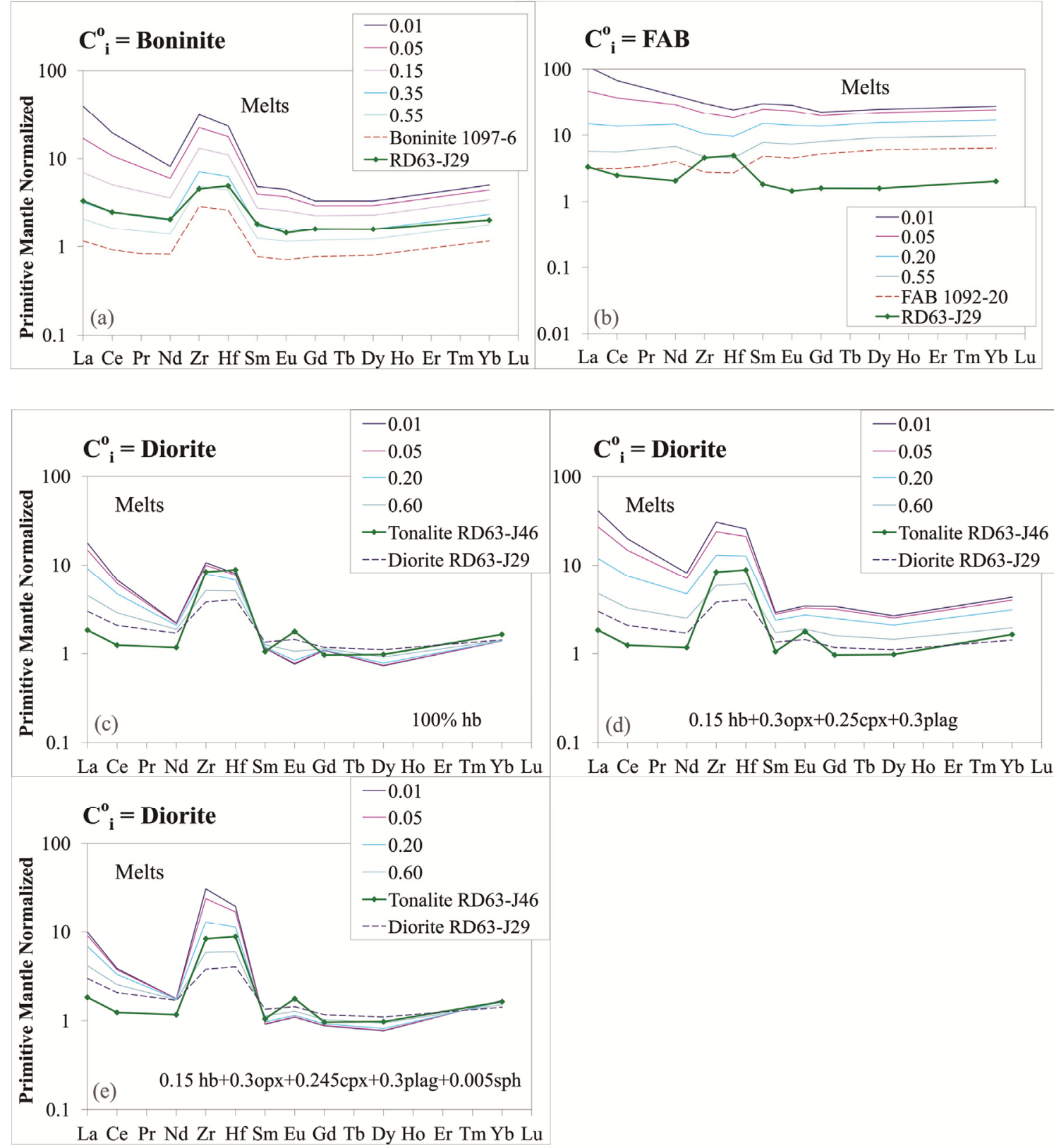

La Ce Pr Nd Zr Hf Sm Eu Gd Tb Dy Ho Er Tm Yb Lu

Figure 5.6. Quantitative trace element modeling of various sources (boninite and FAB: Reagan et al. [2010] and diorite: this study) showing the resultant REE, Zr, and Hf abundances compared with intermediate and felsic plutonic samples from RD63. The REE signature is inherited from boninite during melting and crystallization, a signature unlike FAB. The high Zr-Hf anomaly found in high silica tonalites can be achieved by either crystallization or partial melting, including amphibole and trace sphene. Partition coefficients used in the model are from the GERM website (EarthRef.org). 
5.7.4 Geologic and petrogenetic synthesis

Based on an overview of early IBM arc history, a possible origin of the RD63 and RD64 dredge samples can be described as follows. At 43-50 Ma, after subduction had recently initiated along the southern Mariana trench, boninite magmas were generated and erupted in an extensional environment [Bloomer and Hawkins, 1987; Bloomer et al., 1995; Meijer, 1980; Reagan and Meijer, 1984; Stern, 2004a; Stern and Bloomer, 1992]. Boninite magma was generated at relatively shallow levels in the lithosphere by decompression of depleted mantle and with a large flux of hydrous fluid from the downgoing Pacific plate [Ishizuka et al., 2006; Pearce et al., 1999; Pearce et al., 1992]. FABs, the earliest lavas to erupt following plate subsidence, have varying geochemical characteristics, but are unlike boninites or the RD63 or RD64 plutonic suites. Reagan et al. [2010] hypothesized two scenarios for development of the depleted mantle source responsible for early IBM magmas: 1) mantle was depleted during formation of the West Philippine Basin, which was later remelted as the Pacific plate began to subside, and 2) mantle beneath the continent of Asia became detached and through large-scale mantle convection came to rest near the infant Mariana trench. The former explanation for the depleted source is not ideal because the radiogenic $\mathrm{Nd}$ isotopic composition of FABs does not match those of West Philippine Basin basalts, nor does it explicitly account for differences in $\mathrm{Nd}$ and $\mathrm{Hf}$ isotope ratios between FABs and boninites. The latter explanation attributes the source of the Indian Ocean MORB signature in the Philippine Sea plate to mobilized sub-Asian mantle which provides the $\mathrm{Nd}, \mathrm{Hf}$ and $\mathrm{Pb}$ isotope domains observed for the entire IBM arc-backarc system, in addition to potentially providing the force to initiate convergence between the Philippine Sea and Pacific plates. 
Most boninite magma was erupted at volcanic centers whose remnants are located in the present-day forearc. Storage and differentiation of the boninite magma in at least two locations produced the plutonic suites described in this study. Crystallization of intermediate boninite magma formed gabbro cumulates, consisting primarily of plagioclase, orthopyroxene, and magnetite, whilst boninite lavas were erupted at the surface. Continued differentiation of the magma by separation of these minerals and hornblende produced progressively more felsic intrusive rocks (diorite, quartz diorite, tonalite), which may or may not have had volcanic equivalents. It is also possible that the most felsic rocks formed by partial melting of more mafic boninite rock, leaving a residue containing hornblende and a REE-rich accessory mineral. In this latter case, melting can only have occurred in the forearc during the interval when FABs or boninites were being generated (50-43Ma), since there is no subsequent source of heat to cause partial melting of the forearc crust. Therefore, even without supporting geochronological data, it is likely that the boninite-like plutonic suites in the southern Mariana forearc formed from shallowly emplaced and differentiating boninite magma bodies, with the most felsic members formed by extreme differentiation and/or by partial melting of boninite crust, around the time of subduction initiation.

Exposure of the plutonic rocks on the trench slope near Guam may have been facilitated by tectonic erosion of the overriding plate, as the Mariana forearc here is as much as $50 \mathrm{~km}$ narrower than in the Izu and Bonin forearc segments. Thus more of the arc lithospheric crust would be exposed than in other parts of the arc. Normal faults are also an effective mechanism for mid-crustal exposure. RD64 was recovered from a fault 
scarp, and the serpentine mud volcano located at RD63 may have developed over a fault acting as a conduit for fluids.

\subsection{Conclusions}

1) Plutonic and hypabyssal rocks were recovered in two deep dredges (7800$8100 \mathrm{~m}$ ) in the southern Mariana forearc (University of Hawai'i R/V Kana Keoki 81-0626, RD63 and RD64). 2) RD63 and RD64 include felsic, intermediate and mafic rocks that are boninite derivatives based on major and trace element and isotopic considerations. RD64 also includes volcanic and hypabyssal rocks that are chemically intermediate between boninite and arc tholeiite lava. 3) The RD63 suite is distinct from other highly differentiated rocks suites from the IBM system, such as tonalites dredged from the Komahashi-Daini Seamount, Kyushu-Palau Ridge, and volcanic centers producing rhyolites in the northern IBM and Saipan. The characteristic U-shaped REE patterns and elevated $\mathrm{Zr} / \mathrm{Sm}$ and $\mathrm{Hf} / \mathrm{Sm}$ of the intermediate plutonic rocks are inherited from the boninite parental magmas, but these are modified by further crystallization and/or late stage partial melting to form tonalite. 4) The association of the plutonic rock suite with boninite indicates that the formation of intermediate and felsic arc crust may begin at the earliest stages of intra-oceanic island arc development. 5) The exposure of these plutonic rocks, which may be part of a seismically-imaged low velocity mid crustal layer, was facilitated by tectonic erosion and normal faulting of the forearc lithosphere.

Acknowledgements: This research was carried out with funds granted to us by NSF grant OCE 09028144. Afi Sachi-Kocher (NHMFL) and Adriana Potra (FIU) are thanked for their help and guidance with the sample dissolution procedures and isotope separation and analysis at NHMFL. 


\subsection{SUPRA-SUBDUCTION ZONE (SSZ) OPHIOLITES AND THE MARIANA \\ FOREARC: PLUTONIC SECTIONS IN THE CONTEXT OF SUBDUCTION \\ INITIATION}

This chapter serves as an introduction to supra-subduction zone (SSZ) ophiolites and discusses their relationship to forearc crust with an emphasis on plutonics and boninites that form during subduction initiation. Locations of the ophiolites referenced in this section are primarily from the Mediterranean region associated with the initial closing of the Tethyan Sea (i.e., Tethyan ophiolites), but some major element data from other areas is included to look at the overall differentiation trends for ophiolites (Norway: Karmoy Ophiolite Complex and Papua New Guinea: Papuan ultramafic complex).

\subsection{Introduction to supra-subduction zone ophiolites}

The general definition of an ophiolite is a section of oceanic crust that has been obducted onto continental crust. In a typical ophiolite section (regardless of its origin) there are certain lithologic layers that are expected and can be generalized to fit many different locations and types of ophiolites (Figure 6.1). The lowermost crust consists of upper mantle peridotites: lherzolite and harzburgite which are often serpentinized by hydrous alteration involving seawater. Above the peridotites, are layered ultramafic cumulates which have the same general composition as the unlayered peridotites but have settled from a magma chamber. Layered gabbros consist of mafic minerals that have also settled out of a magma chamber. The next section is sometimes called high level intrusives and contains unlayered (isotropic) gabbros and usually some amount of more differentiated plutonic rocks (a group of intermediate-felsic intrusives sometimes 
generally referred to as plagiogranites: diorites, granites, granodiorites, trondhjemites, tonalites, etc.). Although any of these layers may be cut by dikes, the sheeted dike complex is a layer dominated by dikes that fed the erupted lavas above. The uppermost igneous section is the extrusive sequence of basaltic pillow lavas, which in the Izu-BoninMariana forearc consists of forearc basalts, boninites, transitional lavas, and tholeiitic basalts [Reagan et al., 2013; Reagan et al., 2010] and that sequence may likely be found in SSZ ophiolites [Stern et al., 2012]. After active volcanism ends in the area it is common for marine sediment to accumulate; these might take the form of thick carbonate formations (as shown in the figure), black shales, cherts, etc. depending on the marine environment.

Lastly, pelagic sediments and muds are the topmost layer, which form as a result of gradual settling of sediments and accumulation of biogenic material. This described sequence is highly variable and some sections may be missing entirely, but nonetheless it is highly recognizable as an "ophiolite."

Ophiolites in the Mediterranean have not always been associated with subduction zones and forearcs. Before the clear definition of supra-subduction zone (SSZ) ophiolites by Pearce, et al. [1984] that was later detailed by Pearce [2003], the volcanic and plutonic sequences of an ophiolite were believed to be the archetypical ocean crust marking the magmatic processes of mid-ocean ridge (MOR) seafloor spreading. In particular, extensive sheeted dike sequences with no exposed bounding wall rock indicative of an extensional regime was observed in the Troodos ophiolite [Gass, 1968] and soon after Moores and Vine [1971] incorporated the outcrops of depleted mantle, cumulates and 


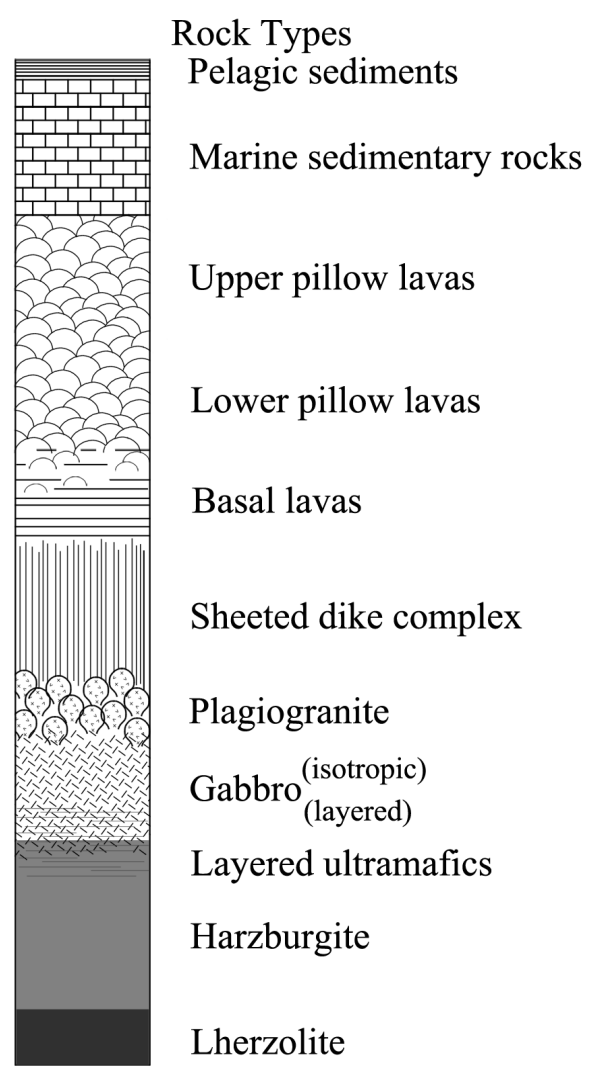

Figure 6.1. Typical oceanic seafloor ophiolite sequence. Lherzolite (fertile mantle), Harzburgite (depleted mantle). SSZ ophiolite sequences are similar to mid-ocean ridge (MOR)-type ophiolites, and all layers may not be present (or in this order) after obduction. In the case of MOR ophiolites, the gabbro and plagiogranite layers may be a result of melting and differentiation at the ridge, but in SSZ they may either be part of the subduction initiation sequence or form later after true subduction begins.

other plutonic layers as part of the sequence to confirm this suite as a coherent section of oceanic crust. In Vine and Moores [1972] and Moores and Jackson [1974], they proposed that the extensional process that magmatically fed and sustained the extensional regime had been formed by the mid-ocean ridge seafloor spreading model described by Vine and Matthews [1963]. This definition of ophiolites persisted for decades and is still the primary explanation (if only in the classroom) for ophiolite sequences, despite well established evidence for other environments forming the same sequences that are actually 
obducted more easily than MOR ocean crust. For example, discrepancies between ophiolites and present-day ocean crust, such as chemical properties, missing critical sections in ophiolites, and the relative thinness of the ophiolite mafic section were pointed out at the same time as the initial ophiolite model [Moores and Jackson, 1974]. Over time, as the geochemical signatures of the ophiolite suite were examined more closely [Pearce et al., 1984], the scientific community began discussing the link between these ophiolite sections and subduction zones [Beccaluva and Serri, 1988; Bèdard et al., 1998; Bloomer et al., 1995; Capedri et al., 1981; Dilek and Furnes, 2009; Jones and Robertson, 1991; Ogawa and Naka, 1984; Pearce et al., 1981; Robinson and Malpas, 1990; Serri, 1981; Stern et al., 1989]. At the same time, the chemical characteristics of subduction-related magmas were further refined as more detailed geochemical research was completed, which was pivotal in revealing the subduction influence in ophiolite sequences, particularly the presence of boninite lavas in both environments [Bèdard, 1999; Dilek and Thy, 2009; Dilek et al., 2007; 2008; Encarnaciòn, 2004; Ishikawa et al., 2002; Miyashiro, 1973; Pearce and Cann, 1973; Pearce et al., 1984; Pedersen and Hertogen, 1990; Robinson and Malpas, 1990; Shervais, 2001; Stern and Bloomer, 1992; Stern et al., 2012; Whattam and Stern, 2011].

The subduction zone markers that are found in supra-subduction zone (SSZ) ophiolites are similar to the signatures found in products of subduction zone, such as elevated LIL (large ion lithophile) elements, higher Th/U, possible $\mathrm{Nb}$-Ta negative anomalies, depleted rare earth elements (REEs) as well as structural evidence of an extensional environment (e.g., dike-parallel high angle normal faults, shear zones with SC fabrics, necking, boudinage, etc). As a result of their chemical, petrologic and 
structural characteristics, and the inference that forearcs are sections of crust that may be incorporated into foldbelts (e.g. Crawford et al [1981]), SSZ ophiolites are now considered analogues for ancient forearcs that are exposed aerially due to obduction. In contrast, in situ forearcs are submerged in deep ocean basins; hence ophiolites are far more accessible for study.

The SSZ ophiolites discussed in this chapter were obducted at the end stage of closing of the Tethys Sea (Figure 6.2) and are located in the Mediterranean (except for Norway included in the major element plots of Figure 6.3) as examples of possible forearc analogues. The information presented is not an exhaustive investigation of the ophiolite, but focuses on the relevant island arc (or "proto arc") processes as evidence for plutonics forming at the initiation of subduction.

\subsection{Subduction initiation and SSZ ophiolites}

The history of subduction initiation is recorded by a specific sequence of volcanics which typically are found adjacent to the trench "attached" to the overriding plate. In the Izu-Bonin-Mariana (IBM) arc, the sequence is the present-day forearc situated between the active arc and the trench (the entire sequence and details of its formation are in chapter 2 and 5). The presence of boninites in a volcanic section is usually interpreted as an indicator of subduction initiation because the archetypical boninite is from the Bonin (Ogasawara) islands in the IBM [Taylor et al., 1994]. They were erupted at the Pacific plate boundary 46-48Ma during or shortly after subduction began, creating an extensional environment in which hydrous melting of the overlying mantle was achieved by the influx of fluids from the sinking Pacific plate [Gill, 1981; 
Hickey-Vargas and Reagan, 1987; Ishizuka et al., 2006; Meijer, 1980; Pearce et al., 1992]. The exposure and composition of volcanic rocks related to subduction initiation is well recognized in the Izu-Bonin-Mariana (IBM) arc [Bloomer et al., 1995; Meijer et al., 1981; Stern and Bloomer, 1992; Stern et al., 1991]. In addition, geochemical evidence from this study (chapter 4 and 5) shows that there are boninite-like plutonics in the southern Mariana forearc that have island arc and subduction characteristics, including $\mathrm{Nb}$-Ta negative anomalies, $\mathrm{Th} / \mathrm{U}$ enrichment and REE patterns that appear to have been inherited from the boninite source magma.

It is understood that SSZ ophiolite crust (pre-obduction) is related to subduction zone processes, but the question of how this oceanic lithosphere gets obducted (or emplaced) is an important concept to understand as it may limit the types of oceanic crust found most often in ophiolite settings. Stern et al. [2012] proposed three modes for ophiolite emplacement which help identify the problems and complications associated with different lithosphere. They considered forearc, backarc basin (BAB), and MOR crust as having potential to be tectonically emplaced as ophiolites. The forearc crust is preferred because geodynamically, it poses the least difficulty to emplace. For example, when buoyant crust on the downgoing plate jams the subduction zone it creates uplift under the adjacent forearc. This scenario is shown in Figure 6.2 as the forearc crust (shaded red) is obducted onto continental crust during the last stage of the Tethys Sea closing as the African/Arabian plate moved north-northeast. Other types of oceanic crust are more difficult to obduct as they are formed at divergent zones and a shift to a convergence force plus a buoyant object collision is required to uplift the BAB or MOR crust. In contrast, the forearc crust already exists at a convergent margin. 

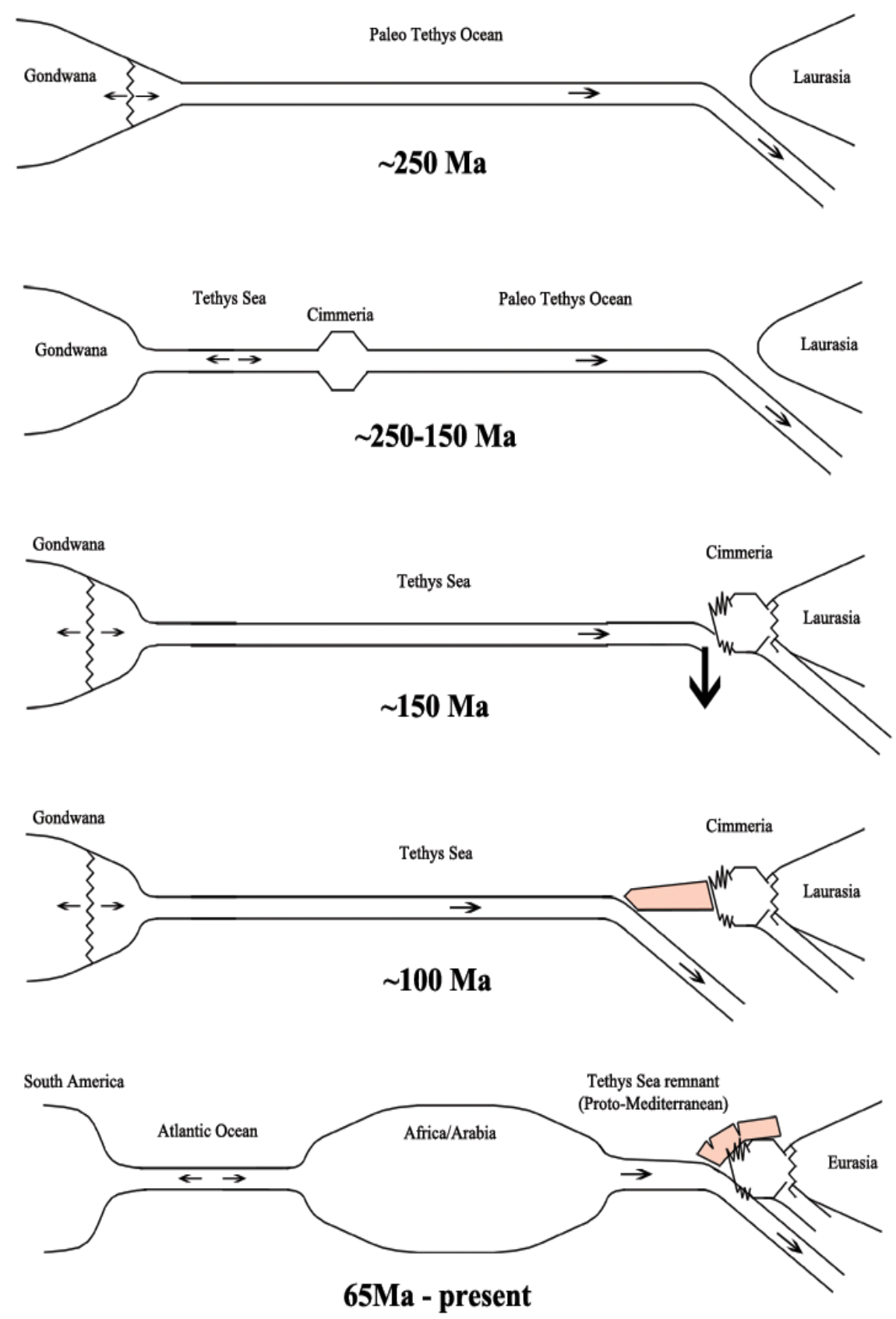

Southwest

Northeast

Figure 6.2. Generalized schematic cross section of the opening and closing of the Tethys Sea, in the context of the initiation of subduction and the formation and obduction of a non-specific forearc/boninite crust (shaded red). Drawn based on widely accepted literature regarding the timeline of the breakup of Pangaea. Note: The opening of the north Atlantic ocean in the early Cenozoic rifted Laurasia, forming Laurentia (not shown) and Eurasia (the latter is depicted the last panel). 


\subsection{Genesis of SSZ ophiolite plagiogranites}

This chapter only looks at a few ophiolites from the many different collision events throughout geologic history of the earth. A small subset was chosen because the focus of this dissertation is the southern Mariana forearc, but also because an exhaustive search for ophiolites with felsic plutonics and accompanying trace element analyses produced very limited results (included isotope analyses were even more rare); the majority of published geochemical analyses in ophiolites is for the volcanic sections (and metavolcanics).

The concept of late stage shallow differentiation of basaltic magma chambers forming 'oceanic' plagiogranites stemmed from the idea that ophiolites are fragments of MOR crust (e.g., Coleman and Donato [1979]; Lippard et al [1986]). Another hypothesis suggests plagiogranites originate by partial melting of MORB crust, and although it is difficult to achieve the temperatures required for a partial melt in a mid-ocean ridge environment, results of experiments done by Koepke et al. [2005; 2004] show that oceanic plagiogranite melts can be achieved through shallow (low pressure) melting of hydrated gabbro at temperatures $900-1000^{\circ} \mathrm{C}$. These experimental results are significant for felsic plutonics in ophiolites; in fact, partial melting studies have been done for the intrusives in northern Oman ophiolites [France et al., 2013]. Unfortunately when searching databases, much of the relevant data seem to be in abstracts presented at conferences (e.g., Ishikawa et al. [2007], Satoh and Takazawa [2008], Rollinson [2008], Yamazaki and Miyashita [2008], Berndt et al. [2009], Wolff et al. [2011], Freund et al. [2013], etc.). However, the published experimental gabbro-plagiogranite data are consistent with conclusions reached by Rollinson [2009], that the felsic plutonic rocks in 
Rajmi and J Fayyad (Oman) were formed by partial melting of local hydrated gabbros unrelated to subduction initiation.

6.4 Geochemical and petrologic comparisons of IBM forearc and ophiolites

There are usually multiple intrusive and extrusive events that can be well characterized because of their aerial exposure, such as the Tethyan ophiolites in the eastern Mediterranean. It has been documented that in many of these ophiolites the early volcanic events were produced from magmas that evolved from MORB-like to island arc tholeiite (IAT) to boninite, often with boninite dykes crosscutting large sections of the ophiolite sequences [Bortolotti et al., 1996; Dilek and Thy, 2009; Dilek and Furnes, 2009; Hoeck et al., 2002; Saccani and Photiades, 2004]. It is important to note that the REE patterns of boninites in the Tethyan ophiolites are slightly different than those identified in the IBM. In general, the Tethyan boninites are still relatively depleted in REEs compared to MORB or IAT, but they are depleted more so in LREEs than HREEs, and there is a pronounced "up-turn" of $\mathrm{La}, \mathrm{Ce}$ and Pr giving them a "spoon shape" rather than the U-shaped in the IBM (due to more relative depletion of the MREEs).

Structural and geochemical studies of the Jurassic aged Pindos and Evros (Greece) ophiolite suites show that they are composed of lavas that are compositionally MORB at lower stratigraphic levels transitioning upwards to IAT and boninite lavas. It is also inferred that the compositions become more IAT- and boninite-like trending toward the ancient trench [Bonev and Stampfli, 2009; Dilek and Furnes, 2009]. The Kizildag (Turkey), Troodos (Cyprus) and the Semail ophiolite (Oman) are slightly younger (early to late Cretaceous) but exhibit the same stratigraphic trend in lava compositions: MORB- 
IAT and boninite lavas. This stratigraphic trend is quite similar to the lava compositions found in the Izu-Bonin-Mariana forearc also and likely represents a common sequence of transitioning volcanism that occurs during the progression of subduction.

The Kizildag ophiolite in Turkey is one of the SSZ ophiolites that were formed during the initial stages of subduction that occurred at the closing of the Tethys Sea in the late Cretaceous [Dilek and Thy, 2009]. The early lavas and sheeted dikes belong to the IAT series and consist of basalts, basaltic andesites, and andesites with low $\mathrm{La} / \mathrm{Sm}_{\mathrm{N}}(0.5$ 0.7), high $\mathrm{Dy} / \mathrm{Yb}_{\mathrm{N}}$, low $\mathrm{MgO}(7-9 \mathrm{wt} \%)$ and high $\mathrm{TiO}_{2}(0.7-1.0 \mathrm{wt} \%)$ [Dilek and Thy, 2009]. Slightly younger dacite dikes are more enriched in LREEs. After prolonged depletion of the source, late-stage lavas were erupted as boninites and cross cutting basaltic dikes of boninite affinity (also referred to as "sakalavites" in Dilek and Thy [2009]) with high $\mathrm{La} / \mathrm{Sm}_{\mathrm{N}}(0.8-1.0)$, higher $\mathrm{MgO}$ (9-11 wt\%), lower $\mathrm{TiO}_{2}(0.3-0.4 \mathrm{wt} \%)$ (Figure 6.3) and strong depletions in LREEs and HREEs (Figure 6.4).

Lavas of the Semail (Oman) ophiolite are a product of multi event volcanism. Plagiogranites from three different locations were analyzed by Rollinson [2009] and deemed to have different petrogenesis from one another. The Wadi Rajmi region has the oldest intrusives that are associated with partial melting of hornblende-gabbros due to an influx of seawater. Many of these samples have elevated $\mathrm{TiO}_{2}$ and represent the “outlying" data points in Figure 6.3. Younger plagiogranites (95.5 Ma +/- 0.24Ma [Warren et al., 2005]) from the Jebel Fayyad area are a result of fractional crystallization of magma derived from a previously depleted harzburgite mantle [Rollinson, 2009] and are emplaced in a sheeted dike unit and upper pillow lavas. Wadi Hamaliya is chemically different than the previous two and consists of plagiogranite dikes and sills which are 
very LREE enriched and enriched in fluid mobile elements shown in Figure 6.5 and intrude mantle harzburgites [Rollinson, 2009]. This plagiogranite is interpreted to have both crustal and mantle sources. Boninites in a fourth location, called the "Alley," have been compared to Chichijima boninites [Ishikawa et al., 2002] and it is in this location that a trondhjemite (a tonalite with oligoclase feldspar) sample was recovered with high $\mathrm{Zr} / \mathrm{Sm}$ and $\mathrm{La} / \mathrm{Sm}$ [Alabaster et al., 1982] similar to RD63 tonalites. This is likely an effect of melting/crystallization from a boninite source. Other plutonics in the Alley (not plotted) are equivalents of more evolved volcanics (calc-alkaline-like rhyolites, dacites, andesite). The Wadi Salahi location has evidence of MOR-type lavas transitioning to low-Ti tholeiitic magmatism [Godard et al., 2006] that corresponds to the timing of boninite dikes and lavas in the nearby Alley and J Fayyad areas, but one study postulates that the isotopic analyses do not show evidence of a SSZ setting [Godard et al., 2006]. However, isotope data are sparse for boninites from the Alley and the comparison may have been premature. In addition, there are few chemical or isotopic data available about the felsic intrusives from W Salahi and in turn, little speculation about their origin. The Mahab Complex has a suite of differentiated plutonic rocks (trondhjemite, diorite and gabbro) that have trace element signatures like W Rajmi and J Fayyad but the complex also has lavas like the Alley and W Salahi [Alabaster et al., 1982]. The origin of the plutonic rocks is not elaborated, but the REEs seem to resemble trace element abundances of the boninite (Figure 6.5).

The Evros ophiolites in NE Greece have tholeiitic to transitional boninite-like volcanic and plutonic rock outcrops. Volcanic rocks have $\mathrm{SiO}_{2}$ of $41-65 \mathrm{wt} \%, \mathrm{TiO}_{2}$ of $0.5-1.0 \mathrm{wt} \%$ and the plutonics have $\mathrm{TiO}_{2}<0.25 \mathrm{wt} \%$ (Figure 6.3). The consensus is that 
these ophiolites formed in the Jurassic to Late Cretaceous and were later obducted and underwent various degrees of metamorphism. Gabbros show boninite affinity, such as REE and HFSE depletions relative to N-MORB suggesting their parental magma formed by melting of a refractory peridotite mantle source overlying the sinking slab [Bonev and Stampfli, 2009]. The plagiogranites are more REE enriched (Figure 6.6), and REE modeling done by Bonev and Stampfli [2009], using Rayleigh fractional crystallization and batch melting, suggested these high-silica rocks formed by at least $75 \%$ fractional crystallization of a basaltic source that is similar to tholeiitic dikes. The isotropic gabbros are older than the tholeiitic and boninite dikes, which appear to have formed in faults and fractures, suggesting the dikes formed in an extensional environment. Interestingly, the micrographs of the plagiogranites published by Bonev and Stampfli [2009] are remarkably similar to the tonalites of RD63 in the southern Mariana forearc, in particular the quartz-feldspar ratio and the granophyric texture. This similarity indicates that the plutonic rocks possibly underwent similar processes of differentiation at some point during their formation, regardless of their source and parental magma composition.

The importance of the source composition that melts/crystallizes is tested in Chapter 4 and highlights specific minerals with partition coefficients that can create trace element ratios and patterns in boninite differentiates. Even though there are petrologic similarities between Evros felsic intrusives and the tonalites from RD63, they have very different trace element abundances (and, a similar observation was made between RD63 and plutonic rocks from the Komahashi-Daini seamount in the northern IBM). This is a significant point because it provides further evidence that differentiation processes alone do not necessarily produce the trace element signatures that are observed in boninites and 
boninite differentiates, and that a particular source composition and mineral assemblage is required to create these patterns. Similarly, the origin and parental magma lineage of extremely felsic rocks cannot be inferred without trace element and isotopic data.

Several sources report the existence of intrusive sequences for Pindos and Troodos ophiolites such as gabbros, dioritic dikes, or hypabyssal intrusives. Major element trends (Figure 6.3) are consistent with those for other ophiolites, though the range of $\mathrm{SiO}_{2}$ is limited (55-60 wt \%). At this time, rare earth element data has not been found for the intrusives described in the literature.

6.5 Analogies between plutonic rocks in SSZ ophiolites and the RD63 Mariana forearc suite

Examining the evidence found in ophiolites is one of the best ways to expand our understanding of their pre-obduction equivalents, and vice versa. We cannot see forearc outcrops under $7 \mathrm{~km}$ of water in the same way we can see ophiolites on land, nor can we see the original organization of the layers of an ophiolite in the same way as through drilling or diving in the forearc. For example, the outcropping of plutonic sections in the ophiolites could be analogous to the plutonic section in RD63 of the southern Mariana forearc. A mix of felsic, intermediate and mafic plutonic pods and/or dikes is a likely scenario for the structure of the forearc mid-crust, and it is indeed observed in outcrops of ophiolites (e.g. shown in figure 3 in Bonev and Stampfli [2009] and in figure 4 in Dilek and Thy [2009]). 

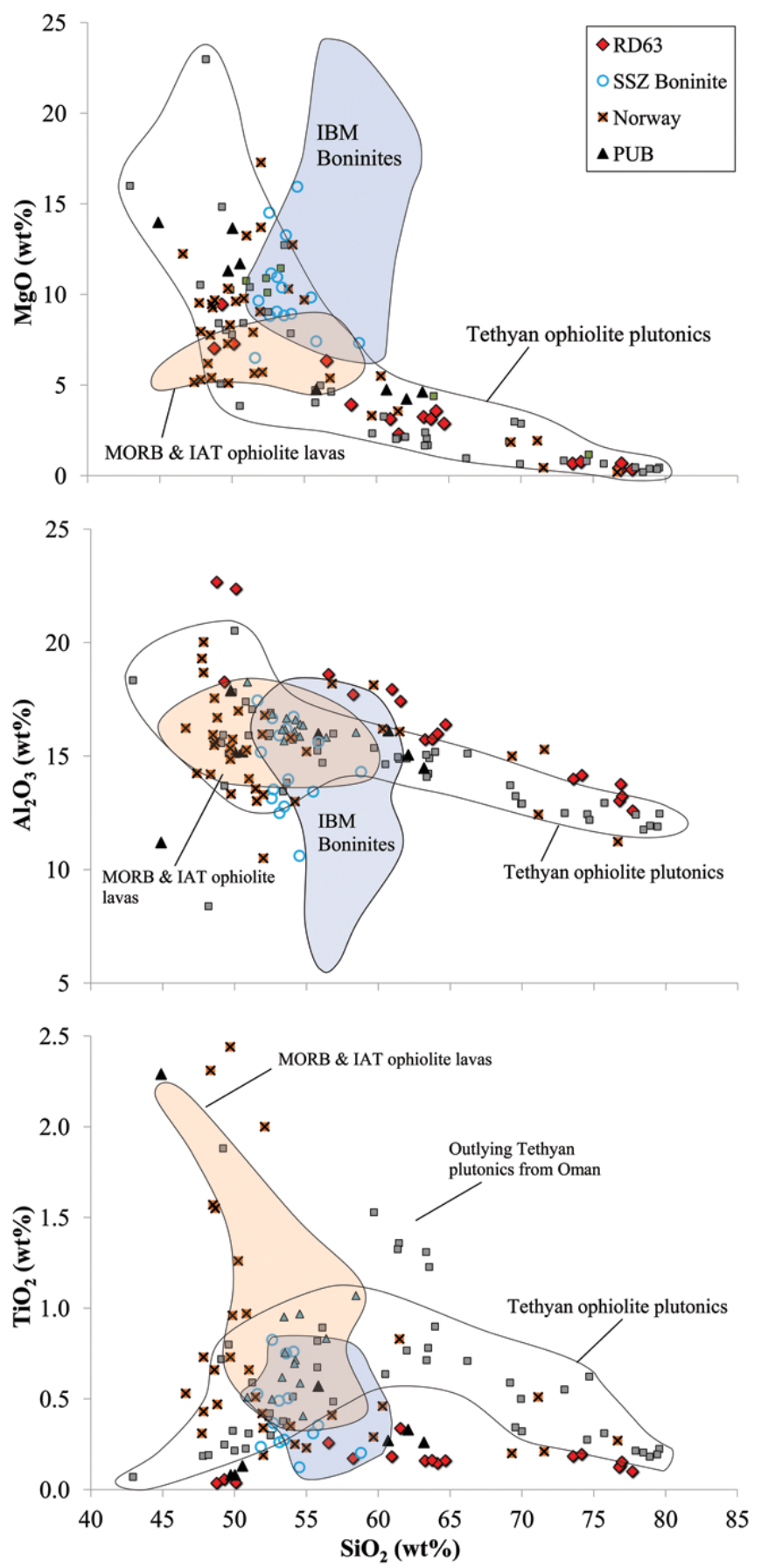

Figure 6.3. Major element diagrams showing trends of SSZ ophiolite plutonics with fields of Tethyan ophiolite lavas (Evros [Bonev and Stampfli, 2009], Troodos [Dilek and Furnes, 2009; Flower and Levine, 1987], Pindos [Saccani and Photiades, 2004], Semail (Oman) [Alabaster et al., 1982; Ishikawa et al., 2002; Rollinson, 2009], Kizildag [Dilek and Thy, 2009]), Karmoy ophiolite (Norway) [Pedersen and Hertogen, 1990] and the Papuan ultramafic belt (PUB) [Jaques and Chappell, 1980]. RD63 plutonics are from southern Mariana forearc (this study). 


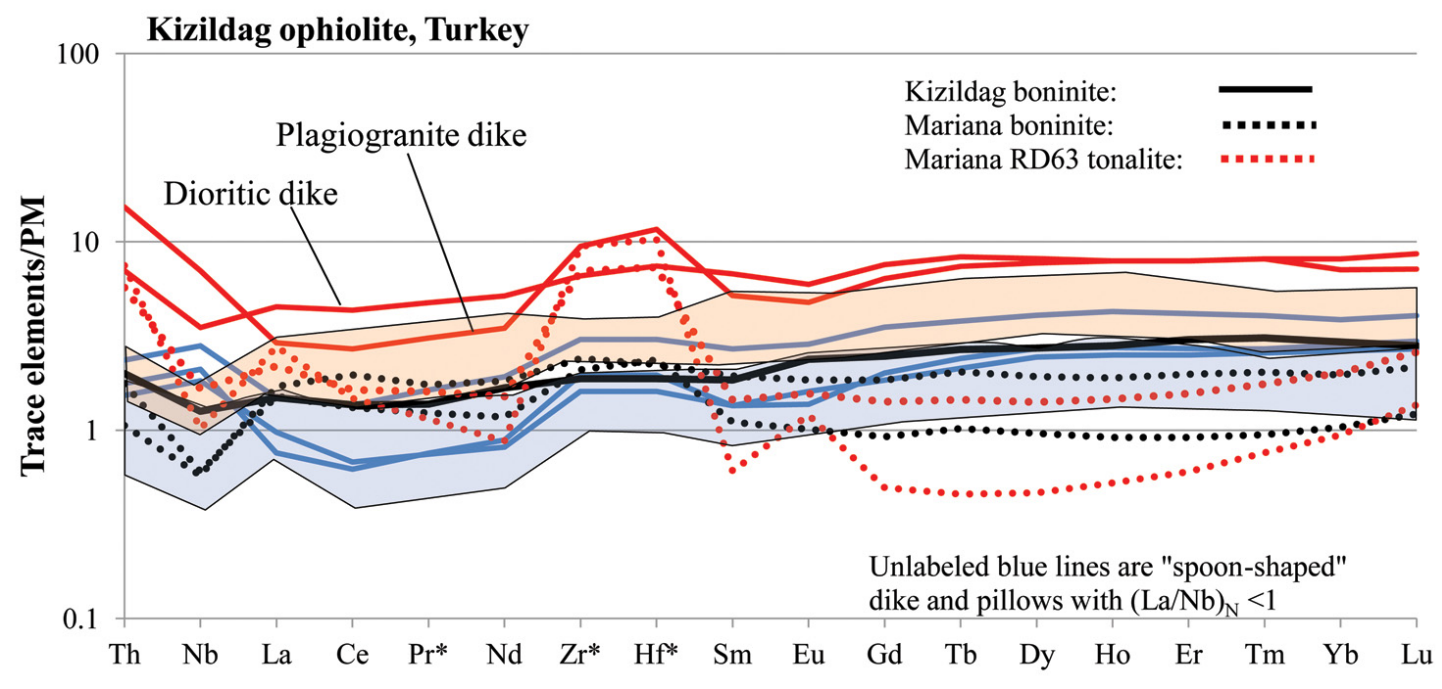

Figure 6.4. Multielement plot of data from Kizildag ophiolite [Dilek and Thy, 2009; Dilek and Furnes, 2009]. Values for $\mathrm{Pr}$ are an average of $\mathrm{Ce}$ and $\mathrm{Nd}$. $\mathrm{Zr}$ was measured by $\mathrm{XRF}$ and in some cases, Hf was not provided so it was estimated from $\mathrm{Zr}$ concentrations. The blue field is gabbroic samples, both isotropic and dikes. The light red field is basaltic pillows and dikes.

Major and trace element data for plutonic rocks in boninite-bearing ophiolites are not easily found, and where published, the compositions vary widely. However, as presented in this chapter, there is some evidence that there are intrusive rocks in some ophiolites with characteristics similar to RD63 in the southern Mariana forearc, in particular trondhjemites from the Alley and Wadi Salahi. Since the RD63 suite has a clear relationship to boninite in an in-situ forearc setting, this observation strengthens the interpretation that some ophiolites may be, or at least include, sections of forearc crust. Further investigation of the geochemical character, proportions and relative ages of plutonic rocks in ophiolites and in-situ forearcs is needed. 


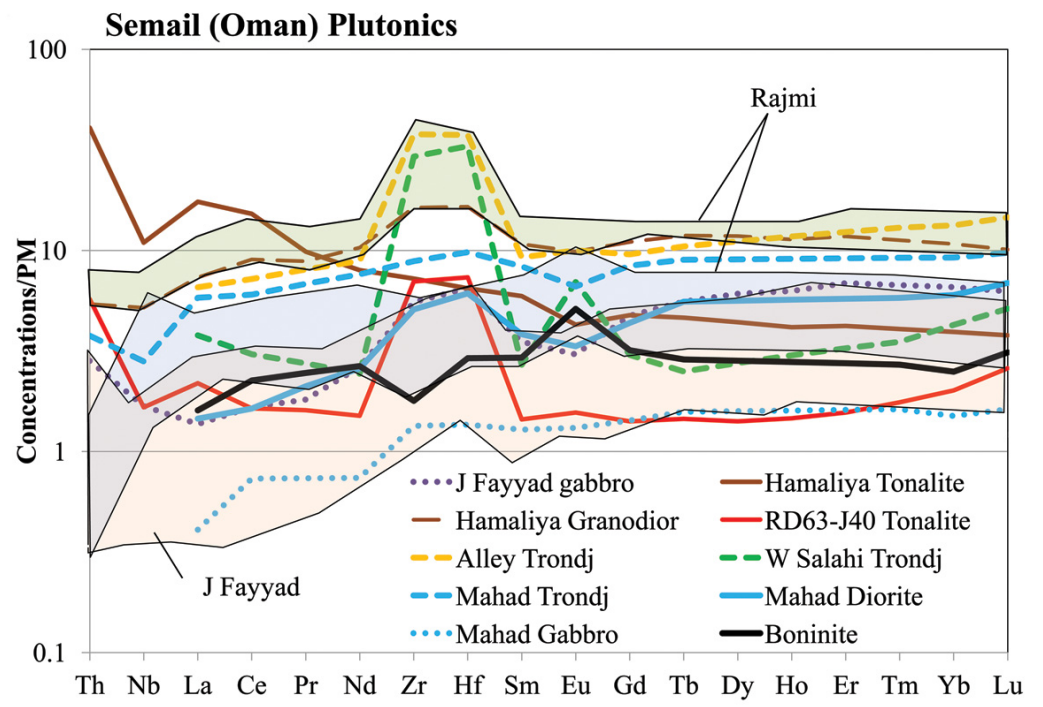

Figure 6.5. Multielement plot of Semail (Oman) ophiolite plutonic rocks [Alabaster et al., 1982; Rollinson, 2009]. Green and blue fields are from Rajmi, red field represents rocks from J Fayyad (fields include tonalite, trondhjemites, diorites and gabbros). The remaining samples plotted are from Hamaliya, Wadi Salahai, the Mahad complex and a locality referred to as the "Alley." The boninite data is from Lippard et al [1986] and was interpreted by Dilek and Furnes [2009] (trace elements measured by ICP-MS, except Zr which was measured by XRF).

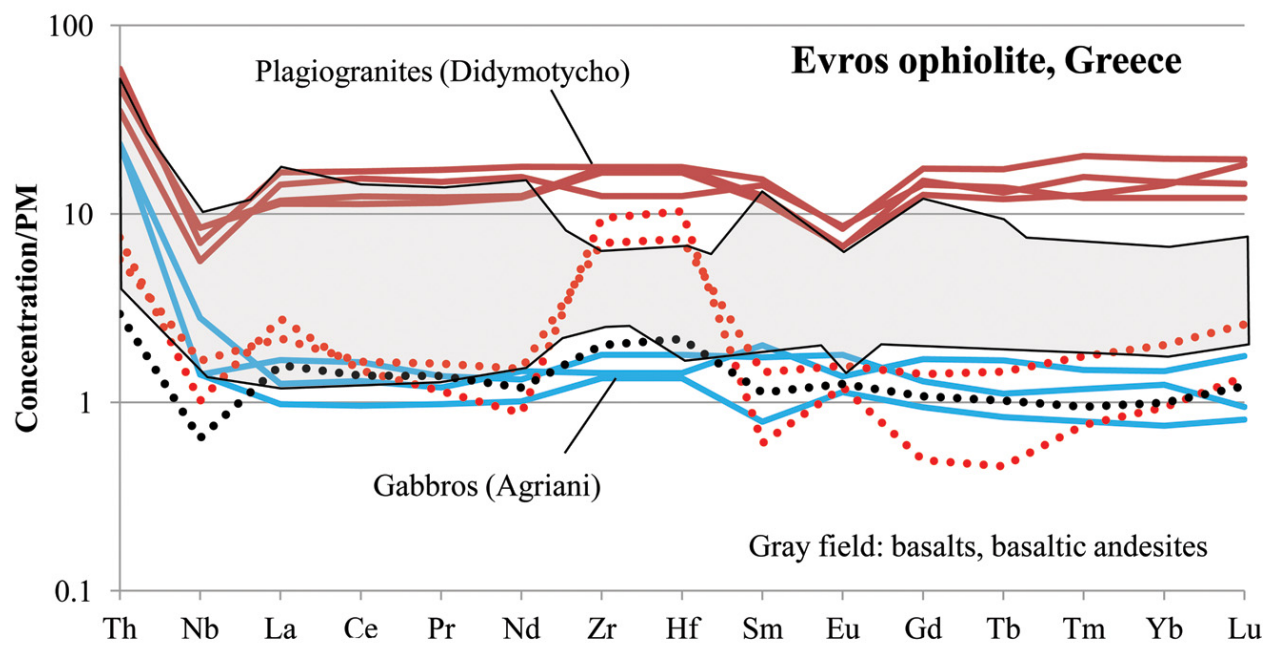

Figure 6.6. Evros ophiolite, Greece. Bonev and Stampfli [2008; 2009] concluded the plagiogranites have tholeiite affinities and the gabbros have some boninite affinity. Red dotted lines are tonalites from the Mariana forearc RD63 (J40 and J45), and the dotted black line is a boninite from the Mariana forearc (974-R6; Reagan et al [2010]). 
6.6 Relationship between SSZ ophiolites, the RD63 suite and felsic to intermediate composition of continental crust

It has been suggested that a significant portion of the "intermediate" average composition of the continental crust can be attributed to the accretion of felsic and intermediate plutonics formed in intra-oceanic island arcs [Rudnick and Fountain, 1995]. However, this study has linked felsic and intermediate plutonic rocks (RD63) to processes that occur prior to the "true subduction" that forms island arc crust, thus it can be hypothesized that part of the contribution to continental crust is due to the accretion (or obduction) of the forearc mid-crust. Because obducted SSZ ophiolites are likely to be sections of forearc crust, and may have intermediate-felsic plutonics related to forearc volcanism, they may provide further evidence that subduction initiation plutonic rocks contribute to the overall intermediate composition of continental crust (e.g., Tethyan ophiolites (references herein), Norway ophiolite [Pedersen and Hertogen, 1990], Papuan New Guinea ophiolites [Jaques and Chappell, 1980], the Tlikakila complex in southern Alaska [Amato et al., 2007; Bogar and Amato, 2004], Betts Cove in Newfoundland [Bèdard et al., 1998], and other ophiolites.

It is not known if the formation of differentiated plutonic rocks like the RD63 suite is a common occurrence before typical island arc volcanism or a rare exception, and whether boninite derivatives form a large or small contribution to this forearc crustal layer, and ultimately the continental crust. Further collection and analyses of the plutonic rocks from forearcs and SSZ ophiolites exposed in continental settings are necessary to form such a conclusion. 


\subsection{SUMMARY AND CONCLUSIONS}

The Izu-Bonin-Mariana intra-oceanic island arc is a well-studied area that is known for its subduction dynamics, the thorough account of its history, and the in-situ, exposed forearc. Research has focused on quantifying the input and output materials in order to understand the "subduction factory" processes, such as fluxing aqueous fluids and gases, recycling crust and sediment, volcanism, seismic activity, and slab and mantle melting. The following sections discuss the conclusions drawn in this dissertation regarding the recovered intrusives and their relationship to subduction.

\subsection{Classification of RD63 and RD64}

Plutonic and hypabyssal rocks recovered from the Izu-Bonin-Mariana forearc by dredging in 1981 have geochemical and isotopic characteristics most similar to nearby boninites. The two dredges (RD63 and RD64) are geographically $74 \mathrm{~km}$ apart and from depths between 8200 and 7200 meters below sea level. It is the first time felsic, intermediate and mafic boninite derivates have been recovered from the inner slope of the Mariana trench. These rocks are compositionally and chemically similar to the boninite differentiates (andesites, dacites, rhyolites) from Chichijima and were classified as gabbro, diorite, quartz diorite and tonalite using normative mineralogy and the QAP diagram. RD64 has a few medium to fine grained samples that are classified as basaltic andesites, andesites and one slightly coarser grained bronzite andesite based on TAS, petrographic analyses and, in the case of the "bronzite andesite," EPMA data.

Boninite liquids evolve by crystallization of orthopyroxene and minor clinopyroxene until plagioclase saturation is reached at a composition of approximately 
$58 \% \mathrm{SiO}_{2}, 5 \% \mathrm{MgO}, 8 \% \mathrm{FeO}_{\mathrm{T}}, 16 \% \mathrm{Al}_{2} \mathrm{O}_{3}$, and $8 \% \mathrm{CaO}$, which is similar to the composition of boninite-derived bronzite andesites found at DSDP Site 458 and Chichijima as demonstrated in major element plots in Chapter 5. Plagioclase and pyroxene accumulated from this melt composition to form rocks $<58 \mathrm{wt} \% \mathrm{SiO}_{2}$ (gabbros) and differentiation forms the other plutonic rocks $>58 \mathrm{wt} \% \mathrm{SiO}_{2}$ (diorites, quartz diorites, tonalites). Chlorite, clays in veins and fractures, sericitization of plagioclase, remineralized pyroxenes, amphiboles and micas, are present in varying degrees and proportions and are evidence of secondary mineralogy typical in seawater alteration.

\subsection{Origin and evolution of dredge suites RD63 and RD64}

The geochemical data indicate that the plutonic rocks from dredges RD63 and RD64 are related to the infant arc volcanic sequence. Based on the petrographic and major element conclusions described above, it is likely that a precursor to the plutonics with a composition like bronzite andesites separated from the boninite magmas. While boninites follow an orthopyroxene crystallization trajectory, they do not crystallize feldspar. However at a certain point of pyroxene and olivine crystallization, the bronzite andesite precursor separated and began to saturate with plagioclase. The separated liquid then accumulated crystals, forming gabbros (with positive Eu anomalies), and differentiated to the intermediate and extreme compositions represented by the tonalites. This conclusion is strengthened by trace element data that show subduction signatures and boninite indicators in both dredges. However, the genesis of RD63 and RD64 are distinct as evidenced primarily by the isotope data ( $\mathrm{Sr}$ and $\mathrm{Nd}$ isotopes are slightly lower, and ${ }^{207} \mathrm{~Pb} /{ }^{204} \mathrm{~Pb}$ is systematically higher in RD63). It is probable that RD64 hypabyssal 
and plutonic rocks are chemically intermediate between boninite and arc tholeiite lavas (transitional boninite) on the basis of their trace element signatures.

A more in-depth examination of the southern Mariana forearc (in particularly RD63) focused on how these plutonic samples are distinct from other highly differentiated rocks suites from the IBM system, such as tonalites dredged from the Komahashi-Daini Seamount, Kyushu-Palau Ridge, and volcanic centers producing rhyolites in the northern IBM and Saipan. Most major elements of plutonic samples behave in a similar way (e.g. $\mathrm{MgO}, \mathrm{CaO}, \mathrm{FeO}_{\mathrm{T}}$ decrease with $\mathrm{SiO}_{2}$ ), even for gabbros and plagiogranites from the Tanzawa Plutonic Complex, which are not related to the IBM arc. However, the important differences in the southern Mariana forearc are in $\mathrm{P}_{2} \mathrm{O}_{5}, \mathrm{TiO}_{2}$ and $\mathrm{K}_{2} \mathrm{O}$ which are uncharacteristically low in RD64 and especially low in RD63 when compared to the other plutonics. These trends, when combined with the characteristic Ushaped REE patterns and elevated $\mathrm{Zr} / \mathrm{Sm}$ and $\mathrm{Hf} / \mathrm{Sm}$ of the RD63, indicate a boninite magma source for RD63 and perhaps a transitioning boninite source for RD64.

Isotopic ratios for RD63 and RD64 are distinct but both are within the $\mathrm{Sr}, \mathrm{Nd}, \mathrm{Hf}$, $\mathrm{Pb}$ isotope ranges for the IBM early arc volcanics. RD64 rocks have systematically higher $\varepsilon_{\mathrm{Nd}}$ and lower ${ }^{207} \mathrm{~Pb} /{ }^{204} \mathrm{~Pb}$ compared with $\mathrm{RD} 63$, but within each suite, there is no systematic change in any isotope ratio with bulk composition or normative lithology. It should be noted that some isotopic data is missing from many sources referenced in this study, e.g., many studies have no Hf isotope data because the study was conducted before Lu-Hf could be reliably measured on common instrumentation. Analyzing and publishing the Hf ratios now (in conjunction with published ${ }^{143} \mathrm{Nd} /{ }^{144} \mathrm{Nd}$ ) could certainly 
help establish a better defined field for products of early subduction processes in the southern Mariana forearc.

The mafic and intermediate plutonic rock trace element signatures in this study were inherited from the boninite parental magmas, but continued fractional crystallization and/or late stage partial melting forms tonalite with the unique trace element compositions. Rare earth element (REE) modeling has shown that the REE patterns cannot be produced by any other source, assuming that source has a typical mineral assemblage. Even melting or crystallization of an "intermediate FAB" for example, can only produce a MREE depleted pattern with $\mathrm{Zr}-\mathrm{Hf}$ anomalies by incorporating a high percentage of unlikely minerals and even then the results are more enriched than the plutonic samples from either dredge. In contrast, an intermediate composition that crystallized from the boninite melt can produce high $\mathrm{Zr} / \mathrm{Sm}$ with only trace amounts of certain accessory minerals in the system, such as apatite, monazite or perhaps another rare-earth bearing accessory.

\subsubsection{Summary of plutonic origin and evolution conclusions}

The association of the plutonic rock suite with boninite indicates that the formation of intermediate and felsic arc crust may begin at the earliest stages of intraoceanic island arc development (Figure 7.1). Boninite magma was being produced at shallow levels for millions of years in what is now the southern Mariana forearc. As the magma rose through the relatively thin and warm crust, a part of the liquid stalled while the some may have been extracted and erupted as boninite lavas. The stalled magma in mid- to upper crust was able to degas and crystallize at low pressure, eventually 


\section{$\sim 52$ - $48 \mathrm{Ma}$}
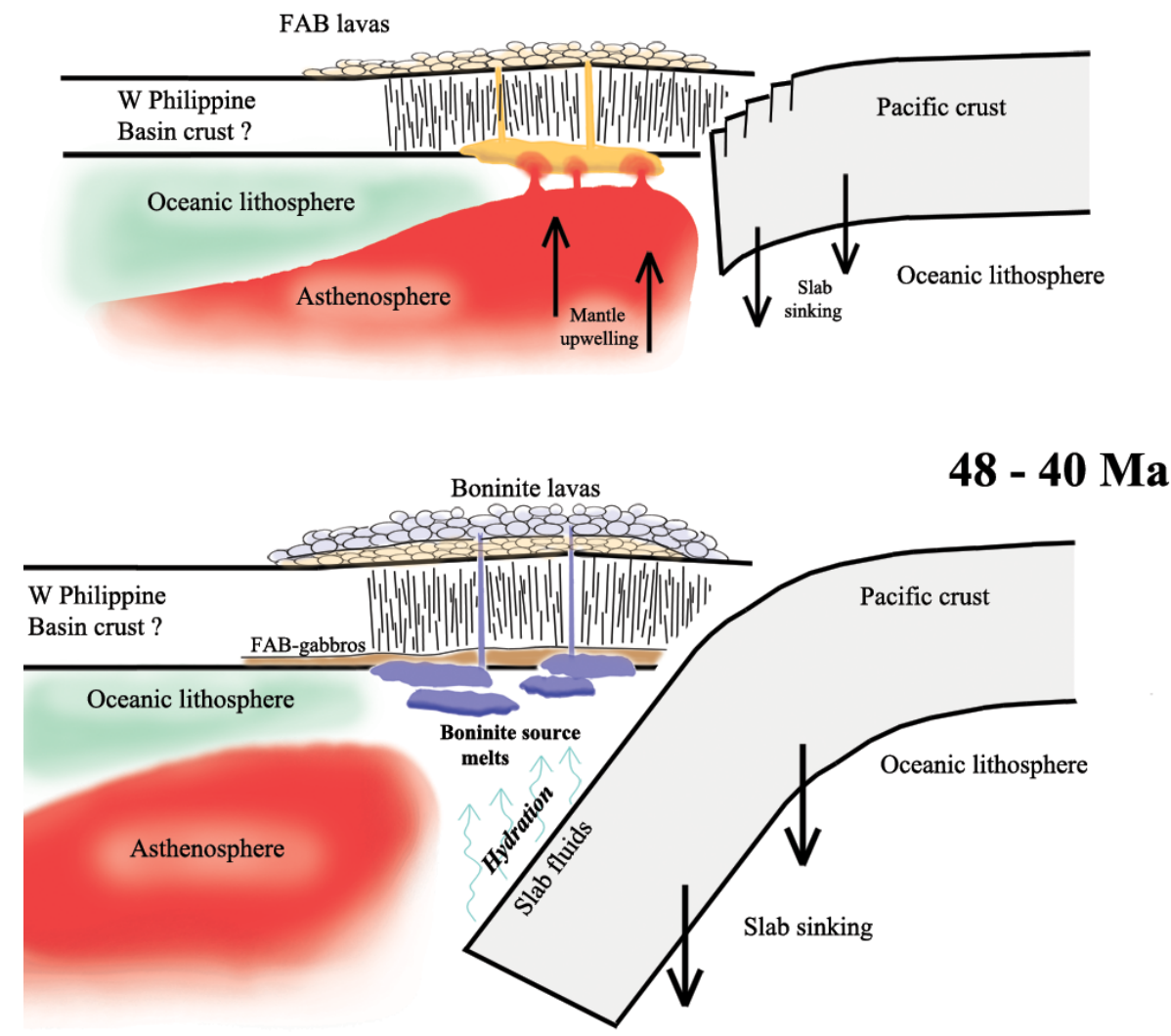

Figure 7.1. Volcanism at subduction initiation leading to FABs, boninites and boninitelike plutonic rocks. The melts formed during 48-40Ma, eventually cooled and solidified forming gabbro cumulates, diorites, quartz diorites and tonalites. Some areas of these melts maintain enough heat to remelt or differentiate further and produce tonalites with granophyric textures and $\mathrm{SiO}_{2}>78 \mathrm{wt} \%$.

becoming saturated in plagioclase. Through accumulation and extensive differentiation, most of the plutonic rocks of RD63 were formed. The high heat flux of the environment during subduction initiation would allow small areas of intermediate composition to partially remelt and differentiate even further, producing the high silica tonalites. A similar process likely produced RD64 plutonics as well, but from a transitional boninite source, possibly a few million years later. 
Once normal subduction began, the heat transferred to the forearc dissipated as melting in the mantle wedge developed at greater depths and produced typical island arc volcanism at a greater distance from the trench. The forearc then remained volcanically inactive, exposed only to the surrounding seawater and some fluids rising up from the sediment and lithospheric crust of the downgoing plate. Normal faulting in the forearc caused by extension in a rapid rollback environment [Fryer et al., 2003; Gvirtzman and Stern, 2004] exposed more of the forearc crust (RD64) and some of these faults acted as conduits for fluids. A serpentine mudvolcano formed over one of these faults and the fluids brought up pieces of the midcrust (and other material) which settle on the flanks of the mudvolcano (RD63).

\subsection{Supra-subduction zone ophiolites}

Ophiolites are found on every continent and represent pieces of ocean lithosphere that were obducted onto continental lithosphere. The origin of that oceanic lithosphere has been under debate since the 1970s. However, it is now fairly well established that many, if not most, ophiolites were formed in the context of a subduction environment, not mid-ocean ridges as previously believed. Thereafter, these types of ophiolites are called suprasubduction zone (SSZ) ophiolites.

Boninites have been commonly identified in SSZ ophiolites and are part of the evidence used to classify ophiolites as SSZ, which led to the comparison of ophiolite sequences to the forearc section of the Izu-Bonin-Mariana (IBM) system. There is reasonable evidence that some SSZ ophiolite crust forms in a similar way as the IBM forearc. This study identified plutonic rocks from the southern Mariana forearc (RD63) 
that appear to be genetically related to the source that produced boninites, placing them in the context of subduction initiation between the Pacific plate and the Philippine Sea Plate.

Volcanic rocks that erupted during the initiation of subduction have been extensively studied both in the IBM and in SSZ ophiolites, but little work has been done (or reported) on plutonic sections. It was an objective of this study to perform a literature search for plutonic rocks (ideally with $\mathrm{SiO}_{2}>62 \mathrm{wt} \%$, i.e. quartz diorites, tonalites or equivalents) in ophiolites in order to compare them with the boninite sections and determine the similarities or differences between them and the southern Mariana forearc section. The SSZ ophiolites discussed in Chapter 6 were primarily examples from the Mediterranean area associated with the closing of the Tethys Sea. Geochemical data for felsic plutonics in the SSZ ophiolites (e.g., plagiogranites, trondhjemites) are not commonly reported but those that are have been described as forming during early melting of MORB sea floor or later stage partial melting of tholeiite. In the latter case, the volcanic and plutonic rocks show signs of forming within a subduction zone and most sections include boninites and/or transitional boninites as pillows or as cross-cutting dikes.

\subsubsection{SSZ ophiolite plutonic rocks}

Areas of Kizildag and Oman ophiolites have plutonic rocks with chemical characteristics like their local Mediterranean boninites (similar REE patterns, La/Nb, $(\mathrm{La} / \mathrm{Sm})_{\mathrm{N}}, \mathrm{LILE}$ abundance in $\left.\mathrm{Ba}, \mathrm{Sr}, \mathrm{Rb}\right)$ and have less in common with southern Mariana boninites and derivatives. However, there are some striking similarities, including some SSZ ophiolite plagiogranites or trondhjemites with U-shaped REEs, extremely low $\mathrm{TiO}_{2}$, and moderate and extreme $\mathrm{Zr} / \mathrm{Sm}$ (20-46 and 80-240, respectively). 
Petrographic textures observed in thin section (granophyric texture as seen in high silica tonalites in RD63) are an important similarity also, but the texture is not indicative of the melt/crystallization source and suggests only that the plutonic samples underwent similar differentiation processes regardless of source composition.

Aside from the few instances of boninite-like plutonic rocks in ophiolites reviewed in this study (the Alley and Salahi in Oman or Kizildag in Turkey) most plutonic rocks from SSZ ophiolites are identified as related to MORB or later tholeiitic lava production, not to boninites. However, there have been reports of plutonic rocks in ophiolite sections which have not yet been studied for their trace element or isotopic composition. In addition, due to the focus on characterizing volcanic sequences, SSZ ophiolite intrusives may have been passed over as less significant in the story of how ophiolites are formed. It would be beneficial to collect more geochemical data for the ophiolite plutonic rocks because they may be as important as the lavas in understanding the magmatic evolution of the ophiolite.

The ophiolite is important as an accessible analog for a subduction zone forearc representing the initial stages of subduction. We cannot see an in situ forearc in the same way we can see ophiolites on land, and it can be far easier to organize and trace the sequence of the SSZ ophiolite on a map than using drilling or diving in the forearc. There are many ophiolites to study and it would be interesting to further investigate the abundance of boninite-like plutonics in subduction initiation settings. 


\subsection{Future directions for RD63 and RD64}

There is still work that can be done on the plutonic suites recovered from RD63 and RD64. Not every sample that was brought back from the repository in Hawai'i was made into a thin section or chemically analyzed. Samples from RD64 are fairly texturally homogenous, but there are some interesting heterogeneous textures in many of the unanalyzed samples in RD63 (which were excluded in this study for the sake of chemical homogeneity). For example, there were observations of finer-grained, mafic pods within a coarser, felsic rock. Also, significant grain size changes occurred in several samples (across a $3 \mathrm{~cm}$ distance the grain sizes change from $\sim 1 \mathrm{~mm}$ to much larger $1-2 \mathrm{~cm}$ grains). And in a few samples, alteration features (large infilled veins with different minerals, fractures with visible large alteration field) were predominant.

Obtaining radiometric dates for the plutonic rocks would be beneficial for constraining their formation in context of the history of the forearc and subsequent arc. Only a few samples have been searched for zircon grains that would be suitable for U-Pb chronology methods (using LA-ICMPS or SHRIMP instruments). Ideally, a thorough search for zircon should be done in all the samples and thin sections (approximately 60).

Although not directly related to the analyses of the plutonic suites in this study, further study on plutonic rocks in SSZ ophiolites can be done, especially in systems that have extensive work done already on the volcanics. It is important to expand the conclusions reached in this study to other areas with possibly similar magmatic histories, such as ophiolites, so that we can better understand the differentiation of magma that leads to intermediate-felsic plutonic sections in the lithospheric crust. The upcoming IODP JOIDES Resolution expedition 352 (July-September 2014) will drill $\sim 1 \mathrm{~km}$ of 
oceanic crust in the Bonin forearc through the volcanic section and perhaps into the underlying intrusive crust. One of the hypotheses to be tested is that forearc lithosphere is indeed the birthplace of SSZ ophiolites. 


\section{LIST OF REFERENCES}

Alabaster, T., J. A. Pearce, and J. Malpas (1982), The volcanic stratigraphy and petrogenesis of the Oman Ophiolite Complex, Contributions to Mineralogy and Petrology, 81, 168-183.

Amato, J., M. Bogar, G. Gehrels, G. Farmer, and W. McIntosh (2007), The Tlikakila complex in southern Alaska: A suprasubduction-zone ophiolite between the Wrangellia Composite terrane and North America, Geological Society of America Special Papers, $431,227-252$.

Annen, C., J. D. Blundy, and R. S. J. Sparks (2006), The genesis of intermediate and silicic magmas in deep crustal hot zones, Journal of Petrology, 47(3), 505-539.

Bacon, C. R., and T. H. Druitt (1988), Compositional Evolution of the Zoned Calcalkaline Magma Chamber of Mount-Mazama, Crater Lake, Oregon, Contributions to Mineralogy and Petrology, 98(2), 224-256.

Bas, M. J. L., and A. L. Streckeisen (1991), The IUGS systematics of igneous rocks, Journal of Geological Society of London, 148, 825-833.

Beccaluva, L., and G. Serri (1988), Boninitic and low-Ti subduction-related lavas from intraoceanic arc-backarc systems and low-Ti ophiolites: a reappraisal of their petrogenesis and original tectonic setting, Tectonophysics, 146, 291-315.

Bèdard, J. H. (1999), Petrogenesis of boninites from the betts cove ophiolite, Newfoundland, Canada: identification of subducted source components, Journal of Petrology, 40, 1853-1889.

Bèdard, J. H., K. Lauziere, A. Tremblay, and A. Sangster (1998), Evidence for forearc seafloor-spreading from the Betts Cove Ophiolite, Newfoundland; oceanic crust of boninitic affinity, Tectonophysics, 284(3-4), 233-245.

Bénard, A., and D. A. Ionov (2012), A new petrogenetic model for low-Ca boninites: Evidence from veined sub-arc xenoliths on melt-mantle interaction and melt fractionation, Geochemistry Geophysics Geosystems, 13(6), Q0AF05.

Berndt, J., R. Benaouda, K. Mezger, and J. Koepke (2009), LREE-enriched plagiogranites from the Oman ophiolite, Geochimica et Cosmochimica Acta, 73(13s), A114.

Blichert-Toft, J., and F. Albarède (1997), The Lu-Hf isotope geochemistry of chondrites and the evolution of the mantle-crust system, Earth and Planetary Science Letters, 148, $242-258$. 
Bloomer, S. H. (1983), Distribution and origin of igneous rocks from the landward slopes of the Mariana Trench: Implications for its structure and evolution, Journal of Geophysical Research, 88(B9), 7411-7428.

Bloomer, S. H., and J. H. Hawkins (1987), Petrology and geochemistry of boninite series volcanic rocks from the Mariana Trench, Contributions to Mineralogy and Petrology, 97, 361-377.

Bloomer, S. H., B. Taylor, C. J. MacLeod, R. J. Stern, P. Fryer, J. H. Hawkins, and L. Johnson (1995), Early arc volcanism and the ophiolite problem: a prospective from drilling in the western Pacific, in Active Margins and Marginal Basins of the Western Pacific, Geophysical Monograph Series 88, edited by B. Taylor and J. Natland, pp. 1-30, American Geophysical Union, Washington, D.C.

Bogar, M., and J. Amato (2004), Geochemistry of the Tlikakila Complex, Lake Clark National Park, Alaska; evidence of origin in a supra-subduction zone setting inboard of the Peninsular Terrane, Abstracts with Programs - Geological Society of America, 36(5), 500 .

Bonev, N., and G. Stampfli (2008), Petrology, geochemistry and geodynamic implications of Jurassic island arc magmatism as revealed by mafic volcanic rocks in the Mesozoic low-grade sequence, eastern Rhodope, Bulgaria, Lithos, 100, 210-233.

Bonev, N., and G. Stampfli (2009), Gabbro, plagiogranite and associated dykes in the supra-subduction zone Evros Ophiolites, NE Greece, Geological Magazine, 146(1), 7291.

Bortolotti, V., A. Kodra, M. Marroni, F. Mustafa, L. Pandolfi, G. Principi, and E. Saccani (1996), Geology and petrology of ophiolitic sequences in the central Mirdita region (Northern Albania), Ofioliti, 21, 3-20.

Cameron, W. E., E. G. Nisbet, and V. J. Dietrich (1979), Boninites, komatiites and ophiolitic basalts, Nature, 280, 550-553.

Capedri, S., G. Venturelli, J. Bèbien, and L. Toscani (1981), Low- and high-Ti ophiolites in Northern Pindos: petrological and geological constraints, Bulletin of Volcanology, 44, 439-449.

Chamberlain, K. R., and S. A. Bowring (2000), Apatite-feldspar U-Pb thermochronometer: A reliable, mid-range $\left(450^{\circ} \mathrm{C}\right)$, diffusion-controlled system, Chemical Geology, 172(1-2), 173-200.

Cherniak, D. J., and E. B. Watson (2000), Pb diffusion in zircon, Chemical Geology, 172, 5-24.

Chew, D. M., P. J. Sylvester, and M. N. Tubrett (2011), U-Pb and Th-Pb dating of apatite by LA-ICMPS, Chemical Geology, 280, 200-216. 
Clague, D. A., and G. B. Dalrymple (1987), The Hawaiian-Emperor Seamount Chain, Part I, Geologic Evolution, U.S. Geological Survey Professional Paper, 1350, 5-54.

Cloud, P. E. J., R. G. Schmidt, and H. W. Burke (1956), Geology of Saipan, Mariana Islands, U.S. Geological Survey Professional Paper, 1350, 5-54.

Coleman, R. G., and M. M. Donato (1979), Oceanic plagiogranite revistedRep., Elsevier Sci. Publ. Co., Amsterdam, Netherlands (NLD).

Cosca, M. A., R. J. Arculus, J. A. Pearce, and J. G. Mitchell (1998), ${ }^{40} \mathrm{Ar} /{ }^{39} \mathrm{Ar}$ and K-Ar geochronological age constraints for the inception and early evolution of the Izu-BoninMariana arc system, Island Arc, 7, 579-595.

Crawford, A. J., L. Beccaluva, and G. Serri (1981), Tectono-magmatic evolution of the West Philippine-Mariana region and the origin of boninites, Earth and Planetary Science Letters, 54(2), 346-356.

Deschamps, A., and S. Lallemand (2003), Geodynamic setting of the Izu-Bonin-Mariana boninites, Geological Society, London, Special Publications, 219, 163-185.

Dilek, Y., and P. Thy (2006), Age and petrogenesis of plagiogranite intrusions in the Ankara melange, central Turkey, Island Arc, 15, 44-57.

Dilek, Y., and P. Thy (2009), Island arc tholeiite to boninitic melt evolution of the Cretaceous Kizildag (Turkey) ophiolite: Model for multi-stage early arc-forearc magmatism in Tethyan subduction factories, Lithos, 113, 68-87.

Dilek, Y., and H. Furnes (2009), Structure and geochemistry of Tethyan ophiolites and their petrogenesis in subduction rollback systems, Lithos, 113, 1-20.

Dilek, Y., H. Furnes, and M. Shallo (2007), Suprasubduction zone ophiolite formation along the periphery of Mesozoic Gondwana, Gondwana Research, 11(4), 453-475.

Dilek, Y., H. Furnes, and M. Shallo (2008), Geochemistry of the Jurassic Mirdita Ophiolite (Albania) and the MORB to SSZ evolution of a marginal basin oceanic crust, Lithos, 100, 174-209.

Dobretsov, N., and V. Kepezhinscas (1981), Three types of ultrabasic magmas and their bearing on the problem of ophiolites, Ofioliti, 6(2), 221-236.

Dostal, J., C. Dupuy, J. P. Carron, M. L. Dekerneizon, and R. C. Maury (1983), PartitionCoefficients of Trace-Elements - Application to Volcanic-Rocks of St-Vincent, WestIndies, Geochimica et Cosmochimica Acta, 47(3), 525-533.

Elliott, T., T. Plank, A. Zindler, W. White, and B. Bourdon (1997), Element transport from slab to volcanic front at the Mariana arc, Journal of Geophysical Research, 102, $14,991-915,019$. 
Ellis, C. H. (1981), Calcareous nannofossil biostratigraphy - Deep Sea Drilling Project Leg 60, in Initial Reports DSDP Leg 60, edited by M. Lee and R. Powell, pp. 507-536, U.S. Government Printing Office, Washington, D.C.

Encarnaciòn, J. (2004), Multiple ophiolite generation preserved in the northern Philippines and the growth of an island arc complex, Tectonophysics, 392, 103-130.

Fenn, P. M. (1986), On the origin of graphic granite, American Mineralogist, 71, 325330.

Flower, M. F. J., and H. M. Levine (1987), Petrogenesis of a tholeiite-boninite sequence from Ayios Mamas, Troodos ophiolite: evidence for splitting of a volcanic arc?, Contributions to Mineralogy and Petrology, 97, 509-524.

Foden, J. D., and D. H. Green (1992), Possible role of amphibole in the origin of andesite: some experimental and natural evidence, Contributions to Mineralogy and Petrology, 109, 479-493.

France, L., B. Ildefonse, and J. Koepke (2013), Hydrous magmatism triggered by assimilation of hydrothermally altered rocks in fossil oceanic crust (northern Oman Ophiolite), Geochemistry Geophysics Geosystems, 14(8), 2598-2614.

Freund, S., M. Erdmann, J. Koepke, F. Hauff, and K. Haase (2013), Crustal evolution and petrogenesis of silicic plutonic rocks within the Oman ophiolite; petrological and geochemical investigations, Mineralogical Magazine, 77(5), 1111.

Fryer, P., N. Becker, B. Appelgate, F. Martinez, M. Edwards, and G. Fryer (2003), Why is the Challenger Deep so deep?, Earth and Planetary Science Letters, 211, 259-269.

Fryer, P., et al. (1990), Proceedings ODP Science Results covering Leg 125 of the cruises of the Drilling Vessel JOIDES Resolution, in Proceedings of the Ocean Drilling Program, Scientific Results, Vol. 125, edited by S. K. Stewart, Ocean Drilling Program, College Station, TX.

Fujimaki, H. (1986), Partition-Coefficients of Hf, Zr, and REE between Zircon, Apatite, and Liquid, Contributions to Mineralogy and Petrology, 94(1), 42-45.

Fujimaki, H., M. Tatsumoto, and K.-i. Aoki (1984), Partition coefficients of Hf, Zr, and REE between phenocrysts and groundmasses, Journal of Geophysical Research, 89, 662672.

Gass, I. G. (1968), Is the Troodos Massif of Cyprus a fragment of Mesozoic ocean floor?, Nature, 220, 39-42.

Gast, P. (1968), Trace element fractionation and the origin of tholeiitic and alkaline magma types, Geochimica et Cosmochimica Acta, 32(10), 1057-1086. 
Gill, J. B. (1981), Orogenic Andesites and Plate Tectonics, Springer-Verlag, Berlin.

Gill, J. B., R. N. Hiscott, and P. Vidal (1994), Turbidite geochemistry and evolution of the Izu-Bonin arc and continents, Lithos, 33, 135-168.

Godard, M., D. Bosch, and F. Einaudi (2006), A MORB source for low-Ti magmatism in the Semail ophiolite, Chemical Geology, 234, 58-78.

Green, T., J. Blundy, J. Adam, and G. Yaxley (2000), SIMS determination of trace element partition coefficients between garnet, clinopyroxene and hydrous basaltic liquids at 2-7.5 $\mathrm{GPa}$ and $1080-1200^{\circ} \mathrm{C}$, Lithos, 53, 165-187.

Gvirtzman, Z., and R. J. Stern (2004), Bathymetry of Mariana trench-arc system and formation of the Challenger Deep as a consequence of weak plate coupling, Tectonics, 23.

Hacker, B. R., G. A. Abers, and S. M. Peacock (2003), Subduction factory: 1. Theoretical mineralogy, densities, seismic wave speeds, and $\mathrm{H}_{2} \mathrm{O}$ contents, Journal of Geophysical Research, 108(B1, 2029), 1-26.

Hall, C. E., M. Gurnis, M. Sdrolias, L. L. Lavier, and R. D. Müller (2003), Catastrophic initiation of subduction following forced convergence across fracture zones, Earth and Planetary Science Letters, 212, 15-30.

Hall, R. (2002), Cenozoic geological and plate tectonic evolution of SE Asia and the SW Pacific: Computer-based reconstructions, model and animations, Journal of Asian Earth Science, 20, 353-431.

Hall, R., M. Fuller, J. R. Ali, and C. D. Anderson (1995), The Philippine Sea Plate: Magnetism and reconstructions, in Active Margins and Marginal Basins of the Western Pacific, Geophysical Monograph Series, edited by B. Taylor and J. Natlund, pp. 371-404, American Geophysical Union, Washington, D.C.

Hanzawa, S. (1947), Eocene foraminifera from Hahajima, Journal of Paleontology, 21, 254-259.

Haraguchi, S., T. Ishii, J.-I. Kimura, and Y. Ohara (2003), Formation of tonalite from basaltic magma at the Komahashi-Daini Seamount, northern Kyuhu-Palau Ridge in the Philippine Sea, and growth of Izu-Ogasawara (Bonin)-Mariana arc crust, Contributions to Mineralogy and Petrology, 145, 151-168.

Haraguchi, S., T. Ishii, J.-I. Kimura, and Y. Kato (2012), The early Miocene ( 25 Ma) volcanism in the northern Kyushu-Palau Ridge, enriched mantle source injection during rifting prior to the Shikoku backarc basin opening, Contributions to Mineralogy and Petrology, 163, 483-504. 
Hart, S. R. (1984), A large-scale isotope anomaly in the Southern Hemisphere mantle, Nature, 309, 753-757.

Hart, S. R., and C. Brooks (1977), The geochemistry and evolution of the early Precambrian mantle, Contributions to Mineralogy and Petrology, 61, 109-128.

Hart, S. R., and T. Dunn (1993), Experimental cpx/melt partitioning of 24 trace elements, Contributions to Mineralogy and Petrology, 113, 1-8.

Hauri, E. H., T. Wagner, and T. L. Grove (1994), Experimental and natural partitioning of $\mathrm{Th}, \mathrm{U}, \mathrm{Pb}$ and other trace elements between garnet, clinopyroxene and basaltic melts, Chemical Geology, 117, 149-166.

Hawkins, J. W., S. H. Bloomer, C. A. Evans, and J. T. Melchior (1984), Evolution of intra-oceanic arc-trench systems, Tectonophysics, 102, 175-205.

Hickey-Vargas, R. (1989), Boninites and tholeiites from DSDP Site 458, Mariana Forearc, in Boninites and Related Rocks, edited by A. J. Crawford, pp. 339-356, Unwin Hyman, London, United Kingdom.

Hickey-Vargas, R., and M. K. Reagan (1987), Temporal variation of isotope and rare earth element abundances in volcanic rocks from Guam: implications for the evolution of the Mariana Arc, Contributions to Mineralogy and Petrology, 97, 497-508.

Hickey, R., and F. A. Frey (1982), Geochemical characteristics of boninite series volcanics: Implications for their source, Geochimica et Cosmochimica Acta, 46, 20992116.

Hilde, T. W. C., and C.-S. Lee (1984), Origin and evolution of the west Philippine Basin: A new interpretation, Tectonophysics, 102, 85-104.

Hilde, T. W. C., S. Uyeda, and L. Kroenke (1977), Evolution of the western Pacific and its margin, Tectonophysics, 38, 145-165.

Hochstaedter, A. G., J. B. Gill, S. Kusakabe, S. Newman, M. Pringle, B. Taylor, and P. Fryer (1990), Volcanism in the Sumisu Rift, 1. Major element, volatile and stable isotope geochemistry, Earth and Planetary Science Letters, 100, 179-194.

Hoeck, V., F. Koller, T. Meisel, K. Onuzi, and E. Kneringer (2002), The Jurassic south Albanian ophilites: MOR- vs. SSZ-type ophiolites, Lithos, 65, 143-164.

Hofmann, A. W. (1988), Chemical differentiation of the Earth: the relationship between mantle, continental crust, and oceanic crust, Earth and Planetary Science Letters, 90, 297-314. 
Honza, E., and K. Fujioka (2004), Formation of arcs and backarc basins inferred from the tectonic evolution of Southeast Asia since the Late Cretaceous, Tectonophysics, 384(1-4), 23-53.

Hunt, J. A., and D. M. Kerrick (1977), The stability of sphene; experimental redetermination and geologic implications, Geochimica et Cosmochimica Acta, 41(2), 279.

Hussong, D. M., et al. (1981), Initial Reports of the Deep Sea Drilling Project Leg 60 covering the cruises of the Drilling Vessel Glomar Challenger, in Initial Reports of the DSDP Leg 60, edited by M. Lee and R. Powell, p. 929, U.S. Government Printing Office, Washington, D.C.

Ishikawa, T., K. Nagaishi, and S. Umino (2002), Boninitic volcanism in the Oman ophiolite: Implications for thermal condition during transition from spreading ridge to arc, Geology, 30(10), 899-902.

Ishikawa, T., K. Nagaishi, and S. Fujisawa (2007), Amphibolite-facies metamorphism of the subducted slab and boninte magma genesis; an inference from hte Oman ophiolite, Geochimica et Cosmochimica Acta, 71(15S), A431.

Ishizuka, O., K. Uto, M. Yuasa, and A. G. Hochstaedter (1998), Preliminary K-Ar ages from seamount chains in the back-arc regoin of the Izu-Ogasawara arc, Island Arc, 7, 408-421.

Ishizuka, O., K. Tani, M. Reagan, K. Kanayama, S. Umino, Y. Harigane, I. Sakamoto, Y. Miyajima, M. Yuasa, and D. J. Dunkley (2011), The timescales of subduction initiation and subsequent evolution of an oceanic island arc, Earth and Planetary Science Letters, $306,229-240$.

Ishizuka, O., et al. (2006), Early stages in the evolution of Izu-Bonin arc volcanism: new age, chemical and isotopic constraints, Earth and Planetary Science Letters, 250(1-2), 385-401.

Jaques, A. L., and B. W. Chappell (1980), Petrology and trace element geochemistry of the Papuan ultramafic belt, Contributions to Mineralogy and Petrology, 75, 55-70.

Jarrad, R. D. (1986), Relations among subduction parameters, Review of Geophysics, 24(2), 217-283.

Johannsen, A. (1931), A descriptive petrography of the igneous rocks, 267 pp., University of Chicago Press, Chicago.

Johnson, D. M., P. R. Hooper, and R. M. Conrey (1999), XRF analysis of rocks and minerals for major and trace elements on a single low dilution Li-tetraborate fused bead, Advances in X-ray analysis, 41, 843-867. 
Jolivet, L., P. Huchon, and C. Rangin (1989), Tectonic setting of western Pacific marginal basins, Tectonophysics, 160, 23-47.

Jones, G., and A. H. F. Robertson (1991), Tectono-stratigraphic evolution of the Mesozoic Pindos ophiolite and related units, northwestern Greece, Journal of Geological Society of London, 148, 267-288.

Kaneoka, I., N. Isshiki, and S. Zashu (1970), K-Ar ages of the Izu-Bonin Islands, Geochemical Journal, 4(2), 53-60.

Karig, D. E. (1974), Evolution of arc systems in the western Pacific, Annual Review of Earth and Planetary Sciences, 2, 51-75.

Kawate, S., and M. Arima (1998), Petrogenesis of the Tanzawa plutonic complex, central Japan: exposed felsic middle crust of the Izu-Bonin-Mariana arc, Island Arc, 7, 342-358.

Kennedy, A. K., and K. Dante (1997), SHRIMP measurement of U-Th-Pb ages of apatites from the Acropolis find ore prospect, south Australia, Abstract of $G A C / M A C$ Annual Meeting, Ottawa, A-77.

Klein, G. d. V., and K. Kobayashi (Eds.) (1980), Geological summary of the north Philippine Sea, based on Deep Sea Drilling Project Leg 58 results, 951-961 pp., U.S. Government Printing Office, Washington, D.C.

Kling, S. A. (1981), Radiolarians from the Mariana Trough and Trench region: Deep Sea Drilling Project Leg 60, in Initial Reports of the DSDP Leg 60, edited by M. Lee and R. Powell, pp. 537-557, U.S. Govt Printing Office, Washington, D.C.

Kobayashi, K., S. Kasuga, and K. Okino (1995), Shikoku Basin and its margins, in Backarc Basins: Tectonics and Magmatism, edited by B. Taylor, pp. 381-405, Plenum Press, New York, N.Y.

Koepke, J., S. T. Feig, and J. Snow (2005), Hydrous partial melting with the lower oceanic crust, Terra Nova, 17, 286-291.

Koepke, J., S. T. Feig, J. Snow, and M. Freise (2004), Petrogenesis of oceanic pagiogranites by partial melting of gabbros: an experimental study, Contributions to Mineralogy and Petrology, 146, 414-432.

Koppers, A. A. P., H. Staudigel, and R. A. Duncan (2003), High-resolution ${ }^{40} \mathrm{Ar} /{ }^{39} \mathrm{Ar}$ dating of the oldest oceanic basement basalts in the western Pacific basin, Geochemistry Geophysics Geosystems, 4(11).

Kroenke, L., et al. (1980), Initial Reports of the Deep Sea Drilling Project Leg 59 covering the cruises of the Drilling Vessel Glomar Challenger, in Initial Reports of the DSDP Leg 59, edited by S. Orlofsky, p. 820, U.S. Government Printing Office, Washington, D.C. 
Kuroda, N., K. Shiraki, and H. Urano (1988), Ferropigeonite quartz dacites from Chichijima, Bonin islands: latest differentiates from boninite-forming magma, Contributions to Mineralogy and Petrology, 100(2), 129-138.

Kushiro, I. (1981), Petrology of high-MgO bronzite andesite resembling boninite from Site 458 near the Mariana Trench, in Initial Reports of the Deep Sea Drilling Project Leg 60, edited by M. Lee and R. Powell, pp. 731-733, U.S. Government Printing Office, Washington D.C.

Leake, B. E., et al. (1997), Nomenclature of Amphiboles: Report of the Subcommittee on Amphiboles of the International Mineralogical Association Commission on New Minerals and Mineral Names, American Mineralogist, 82, 1019-1037.

Lee, J. K. W., I. S. Williams, and D. J. Ellis (1997), Pb, U and Th diffusion in natural zircon, Nature, 390, 159-161.

Leng, W., and M. Gurnis (2011), Dynamics of subduction initiation with different evolutionary pathways, Geochemistry Geophysics Geosystems, 12(12), Q12018.

Lentz, D. R., and A. D. Fowler (1992), A dynamic model for graphic quartz-feldspar intergrowths in granitic pegmatites in the southwestern Grenville Province, Canadian Mineralogist, 30, 571-585.

Lippard, S. J., A. W. Shelton, and I. G. Gass (1986), The ophiolite of northern Oman, Memoirs of the Geological Society of London, 11.

London, D., G. B. I. Morgan, and R. L. Hervig (1989), Vapor-undersaturated experiments with Macusani glass $+\mathrm{H} 2 \mathrm{O}$ at $200 \mathrm{MPa}$, and the internal differentiation of pegmatites, Contributions to Mineralogy and Petrology, 102, 1-17.

Lowenstern, J. B., M. A. Clynne, and T. D. Bullen (1997), Comagmatic A-type granophyre and rhyolite from the Alid volcanic center, Eritrea, northeast Africa, Journal of Petrology, 38(12), 1707-1721.

Luhr, J. F., and I. S. E. Carmichael (1980), The Colima volcanic complex, Mexico. I: post-caldera andesites from Volcan Colima, Contributions to Mineralogy and Petrology, $71,343-372$.

Mahoney, J. (1987), An isotopic survey of Pacific oceanic plateaus: implications for their nature and origin, in Seamounts, Islands, and Atolls, Geophysical Monograph Series 43, edited by B. H. Keating, P. Fryer, R. Batiza and G. W. Boehlert, pp. 207-220, American Geophysical Union, Washington, D.C.

Maitre, R. W. L., et al. (1989), A Classification of Igneous Rocks and Glossary of terms: Recommendations of the International Union of Geological Sciences Subcommission on the Systematics of Igneous Rocks, Blackwell Scientific Publications, Oxford, U.K. 
Manhès, G., J.-P. Minster, and C. J. Allègre (1978), Comparative uranium-thorium-lead and rubidium-strontium of St. Severin amphoterite: consequences for early solar system chronology, Earth and Planetary Science Letters, 39, 14-24.

McKenzie, D., and R. K. O'Nions (1991), Partial melt distributions from inversion of rare Earth element concentrations, Journal of Petrology, 32, 1021-1091.

Meijer, A. (1980), Primitive arc volcanism and a boninite series: Examples from western Pacific island arcs, in The Tectonic and Geologic Evolution of Southeast Asian Seas and Islands (Part II), Geophysical Monograph Series 23, edited by D. E. Hayes, pp. 271-282, American Geophysical Union, Washington, D.C.

Meijer, A., E. Anthony, and M. K. Reagan (1981), Petrology of volcanic rocks from the fore-arc sites, in Initial Reports of the DSDP Leg 60, edited by M. Lee and R. Powell, pp. 709-729, U.S. Government Printing Office, Washington, D.C.

Meijer, A., M. K. Reagan, H. Ellis, M. Shafiqullah, J. Sutter, P. Damon, and J. Kling (1983), Chronology of volcanic events in the eastern Philippine Sea, in The Tectonic and Geologic Evolution of Southeast Asian Seas and Islands (Part II), Geophysical

Monograph Series 27, edited by D. E. Hayes, pp. 349-359, American Geophysical Union, Washington, D.C.

Mitchell, J. G., D. W. Peate, B. J. Murton, J. A. Pearce, R. J. Arculus, and S. R. van der Laan (1992), K-Ar dating of samples from sites 782 and 786 (Leg 125); the Izu-Bonin forearc region, in Proceedings of the Ocean Drilling Program, Scientific Results, Vol. 125, edited by S. K. Stewart, pp. 203-210, Ocean Drilling Program, College Station, TX.

Miyashiro, A. (1973), The Troodos ophiolitic complex was probably formed in an island arc, Earth and Planetary Science Letters, 19(2), 218-224.

Moores, E. M., and F. J. Vine (1971), The Troodos massif, Cyprus and other ophiolites as oceanic crust; evaluation and implications, Philosophical Transactions of the Royal Society of London, Series A: Mathematical and Physical Sciences, 268(1192), 443-466.

Moores, E. M., and E. D. Jackson (1974), Ophiolites and oceanic crust, Nature, 250, 136139.

Münker, C., S. Weyer, E. Scherer, and K. Mezger (2001), Separation of high field strength elements ( $\mathrm{Nb}, \mathrm{Ta}, \mathrm{Zr}, \mathrm{Hf})$ and Lu from rock samples for MC-ICPMS measurements, Geochemistry Geophysics Geosystems, 2(12).

Müntener, O., P. B. Keleman, and T. L. Grove (2001), The role of H2O during crystallization of primitive arc magmas under upper-most mantle conditions and genesis of igneous pyroxenites: an experimental study, Contributions to Mineralogy and Petrology, 141, 646-658. 
Nagasawa, H., and C. C. Schnetzler (1971), Partitioning of rare Earth, alkali, and alkaline Earth elements between phenocrysts and acidic igneous magmas, Geochimica et Cosmochimica Acta, 35, 953-968.

Natland, J. H., and J. Tarney (1981), Petrologic evolution of the Mariana arc and back-arc basin system - A synthesis of drilling results in the south Philippine Sea, in Initial Reports of the Deep Sea Drilling Project Leg 60, edited by M. Lee and R. Powell, pp. 877-908, U.S. Government Printing Office, Washington D.C.

O'Brien, P. (2001), Subduction followed by collision: Alpine and Himalayan examples, Physics of the Earth and Planetary Interiors, 127, 227-291.

Ogawa, Y., and J. Naka (Eds.) (1984), Emplacement of ophiolitic rocks in forearc areas: Examples from central Japan and Izu-Mariana-Yap island arc system, 291-302 pp., Blackwell Science Publications, Oxford.

Ohara, Y., et al. (2008), R/V Yokosuka YK08-08 Leg 2 Cruise: Structure and origin of the Mariana forearc and implications for the origin of continental crust: A Shinkai 6500 study of the southern Mariana forearc, in Cruise Report, Japan Agency for Marine-Earth Science and Technology, edited, IFREE/JAMSTEC, Japan.

Paster, T. P., D. S. Schauwecker, and L. A. Haskin (1974), The behavior of some trace elements during solidification of the Skaergaard layered series, Geochimica et Cosmochimica Acta, 38(10), 1549-1577.

Pearce, J. A. (2003), Subduction zone ophiolites: The search for modern analogues, in Ophiolite Concept and the Evolution of Geological Thought, edited by Y. Dilek and S. Newcomb, pp. 269-294, Geological Society of America Special Paper, Boulder, CO.

Pearce, J. A., and J. R. Cann (1973), Tectonic setting of basic volcanic rocks determined using trace element analyses, Earth and Planetary Science Letters, 19(2), 280-300.

Pearce, J. A., S. J. Lippard, and S. Roberts (1984), Characteristics and tectonic significance of supra-subduction zone ophiolites, in Marginal Basin Geology: Volcanic and Associated Sedimentary and Tectonic Processes in Modern and Ancient Marginal Basins, edited by B. P. Kokelaar and M. F. Howells, pp. 77-94, Geological Society of London Special Publications, London.

Pearce, J. A., T. Alabaster, A. W. Shelton, and M. P. Searle (1981), The Oman ophiolite as a Cretaceous arc-basin complex: Evidence and implications, Philosophical Transactions of the Royal Society of London, Series A: Mathematical and Physical Sciences, 300(1454), 299-317.

Pearce, J. A., P. D. Kempton, G. M. Nowell, and S. R. Noble (1999), Hf-Nd element and isotope perspective on the nature and provenance of mantle and subduction components in western Pacific arc-basin systems, Journal of Petrology, 40(11), 1579-1611. 
Pearce, J. A., S. R. van der Laan, R. J. Arculus, B. J. Murton, and T. Ishii (1992), Boninite and harzburgite from ODP Leg 125 (Bonin-Mariana forearc): a case study in magma genesis during the initial stages of subduction, in Proceedings of the Ocean Drilling Program, Scientific Results Leg 126, edited by S. K. Stewart, pp. 623-659, Ocean Drilling Program, College Station, TX.

Pedersen, R. B., and J. Hertogen (1990), Magmatic evolution of the Karmoy ophiolite complex, SW Norway; relationships between MORB-IT-boninitic-calc-alkaline and alkaline magmatism, Contributions to Mineralogy and Petrology, 104(3), 277-293.

Reagan, M. K., and A. Meijer (1984), Geology and geochemistry of early arc-volcanic rocks from Guam, Geological Society of America Bulletin, 95, 701-713.

Reagan, M. K., B. Hanan, M. Heizler, B. Hartman, and R. Hickey-Vargas (2008), Petrogenesis of volcanic rocks from Saipan and Rota, Mariana Islands, and implications for the evolution of nascent island arcs, Journal of Petrology, 49(3), 441-464.

Reagan, M. K., W. C. McClelland, G. Girard, K. R. Goff, D. W. Peate, Y. Ohara, and R. J. Stern (2013), The geology of the southern Mariana fore-arc crust: implications for the scale of Eocene volcanism in the western Pacific, Earth and Planetary Science Letters, $380,41-51$.

Reagan, M. K., et al. (2010), Fore-arc basalts and subduction initiation in the Izu-BoninMariana system, Geochemistry Geophysics Geosystems, 11(3).

Richard, P. N., N. Shimizu, and C. J. Allègre (1976), ${ }^{143} \mathrm{Nd} /{ }^{144} \mathrm{Nd}$, a natural tracer: an application to oceanic basalts, Earth and Planetary Science Letters, 31, 269-278.

Robinson, P. T., and J. Malpas (1990), The Troodos Ophiolite of Cyprus; new perspectives on its origin and emplacement, in Ophiolites, Oceanic Crustal Analogues. Proceedings of the Symposium "Troodos 1987", edited by J. Malpas, E. M. Moores, A. Panayiotou and C. Xenophontos, pp. 13-26, Geological Survey Department, Nicosia, Cyprus (CYP).

Rollinson, H. (1993), Using Geochemical Data: Evaluation, Presentation, Interpretation, Longman Scientific and Technical Publishing Group, London.

Rollinson, H. (2008), MORB and boninitic melts parental to mantle chromites in a single section through the northern Oman ophiolite, Geophysical Research Abstracts, 10, EGU2008-A-02077.

Rollinson, H. (2009), New models for the genesis of plagiogranites in the Oman ophiolite, Lithos, 112, 603-614.

Rudnick, R. L., and D. M. Fountain (1995), Nature and composition of the continental crust: a lower crustal perspective, Review of Geophysics, 33, 267-309. 
Saccani, E., and A. Photiades (2004), Mid-ocean ridge and suprea-subduction affinities in the Pindos ophiolites (Greece): implications for magma genesis in a forearc setting, Lithos, 73, 229-253.

Salters, V. J. M. (1994), ${ }^{176} \mathrm{Hf} /{ }^{177} \mathrm{Hf}$ determination in small samples by a high temperature SIMS technique, Analytical Chemistry, 66, 4186-4189.

Salters, V. J. M., S. Mallick, S. R. Hart, C. E. Langmuir, and A. Stracke (2011), Domains of depleted mantle; new evidence from hafnium and neodymium isotopes, Geochemistry Geophysics Geosystems, 12(8).

Sano, Y., T. Oyama, K. Terada, and H. Hidaka (1999), Ion microprobe U-Pb dating of apatite, Chemical Geology, 153(1-4), 249-258.

Satoh, R., and E. Takazawa (2008), Genetic relation between boninite and mantle section in the northernmost part of the Fizh Block, the Oman ophiolite, Abstract - Japan Geoscience Union Meeting, K129-P004.

Schoene, B., and S. A. Bowring (2007), Determining accurate temperature-time paths from $\mathrm{U}-\mathrm{Pb}$ thermochronology: An example from the Kaapvaal craton, southern Africa, Geochimica et Cosmochimica Acta, 71(1), 165-185.

Scholz, C. H., and J. Campos (1995), On the mechanism of seismic decoupling and back arc spreading at subduction zones, Journal of Geophysical Research, 100(B11), 2210322115.

Scott, R., L. Kroenke, G. Zakariadze, and A. Sharaskin (1980), Evolution of the south Philippine Sea: Deep Sea Drilling Project Leg 59 results, in Initial Reports of the Deep Sea Drilling Project Leg 59, edited by S. Orlofsky, pp. 803-816, U.S. Government Printing Office, Washington, D.C.

Seno, T., and S. Maruyama (1984), Paleogeographic reconstruction and origin of the Philippine Sea, Tectonophysics, 102, 53-84.

Serri, G. (1981), The petrochemistry of ophiolite gabbroic complexes: a key for the classification of ophiolites into low-Ti and high-Ti types, Earth and Planetary Science Letters, 52, 203-212.

Sharp, W. D., and D. A. Clague (2006), 50-Ma initiation of Hawaiian-Emperor Bend records major change in Pacific plate motion, Science, 313, 1281-1284.

Shaw, D. (1970), Trace element fractionation during anatexis, Geochimica et Cosmochimica Acta, 34(2), 237-243.

Shervais, J. W. (2001), Birth, death, and resurrection; the life cycle of suprasubduction zone ophiolites, Geochemistry Geophysics Geosystems, 2(1). 
Shibata, K., A. Mizuno, M. Yuasa, S. Uchida, and T. Nakagawa (1977), Further K-Ar dating of tonalite dredged from the Komahashi-Daini Seamount, Bulletin of Geological Survey of Japan, 28, 1-4.

Shih, T. C. (Ed.) (1980), Marine magnetic anomalies from the western Philippine Sea: implications for the evolution of marginal basins, 49-75 pp.

Siegrist, H. G., and M. Reagan (2008), Generalized Geology of Guam, Mariana Islands, Guam Hydrologic Survey Program, funded by Water \& Environmental Research Institute at the Univeristy of Guam.

Sisson, T. W. (1991), Pyroxene-High Silica Rhyolite Trace-Element PartitionCoefficients Measured by Ion Microprobe, Geochimica et Cosmochimica Acta, 55(6), $1575-1585$.

Sisson, T. W. (1994), Hornblende-Melt Trace-Element Partitioning Measured by Ion Microprobe, Chemical Geology, 117(1-4), 331-344.

Stern, R. J. (2002), Subduction Zones, Review of Geophysics, 40(4), 1012.

Stern, R. J. (2004a), Suubduction initiation: spontaneous and induced, Earth and Planetary Science Letters, 226, 275-292.

Stern, R. J. (2004b), Subduction initiation: spontaneous and induced, Earth and Planetary Science Letters, 226, 275-292.

Stern, R. J., and S. H. Bloomer (1992), Subduction zone infancy: examples from the Eocene Izu-Bonin-Mariana and Jurassic California arcs, Geological Society of America Bulletin, 104, 1621-1636.

Stern, R. J., M. J. Fouch, and S. Klemperer (Eds.) (2003), An overview of the Izu-BoninMariana subduction factory, 175-222 pp., American Geophysical Union.

Stern, R. J., S. H. Bloomer, P.-N. Lin, and N. C. Smoot (1989), Submarine arc volcanism in the southern Mariana arc as an ophiolite analogue, Tectonophysics, 168, 151-170.

Stern, R. J., J. D. Morris, S. H. Bloomer, and J. W. Hawkins (1991), The source of the subduction component in convergent margin magmas; trace element and radiogenic isotope evidence from Eocene boninites, Mariana Forearc, Geochimica et Cosmochimica Acta, 55(5), 1497-1481.

Stern, R. J., M. Reagan, O. Ishizuka, Y. Ohara, and S. Whattam (2012), To understand subduction initiation, study forearc crust; to understand forearc crust, study ophiolites, Lithosphere, 4, 469-483. 
Straub, S. M. (2003), The evolution of the Izu Bonin Mariana volcanic arcs (NW Pacific) in terms of major element chemistry, Geochemistry Geophysics Geosystems, 4, paper number $2002 \mathrm{GC} 000357$.

Streckeisen, A. L. (1974), Classification and nomenclature of plutonic rocks: recommendations for the IUGS subcommision on the systematics of igneous rocks, Geologische Rundschau. Internationale Zeitschrift für Geologie, 63, 773-785.

Sun, S.-s., and W. F. McDonough (1989), Chemical and isotopic systematics of oceanic basalts: implications for mantle composition and processes, Geological Society, London, Special Publications, 42, 313-345.

Sutter, J. F., et al. (1980), K/Ar and 40Ar/39Ar dating of basaltic rocks from Deep Sea Drilling Project Leg 59, in Initial Reports of the Deep Sea Drilling Project 59, edited by S. Orlofsky, pp. 729-734, Texas A\&M University, Ocean Drilling Program, College Station, TX.

Suyehiro, K., N. Takahashi, Y. Ariie, Y. Yokoi, R. Hino, M. Shinohara, T. Kanazawa, N. Hirata, H. Tokuyama, and A. Taira (1996), Continental crust, crustal underplating and low-Q upper mantle beneath an oceanic island arc, Science, 272, 390-392.

Takahashi, N., K. Suyehiro, and M. Shinohara (1998), Implications from the seismic crustal structure of the northern Izu-Bonin arc, Island Arc, 7, 383-394.

Takahashi, N., S. Kodaira, Y. Tatsumi, Y. Kaneda, and K. Suyehiro (2008), Structure and growth of the Izu-Bonin-Mariana arc crust: 1. Seismic constraint on crust and mantle structure of the Mariana arc-back-arc system, Journal of Geophysical Research, 113(B01 104), 1-18.

Tamura, Y., and Y. Tatsumi (2002), Remelting of an andesitic crust as a possible source for rhyolitic magma in oceanic arcs: an example from the Izu-Bonin arc, Journal of Petrology, 43, 1029-1047.

Tamura, Y., et al. (2009), Silicic magmas in the Izu-Bonin oceanic arc and implications for crustal evolution, Journal of Petrology, 50(4), 685-723.

Tani, K., D. J. Dunkley, J.-I. Kimura, R. J. Wysoczanski, K. Yamada, and Y. Tatsumi (2012), Syncollisional rapid granitic magma formation in an arc-arc collision zone: evidence from the Tanzawa plutonic complex, Japan, Contributions to Mineralogy and Petrology, 38(3), 215-218.

Taylor, B. (1992a), Rifting and the volcanic-tectonic evolution of the Izu-Bonin-Mariana arc, in Proceedings of the Ocean Drilling Program, Scientific Results Leg 126, edited by E. M. Barbu and A. P. Julson, pp. 627-651, Ocean Drilling Program, College Station, TX. 
Taylor, B. (1992b), Rifting and the volcanic-tectonic evolution of the Izu-Bonin-Mariana arc, in Proceedings ODP Scientific Results, B. Taylor, K. Fujioka, et al., Ocean Drilling Program, College Station, TX, 126, 627-653.

Taylor, R. N., and J. G. Mitchell (1992), K-Ar dating results from whole rock and mineral separates of the Izu-Bonin forearc basement, Leg 126, in Proceedings of the Ocean Drilling Program, Scientific Results Leg 126, edited by E. M. Barbu and A. P. Julson, pp. 677-680, Ocean Drilling Program, College Station, TX.

Taylor, R. N., and R. W. Nesbitt (1995), Arc volcanism in an extensional regime at the initiation of subduction: a geochemical study of Hahajima, Bonin Islands, Japan, in Volcanism Associated with Extension at Consuming Plate Margins Geological Society Special Publications, vol. 81, edited by J. Smellie, Geological Society of London, London.

Taylor, R. N., O. Ishizuka, and C. G. Macpherson (2003), Pb isotope constraints on the source of boninite and arc magmatism in the Bonin islands, Japan, Geochimica et Cosmochimica Acta (Supplement), 67, A478.

Taylor, R. N., R. W. Nesbitt, P. Vidal, R. S. Harmon, B. Auvray, and I. W. Croudace (1994), Mineralogy, chemistry, and genesis of the boninite series volcanics, Chichijima, Bonin Islands, Japan, Journal of Petrology, 35(3), 577-617.

Todt, W., R. A. Cliff, A. Hanser, and A. W. Hofmann (1996), Evaluation of a ${ }^{202} \mathrm{~Pb}+$ ${ }^{205} \mathrm{~Pb}$ double spike for high precision lead isotope analyses, in Earth processes: reading the isotopic code, Geophysical Monograph Series 95, edited by A. Basu and S. R. Hart, pp. 429-437, American Geophysical Union, Washington, D.C.

Tracey, J. L., S. O. Schlanger, J. T. Stark, and D. B. Doan (1964), General Geology of Guam, U.S. Geological Survey Professional Paper, 403-A.

Umino, S. (1985), Volcanic geology of Chichijima, the Bonin Islands (Ogasawara Islands), Journal of Geological Society of Japan, 91, 505-523.

Uyeda, S., and Z. Ben-Avraham (1972), Origin and development of the Philippine Sea, Nature Physical Sciences, 240, 176-178.

Uyeda, S., and H. Kanamori (1979), Back-arc opening and the mode of subduction, Journal of Geophysical Research, 84, 1049-1061.

Vine, F. J., and D. H. Matthews (1963), Magnetic anomalies over oceanic ridges, Nature, 199, 947-949.

Vine, F. J., and E. M. Moores (1972), A model for the gross structure, petrology, and magnetic properties of oceanic crust, Geological Society of America Memoir, 132, 195205. 
Warren, C. J., R. R. Parrish, D. J. Waters, and M. Searle (2005), Dating the geologic history of Oman's Semail ophiolite: insights from U-Pb geochronology, Contributions to Mineralogy and Petrology, 150, 403-422.

Watts, A. B., J. K. Weissel, and R. L. Larson (1977), Sea-floor spreading in marginal basins of the western Pacific, Tectonophysics, 37, 167-181.

Weis, D., and F. A. Frey (1991), Isotope geochemistry of Ninety-east Ridge basalts: Sr, $\mathrm{Nd}, \mathrm{Pb}$ evidence for the involvement of the Kerguelen hot spot, in Proceedings of the Ocean Drilling Program, Scientific Results Leg 121, edited by E. K. Mazullo, pp. 591610, Ocean Drilling Program, College Station, TX.

Weis, D., and F. A. Frey (1996), Role of the Kerguelen plume in generating the eastern Indian ocean seafloor, Journal of Geophysical Research, 101(B6), 13831-13849.

Whattam, S. A., and R. J. Stern (2011), The 'subduction initiation rule:' a key for linking ophiolites, intra-oceanic forearcs, and subduction initiation, Contributions to Mineralogy and Petrology, 162, 1031-1045.

Wolff, P. E., D. Garbe-Schoenberg, J. Koepke, and K. Streuff (2011), High-temperature hydrothermal activity in the lower oceanic crust; petrological and geochemical evidence for fluid pathways in the Oman Ophiolite, Mineralogical Magazine, 75(3), 2171.

Yamazaki, S., and S. Miyashita (2008), Geochemistry of high-Ca boninite dike swarms and the related plutonic rocks in the Oman ophiolite, Eos Transactions, American Geophysical Union, 89(53), T21A-1939.

Zindler, A., S. R. Hart, F. A. Frey, and S. P. Jakobsson (1979), Nd and Sr isotope ratios and rare earth element abundances in Reykjanes peninsula basalts: evidence for mantle heterogeneity beneath Iceland, Earth and Planetary Science Letters, 45, 249-262. 
APPENDICES 
APPENDIX 1

A1. List of labels and recovery locations for samples analyzed in this study

\begin{tabular}{|c|c|c|c|c|c|c|}
\hline Cruise* & Dredge & $\begin{array}{l}\text { Sample } \\
\text { No. }\end{array}$ & $\begin{array}{l}\text { Starting } \\
\text { Latitude }\end{array}$ & $\begin{array}{l}\text { Starting } \\
\text { Longitude }\end{array}$ & $\begin{array}{c}\text { Depth Range } \\
\text { (below sea level) }\end{array}$ & $\begin{array}{l}\text { Approximate sample } \\
\text { size }^{* *}\end{array}$ \\
\hline KK81-06-26 & 63 & $\mathrm{~J} 07$ & $13.150^{\circ} \mathrm{N}$ & $146.067^{\circ} \mathrm{E}$ & $8150-7420 \mathrm{~m}$ & $6.5 \times 7.5 \times 8.5 \mathrm{~cm}$ \\
\hline KK81-06-26 & 63 & $\mathrm{~J} 15$ & $13.150^{\circ} \mathrm{N}$ & $146.067^{\circ} \mathrm{E}$ & $8150-7420 m$ & $4.2 \times 4.5 \times 6.7 \mathrm{~cm}$ \\
\hline KK81-06-26 & 63 & $\mathrm{~J} 19$ & $13.150^{\circ} \mathrm{N}$ & $146.067^{\circ} \mathrm{E}$ & $8150-7420 \mathrm{~m}$ & $3.2 \times 5.0 \times 5.6 \mathrm{~cm}$ \\
\hline KK81-06-26 & 63 & $\mathrm{~J} 22$ & $13.150^{\circ} \mathrm{N}$ & $146.067^{\circ} \mathrm{E}$ & $8150-7420 \mathrm{~m}$ & $4.0 \times 4.2 \times 5.0 \mathrm{~cm}$ \\
\hline KK81-06-26 & 63 & $\mathrm{~J} 23$ & $13.150^{\circ} \mathrm{N}$ & $146.067^{\circ} \mathrm{E}$ & $8150-7420 \mathrm{~m}$ & $2.5 \times 4.0 \times 5.0 \mathrm{~cm}$ \\
\hline KK81-06-26 & 63 & $\mathrm{~J} 27$ & $13.150^{\circ} \mathrm{N}$ & $146.067^{\circ} \mathrm{E}$ & $8150-7420 \mathrm{~m}$ & $4.2 \times 7.0 \times 8.5 \mathrm{~cm}$ \\
\hline KK81-06-26 & 63 & $\mathrm{~J} 28$ & $13.150^{\circ} \mathrm{N}$ & $146.067^{\circ} \mathrm{E}$ & $8150-7420 \mathrm{~m}$ & $6.0 \times 10.0 \times 10.5 \mathrm{~cm}$ \\
\hline KK81-06-26 & 63 & $\mathrm{~J} 29$ & $13.150^{\circ} \mathrm{N}$ & $146.067^{\circ} \mathrm{E}$ & $8150-7420 \mathrm{~m}$ & $4.0 \times 5.5 \times 7.7 \mathrm{~cm}$ \\
\hline KK81-06-26 & 63 & $\mathrm{~J} 32$ & $13.150^{\circ} \mathrm{N}$ & $146.067^{\circ} \mathrm{E}$ & $8150-7420 \mathrm{~m}$ & $5.3 \times 7.5 \times 8.0 \mathrm{~cm}$ \\
\hline KK81-06-26 & 63 & $\mathrm{~J} 34$ & $13.150^{\circ} \mathrm{N}$ & $146.067^{\circ} \mathrm{E}$ & $8150-7420 \mathrm{~m}$ & $6.3 \times 6.5 \times 10.8 \mathrm{~cm}$ \\
\hline KK81-06-26 & 63 & $\mathrm{~J} 35$ & $13.150^{\circ} \mathrm{N}$ & $146.067^{\circ} \mathrm{E}$ & $8150-7420 \mathrm{~m}$ & $4.5 \times 5.5 \times 6.0 \mathrm{~cm}$ \\
\hline KK81-06-26 & 63 & $\mathrm{~J} 36$ & $13.150^{\circ} \mathrm{N}$ & $146.067^{\circ} \mathrm{E}$ & $8150-7420 m$ & $4.0 \times 6.0 \times 7.0 \mathrm{~cm}$ \\
\hline KK81-06-26 & 63 & J39 & $13.150^{\circ} \mathrm{N}$ & $146.067^{\circ} \mathrm{E}$ & $8150-7420 \mathrm{~m}$ & $5.0 \times 8.6 \times 11.5 \mathrm{~cm}$ \\
\hline KK81-06-26 & 63 & $\mathrm{~J} 40$ & $13.150^{\circ} \mathrm{N}$ & $146.067^{\circ} \mathrm{E}$ & $8150-7420 \mathrm{~m}$ & $3.3 \times 4.8 \times 5.7 \mathrm{~cm}$ \\
\hline KK81-06-26 & 63 & $\mathrm{~J} 43$ & $13.150^{\circ} \mathrm{N}$ & $146.067^{\circ} \mathrm{E}$ & $8150-7420 \mathrm{~m}$ & $4.5 \times 4.6 \times 10.5 \mathrm{~cm}$ \\
\hline KK81-06-26 & 63 & $\mathrm{~J} 45$ & $13.150^{\circ} \mathrm{N}$ & $146.067^{\circ} \mathrm{E}$ & $8150-7420 \mathrm{~m}$ & $4.5 \times 5.2 \times 5.5 \mathrm{~cm}$ \\
\hline KK81-06-26 & 63 & $\mathrm{~J} 46$ & $13.150^{\circ} \mathrm{N}$ & $146.067^{\circ} \mathrm{E}$ & $8150-7420 m$ & $3.5 \times 5.5 \times 5.8 \mathrm{~cm}$ \\
\hline KK81-06-26 & 63 & $\mathrm{~J} 67$ & $13.150^{\circ} \mathrm{N}$ & $146.067^{\circ} \mathrm{E}$ & $8150-7420 \mathrm{~m}$ & $* * *$ \\
\hline KK81-06-26 & 64 & $\mathrm{~J} 49$ & $12.750^{\circ} \mathrm{N}$ & $145.550^{\circ} \mathrm{E}$ & $7390-7195 \mathrm{~m}$ & $4.2 \times 4.8 \times 5.0 \mathrm{~cm}$ \\
\hline KK81-06-26 & 64 & $\mathrm{~J} 50$ & $12.750^{\circ} \mathrm{N}$ & $145.550^{\circ} \mathrm{E}$ & $7390-7195 \mathrm{~m}$ & $3.2 \times 4.6 \times 4.7 \mathrm{~cm}$ \\
\hline KK81-06-26 & 64 & $\mathrm{~J} 53$ & $12.750^{\circ} \mathrm{N}$ & $145.550^{\circ} \mathrm{E}$ & $7390-7195 m$ & $3.2 \times 3.7 \times 5.2 \mathrm{~cm}$ \\
\hline KK81-06-26 & 64 & $\mathrm{~J} 55$ & $12.750^{\circ} \mathrm{N}$ & $145.550^{\circ} \mathrm{E}$ & $7390-7195 \mathrm{~m}$ & $5.0 \times 5.3 \times 8.5 \mathrm{~cm}$ \\
\hline KK81-06-26 & 64 & $\mathrm{~J} 56$ & $12.750^{\circ} \mathrm{N}$ & $145.550^{\circ} \mathrm{E}$ & $7390-7195 \mathrm{~m}$ & $4.5 \times 4.5 \times 5.5 \mathrm{~cm}$ \\
\hline KK81-06-26 & 64 & $\mathrm{~J} 58$ & $12.750^{\circ} \mathrm{N}$ & $145.550^{\circ} \mathrm{E}$ & $7390-7195 \mathrm{~m}$ & $4.5 \times 8.4 \times 10.5 \mathrm{~cm}$ \\
\hline KK81-06-26 & 64 & $\mathrm{~J} 59$ & $12.750^{\circ} \mathrm{N}$ & $145.550^{\circ} \mathrm{E}$ & $7390-7195 \mathrm{~m}$ & $6.5 \times 7.5 \times 9.5 \mathrm{~cm}$ \\
\hline KK81-06-26 & 64 & $\mathrm{~J} 60$ & $12.750^{\circ} \mathrm{N}$ & $145.550^{\circ} \mathrm{E}$ & $7390-7195 m$ & $4.5 \times 4.7 \times 7.2 \mathrm{~cm}$ \\
\hline KK81-06-26 & 64 & $\mathrm{~J} 61$ & $12.750^{\circ} \mathrm{N}$ & $145.550^{\circ} \mathrm{E}$ & $7390-7195 m$ & $5.0 \times 6.5 \times 7.2 \mathrm{~cm}$ \\
\hline KK81-06-26 & 64 & $\mathrm{~J} 63$ & $12.750^{\circ} \mathrm{N}$ & $145.550^{\circ} \mathrm{E}$ & $7390-7195 \mathrm{~m}$ & $4.0 \times 5.8 \times 7.0 \mathrm{~cm}$ \\
\hline KK81-06-26 & 64 & $\mathrm{~J} 64$ & $12.750^{\circ} \mathrm{N}$ & $145.550^{\circ} \mathrm{E}$ & $7390-7195 m$ & $3.0 \times 3.4 \times 3.5 \mathrm{~cm}$ \\
\hline KK81-06-26 & 64 & $\mathrm{~J} 65$ & $12.750^{\circ} \mathrm{N}$ & $145.550^{\circ} \mathrm{E}$ & $7390-7195 \mathrm{~m}$ & $4.5 \times 6.8 \times 9.0 \mathrm{~cm}$ \\
\hline
\end{tabular}

$* \mathrm{KK}=\mathrm{R} / \mathrm{V}$ Kana Keoki of University of Hawai' $\mathrm{i}$

**Sample size is measurement of the sample brought to FIU for analysis. If there were multiple fragments, the largest fragment is listed.

***Not measured, but stored with other samples for future access. 


\section{APPENDIX 2}

\section{A2. Analytical Methods}

A2.1. Select samples for trace element analyses at FIU

Samples were prepared for select trace element analysis on ICP-MS in the Trace Evidence Acquisition Facility (TEAF) at Florida International University, MMC.

Preparation followed the procedure outlined by the Plasma Analytical Laboratory at Kansas University (in Appendix 3 of Murong Sun Dissertation, 2001), but some changes were made to accommodate resources at FIU and TEAF.

Powdered samples were weighed out to $10.00 \mathrm{mg}$ and placed in a savillex beaker. A mixed-acid $\left(\mathrm{HNO}_{3}-\mathrm{HF}\right)$ solution was added to the powder, capped and left to digest overnight then dried down. Then $\mathrm{HCl}$ was added and dried down, then $8 \mathrm{~N} \mathrm{HNO}_{3}$ was added and dried down. Finally $\mathrm{HNO}_{3}$ was added to the dry beaker in order to pick up the sample.

Dilution was performed in a 250mL Nalgene HDPE bottle so that the final solution was $2 \% \mathrm{HNO}_{3}$. An internal standard was included in the dilution. The diluted samples were shaken to homogenize the solution and then transferred to leached $15 \mathrm{~mL}$ centrifuge tubes for analysis on a Finnegan Element2 ICP-MS. Analyses of five samples were performed in the Trace Element Analysis Facility on Florida International University (MMC) campus.

Powdered samples were weighed out to $0.1000 \mathrm{~g}$ for open beaker dissolution in savillex teflon beakers. All work with acids was done in a laminar flow box. First, $4 \mathrm{~mL}$ of $8 \mathrm{~N} \mathrm{HNO}_{3}$ and $1.5 \mathrm{~mL}$ concentrated $\mathrm{HF}$ was added to the powder. The beaker was tilted slightly and rotated so the solution captured any powder that was on the inside wall 
of the beaker. The solution and powder was left on a hot plate at $80^{\circ} \mathrm{C}$ for at least 8 hours with the cap securely screwed on in order to assist complete digestion. Then the cap was removed and the solution was allowed to dry down completely which was accomplished over approximately 36 hours. Then $1 \mathrm{~mL}$ of $6 \mathrm{~N} \mathrm{HCl}$ was added to the beaker and dried down on the hot plate at $80^{\circ} \mathrm{C}$. When dry, $1 \mathrm{~mL}$ of $8 \mathrm{~N} \mathrm{HNO}_{3}$ was added to the beaker and dried down on the hot plate. The final step of digestion is completed by adding $6 \mathrm{~mL}$ of $8 \mathrm{~N} \mathrm{HNO}_{3}$ to the beaker and capping it securely for at least 8 hours. This step is also referred to as "picking up" the sample. The solution is ultimately transferred to a clean $250 \mathrm{~mL}$ Nalgene high-density polyethylene screw-top bottle.

A 50mL 50ppb Ge internal spike was added to the solution with an autodispenser, which was then diluted with double distilled water (low blank?) 2500 times (first batch) or 2000 times (second batch). The diluted samples were shaken to homogenize the solution and then transferred to leached $15 \mathrm{~mL}$ centrifuge tubes for analysis on a Finnegan Element2 ICP-MS. Analyses of five samples (list-table?) were performed in the Trace Element Analysis Facility on Florida International University (MMC) campus.

Six USGS standards (BIR-1, DNC-1, QLO-1, AGV-1, BHVO-1, W-2) were analyzed to create a calibration curve, which was used to correlate the sample data with the intensities measured by the ICP-MS. The internal Ge standard was used to normalize the measured intensities and correct for instrument drift, variations in sample introduction, or other measurement inconsistencies. 
A2.2. Procedures for preparation for isotope analyses

\section{A2.2.1. Procedure to clean savillex beakers for isotope analyses}

Some savillex beakers were reused and were thoroughly brushed and rinsed until no sample remained. The beakers and lids were placed in $1000 \mathrm{~mL}$ pyrex beaker of $\mathrm{HCl}$ on a hot plate. The temperature was increases until the acid was boiling, but not too vigorously (as a safety precaution). The acid and beakers boiled for approximately one hour, then the hot plate was turned off to let the pyrex cool to the touch. Savillex beakers and lids were removed one at a time with Teflon tongs and placed in a large rinse container. The container was filled with deionized water and emptied and repeated many times (at least three times). Savillex beakers were then placed in $\mathrm{HNO}_{3}$ and boiled in the same manner as the $\mathrm{HCl}$ for approximately an hour. Then they were removed one at a time with tongs and placed in the large rinse container again. The container was filled with deionized water and emptied many times (at least three times). Finally, each savillex beaker and lid was rinsed with DI, DD, Quartz water (three rinses each) and one rinse with $2 \mathrm{~B}$ water. Beakers were dried completely before starting the leaching process. A2.2.2. National High Magnetic Field Laboratory (NHMFL) column separation methods

\section{Pb columns}

COLUMNS: The $\mathrm{Pb}$ columns are made by heating Teflon tubes. The top of the column is wider for introduction of $\sim 1 \mathrm{~mL}$ of sample solution and the lower thin portion holds the resin (100 $\mu \mathrm{L}$ of AG1-X8 100-200 mesh). The clean columns are stored in QD water and rinsed when the samples are ready to be loaded. A small quantity of QD is left in the wider portion to help keep air bubbles from becoming trapped in the resin. Then the resin is introduced to the columns using a pipette, making sure the thin portion fills 
evenly and has no air bubbles. The resin is discarded in the trash after each run and added from the reserve of new resin.

\section{Dissolution for $\mathbf{P b}$ columns}

Weigh $200 \mathrm{mg}$ of sample into a clean savillex beaker.

Add 7-8 mL of concentrated $\mathrm{HF}: \mathrm{HNO}_{3}(3: 1)$ to dissolve the powder.

Close the cover tightly and leave the beaker on the hot plate overnight at $120^{\circ} \mathrm{C}$.

After at least 8 hours, remove the cap and dry the solution at $100^{\circ} \mathrm{C}$

When completely dry, add $1 \mathrm{~mL}$ of concentrated $\mathrm{HNO}_{3}$ and dry the solution at

$100^{\circ} \mathrm{C}$.

Repeat the $\mathrm{HNO}_{3}$ addition two more times.

Add $1 \mathrm{~mL}$ of $6 \mathrm{~N} \mathrm{HCl}$ and dry the solution at $100^{\circ} \mathrm{C}$.

Repeat the $\mathrm{HCl}$ addition one more time.

Add $1 \mathrm{~mL}$ of $9 \mathrm{~N} \mathrm{HBr}$ and dry the solution at $100^{\circ} \mathrm{C}$.

Repeat the $\mathrm{HBr}$ step two more times.

When dry, remove the beakers from the hot plate.

When cool and ready to start column chemistry, add $0.5-1 \mathrm{~mL}$ of Solution A (see below).

Ultrasonicate beakers for 30 minutes.

Transfer solution to centrifuge tubes and centrifuge for 2-3 minutes.

Load the sample from the centrifuge tube into the clean and conditioned $100 \mu \mathrm{L}$ Anion resin column following the guidelines on the "Pb column" excel worksheet. 
Solutions used during $\mathrm{Pb}$ column chemistry:

Solution A: $7 \mathrm{~mL} \mathrm{H}_{2} \mathrm{O}+1 \mathrm{~mL} 2 \mathrm{~N} \mathrm{HBr}+2 \mathrm{~mL} 2.5 \mathrm{~N} \mathrm{HNO}_{3}$

Solution B: $7.85 \mathrm{~mL} \mathrm{H} \mathrm{H}_{2} \mathrm{O}+0.15 \mathrm{~mL} \mathrm{HBr}+2 \mathrm{~mL} 2.5 \mathrm{~N} \mathrm{HNO}_{3}$

The $\mathrm{Hf} / \mathrm{Sr} / \mathrm{Nd}$ fraction must be collected from the $\mathrm{Pb}$ columns and converted for the $\mathrm{Hf}$ columns as follows:

Dry down the collected solution at $100^{\circ} \mathrm{C}$.

Add $3-4 \mathrm{~mL}$ of $6 \mathrm{~N} \mathrm{HCl}$ and dry down at $100^{\circ} \mathrm{C}$.

Add $2-3 \mathrm{~mL}$ of $3 \mathrm{~N} \mathrm{HCl}$ and dry down at $100^{\circ} \mathrm{C}$.

The $\mathrm{Pb}$ fraction solution is dried down at $100^{\circ} \mathrm{C}$ and is then ready for analysis. To analyze on the Neptune, $200 \mu \mathrm{L}$ of $2 \% \mathrm{HNO}_{3}$ is added.

\section{Hf columns}

The technique is based on Munker et al, 2001, "Separation of high field..." G-cubed, vol. 2, doi: 10/1029:2001GC000183

Column Preparation for Hf chemistry (written by Michael Bizimis)

The columns are made from Teflon and ordered directly from Savillex. I use the $1 / 4$ inch ID tube on a $30 \mathrm{~mL}$ reservoir. The length of the column stem is $\sim 10 \mathrm{~cm}$. I use 1.2 $\mathrm{mL}$ of Ln resin from Eichrom (http://www.eichrom.com/products/parts/lnresin.cfm) part\# LNB50-A. I put the resin in a large beaker and rinse it with water a few times. Then I use a pipette to fill the column to the desired length (I close the end of the column with polyethylene frits). With an ID of $1 / 4$ inch, I use $4 \mathrm{~cm}$ resin bed. It settles down fast so just add water on top for pressure and tap the column; do NOT try to compact it like the 
old HDEHP REE columns. When I have the right length, I cap the column with anion resin, use a coarse size as in the $\mathrm{Pb}$ chemistry, which settles down fast. I use $\sim 1 / 2 \mathrm{~cm}$ length to make sure the resin is not stirred when I put in the acids.

Dissolution (if not done already)

Dissolve sample in $\mathrm{HF}: \mathrm{HNO}_{3}(3: 1)$

After the sample is dissolved, dry down gently at $100-120^{\circ} \mathrm{C}$ and redissolve in 3-4 $\mathrm{mL} 6 \mathrm{~N} \mathrm{HCl}$. It is good to cup the beaker when heating on a hot plate and sonicate in order to attack all fluorides. For basalts, this results in a clear solution most of the time. Repeat the $6 \mathrm{~N} \mathrm{HCl}$ step two more times.

If the dissolution was done as described immediately above, skip these conversion steps. However if $\mathrm{Hf} / \mathrm{Sr} / \mathrm{Nd}$ fraction was collected from the $\mathrm{Pb}$ columns (previous pages), the solution must be converted before the following Hf chemistry is done. The conversion steps are:

*Dry down solution collected from the Pb columns (the first five Soln A steps after conditioning)

*Add $4-5 \mathrm{~mL}$ of $6 \mathrm{~N} \mathrm{HCl}$ and dry down at $100-120^{\circ} \mathrm{C}$

*Add $2-3 \mathrm{~mL}$ of $3 \mathrm{~N} \mathrm{HCl}$ and dry down at $100-120^{\circ} \mathrm{C}$

*Add $3 \mathrm{~N} \mathrm{HCl} /$ Ascorbic acid as per procedure below.

Samples are loaded on the Ln-resin columns in a solution of 2-5 mL 3N $\mathrm{HCl} / 0.1 \mathrm{M}$ ascorbic acid. The amount of solution depends on the sample dissolved. I use $5 \mathrm{~mL}$ for $100 \mathrm{mg}$ of sample, $2 \mathrm{~mL}$ for $10-15 \mathrm{mg}$ (when I measure IDs), $10 \mathrm{~mL}$ for $300-$ 
500mg. Ascorbic acid is used to reduce $\mathrm{Fe}^{3+}$ to $\mathrm{Fe}^{2+}$ and to decrease the compatibility of $\mathrm{Fe}^{3+}$ in the resin. Because ascorbic acid breaks down in acid solutions after a couple of days, you cannot keep this mixed acid for a long time. So this is how I make it:

- For every batch of samples, I make $1 \mathrm{M}$ ascorbic acid in QD water. The mole weight of ascorbic is 176.14 grams so I dissolve 1.7614 grams in QD water in 10 grams total solution weight (use a $15 \mathrm{~mL}$ savillex beaker). The solution clears out in about 10-20 minutes in the sonic bath or shaking helps too.

Put $4.75 \mathrm{~mL} 3 \mathrm{~N} \mathrm{HCl}$ in the sample, and make sure it is dissolved. Then add 0.25 $\mathrm{mL}$ of $1 \mathrm{M}$ ascorbic acid, which gives $\sim 5 \mathrm{~mL} 3 \mathrm{~N} \mathrm{HCl} / 0.1 \mathrm{M}$ ascorbic acid. Before the ascorbic acid is added, the solution should be yellow/green but when the ascorbic acid is added and centrifuged, the solution should turn nearly white or very light blue. The color depends on the chemistry too because pyroxenes remain green-blue because of $\mathrm{Cr}-\mathrm{Ni}$. For samples with higher Fe content more ascorbic acid can be added accordingly. If you use more or less volume of the loading acid, adjust the ascorbic acid accordingly.

Samples are then centrifuged and loaded on the Hf columns. Separation is done and collected according to the "Hf column" Excel worksheet. This chemistry is not too sensitive to the exact volume of the resin. As long as the resin bed is $4 \mathrm{~cm}$, the calibration stays constant.

After the separation steps, the $\mathrm{Hf}$ fraction is collected and dried down at $120^{\circ} \mathrm{C}$. There will be a small spot on the inside of the beaker, which is the Hf sample. It is better to keep these samples in a small amount of (diluted) $\mathrm{HNO}_{3}$ acid until ready to analyze on 
the ICPMS. The location of the small spot is outlined on the outside of the beaker so that you know where to pipette the sample when ready. Then $1-2 \mathrm{~mL}$ of (diluted) $\mathrm{HNO}_{3}$ acid is added to the top of the sample, the beaker is capped and stored.

\section{$\underline{\text { Notes }}$}

The critical step for running Hf on the ISOLAB is the $\mathrm{Zr} / \mathrm{Hf}$ separation, but ICP machines are more forgiving on how much $\mathrm{Zr}$ is in the Hf cut. Also, you must keep a close eye on the Yb-Lu that might stay in the column and becomes mobilized with Hf. If

you have too much $\mathrm{Yb}$-Lu and your correction is more than $50 \mathrm{ppm}$ on the ${ }^{176} \mathrm{Hf} /{ }^{177} \mathrm{Hf}$, then rerun the sample on the column by loading in $6 \mathrm{~N} \mathrm{HCl}$, then $20 \mathrm{~mL} 6 \mathrm{~N} \mathrm{HCl}$ and then $6 \mathrm{~mL} 6 \mathrm{~N} \mathrm{HCl} / 0.2 \mathrm{~N} \mathrm{HF}$. This takes care of any possible Yb-Lu.

Titanium: The more Ti in the sample, the more Citric/ $\mathrm{HNO}_{3} / \mathrm{H}_{2} \mathrm{O}_{2}$ acid you will need. You can adjust the volume by making sure that all of the orange $\mathrm{Ti}-\mathrm{H}_{2} \mathrm{O}_{2}$ complex is gone through the column and then add another $20 \mathrm{~mL}$ on top of that.

LONGEVITY: You can run the resin 4-5 times, but after that the columns become unpredictable. Others can run the columns more than ten times before changing the resin.

NOTE: For the mixed acids containing Citric acid, I have a stock 0.5M Citric acid in $\mathrm{QD}$ water and make the mixed acids as needed. The $0.5 \mathrm{M}$ Citric is made from pure Citric acid powder in a 1L bottle (mole weight of Citric acid: 192.14 grams). I normally make $0.5 \mathrm{~L}$ of Citric acid because it's easier to weigh $(48.035 \mathrm{~g}$ Citric acid powder in $500 \mathrm{~mL}$ total solution weight).

Cation Columns (Sr, REEs)

Sample conversion of Sr/REE fraction from Hf columns to Cation columns 
Collect the $\mathrm{Sr} / \mathrm{REE}$ fraction (as $5 \mathrm{~mL}$ of $3 \mathrm{~N} \mathrm{HCl} / 0.05 \mathrm{M}$ Ascorbic acid) from the Hf column and dry down at $100^{\circ} \mathrm{C}$.

Add $\sim 0.5 \mathrm{~mL}$ concentrated $\mathrm{HNO}_{3}$ and $\sim 0.5 \mathrm{~mL}$ of $\mathrm{HClO}_{4}$.

Dry on hot plate at $100^{\circ} \mathrm{C}$ for about 2 hours then turn up the heat to just under $150^{\circ} \mathrm{C}$ for $0.5-1$ hour (to boil off the perchloric acid, which fumes) and dry down.

Add 3-4 $\mathrm{mL}$ of $7 \mathrm{~N} \mathrm{HNO}_{3}$ and dry down at $120^{\circ} \mathrm{C}$.

Add $\sim 10 \mathrm{~mL}$ of $6 \mathrm{~N} \mathrm{HCl}$ and dry down at $125^{\circ} \mathrm{C}$ if overnight, or $140^{\circ} \mathrm{C}$ if day time. Add $2-3 \mathrm{~mL}$ of $2.5 \mathrm{~N} \mathrm{HCl}$ and dry down at $125^{\circ} \mathrm{C}$.

NOTE: If a film of moisture develops on inside of beaker at the last stage of drying down, a few mLs of that acid (usually the $\mathrm{HCl}$ ) needs to be added to bring the micro-droplets to the base where they can evaporate. Otherwise, the upper walls of the beakers do not get hot enough to completely evaporate the acid and it's not a good idea to just let the dried sample cook. Pipette tips can be used to collect these microdroplets into larger drops and suck them out before they fall back into the beaker.

\section{Chemical Procedure for Sr, Nd and Sm Separation}

A two column procedure is used. On the first, the Sr and REEs are separated from other metals. On the second column, the REEs are separated from one another.

\section{Sample Preparation (if coming from the Hf columns, follow the conversion steps above and start at step 9 with the dry beaker)}

1. Weigh $50-100 \mathrm{mg}$ of sample powder into a dry clean beaker. Weigh in the spike. 
2. Add about $5-7 \mathrm{~mL}$ of $\mathrm{HF}: \mathrm{HClO}_{4}(4: 1)$ dissolution mix. It's good practice to add this slowly, making sure any powder clinging to the sides of the beakers get washed down completely. Keep the squirt bottle at a distance from the beaker so the squirt bottle does not get contaminated from splashing sample.

3. Put the covers on the beakers and close them tightly. Leave them overnight on the hot plate at $\sim 125^{\circ} \mathrm{C}$.

4. The next day, remove the covers and let the solutions evaporate. Dry at a lower temperature at first, then increase it to $250^{\circ} \mathrm{C}$ to remove all the perchloric acid, especially the drops condensed on the side of the beakers.

5. Add about $3 \mathrm{~mL}$ of $6.2 \mathrm{~N} \mathrm{HCl}$, washing down the beaker sides.

6. Evaporate to dryness.

7. Repeat $6.2 \mathrm{~N} \mathrm{HCl}$ step two more times to ensure removal of all perchloric acid.

8. Remove the beakers from the hot plate to cool off.

9. Add $0.2 \mathrm{~mL}$ of $2.5 \mathrm{~N} \mathrm{HCl}$ to the beakers and let them sit for about $30-60$ minutes to assure the dissolution of the entire dry sample.

10. Pour the solutions into clean centrifuge tubes and rinse the remainder from the beakers with small additional quantities of $2.5 \mathrm{~N} \mathrm{HCl}$ into the tubes.

11. Centrifuge them for 2 minutes until the solution is clear.

\section{Sr Column (or "First column" - separates Sr and REEs)}

The first column consists of a $0.5 \mathrm{~cm}$ diameter $\mathrm{x} 19 \mathrm{~cm}$ height volume of cleaned (in $6.2 \mathrm{~N}$ HCl) Dowex AG50WX-8 (200-400 mesh) cation exchange resin obtained from Bio-Rad laboratories. 
The cation columns are cleaned with $30 \mathrm{~mL} 6.2 \mathrm{~N} \mathrm{HCl}$ and stored in $2-5 \mathrm{~mL}$ of $6.2 \mathrm{~N} \mathrm{HCl}$ and they need to be converted to $2.5 \mathrm{~N} \mathrm{HCl}$ for sample processing. The $6.2 \mathrm{~N} \mathrm{HCl}$ is drained then the resin is backwashed with $2.5 \mathrm{~N} \mathrm{HCl}$. A savillex beaker is filled with $\sim 8$ $10 \mathrm{~mL}$ of $2.5 \mathrm{~N} \mathrm{HCl}$ and the end of the column is placed in it. A "vacuum hand pump?" is attached to the top of the column and used to draw the $2.5 \mathrm{~N} \mathrm{HCl}$ up into the column through the bottom. The resin rises to the wider portion of the column so when it expands it does not shatter the quartz glass. Then the resin separates and slowly settles to the bottom again. When the vacuum is removed the acid drips back out the bottom into a waste beaker.

\section{Sample processing}

1. Load the sample by pipette in $0.25 \mathrm{~mL}$ of $2.5 \mathrm{~N} \mathrm{HCl}$ and wash with three aliquots of $0.25 \mathrm{~mL} 2.5 \mathrm{~N} \mathrm{HCl}$ (totaling $1 \mathrm{~mL}$ ).

2. Add $18 \mathrm{~mL}$ of $2.5 \mathrm{~N} \mathrm{HCl}$ (in two steps because the columns only hold a maximum of $12 \mathrm{~mL}$ ). This fraction is discarded. (Alkalis?)

3. Add $5.5 \mathrm{~mL}$ of $2.5 \mathrm{~N} \mathrm{HCl}$ for $\mathrm{Sr}$ collection. Collect this in small beaker. Set on a hotplate to dry down overnight.

4. Add $3.5 \mathrm{~mL}$ of $6.0 \mathrm{~N} \mathrm{HCl}$ and discard (this conditions the columns for REE collection).

5. Add $4.5 \mathrm{~mL}$ of $6.0 \mathrm{~N} \mathrm{HCl}$ for REE collection. Collect this in another small beaker and set on hot plate to dry down overnight.

\section{Column cleaning}


- A total of three times, fill columns with $12 \mathrm{~mL}$ of $6 \mathrm{~N} \mathrm{HCl}$ (let acid "dome" at the top) and let them drain completely. Adding $15 \mathrm{~mL}$ of DI water to the waste beaker helps dilute the acid as it drips and makes discarding it to the sink safer after each cleaning step.

- Put parafilm across the bottom of the column and fill with $2 \mathrm{~mL}$ of $6 \mathrm{~N} \mathrm{HCl}$ to store.

\section{Drydown after Sr column (First Column)}

\section{Alkali fraction}

Dry at $125^{\circ} \mathrm{C}$ until $\mathrm{HCl}$ has evaporated.

Add 1-5 drops of $20 \% \mathrm{H}_{2} \mathrm{SO}_{4}$ (depending on sample volume) and cook at $175^{\circ} \mathrm{C}$ for about 30 minutes. Increase temperature incrementally to $250^{\circ} \mathrm{C}$ over a period of one hour. Cook for 1-2 hours, turning beakers $180^{\circ}$ at some point.

Cool, then add a few drops of QD water and dry at $125^{\circ} \mathrm{C}$.

\section{Sr fraction}

Dry well-spaced samples on the hot plate at $125^{\circ} \mathrm{C}$ (overnight) until $\mathrm{HCl}$ is gone. The sample will be a small brown/yellow spot or a somewhat transparent "smudge."

Add one drop of $\mathrm{HClO}_{4}$ onto the sample spot and dry at $175^{\circ} \mathrm{C}$. Then increase the temperature incrementally to $250^{\circ} \mathrm{C}$. Cook for about 1 hour, turning the beakers $180^{\circ}$ at some point to evaporate the perchloric acid (or make quarter-turns throughout the drying).

Repeat $\mathrm{HClO}_{4}$ step twice. 
Let cool; add 2 drops of concentrated $\mathrm{HNO}_{3}$ and dry at $150^{\circ} \mathrm{C}$.

Repeat $\mathrm{HNO}_{3}$ step twice.

\section{REE fraction}

Dry samples on the hot plate at $125^{\circ} \mathrm{C}$ (overnight) until the $\mathrm{HCl}$ is gone.

Add $0.25 \mathrm{~mL}$ of $0.25 \mathrm{~N} \mathrm{HCl}$. Let them sit (or ultrasonicate) for about $30-60$

minutes to dissolve completely in order to condition them for the second column step.

\section{REE Column (or "Second column" - separates Nd from other REEs)}

The second column consists of $0.5 \mathrm{~cm}$ diameter $\mathrm{x} 10 \mathrm{~cm}$ height volume of compact column material ( $\mathrm{Ln}$ resin - same as the Hf columns). The column material is capped with $0.5 \mathrm{~cm}$ of Dowex AG1-X8 (200-400 mesh) anion resin to prevent teflon flotation.

The columns are stored in QD water so they must be conditioned for the $\mathrm{HCl}$. Load $5 \mathrm{~mL}$ of $0.25 \mathrm{~N} \mathrm{HCl}$. Use a wash bottle to add the acid directly to the resin, aiming the tip of the bottle into the opening of the thin portion of the column. Repeat this conditioning step once more.

Add $0.25 \mathrm{~mL}$ of REE sample in $0.25 \mathrm{~N} \mathrm{HCl}$ to the anion resin through the small hole in the column. Care must be taken to use a pipette tip that fits into that hole and that no air bubbles are trapped when loading. At NHMFL the largest pipette tip that fits the hole is only $200 \mu \mathrm{L}$ so the sample loading and the two wash steps were done in two steps $(200 \mu \mathrm{L}+50 \mu \mathrm{L})$

Larger volumes of acid are added next to separate the REEs. The first addition is $5.25 \mathrm{~mL}$ of $0.25 \mathrm{~N} \mathrm{HCl}$ (for Ce collection or discard). To load this volume without trapping air bubbles in the column, use a similar method as described above with the 
$200 \mu \mathrm{L}$ pipette tip. Once the $250 \mu \mathrm{L}$ are added to the column, a larger pipette tip is used for the remaining $5 \mathrm{~mL}$ of $0.25 \mathrm{~N} \mathrm{HCl}$ (this larger pipette tip can also be reused as long as it does not touch the any part of the columns).

After the Ce separation, $2.5 \mathrm{~mL}$ of $0.25 \mathrm{~N} \mathrm{HCl}$ is added to the column to collect $\mathrm{Nd}$ in a small clean beaker. The loading of this volume is via similar method as the previous step; first load $500 \mu \mathrm{L}$ with the small pipette tip, then add $2.0 \mathrm{~mL}$ using the larger pipette tip.

Cleaning the columns is done after the $\mathrm{Nd}$ has been collected. Add $10 \mathrm{~mL}$ of $6.0 \mathrm{~N}$ $\mathrm{HCl}$ using a similar method as the conditioning steps. The cleaning step is done a total of four times. The clean columns are stored in vials filled with QD water.

\section{Drydown after REE column (second column)}

\section{Nd and Sm}

Dry down at $125^{\circ} \mathrm{C}$ until acid is gone.

Add 1 drop $(\sim 0.3 \mathrm{~mL})$ of $\mathrm{HClO}_{4}$ and dry down at $175^{\circ} \mathrm{C}$. Increase the temperature incrementally to $250^{\circ} \mathrm{C}$ (or a little less) over a period of one hour. Heat for another hour, turning the beaker $180^{\circ}$ at some point to ensure all the acid dries.

Repeat $\mathrm{HClO}_{4}$ step two more times.

Cool the beaker so there are no fumes when adding the next acid.

Add 2 drops $(\sim 0.6 \mathrm{~mL})$ of concentrated $\mathrm{HNO}_{3}$ and dry at $175^{\circ} \mathrm{C}$.

Repeat $\mathrm{HNO}_{3}$ step 2 more times. 


\section{A2.2.3. NHMFL Degassing the filaments for loading Sr samples on TIMS}

- Prepare the filaments by bending a tungsten strip and soldering the ends to the contacts.

- Load the filaments into the degasser. Make sure current will flow through the series of filaments.

- Turn on the vacuum in the degasser.

- Wait until chamber reaches $<10^{-6}$ torr.

- Turn up the current slowly until the filaments reach maximum current (3.8 Amps).

- Hold the current at this maximum current for about 20 seconds.

- Turn the current down to $\sim 1$ Amp.

- Leave them at $1 \mathrm{Amp}$ for about 20 minutes. The chamber pressure will have increased from the current, but it will decrease again slowly.

- Remove the filaments when the 20 minutes is passed and the pressure is $<10^{-6}$ torr again.

- Carefully load samples and standards onto the degassed filaments using microliter pipetters.

- Load filaments into the barrel for TIMS analysis, noting the position of each sample in the barrel.

- Load the barrel into the sample chamber of the TIMS. 


\section{APPENDIX 3}

\section{A3. Thin Section Descriptions}

All thin sections described below were made from rocks that were recovered in a 1981 University of Hawai'i cruise of the Kana Keoki, and have the label "KK81-06-26" preceding the labels given below. RD63 and RD64 correspond to dredge 63 and dredge 64 , respectively. The letter "J" was an added prefix to distinguish the samples numbered in this study from some samples that were reportedly analyzed by Dr. Mark Reagan (University of Iowa). Numbers after the prefix were assigned arbitrarily, except for those that were analyzed by Dr. Reagan (even though his analyses have not been located at the time of this dissertation). Samples that were analyzed by Dr. Mark Reagan have the prefix "TS" and are numbered. Details about the corresponding TS samples can be found in the dark red notebook kept with the dredge samples in PC340.

Samples that are followed by an "*” were analyzed for isotopes as well as major and trace elements.

RD63-J01a - Feldspar + pyroxene + muscovite + amphibole + quartz (no chlorite); a few large $(0.5-0.8 \mathrm{~cm})$ grains of feldspar and pyroxene. Other areas on the slide are much finer grained, where the original minerals appear to have broken down; feldspar grains, where very coarse, have "pits" with acicular, radiating yellow/gray minerals; also gradational and irregular zoning. A semi-circular area of much finer needle-like feldspar. Muscovite is general very fine grained (probably secondary). Fractures.

RD63-J01b - Quartz (90\%), feldspar (10\%). No chlorite or amphiboles. Grain sizes vary, except for $\sim 1 / 3$ of the slide with a homogenous size of possibly all weathered quartz (also many "pores" in this area). Texture is closely interlocking and mingling of feldspar and quartz, sometimes within larger grains; In plane polarized light, quartz looks like many smaller grains, but in cross polarized light they are larger grains with clear boundaries (like subgrain texture). Feldspar looks highly deformed, very thin cleavage and not continuous. 
RD63-J07 - Plagioclase (65\%), pyroxene (35\%), trace oxides; grains are interlocking cumulus texture. Plagioclase has extensive sericitic alteration primarily at cores, but often throughout the entire mineral. Grain size varies in the slide as two different zones of larger grains and smaller grains. The boundary between the zones is gradational; the area with larger grain sizes has more pyroxene (cpx); the areas with smaller grain sizes have more orthopyroxene. Plagioclase without sericite alteration has albite twinning, and some also exhibit pericline twinning. All pyroxenes are partially altered. There are many thin veins throughout slide, filled with very fine grained clays (which cut through minerals or not?).

RD63-J15a* - Plagioclase (40\%), quartz (55\%), minor mafic minerals (3-4\%) (green hornblende, chlorite), oxides (1-2\%); interlocking texture. Some of the feldspar (plagioclase) grains have oscillatory zoning, especially in the larger grains; some have albite twinning and/or pericline twinning as well. Most quartz grains are smaller than the feldspar. Purple chlorite is found near some of the green hornblende. A vein through the middle of the slide is filled with pyroxenes (cpx and minor opx).

RD63-J19 - Plagioclase (60\%), quartz (5\%), amphibole (7\%), pyroxene (28\%), trace oxide $(<1 \%)$. Most plagioclase grains are subhedral, with some boundaries reacting with adjacent minerals. Other plagioclase grains have albite twinning at their core surrounded by a zone with oscillatory extinction. There are grains with the same zone of oscillatory extinction without the albite twinning. All plagioclase cores are highly fractured, but fractures do not extend into the oscillatory zone. A few percent of the plag grains are almost completely replaced by clay/sericite. Based on birefringence colors $\left(1^{\text {st }}\right.$ order yellows) the opx is enstatite, though the grains are degraded and there has been some remineralization mostly around the rims (in some, remineralization is throughout the grain). Some opx grains are partially euhedral but with some boundaries showing reaction with adjacent minerals. These grains tend to show twinning also. Other opx grains are subhedral. The pyroxenes and (few, small) amphiboles are weakly pleochroic. The quartz grains are altered and have uneven extinction. Within the grains, there are 
short filled fractures and a small fraction have inclusions that have medium to high relief and second order birefringence colors.

RD63-J20 - Quartz/feldspar 65/35\% (no minor minerals). Granophyric texture in 40-45\% of the slide. Fairly coarse grained. Feldspar grains have some sericitic alteration and pericline twinning (fewer have albite twinning and tend to be smaller), also quartz intergrowths. One thick and one thinner fracture filled with opx ( $\sim$ straight extinctions). There are other thin fractures throughout the sample.

RD63-J23* - Plagioclase (60-70\%), quartz (15-20\%), pyroxene (7-10\%), trace oxides $(<1 \%)$. Plagioclase grains are long and lath-like, subhedral grains with degraded cores; outside of the core has oscillatory extinction; the pyroxene (hypersthenes and enstatite) have second order birefringence colors (blue, purple and orange) and are anhedral with no original borders, with reaction with adjacent minerals; quartz grains in most of the slide have oscillatory extinction but show very little degradation. There are very short fractures in these quartz grains. There are areas with very large quartz grains with subgrain alteration; these large quartz grains are surrounded by plag and opx that are larger than the average size in the rest of the slide.

RD63-J24 - Quartz /alkali feldspar/plagioclase 40/40/20\% + muscovite $<1 \%$; plagioclase grains are "grungy;" most have albite twinning and some have slight sericitic alteration. In contrast, the alkali feldspar are clear, gray single grains. Quartz has subgrain texture; some are grungy like the plagioclase; colors vary between yellowish to gray. Grain sizes are fairly consistent and homogeneous: plagioclase grains are slightly smaller than other minerals; a few very thin fractures.

RD63-J29* - Plagioclase/amphibole $\sim 50 / 50 \%+$ oxides $\sim 5 \%$; interlocking texture. Several zones of coarser grains have higher feldspar/amphibole ratios $(\sim 75 / 25 \%)-$ corresponds to the lighter/whiter areas in the hand sample. A few feldspar grains have albite twinning; most have core alteration; a few feldspar grains are elongated, have faint cores that are exhibit a sieve texture. Amphibole grains range in size, generally smaller 
than the feldspar grains; some show $60^{\circ} / 120^{\circ}$ cleavage and are elongate/bladed; most are very anhedral and small with moderate relief.

RD63-J32* - Feldspar/amphibole $\sim 50 / 50 \%+$ oxides $\sim 1 \%+$ minor quartz; interlocking texture. Same as J29, but generally coarser and with less oxides; homogenous throughout the slide. Feldspar is mostly plagioclase with zoning, but possibly some alkali feldspar also (no zoning, no cores, and larger) - ratio of plagioclase/alkali feldspar $\sim 70 / 30 \%$. A few very thin fractures, most are not filled (or with epoxy); one of the thicker fractures may be filled with sericite.

RD63-J30 - Feldspar 60-65\% + muscovite 15\% + chlorite 10\% + quartz 10\% + brown amphibole $<5 \%$; feldspar has sieve textures; a few grains look like cpx/muscovite: bladed and twinned (high blue-red birefring colors, green in pp and pleochroic); amphiboles have good cleavage, edges often in reaction with muscovite.

RD63-J33a - Feldspar/pyroxene 50/50\% + amphibole (these are the primary minerals). Coarse grained sample. Pyroxenes have been partially replaced with.. mica or chlorite. They are fractured; some appear to maintain subhedral habits. Feldspar has some sericitic alteration; some grains have albite twinning. Possibly some alkali feldspar.

RD63-J34* - Plagioclase + amphibole + muscovite + oxides + quartz + purple chlorite; interlocking texture. This slide resembles J32; several thick fractures filled with sericite. Most feldspar grains have sieve textures in their cores, and untwinned rims. Smaller plagioclase grains are zoned, some have albite twinning, either with a very thin or no rim. One large plagioclase grain in particular: large, fractured sieve texture core with a thinner rim that has albite twinning. Green amphiboles look recrystallized and are small with no clear habit; often found with purple chlorite.

RD63-J35 - Feldspar + unaltered pyroxene + chlorite; this slide is somewhat coarser grained than others. Feldspar has sericitic alteration, but less than what is present in J07. 
Serpentine or chlorite replacement in pyroxenes. Relict twinned pyroxenes. Albite twinning is common in feldspar grains.

RD63-J40* - Na-Plagioclase/quartz $\sim 45 / 45 \%+$ chlorite $5 \%+$ oxides $<1 \%$; granophyric texture; coarse grained (but hard to tell original grain sizes), many thin fractures (squiggly); thicker fractures are not squiggly; some feldspar grains have albite twinning

RD63-J41 - Na-plagioclase/quartz 50/50\% + minor chlorite 5\%; Same as J40.

Granophyric texture, some cases are textbook. Feldspar has some sericitic alteration, some albite twinning more often than just twinned. Green amphiboles are small with poor habit (possibly secondary or just badly altered). Quite a few thin fractures, some filled with fine-grained brown mineral (clay?). Appears medium grained but hard to tell because of the overprinted texture.

RD63-J43 - Na-plagioclase/quartz $~ 45 / 45 \%+$ chlorite $5 \%+$ oxides $<1 \%$; Same as J40; granophyric texture; coarse grained-hard to tell; a thick fracture filled with sericite? Some feldspar grains have euhedral/subhedral cores; some feldspar grains with albite and/or pericline twinning; a spot with a missing grain, surrounded by amphibole.

RD63-J45* - Na-plagioclase/quartz $\sim 45 / 45 \%+$ chlorite $5 \%+$ oxides $<1 \%$; Same as J40; granophyric texture; coarse grained-hard to tell; a thick fracture filled with sericite? Some feldspar grains have euhedral/subhedral cores; some feldspar grains with albite and/or pericline twinning; a spot with a missing grain, surrounded by amphibole.

RD64-J49 - Feldpar 65\% + opx 30\% + phenocrysts 5-10\% + cpx $<5 \%$; Serpentinized euhedral/subhedral olivine phenocrysts; feldspar and opx phenocrysts are often clustered, subhedral/anhedral; most matrix is the same grain size; some circular areas in the slide (the size of other phenocrysts) have less opx/amphibole and larger plagioclase grains; some areas where cpx? is bladed; opx/amphibole in the matrix is grungy 
RD64-J55* - Feldspar (40\%), quartz (35\%), amphibole (10-20\%), pyroxene (5-10\%), mica (1\%), oxides (1-2\%); large euhedral feldspar grains have gradational zoning, large cores, thin rim OR oscillatory zoning (oscillations in the core, rim is much thinning, encompasses several cores); smaller feldspar grains have regular core/rim zoning; cpx/opx, amphiboles, muscovite appear to be chloritized.

RD64-J57 - Feldspar 50-60\% + cpx 30\% + amphibole 10\%; Feldspar is subhedral with sieve textures (rims are intact); exhibit gradational zoning, especially in the rims; some feldspar grains have three zones: altered core and 2 "rims." Amphiboles are elongate and bladed, some are reacting with adjacent feldspar: some show twinning? Are they secondary? Relatively thick vein filled with feldspar, but a thinner vein of finer grained plagioclase runs through its middle

RD64-J58* - 10\% quartz, 20\% feldspar, 70\% ferromagnesian, oxides $2 \%$; glomerocrysts and phenocrysts present in the matrix, probably serpentinized pyroxenes (relict parallel fractures in center of grains); feldspar grains are very weathered and anhedral; oxides are present within areas of chlorite mineralization [similar mineralogy as RD64-J49]

RD64-J60 - coarse grained, diorite. Feldspar has few occurrences of albite twinning, the outlines of former grains as completely different extinctions; pyroxenes; sample is highly fractured with fractures running through most grains; large amphibole and feldspar grains exhibit poikolitic texture where the smaller grains are anhedral feldspar; large cpx grains are ophitic to subophitic

RD64-J65* - Feldspar + muscovite $+\mathrm{opx}+\mathrm{cpx} \%$; reaction rims around the mafic minerals; a yellow/gray mineral that grew in an acicular, radial pattern; medium grained. 


\section{APPENDIX 4}

A4. Bulk rock geochemical and isotopic analyses of samples in this study

A4.1. Major and trace elements analyses by XRF and ICPMS (as noted)

\begin{tabular}{|c|c|c|c|c|c|c|c|c|c|c|c|}
\hline \multicolumn{12}{|c|}{ Measured by XRF (wt\%) } \\
\hline $\begin{array}{l}\text { Norm } \\
\text { Lith }^{\mathrm{c}}\end{array}$ & Gbr & Ton & Gbr & Gbr & QDior & QDior & Ton & Dior & Ton & Ton & Gbr \\
\hline Dredge & RD63 & RD63 & RD63 & RD63 & RD63 & RD63 & RD63 & RD63 & RD63 & RD63 & RD63 \\
\hline Sample & J07 & J15 & J19 & $\mathrm{J}^{2} 2^{\mathrm{a}}$ & $\mathbf{J} 23$ & J27 & $\mathrm{J} 28$ & J29 & J32 & J34 & J35 \\
\hline $\mathrm{SiO}_{2}$ & 46.87 & 73.08 & 56.31 & 49.32 & 62.92 & 60.29 & 73.39 & 57.74 & 63.48 & 60.87 & 47.85 \\
\hline $\mathrm{TiO}_{2}$ & 0.054 & 0.183 & 0.257 & 0.038 & 0.159 & 0.181 & 0.193 & 0.171 & 0.144 & 0.334 & 0.035 \\
\hline $\mathbf{A l}_{2} \mathbf{O}_{3}$ & 17.38 & 13.90 & 18.53 & 22.02 & 15.65 & 17.75 & 14.01 & 17.56 & 15.83 & 17.24 & 22.25 \\
\hline $\mathrm{FeO}_{\mathrm{T}}^{\mathrm{b}}$ & 6.36 & 3.75 & 4.79 & 4.65 & 6.27 & 6.18 & 2.98 & 7.83 & 5.61 & 8.01 & 6.31 \\
\hline $\mathrm{MnO}$ & 0.143 & 0.018 & 0.058 & 0.090 & 0.086 & 0.076 & 0.013 & 0.130 & 0.099 & 0.085 & 0.119 \\
\hline MgO & 9.00 & 0.68 & 6.31 & 7.18 & 3.23 & 3.10 & 0.76 & 3.89 & 3.54 & 2.27 & 6.90 \\
\hline $\mathrm{CaO}$ & 12.05 & 3.10 & 8.21 & 13.44 & 6.39 & 6.61 & 2.15 & 7.78 & 5.82 & 6.03 & 13.12 \\
\hline $\mathrm{Na}_{2} \mathrm{O}$ & 1.08 & 4.38 & 4.85 & 1.18 & 4.38 & 4.37 & 5.20 & 3.67 & 4.08 & 3.60 & 1.19 \\
\hline $\mathbf{K}_{2} \mathbf{O}$ & 2.16 & 0.19 & 0.27 & 0.54 & 0.37 & 0.36 & 0.23 & 0.34 & 0.37 & 0.40 & 0.37 \\
\hline $\mathbf{P}_{2} \mathbf{O}_{5}$ & 0.007 & 0.053 & 0.018 & 0.012 & 0.030 & 0.027 & 0.057 & 0.030 & 0.025 & 0.091 & 0.005 \\
\hline Sum & 95.11 & 99.35 & 99.61 & 98.46 & 99.49 & 98.93 & 98.98 & 99.15 & 99.01 & 98.92 & 98.14 \\
\hline LOI & 4.823 & 0.778 & 1.928 & 1.918 & 0.800 & 19.503 & 0.862 & 0.959 & 1.263 & 0.979 & 2.437 \\
\hline \multicolumn{12}{|c|}{ Measured by ICPMS (ppm) } \\
\hline $\mathbf{R b}$ & 44.1 & 3.9 & 3.9 & 10.8 & 7.6 & 6.3 & 4.1 & 4.3 & 6.4 & 6.9 & 7.4 \\
\hline $\mathbf{S r}$ & 183 & 149 & 259 & 173 & 132 & 215 & 151 & 144 & 159 & 165 & 195 \\
\hline $\mathbf{Y}$ & 1.69 & 5.30 & 2.50 & 0.97 & 7.59 & 5.33 & 8.28 & 6.94 & 5.33 & 5.87 & 0.79 \\
\hline Sc & 54.7 & 14.0 & 38.0 & 33.7 & 30.4 & 24.9 & 13.0 & 36.8 & 26.0 & 27.1 & 33.2 \\
\hline $\mathbf{Z r}$ & 6 & 56 & 17 & 5 & 59 & 43 & 74 & 51 & 52 & 41 & 3 \\
\hline $\mathbf{N b}$ & 0.16 & 0.90 & 0.38 & 0.09 & 0.99 & 0.64 & 1.36 & 0.56 & 0.87 & 0.73 & 0.04 \\
\hline Cs & 0.12 & 0.18 & 0.07 & 0.06 & 0.13 & 0.15 & 0.10 & 0.12 & 0.09 & 0.17 & 0.06 \\
\hline $\mathbf{B a}$ & 92 & 50 & 20 & 33 & 55 & 36 & 51 & 41 & 47 & 39 & 14 \\
\hline La & 0.36 & 2.25 & 0.74 & 0.37 & 3.30 & 2.05 & 2.59 & 2.29 & 2.45 & 2.51 & 0.21 \\
\hline $\mathrm{Ce}$ & 0.81 & 4.15 & 1.56 & 0.66 & 7.40 & 3.68 & 5.21 & 4.41 & 4.78 & 4.76 & 0.39 \\
\hline Pr & 0.13 & 0.60 & 0.23 & 0.09 & 1.14 & 0.54 & 0.78 & 0.64 & 0.65 & 0.69 & 0.06 \\
\hline Nd & 0.58 & 2.54 & 0.94 & 0.39 & 4.63 & 2.30 & 3.52 & 2.78 & 2.67 & 3.06 & 0.25 \\
\hline Sm & 0.18 & 0.64 & 0.27 & 0.11 & 1.06 & 0.60 & 1.02 & 0.81 & 0.67 & 0.80 & 0.07 \\
\hline $\mathbf{E u}$ & 0.08 & 0.28 & 0.14 & 0.07 & 0.23 & 0.24 & 0.28 & 0.24 & 0.17 & 0.31 & 0.07 \\
\hline Gd & 0.22 & 0.73 & 0.32 & 0.13 & 1.08 & 0.70 & 1.13 & 0.95 & 0.71 & 0.95 & 0.10 \\
\hline $\mathbf{T b}$ & 0.04 & 0.13 & 0.06 & 0.02 & 0.19 & 0.13 & 0.20 & 0.17 & 0.13 & 0.16 & 0.02 \\
\hline Dy & 0.28 & 0.86 & 0.41 & 0.17 & 1.19 & 0.81 & 1.33 & 1.16 & 0.85 & 1.04 & 0.12 \\
\hline Но & 0.06 & 0.19 & 0.09 & 0.04 & 0.27 & 0.18 & 0.29 & 0.27 & 0.19 & 0.23 & 0.03 \\
\hline $\mathbf{E r}$ & 0.20 & 0.56 & 0.28 & 0.12 & 0.83 & 0.58 & 0.87 & 0.80 & 0.62 & 0.66 & 0.09 \\
\hline Tm & 0.03 & 0.09 & 0.05 & 0.02 & 0.14 & 0.10 & 0.14 & 0.14 & 0.10 & 0.11 & 0.02 \\
\hline $\mathbf{Y b}$ & 0.23 & 0.70 & 0.34 & 0.14 & 1.00 & 0.70 & 1.04 & 1.00 & 0.77 & 0.76 & 0.13 \\
\hline Lu & 0.04 & 0.13 & 0.06 & 0.03 & 0.18 & 0.13 & 0.19 & 0.18 & 0.14 & 0.14 & 0.02 \\
\hline Hf & 0.22 & 1.64 & 0.52 & 0.15 & 1.69 & 1.25 & 2.16 & 1.53 & 1.56 & 1.22 & 0.10 \\
\hline $\mathbf{T a}$ & 0.02 & 0.09 & 0.03 & 0.01 & 0.10 & 0.06 & 0.12 & 0.06 & 0.08 & 0.06 & 0.00 \\
\hline $\mathbf{P b}$ & 0.58 & 0.47 & 0.36 & 0.40 & 0.67 & 0.53 & 0.46 & 1.04 & 0.96 & 0.74 & 0.43 \\
\hline Th & 0.06 & 0.37 & 0.12 & 0.05 & 0.34 & 0.25 & 0.42 & 0.27 & 0.34 & 0.24 & 0.03 \\
\hline $\mathbf{U}$ & 0.06 & 0.36 & 0.11 & 0.05 & 0.28 & 0.33 & 0.49 & 0.32 & 0.33 & 0.28 & 0.02 \\
\hline
\end{tabular}


(Table A4.1 con't)

Measured by XRF (wt\%)

\begin{tabular}{|c|c|c|c|c|c|c|c|c|c|c|c|}
\hline $\begin{array}{l}\text { Norm } \\
\text { Lith }^{c}\end{array}$ & Ton & Ton & Ton & Ton & Ton & Ton & Ton & Br.And & QDior & QDior & Ton \\
\hline Dredge & RD63 & RD63 & RD63 & RD63 & RD63 & RD63 & RD63 & RD64 & RD64 & RD64 & RD64 \\
\hline Sample & J36 & J39 & $\mathrm{J40}$ & $\mathrm{J} 43$ & $\mathrm{~J} 45$ & J46 & $\mathrm{J67}^{\mathrm{a}}$ & J49 & J53 & J55 & J56 \\
\hline $\mathrm{SiO}_{2}$ & 63.09 & 63.60 & 75.35 & 75.47 & 76.31 & 77.10 & 62.83 & 55.56 & 58.70 & 58.65 & 60.38 \\
\hline $\mathrm{TiO}_{2}$ & 0.160 & 0.157 & 0.131 & 0.121 & 0.152 & 0.099 & 0.262 & 0.335 & 0.376 & 0.370 & 0.321 \\
\hline $\mathbf{A l}_{2} \mathbf{O}_{3}$ & 15.58 & 16.12 & 13.50 & 12.81 & 13.13 & 12.50 & 16.09 & 13.42 & 14.89 & 16.65 & 15.63 \\
\hline $\mathrm{FeO}_{\mathrm{T}}^{\mathrm{b}}$ & 5.72 & 5.65 & 1.21 & 1.62 & 1.42 & 1.12 & 7.55 & 6.25 & 6.98 & 7.35 & 6.40 \\
\hline MnO & 0.080 & 0.076 & 0.028 & 0.019 & 0.015 & 0.025 & 0.070 & 0.116 & 0.083 & 0.096 & 0.078 \\
\hline MgO & 3.11 & 2.83 & 0.33 & 0.42 & 0.69 & 0.34 & 2.58 & 9.45 & 5.26 & 3.66 & 4.37 \\
\hline $\mathrm{CaO}$ & 6.64 & 5.06 & 1.07 & 1.97 & 2.06 & 1.89 & 4.65 & 9.43 & 7.17 & 7.01 & 8.21 \\
\hline $\mathrm{Na}_{2} \mathrm{O}$ & 3.95 & 4.43 & 6.11 & 5.76 & 5.10 & 6.02 & 4.18 & 2.31 & 3.21 & 3.64 & 3.26 \\
\hline $\mathbf{K}_{2} \mathbf{O}$ & 0.62 & 0.40 & 0.26 & 0.11 & 0.25 & 0.12 & 0.62 & 0.08 & 0.46 & 0.35 & 0.26 \\
\hline $\mathbf{P}_{2} \mathbf{O}_{5}$ & 0.029 & 0.027 & 0.044 & 0.022 & 0.047 & 0.032 & 0.045 & 0.037 & 0.053 & 0.056 & 0.053 \\
\hline Sum & 98.97 & 98.35 & 98.04 & 98.33 & 99.17 & 99.25 & 98.88 & 96.99 & 97.18 & 97.83 & 98.97 \\
\hline LOI & 0.804 & 1.504 & 1.380 & 0.872 & 0.842 & 1.015 & 1.388 & 2.583 & 2.594 & 1.394 & 1.650 \\
\hline \multicolumn{12}{|c|}{ Measured by ICPMS (ppm) } \\
\hline $\mathbf{R b}$ & 9.6 & 5.8 & 3.5 & 2.2 & 3.7 & 1.3 & 14.1 & 0.5 & 2.9 & 3.0 & 1.5 \\
\hline $\mathrm{Sr}$ & 120 & 223 & 87 & 113 & 146 & 86 & 175 & 113 & 173 & 208 & 177 \\
\hline $\mathbf{Y}$ & 7.01 & 7.08 & 6.68 & 4.24 & 2.51 & 4.99 & 5.58 & 10.26 & 10.84 & 10.53 & 9.95 \\
\hline Sc & 29.0 & 23.7 & 10.8 & 10.8 & 5.4 & 11.7 & 28.0 & 33.1 & 28.8 & 27.5 & 30.1 \\
\hline $\mathbf{Z r}$ & 62 & 47 & 78 & 73 & 106 & 94 & 51 & 27 & 46 & 46 & 44 \\
\hline $\mathbf{N b}$ & 1.05 & 0.87 & 1.18 & 0.78 & 0.73 & 0.97 & 0.84 & 0.35 & 0.51 & 0.50 & 0.49 \\
\hline Cs & 0.11 & 0.20 & 0.19 & 0.10 & 0.10 & 0.05 & 0.19 & 0.01 & 0.04 & 0.03 & 0.02 \\
\hline Ba & 120 & 50 & 27 & 30 & 54 & 23 & 47 & 8 & 17 & 13 & 13 \\
\hline La & 3.48 & 2.62 & 1.50 & 1.10 & 1.91 & 1.26 & 2.41 & 1.38 & 2.16 & 2.40 & 1.89 \\
\hline $\mathrm{Ce}$ & 7.75 & 5.79 & 2.91 & 2.02 & 2.62 & 2.20 & 4.40 & 3.83 & 5.74 & 6.14 & 4.95 \\
\hline Pr & 1.16 & 0.86 & 0.44 & 0.30 & 0.32 & 0.34 & 0.62 & 0.61 & 0.93 & 0.93 & 0.81 \\
\hline Nd & 4.51 & 3.63 & 2.04 & 1.36 & 1.18 & 1.58 & 2.63 & 3.09 & 4.45 & 4.37 & 3.87 \\
\hline Sm & 0.97 & 0.92 & 0.64 & 0.41 & 0.27 & 0.47 & 0.69 & 1.07 & 1.38 & 1.35 & 1.21 \\
\hline $\mathbf{E u}$ & 0.24 & 0.22 & 0.26 & 0.29 & 0.20 & 0.30 & 0.22 & 0.40 & 0.46 & 0.48 & 0.44 \\
\hline Gd & 1.06 & 1.03 & 0.84 & 0.47 & 0.29 & 0.57 & 0.80 & 1.44 & 1.66 & 1.61 & 1.51 \\
\hline $\mathbf{T b}$ & 0.19 & 0.18 & 0.16 & 0.09 & 0.05 & 0.10 & 0.14 & 0.27 & 0.30 & 0.28 & 0.27 \\
\hline Dy & 1.14 & 1.17 & 1.04 & 0.61 & 0.34 & 0.72 & 0.93 & 1.88 & 1.96 & 1.87 & 1.80 \\
\hline Но & 0.25 & 0.27 & 0.24 & 0.15 & 0.09 & 0.17 & 0.20 & 0.41 & 0.42 & 0.41 & 0.39 \\
\hline $\mathbf{E r}$ & 0.78 & 0.79 & 0.75 & 0.49 & 0.29 & 0.56 & 0.61 & 1.20 & 1.20 & 1.16 & 1.09 \\
\hline $\mathbf{T m}$ & 0.13 & 0.14 & 0.13 & 0.09 & 0.06 & 0.10 & 0.10 & 0.18 & 0.18 & 0.18 & 0.17 \\
\hline $\mathbf{Y b}$ & 0.94 & 0.99 & 0.99 & 0.69 & 0.46 & 0.81 & 0.74 & 1.10 & 1.16 & 1.15 & 1.07 \\
\hline $\mathbf{L u}$ & 0.17 & 0.18 & 0.19 & 0.14 & 0.10 & 0.16 & 0.14 & 0.19 & 0.19 & 0.18 & 0.18 \\
\hline Hf & 1.77 & 1.48 & 2.27 & 2.21 & 3.19 & 2.73 & 1.58 & 0.79 & 1.37 & 1.39 & 1.35 \\
\hline Ta & 0.08 & 0.08 & 0.11 & 0.09 & 0.13 & 0.12 & 0.08 & 0.02 & 0.04 & 0.04 & 0.04 \\
\hline $\mathbf{P b}$ & 0.64 & 0.49 & 0.27 & 0.43 & 0.47 & 0.37 & 0.76 & 0.46 & 0.34 & 0.29 & 0.25 \\
\hline Th & 0.38 & 0.38 & 0.49 & 0.32 & 0.64 & 0.44 & 0.31 & 0.14 & 0.24 & 0.24 & 0.24 \\
\hline $\mathbf{U}$ & 0.22 & 0.31 & 0.52 & 0.46 & 0.79 & 0.60 & 0.37 & 0.09 & 0.18 & 0.19 & 0.16 \\
\hline
\end{tabular}


(Table A4.1 con't)

Measured by XRF (wt\%)

\begin{tabular}{|c|c|c|c|c|c|c|c|c|c|c|}
\hline $\begin{array}{l}\text { Norm } \\
\text { Lith }^{\mathbf{c}}\end{array}$ & QDior & QDior & $\begin{array}{c}\text { Alt } \\
\text { Dior. }\end{array}$ & Dior & $\begin{array}{c}\text { Alt } \\
\text { Dior. }\end{array}$ & $\begin{array}{c}\text { Alt } \\
\text { Dior. }\end{array}$ & Ton & Basalt & Gbr & Ton \\
\hline Dredge & RD64 & RD64 & RD64 & RD64 & RD64 & RD64 & RD64 & USGS Std & RD63 & RD63 \\
\hline Sample & J58 & J59 & $\mathbf{J 6 0}$ & J61 & J63 & J64 & J65 & BHVO-2 & J22-R & J67-R \\
\hline $\mathrm{SiO}_{2}$ & 58.80 & 60.34 & 55.05 & 55.41 & 55.10 & 59.63 & 66.67 & 50.18 & 48.84 & 63.23 \\
\hline $\mathrm{TiO}_{2}$ & 0.300 & 0.285 & 0.140 & 0.179 & 0.106 & 0.280 & 0.354 & 2.772 & 0.032 & 0.265 \\
\hline $\mathbf{A l}_{2} \mathbf{O}_{3}$ & 14.55 & 15.02 & 5.75 & 12.62 & 4.52 & 13.38 & 14.09 & 13.76 & 21.83 & 16.20 \\
\hline $\mathrm{FeO}_{\mathbf{T}}{ }^{\mathrm{b}}$ & 6.71 & 7.18 & 7.75 & 6.59 & 8.63 & 7.39 & 6.10 & 10.99 & 4.67 & 7.73 \\
\hline MnO & 0.077 & 0.098 & 0.165 & 0.110 & 0.179 & 0.127 & 0.086 & 0.173 & 0.088 & 0.071 \\
\hline MgO & 7.14 & 5.14 & 21.93 & 10.36 & 22.65 & 5.57 & 1.12 & 7.25 & 7.11 & 2.58 \\
\hline $\mathrm{CaO}$ & 5.60 & 4.75 & 5.55 & 8.77 & 3.68 & 9.07 & 6.59 & 11.51 & 13.34 & 4.65 \\
\hline $\mathrm{Na}_{2} \mathrm{O}$ & 3.33 & 4.55 & 0.95 & 2.73 & 0.76 & 1.49 & 2.62 & 2.24 & 1.17 & 4.20 \\
\hline $\mathbf{K}_{2} \mathbf{O}$ & 0.17 & 0.20 & 0.16 & 0.51 & 0.17 & 0.02 & 0.01 & 0.52 & 0.53 & 0.63 \\
\hline $\mathbf{P}_{2} \mathbf{O}_{5}$ & 0.048 & 0.047 & 0.022 & 0.027 & 0.016 & 0.044 & 0.065 & 0.267 & 0.009 & 0.047 \\
\hline Sum & 96.72 & 97.62 & 97.47 & 97.31 & 95.82 & 97.00 & 97.70 & 99.66 & 97.63 & 99.61 \\
\hline LOI & 2.846 & 2.523 & 1.846 & 2.529 & 3.764 & 3.308 & 1.466 & & & \\
\hline \multicolumn{11}{|c|}{ Measured by ICPMS (ppm) } \\
\hline $\mathbf{R b}$ & 0.9 & 1.1 & 2.3 & 4.0 & 3.2 & 0.3 & 0.2 & 23.0 & 6.3 & 0.9 \\
\hline $\mathrm{Sr}$ & 185 & 183 & 58 & 172 & 37 & 207 & 198 & 156 & 215 & 185 \\
\hline $\mathbf{Y}$ & 10.38 & 9.03 & 3.44 & 8.81 & 3.15 & 8.66 & 14.13 & 10.68 & 5.33 & 10.38 \\
\hline Sc & 27.4 & 25.7 & 29.2 & 36.4 & 28.0 & 26.4 & 20.5 & 8.1 & 24.9 & 27.4 \\
\hline $\mathrm{Zr}$ & 40 & 46 & 15 & 28 & 12 & 40 & 68 & 84 & 43 & 40 \\
\hline $\mathbf{N b}$ & 0.45 & 0.46 & 0.20 & 0.31 & 0.16 & 0.41 & 0.67 & 1.40 & 0.64 & 0.45 \\
\hline Cs & 0.01 & 0.02 & 0.05 & 0.09 & 0.16 & 0.02 & 0.02 & 0.12 & 0.15 & 0.01 \\
\hline $\mathbf{B a}$ & 11 & 5 & 6 & 22 & 6 & 2 & 2 & 163 & 36 & 11 \\
\hline La & 1.85 & 2.40 & 0.74 & 1.50 & 0.62 & 1.96 & 3.43 & 5.67 & 2.05 & 1.85 \\
\hline $\mathrm{Ce}$ & 4.59 & 5.79 & 1.85 & 3.91 & 1.46 & 4.69 & 8.25 & 12.15 & 3.68 & 4.59 \\
\hline Pr & 0.75 & 0.91 & 0.28 & 0.60 & 0.23 & 0.75 & 1.27 & 1.52 & 0.54 & 0.75 \\
\hline Nd & 3.67 & 4.27 & 1.29 & 2.93 & 1.07 & 3.52 & 6.00 & 6.01 & 2.30 & 3.67 \\
\hline Sm & 1.20 & 1.34 & 0.40 & 0.97 & 0.35 & 1.12 & 1.80 & 1.43 & 0.60 & 1.20 \\
\hline $\mathbf{E u}$ & 0.45 & 0.49 & 0.14 & 0.38 & 0.12 & 0.41 & 0.58 & 0.44 & 0.24 & 0.45 \\
\hline Gd & 1.52 & 1.52 & 0.52 & 1.30 & 0.44 & 1.37 & 2.18 & 1.49 & 0.70 & 1.52 \\
\hline $\mathbf{T b}$ & 0.28 & 0.26 & 0.09 & 0.24 & 0.08 & 0.24 & 0.38 & 0.26 & 0.13 & 0.28 \\
\hline Dy & 1.84 & 1.63 & 0.61 & 1.61 & 0.55 & 1.56 & 2.47 & 1.74 & 0.81 & 1.84 \\
\hline Но & 0.40 & 0.34 & 0.14 & 0.35 & 0.12 & 0.33 & 0.54 & 0.39 & 0.18 & 0.40 \\
\hline $\mathbf{E r}$ & 1.14 & 0.95 & 0.39 & 0.98 & 0.36 & 0.93 & 1.55 & 1.14 & 0.58 & 1.14 \\
\hline Tm & 0.17 & 0.14 & 0.06 & 0.15 & 0.06 & 0.14 & 0.24 & 0.18 & 0.10 & 0.17 \\
\hline Yb & 1.08 & 0.92 & 0.39 & 0.94 & 0.39 & 0.93 & 1.53 & 1.31 & 0.70 & 1.08 \\
\hline $\mathbf{L u}$ & 0.18 & 0.15 & 0.06 & 0.15 & 0.07 & 0.16 & 0.25 & 0.23 & 0.13 & 0.18 \\
\hline Hf & 1.22 & 1.39 & 0.45 & 0.87 & 0.38 & 1.18 & 2.00 & 2.57 & 1.25 & 1.22 \\
\hline Ta & 0.03 & 0.04 & 0.01 & 0.02 & 0.01 & 0.03 & 0.05 & 0.12 & 0.06 & 0.03 \\
\hline $\mathbf{P b}$ & 0.41 & 0.45 & 0.16 & 0.26 & 0.33 & 0.92 & 1.29 & 1.36 & 0.53 & 0.41 \\
\hline Th & 0.18 & 0.29 & 0.09 & 0.16 & 0.06 & 0.20 & 0.35 & 1.10 & 0.25 & 0.18 \\
\hline $\mathbf{U}$ & 0.18 & 0.26 & 0.06 & 0.11 & 0.06 & 0.20 & 0.30 & 0.47 & 0.33 & 0.18 \\
\hline
\end{tabular}

${ }^{\text {a }}$ Values reported as an average from duplicate analyses. Standard deviations for most values are less than 0.67

b FeOT as total Fe

c Normative lithologies, abbreviations: Gbr (gabbro), Dior (diorite), QDior (quartz diorite), Alt Dior (altered diorite), Br And (bronzite andesite), Ton (tonalite) 
A4.2. Compatible elements analyzed by GeoAnalytical Lab at WSU. Superscript notations are the same as in 0 .

\begin{tabular}{|c|c|c|c|c|c|c|c|c|c|}
\hline Norm Lith ${ }^{\mathrm{c}}$ & Dredge & Sample & $\mathbf{N i}$ & $\mathrm{Cr}$ & $\mathbf{V}$ & $\mathbf{Z r}$ & $\mathbf{G a}$ & $\mathbf{C u}$ & $\mathbf{Z n}$ \\
\hline Gbr & RD63 & J07 & 123 & 204 & 148 & 8 & 10 & 7 & 38 \\
\hline Ton & RD63 & J15 & 2 & 5 & 60 & 57 & 11 & 4 & 7 \\
\hline Gbr & RD63 & J19 & 191 & 10 & 229 & 20 & 11 & 2 & 18 \\
\hline Gbr & RD63 & $\mathrm{J}^{22^{\mathrm{a}}}$ & 102 & 47 & 104 & 6 & 14 & 19 & 25 \\
\hline QDior & RD63 & $\mathbf{J} 23$ & 37 & 14 & 188 & 60 & 13 & 10 & 25 \\
\hline QDior & RD63 & J27 & 34 & 6 & 200 & 44 & 14 & 26 & 24 \\
\hline Ton & RD63 & $\mathrm{J} 28$ & 2 & 4 & 61 & 74 & 13 & 6 & 8 \\
\hline Dior & RD63 & J29 & 36 & 16 & 241 & 52 & 13 & 12 & 40 \\
\hline Ton & RD63 & J32 & 36 & 20 & 158 & 54 & 9 & 12 & 37 \\
\hline Ton & RD63 & J34 & 13 & 19 & 197 & 43 & 14 & 38 & 32 \\
\hline Gbr & RD63 & J35 & 98 & 102 & 119 & 5 & 14 & 5 & 35 \\
\hline Ton & RD63 & J36 & 36 & 15 & 190 & 64 & 12 & 9 & 25 \\
\hline Ton & RD63 & J39 & 28 & 15 & 176 & 48 & 12 & 6 & 20 \\
\hline Ton & RD63 & $\mathbf{J 4 0}$ & 2 & 2 & 13 & 79 & 11 & 10 & 6 \\
\hline Ton & RD63 & $\mathbf{J 4 3}$ & 3 & 2 & 54 & 73 & 10 & 5 & 6 \\
\hline Ton & RD63 & J45 & 14 & 5 & 37 & 105 & 12 & 3 & 7 \\
\hline Ton & RD63 & J46 & 8 & 3 & 32 & 92 & 11 & 8 & 4 \\
\hline Ton & RD63 & $\mathrm{J} 67^{\mathrm{a}}$ & 20 & 4 & 297 & 53 & 13 & 27 & 24 \\
\hline Br.And & RD64 & J49 & 85 & 414 & 195 & 28 & 9 & 2 & 33 \\
\hline QDior & RD64 & $\mathbf{J 5 3}$ & 39 & 43 & 273 & 46 & 16 & 3 & 23 \\
\hline QDior & RD64 & J55 & 25 & 29 & 272 & 46 & 15 & 4 & 24 \\
\hline Ton & RD64 & J56 & 43 & 55 & 228 & 45 & 14 & 2 & 17 \\
\hline QDior & RD64 & J58 & 85 & 169 & 199 & 40 & 15 & 1 & 22 \\
\hline QDior & RD64 & J59 & 36 & 48 & 201 & 47 & 17 & 5 & 40 \\
\hline Alt Dior. & RD64 & J60 & 378 & 1919 & 105 & 16 & 6 & 9 & 52 \\
\hline Dior & RD64 & J61 & 166 & 623 & 159 & 29 & 11 & 11 & 35 \\
\hline Alt Dior. & RD64 & J63 & 228 & 1697 & 102 & 12 & 5 & 45 & 52 \\
\hline Alt Dior. & RD64 & J64 & 68 & 200 & 237 & 40 & 17 & 41 & 50 \\
\hline Ton & RD64 & J65 & 2 & 2 & 113 & 66 & 15 & 5 & 25 \\
\hline Basalt & USGS Std & BHVO-2 & 114 & 277 & 311 & 167 & 21 & 134 & 104 \\
\hline Gbr & RD63 & J22-R & 101 & 48 & 101 & 6 & 13 & 18 & 24 \\
\hline Ton & RD63 & J67-R & 21 & 5 & 299 & 51 & 13 & 29 & 26 \\
\hline
\end{tabular}


A4.3. Isotope ratios measured at NHMFL at Tallahassee, FL (present day values).

\begin{tabular}{|c|c|c|c|c|c|c|c|c|c|c|c|c|c|c|}
\hline & ${ }^{87} \mathrm{Sr} /{ }^{86} \mathrm{Sr}$ & $\pm 2 \sigma$ & ${ }^{143} \mathrm{Nd} /{ }^{144} \mathrm{Nd}$ & $\pm 1 \sigma$ & ${ }^{176} \mathrm{Hf} /{ }^{177} \mathrm{Hf}$ & $\pm 1 \sigma$ & ${ }^{206} \mathrm{~Pb} /{ }^{204} \mathrm{~Pb}$ & $\begin{array}{l} \pm \\
1 \sigma\end{array}$ & ${ }^{207} \mathrm{~Pb} /{ }^{204} \mathrm{~Pb}$ & $\begin{array}{l} \pm \\
1 \sigma\end{array}$ & ${ }^{208} \mathrm{~Pb} /{ }^{204} \mathrm{~Pb}$ & $\begin{array}{l} \pm \\
1 \sigma\end{array}$ & $\varepsilon N d_{0}$ & $\varepsilon \mathbf{H f}_{0}$ \\
\hline $\begin{array}{l}\text { RD63 } \\
\text { J15 }\end{array}$ & 0.704029 & 7 & 0.512943 & 6 & 0.283050 & 44 & 18.9400 & 5 & 15.5612 & 4 & 38.4452 & 10 & 5.90 & 9.84 \\
\hline $\begin{array}{l}\text { RD63 } \\
\text { J23 }\end{array}$ & 0.704074 & 8 & 0.512942 & 5 & 0.283115 & 4 & 18.9677 & 8 & 15.5536 & 7 & 38.4301 & 16 & 5.89 & 12.13 \\
\hline $\begin{array}{l}\text { RD63 } \\
\text { J28 }\end{array}$ & 0.704219 & 7 & 0.512961 & 6 & 0.283174 & 9 & 19.0648 & 5 & 15.5649 & 4 & 38.4711 & 11 & 6.26 & 14.23 \\
\hline $\begin{array}{l}\text { RD63 } \\
\text { J29 }\end{array}$ & 0.703890 & 7 & 0.512962 & 5 & 0.283106 & 3 & 19.0111 & 7 & 15.5596 & 6 & 38.4335 & 15 & 6.28 & 11.81 \\
\hline $\begin{array}{l}\text { RD63 } \\
\text { J32 }\end{array}$ & 0.704253 & 7 & 0.512947 & 5 & 0.283123 & 3 & 18.9928 & 6 & 15.5559 & 5 & 38.4134 & 13 & 5.99 & 12.41 \\
\hline $\begin{array}{l}\text { RD63 } \\
\text { J34 }\end{array}$ & 0.703903 & 8 & 0.512957 & 4 & 0.283110 & 4 & 18.9594 & 5 & 15.5493 & 4 & 38.3911 & 12 & 6.19 & 11.96 \\
\hline $\begin{array}{l}\text { RD63 } \\
\text { J40 }\end{array}$ & 0.704330 & 7 & 0.512960 & 7 & 0.283099 & 4 & 19.7930 & 9 & 15.6000 & 5 & 38.5797 & 13 & 6.24 & 11.55 \\
\hline $\begin{array}{l}\text { RD63 } \\
\text { J45 }\end{array}$ & 0.704197 & 7 & 0.512917 & 5 & 0.283089 & 4 & 19.4053 & 5 & 15.5797 & 4 & 38.4545 & 11 & 5.41 & 11.22 \\
\hline $\begin{array}{l}\text { RD64 } \\
\text { J55 }\end{array}$ & 0.703666 & 7 & 0.513050 & 7 & 0.283164 & 5 & 19.1504 & 5 & 15.5145 & 4 & 38.3734 & 11 & 8.00 & 13.86 \\
\hline $\begin{array}{l}\text { RD64 } \\
\text { J58 }\end{array}$ & 0.703979 & 11 & 0.513057 & 6 & 0.283154 & 3 & 18.9907 & 6 & 15.5011 & 5 & 38.2362 & 12 & 8.13 & 13.50 \\
\hline $\begin{array}{l}\text { RD64 } \\
\text { J64 }\end{array}$ & 0.703614 & 7 & 0.513044 & 5 & 0.283130 & 2 & 18.9077 & 4 & 15.4992 & 4 & 38.2375 & 9 & 7.88 & 12.67 \\
\hline $\begin{array}{l}\text { RD64 } \\
\text { J65 } \\
\end{array}$ & 0.703847 & 7 & 0.513043 & 5 & 0.283140 & 2 & 18.9193 & 4 & 15.4990 & 4 & 38.2428 & 10 & 7.86 & 13.02 \\
\hline
\end{tabular}

Note: Sr ratios measured on TIMS, standard E \& A: $(87 \mathrm{Sr} / 86 \mathrm{Sr}=0.70808) ; \mathrm{Nd}, \mathrm{Hf}$, Pb ratios measured on Neptune ICPMS; Nd standard LaJolla: $(143 \mathrm{Nd} / 144 \mathrm{Nd}=0.511850) ; \mathrm{Hf}$ standard JMC475: $(176 \mathrm{Hf} / 177 \mathrm{Hf}=0.282000) ; \mathrm{Pb}$ standard NBS 981:

$(206 \mathrm{~Pb} / 204 \mathrm{~Pb}=16.9356 ; 207 \mathrm{~Pb} / 204 \mathrm{~Pb}=15.4891 ; 208 \mathrm{~Pb} / 204 \mathrm{~Pb}=36.7006$; Todt et al. [1996]); $\varepsilon \mathrm{Hf}$ values calculated using the CHUR value (0.282772) established in Blichert-Toft and Albarède [1997] 
A4.4. Initial isotope ratios calculated to $50 \mathrm{Ma}$

\begin{tabular}{lcccccccc}
\hline & ${ }^{\mathbf{8 7}} \mathbf{S r} /{ }^{\mathbf{8 6}} \mathbf{S r}_{\mathbf{i}}$ & ${ }^{\mathbf{1 4 3}} \mathbf{N d} /{ }^{\mathbf{1 4 4}} \mathbf{N d}_{\mathbf{i}}$ & ${ }^{\mathbf{1 7 6}} \mathbf{H} \mathbf{f} /{ }^{\mathbf{1 7 7}} \mathbf{H f}_{\mathbf{i}}$ & ${ }^{\mathbf{2 0 6}} \mathbf{P b} /{ }^{\mathbf{2 0 4}} \mathbf{P b}_{\mathbf{i}}$ & ${ }^{{ }^{207}} \mathbf{P b} /{ }^{\mathbf{2 0 4}} \mathbf{P b}_{\mathbf{i}}$ & ${ }^{{ }^{\mathbf{0 0}}} \mathbf{P b} /{ }^{\mathbf{2 0 4}} \mathbf{P} \mathbf{b}_{\mathbf{i}}$ & $\mathbf{\varepsilon N d}_{(\mathbf{t})}$ & $\boldsymbol{\varepsilon H f}_{(\mathbf{t})}$ \\
\hline RD63-J15 & 0.703975 & 0.512893 & 0.283039 & 18.561 & 15.543 & 38.318 & 6.18 & 10.55 \\
RD63-J23 & 0.703957 & 0.512897 & 0.283100 & 18.759 & 15.544 & 38.346 & 6.25 & 12.71 \\
RD63-J28 & 0.704163 & 0.512904 & 0.283162 & 18.526 & 15.539 & 38.319 & 6.40 & 14.92 \\
RD63-J29 & 0.703829 & 0.512905 & 0.283090 & 18.858 & 15.552 & 38.392 & 6.42 & 12.35 \\
RD63-J32 & 0.704171 & 0.512898 & 0.283110 & 18.820 & 15.548 & 38.355 & 6.28 & 13.08 \\
RD63-J34 & 0.703817 & 0.512906 & 0.283094 & 18.770 & 15.540 & 38.339 & 6.43 & 12.50 \\
RD63-J40 & 0.704247 & 0.512898 & 0.283087 & 18.813 & 15.554 & 38.277 & 6.29 & 12.24 \\
RD63-J45 & 0.704145 & 0.512873 & 0.283085 & 18.572 & 15.541 & 38.233 & 5.78 & 12.16 \\
RD64-J55 & 0.703636 & 0.512989 & 0.283145 & 18.828 & 15.499 & 38.239 & 8.07 & 14.33 \\
RD64-J58 & 0.703969 & 0.512992 & 0.283134 & 18.780 & 15.491 & 38.166 & 8.13 & 13.91 \\
RD64-J64 & 0.703611 & 0.512981 & 0.283112 & 18.802 & 15.494 & 38.203 & 7.91 & 13.15 \\
RD64-J65 & 0.703845 & 0.512984 & 0.283123 & 18.804 & 15.494 & 38.198 & 7.96 & 13.52 \\
\hline
\end{tabular}

Note: Sr ratios measured on TIMS, standard E \& A $(87 \mathrm{Sr} / 86 \mathrm{Sr}=0.70808) ; \mathrm{Nd}, \mathrm{Hf}, \mathrm{Pb}$ ratios measured on Neptune ICPMS; Nd standard LaJolla $(143 \mathrm{Nd} / 144 \mathrm{Nd}=0.511850) ; \mathrm{Hf}$ standard JMC475 $(176 \mathrm{Hf} / 177 \mathrm{Hf}=0.282000) ; \mathrm{Pb}$ standard NBS $981(206 \mathrm{~Pb} / 204 \mathrm{~Pb}=16.9356$;

$207 \mathrm{~Pb} / 204 \mathrm{~Pb}=15.4891 ; 208 \mathrm{~Pb} / 204 \mathrm{~Pb}=36.7006$; Todt et al. [1996]); $\varepsilon \mathrm{Hf}$ values calculated using the CHUR value (0.282772) established in Blichert-Toft and Albarède [1997] 


\section{APPENDIX 5}

A5. EPMA mineral chemistry

A5.1. Sample: RD63-J07, Gabbro

\begin{tabular}{|c|c|c|c|c|c|c|c|c|c|c|c|c|c|c|}
\hline No. & $\mathrm{SiO}_{2}$ & $\mathbf{K}_{2} \mathbf{O}$ & MnO & $\mathrm{Na}_{2} \mathrm{O}$ & $\mathbf{P}_{2} \mathbf{O}_{5}$ & $\mathbf{A l}_{2} \mathbf{O}_{3}$ & $\mathrm{TiO}_{2}$ & $\mathrm{FeO}_{\mathrm{T}}$ & MgO & $\mathrm{CaO}$ & $\mathrm{Cr}_{2} \mathrm{O}_{3}$ & Total & $\begin{array}{l}\text { Circle- } \\
\text { label* }\end{array}$ & Revised mineral \\
\hline 1 & 46.024 & 0.041 & 0.005 & 0.988 & 0.000 & 34.068 & 0.002 & 0.537 & 0.009 & 18.256 & -- & 99.93 & 4-fsp1 & Ca-Fsp \\
\hline 2 & 46.394 & 0.036 & 0.022 & 1.018 & 0.002 & 34.434 & 0.012 & 0.632 & 0.025 & 18.379 & -- & 100.95 & 4-fsp2 & Ca-Fsp \\
\hline 3 & 46.509 & 0.032 & 0.000 & 1.032 & 0.000 & 34.590 & 0.001 & 0.512 & 0.000 & 18.583 & -- & 101.26 & 4-fsp3 & Ca-Fsp \\
\hline 4 & 56.504 & 0.222 & 0.011 & 5.291 & 0.018 & 28.446 & 0.043 & 0.415 & 0.000 & 10.553 & -- & 101.50 & 4-fsp4 & Ca-Na Fsp rim \\
\hline 5 & 56.677 & 0.141 & 0.000 & 5.646 & 0.026 & 26.866 & 0.000 & 0.470 & 0.023 & 10.387 & -- & 100.24 & 4-fsp5 & Ca-Na Fsp rim \\
\hline 6 & 53.408 & 0.096 & 0.011 & 3.989 & 0.000 & 29.991 & 0.009 & 0.370 & 0.007 & 13.137 & -- & 101.02 & 4-fsp6 & Ca-Na Fsp rim \\
\hline 7 & 49.469 & 9.106 & 0.000 & 0.241 & 0.012 & 35.397 & 0.000 & 1.084 & 0.914 & 0.145 & -- & 96.37 & 4-fsp7 & Fsp core - Sericite \\
\hline 8 & 48.039 & 9.638 & 0.000 & 0.199 & 0.019 & 35.722 & 0.000 & 0.821 & 0.631 & 0.135 & -- & 95.20 & 4-fsp8 & Fsp core - Sericite \\
\hline 9 & 50.155 & 8.344 & 0.002 & 0.179 & 0.016 & 35.213 & 0.000 & 0.815 & 0.748 & 0.090 & -- & 95.56 & 4-fsp9 & Fsp core - Sericite \\
\hline 16 & 53.780 & 0.034 & 0.257 & 0.204 & 0.000 & 2.451 & 0.047 & 10.508 & 16.561 & 12.801 & -- & 96.64 & 4-px1 & -- \\
\hline 17 & 53.933 & 0.027 & 0.266 & 0.134 & 0.008 & 2.009 & 0.045 & 12.440 & 16.390 & 12.610 & -- & 97.86 & 4-px2 & -- \\
\hline 18 & 54.382 & 0.024 & 0.302 & 0.132 & 0.000 & 1.936 & 0.066 & 13.338 & 15.963 & 12.456 & -- & 98.60 & $4-p \times 3$ & -- \\
\hline 19 & 54.307 & 0.030 & 0.269 & 0.119 & 0.014 & 2.154 & 0.041 & 12.986 & 15.948 & 12.478 & -- & 98.35 & 4-px4 & -- \\
\hline 20 & 54.061 & 0.028 & 0.293 & 0.140 & 0.003 & 2.073 & 0.031 & 13.477 & 15.661 & 12.221 & -- & 97.99 & 4-px5 & -- \\
\hline 21 & 51.472 & 0.040 & 0.242 & 0.211 & 0.000 & 4.692 & 0.067 & 12.709 & 17.364 & 11.081 & -- & 97.88 & 4-px6 & -- \\
\hline 22 & 29.844 & 0.007 & 0.203 & 0.000 & 0.000 & 17.242 & 0.006 & 17.545 & 23.850 & 0.075 & -- & 88.77 & 4-px7 & secondary "clay" \\
\hline 35 & 48.116 & 0.036 & 0.051 & 1.518 & 0.006 & 33.273 & 0.009 & 0.525 & 0.006 & 17.226 & -- & 100.77 & $3-\mathrm{fsp} 1$ & Ca-fsp rim \\
\hline 36 & 47.436 & 0.040 & 0.000 & 1.038 & 0.004 & 34.132 & 0.000 & 0.611 & 0.019 & 18.317 & -- & 101.60 & 3 -fsp2 & Ca-fsp \\
\hline 37 & 47.327 & 0.039 & 0.000 & 1.031 & 0.008 & 34.038 & 0.008 & 0.420 & 0.000 & 18.315 & -- & 101.19 & 3 -fsp3 & Ca-fsp rim \\
\hline 38 & 61.815 & 0.056 & 0.063 & 7.598 & 0.011 & 25.066 & 0.000 & 0.193 & 0.000 & 7.082 & -- & 101.88 & $3-\mathrm{fsp} 4$ & Fsp core - Sericite \\
\hline 39 & 60.708 & 0.049 & 0.028 & 7.015 & 0.015 & 25.934 & 0.000 & 0.234 & 0.008 & 8.067 & -- & 102.06 & 3-fsp5 & Fsp core - Sericite \\
\hline
\end{tabular}




\begin{tabular}{|c|c|c|c|c|c|c|c|c|c|c|c|c|c|c|}
\hline \multicolumn{15}{|c|}{ RD63-J07 gabbro (con’t) } \\
\hline No. & $\mathrm{SiO}_{2}$ & $\mathbf{K}_{2} \mathbf{O}$ & MnO & $\mathrm{Na}_{2} \mathrm{O}$ & $\mathbf{P}_{2} \mathbf{O}_{5}$ & $\mathbf{A l}_{2} \mathbf{O}_{3}$ & $\mathrm{TiO}_{2}$ & $\mathrm{FeO}_{\mathrm{T}}$ & MgO & $\mathrm{CaO}$ & $\mathrm{Cr}_{2} \mathrm{O}_{3}$ & Total & $\begin{array}{l}\text { Circle- } \\
\text { label** }\end{array}$ & Revised mineral \\
\hline 40 & 50.823 & 0.119 & 0.391 & 0.780 & 0.017 & 5.062 & 0.428 & 10.626 & 16.787 & 11.396 & -- & 96.43 & 3-amph6 & -- \\
\hline 41 & 51.299 & 0.160 & 0.359 & 0.703 & 0.018 & 5.018 & 0.448 & 9.994 & 16.851 & 11.352 & -- & 96.20 & 3-amph7 & -- \\
\hline 42 & 51.141 & 0.152 & 0.324 & 0.827 & 0.014 & 5.374 & 0.577 & 10.392 & 16.654 & 11.368 & -- & 96.82 & 3-amph8 & -- \\
\hline 43 & 47.274 & 0.024 & 0.000 & 0.948 & 0.012 & 33.993 & 0.005 & 0.407 & 0.000 & 18.336 & -- & 101.00 & 3-fsp1 & Ca-fsp \\
\hline 44 & 47.289 & 0.050 & 0.062 & 1.171 & 0.016 & 34.626 & 0.012 & 0.440 & 0.000 & 18.154 & -- & 101.82 & $3-\mathrm{fsp} 2$ & Ca-fsp \\
\hline 45 & 49.824 & 9.484 & 0.010 & 0.178 & 0.007 & 35.383 & 0.000 & 0.743 & 0.603 & 0.108 & -- & 96.34 & 3-musc3 & Fsp core - Sericite \\
\hline 46 & 48.948 & 9.727 & 0.022 & 0.169 & 0.005 & 35.616 & 0.021 & 1.343 & 0.744 & 0.128 & -- & 96.72 & 3-musc4 & Fsp core - Sericite \\
\hline 47 & 47.814 & 9.958 & 0.010 & 0.139 & 0.000 & 36.115 & 0.004 & 1.881 & 0.778 & 0.096 & -- & 96.80 & 3-musc 5 & Fsp core - Sericite \\
\hline 48 & 50.926 & 8.942 & 0.054 & 0.215 & 0.010 & 35.770 & 0.000 & 0.942 & 1.054 & 0.151 & -- & 98.06 & 3-musc6 & Fsp core - Sericite \\
\hline
\end{tabular}

A5.2. Sample: RD63-J15, Tonalite

\begin{tabular}{|c|c|c|c|c|c|c|c|c|c|c|c|c|c|c|}
\hline No. & $\mathrm{SiO}_{2}$ & $\mathbf{K}_{2} \mathbf{O}$ & MnO & $\mathrm{Na}_{2} \mathrm{O}$ & $\mathbf{P}_{2} \mathbf{O}_{5}$ & $\mathbf{A l}_{2} \mathbf{O}_{3}$ & $\mathrm{TiO}_{2}$ & $\mathrm{FeO}_{\mathrm{T}}$ & MgO & $\mathrm{CaO}$ & $\mathrm{Cr}_{2} \mathrm{O}_{3}$ & Total & $\begin{array}{l}\text { Circle- } \\
\text { label* }\end{array}$ & Revised mineral \\
\hline 1 & 59.029 & 0.289 & 0.023 & 6.373 & 0.002 & 27.000 & 0.040 & 0.094 & 0.013 & 9.128 & -- & 101.99 & 4-fsp1 & Ca-fsp fresh "core" \\
\hline 2 & 58.307 & 0.249 & 0.015 & 5.651 & 0.014 & 27.351 & 0.033 & 0.192 & 0.000 & 10.049 & -- & 101.86 & 4-fsp2 & Ca-fsp fresh "core" \\
\hline 3 & 58.106 & 0.231 & 0.026 & 5.629 & 0.019 & 28.066 & 0.000 & 0.135 & 0.001 & 10.139 & -- & 102.35 & 4-fsp3 & Ca-fsp fresh "core" \\
\hline 4 & 62.046 & 0.224 & 0.010 & 7.659 & 0.002 & 25.222 & 0.000 & 0.119 & 0.000 & 6.637 & -- & 101.92 & 4-fsp4 & altered center \\
\hline 5 & 61.504 & 0.232 & 0.007 & 7.462 & 0.018 & 25.584 & 0.000 & 0.147 & 0.016 & 6.893 & -- & 101.86 & $4-f s p 5$ & altered center \\
\hline 6 & 64.812 & 0.385 & 0.000 & 8.460 & 0.007 & 23.950 & 0.000 & 0.209 & 0.002 & 5.279 & -- & 103.10 & 4-fsp6 & altered center \\
\hline 7 & 60.748 & 0.283 & 0.000 & 6.954 & 0.006 & 26.281 & 0.000 & 0.245 & 0.000 & 7.923 & -- & 102.44 & 4-fsp7 & Ca-fsp "core" \\
\hline 8 & 59.803 & 0.287 & 0.035 & 6.537 & 0.011 & 26.053 & 0.000 & 0.200 & 0.000 & 8.763 & -- & 101.69 & 4-fsp8 & Ca-fsp "core" \\
\hline 9 & 58.605 & 0.273 & 0.014 & 6.575 & 0.001 & 26.736 & 0.020 & 0.188 & 0.000 & 8.651 & -- & 101.06 & 4-fsp9 & Ca-fsp "core" \\
\hline 10 & 58.593 & 0.183 & 0.000 & 6.114 & 0.012 & 27.355 & 0.004 & 0.184 & 0.000 & 9.363 & -- & 101.81 & 2-fsp1 & Ca-fsp fresh "core" \\
\hline
\end{tabular}




\begin{tabular}{|c|c|c|c|c|c|c|c|c|c|c|c|c|c|c|}
\hline \multicolumn{15}{|c|}{ RD63-J15 tonalite (con't) } \\
\hline No. & $\mathrm{SiO}_{2}$ & $\mathbf{K}_{2} \mathbf{O}$ & MnO & $\mathrm{Na}_{2} \mathrm{O}$ & $\mathbf{P}_{2} \mathbf{O}_{5}$ & $\mathrm{Al}_{2} \mathrm{O}_{3}$ & $\mathrm{TiO}_{2}$ & $\mathrm{FeO}_{\mathrm{T}}$ & MgO & $\mathrm{CaO}$ & $\mathrm{Cr}_{2} \mathrm{O}_{3}$ & Total & $\begin{array}{l}\text { Circle- } \\
\text { label* }\end{array}$ & Revised mineral \\
\hline 11 & 57.826 & 0.204 & 0.000 & 6.065 & 0.017 & 27.134 & 0.000 & 0.102 & 0.015 & 9.480 & -- & 100.84 & $2-\mathrm{fsp} 2$ & Ca-fsp fresh "core" \\
\hline 12 & 58.628 & 0.331 & 0.000 & 6.119 & 0.009 & 27.522 & 0.000 & 0.270 & 0.030 & 8.887 & -- & 101.80 & $2-\mathrm{fsp} 3$ & Ca-fsp fresh "core" \\
\hline 13 & 67.212 & 0.067 & 0.000 & 10.173 & 0.018 & 21.626 & 0.000 & 0.045 & 0.000 & 2.539 & -- & 101.68 & $2-f s p 4$ & Na-fsp rim \\
\hline 14 & 67.537 & 0.067 & 0.046 & 9.968 & 0.016 & 22.003 & 0.013 & 0.127 & 0.000 & 2.851 & -- & 102.63 & $2-\mathrm{fsp} 5$ & Na-fsp rim \\
\hline 15 & 68.086 & 0.283 & 0.000 & 9.949 & 0.007 & 21.557 & 0.000 & 0.127 & 0.000 & 2.537 & -- & 102.55 & $2-f s p 6$ & Na-fsp rim \\
\hline 16 & 62.359 & 0.421 & 0.018 & 7.338 & 0.000 & 25.555 & 0.000 & 0.221 & 0.000 & 6.990 & -- & 102.90 & 2-fsp7 & Ca-fsp "core" \\
\hline 17 & 59.490 & 0.314 & 0.000 & & & & 0.000 & & 0.000 & & -- & & $2-f s p 8$ & Ca-fsp "core" \\
\hline 18 & 61.342 & 0.094 & 0.014 & 7.063 & 0.007 & 26.441 & 0.040 & 0.090 & 0.000 & 7.759 & -- & 102.85 & 2-fsp9 & Ca-fsp "core" \\
\hline 19 & 60.679 & 0.273 & 0.000 & 6.778 & 0.011 & 26.855 & 0.013 & 0.279 & 0.000 & 8.311 & -- & 103.20 & 2 -fsp10 & Ca-fsp "core" \\
\hline 20 & 61.426 & 0.325 & 0.000 & 6.976 & 0.007 & 26.064 & 0.014 & 0.262 & 0.014 & 7.665 & -- & 102.75 & 2-fsp11 & Ca-fsp "core" \\
\hline 21 & 60.517 & 0.309 & 0.000 & 6.601 & 0.007 & 26.337 & 0.003 & 0.172 & 0.000 & 8.135 & -- & 102.08 & 2-fsp12 & Ca-fsp "core" \\
\hline 22 & 59.016 & 0.242 & 0.016 & 6.007 & 0.018 & 27.646 & 0.030 & 0.193 & 0.004 & 9.476 & -- & 102.65 & 2-fsp13 & Ca-fsp rim \\
\hline 23 & 58.927 & 0.342 & 0.000 & 6.083 & 0.015 & 27.009 & 0.005 & 0.238 & 0.000 & 9.184 & -- & 101.80 & 2 -fsp14 & Ca-fsp rim \\
\hline 24 & 59.725 & 0.241 & 0.055 & 6.084 & 0.014 & 27.389 & 0.008 & 0.143 & 0.000 & 9.193 & -- & 102.85 & 2-fsp15 & Ca-fsp rim \\
\hline 25 & 60.302 & 0.173 & 0.000 & 6.767 & 0.004 & 26.944 & 0.006 & 0.160 & 0.009 & 8.440 & -- & 102.81 & 2-fsp16 & Ca-fsp "core" \\
\hline 26 & 59.794 & 0.267 & 0.038 & 6.477 & 0.011 & 26.982 & 0.012 & 0.274 & 0.000 & 8.642 & -- & 102.50 & 2-fsp17 & Ca-fsp "core" \\
\hline 27 & 60.709 & 0.235 & 0.000 & 6.547 & 0.012 & 26.978 & 0.030 & 0.184 & 0.003 & 8.601 & -- & 103.30 & 2-fsp 18 & Ca-fsp "core" \\
\hline
\end{tabular}


A5.3. Sample: RD63-J40, Tonalite

\begin{tabular}{|c|c|c|c|c|c|c|c|c|c|c|c|c|l|l|}
\hline No. & $\mathbf{S i O}_{2}$ & $\mathbf{K}_{\mathbf{2}} \mathbf{O}$ & $\mathbf{M n O}$ & $\mathbf{N a}_{\mathbf{2}} \mathbf{O}$ & $\mathbf{P}_{\mathbf{2}} \mathbf{O}_{\mathbf{5}}$ & $\mathbf{A l}_{\mathbf{2}} \mathbf{O}_{\mathbf{3}}$ & $\mathbf{T i O}_{\mathbf{2}}$ & $\mathbf{F e O}_{\mathbf{T}}$ & $\mathbf{M g O}$ & $\mathbf{C a O}$ & $\mathbf{C r}_{2} \mathbf{O}_{3}$ & $\mathbf{T o t a l}$ & $\begin{array}{l}\text { Circle- } \\
\text { label* }\end{array}$ & Revised mineral \\
\hline 1 & 67.615 & 0.040 & 0.012 & 10.929 & -- & 19.348 & 0.000 & 0.028 & 0.000 & 0.475 & -- & 98.45 & 3 -fsp1 & Na-plag \\
\hline 2 & 67.543 & 0.032 & 0.023 & 11.042 & -- & 19.551 & 0.006 & 0.051 & 0.000 & 0.587 & -- & 98.84 & 3-fsp2 & "rim" of euhedral plag \\
\hline 3 & 68.930 & 0.028 & 0.000 & 11.362 & -- & 19.662 & 0.000 & 0.069 & 0.011 & 0.378 & -- & 100.44 & 3 -fsp3 & "rim" of euhedral plag \\
\hline 4 & 68.276 & 0.149 & 0.000 & 11.129 & -- & 20.024 & 0.000 & 0.000 & 0.013 & 0.637 & -- & 100.23 & 3 -fsp4 & "rim" of euhedral plag \\
\hline 5 & 69.350 & 0.023 & 0.000 & 11.642 & -- & 19.938 & 0.000 & 0.070 & 0.000 & 0.317 & -- & 101.34 & 3 -fsp5 & Granophyric Na-plag \\
\hline 6 & 68.163 & 0.032 & 0.000 & 11.332 & -- & 19.495 & 0.007 & 0.049 & 0.007 & 0.527 & -- & 99.61 & 3 -fsp6 & Granophyric Na-plag \\
\hline 7 & 67.172 & 0.058 & 0.000 & 9.410 & -- & 20.277 & 0.000 & 0.000 & 0.001 & 0.611 & -- & 97.53 & 3 -fsp7 & Na-plag \\
\hline 8 & 68.050 & 0.049 & 0.008 & 11.328 & -- & 20.779 & 0.000 & 0.000 & 0.000 & 0.703 & -- & 100.92 & 3 -fsp8 & "rim" of euhedral plag \\
\hline 9 & 68.811 & 0.049 & 0.000 & 11.563 & -- & 20.780 & 0.000 & 0.000 & 0.000 & 0.430 & -- & 101.63 & 3 -fsp9 & "rim" of euhedral plag \\
\hline 10 & 69.686 & 0.043 & 0.006 & 11.391 & -- & 20.958 & 0.000 & 0.000 & 0.019 & 0.548 & -- & 102.65 & 3-fsp10 & Granophyric Na-plag \\
\hline 11 & 70.309 & 0.035 & 0.022 & 11.385 & -- & 19.736 & 0.010 & 0.000 & 0.000 & 0.490 & -- & 101.99 & 3-fsp11 & Granophyric Na-plag \\
\hline
\end{tabular}

A5.4. Sample: RD64-J49, Bronzite andesite (Note: “Augite-1" composition is $\mathrm{En}_{0.40}$ or less)

\begin{tabular}{|c|c|c|c|c|c|c|c|c|c|c|c|c|c|c|}
\hline No. & $\mathrm{SiO}_{2}$ & $\mathbf{K}_{2} \mathbf{O}$ & MnO & $\mathrm{Na}_{2} \mathrm{O}$ & $\mathbf{P}_{2} \mathbf{O}_{5}$ & $\mathbf{A l}_{2} \mathbf{O}_{3}$ & $\mathrm{TiO}_{2}$ & $\mathrm{FeO}_{\mathrm{T}}$ & MgO & $\mathrm{CaO}$ & $\mathrm{Cr}_{2} \mathrm{O}_{3}$ & Total & $\begin{array}{l}\text { Circle- } \\
\text { label* }\end{array}$ & $\begin{array}{l}\text { Revised } \\
\text { mineral }\end{array}$ \\
\hline 1 & 32.075 & 0.084 & 0.418 & 0.105 & 0.017 & 19.536 & 0.016 & 17.467 & 29.431 & 0.081 & 0.000 & 99.230 & 2-px1 & Serpentinite \\
\hline 2 & 31.383 & 0.053 & 0.435 & 0.068 & 0.009 & 18.506 & 0.031 & 18.172 & 29.730 & 0.058 & 0.000 & 98.445 & $2-p \times 2$ & Serpentinite \\
\hline 3 & 31.703 & 0.069 & 0.443 & 0.048 & 0.000 & 18.873 & 0.018 & 18.510 & 29.547 & 0.051 & 0.000 & 99.262 & $2-p \times 3$ & Serpentinite \\
\hline 4 & 52.943 & 0.005 & 0.645 & 0.260 & 0.026 & 0.788 & 0.032 & 8.419 & 13.917 & 22.984 & 0.000 & 100.019 & 2-px4 & Augite-1 \\
\hline 5 & 52.905 & 0.000 & 0.518 & 0.161 & 0.014 & 2.190 & 0.078 & 6.265 & 17.979 & 19.719 & 0.000 & 99.829 & $2-p \times 5$ & Augite-2 \\
\hline 7 & 53.504 & 0.022 & 0.025 & 3.334 & 0.003 & 30.547 & 0.015 & 1.250 & 0.250 & 14.379 & 0.000 & 103.329 & 2-fsp7 & Ca-fsp \\
\hline 8 & 30.923 & 0.049 & 0.172 & 0.036 & 0.000 & 19.127 & 0.000 & 20.339 & 45.798 & 0.038 & 0.000 & 116.482 & 2-chl8 & "Chlorite" \\
\hline
\end{tabular}




\begin{tabular}{|c|c|c|c|c|c|c|c|c|c|c|c|c|c|c|}
\hline \multicolumn{15}{|c|}{ RD64-J49 bronzite andesite (con't) } \\
\hline No. & $\mathrm{SiO}_{2}$ & $\mathbf{K}_{2} \mathbf{O}$ & MnO & $\mathrm{Na}_{2} \mathbf{O}$ & $\mathbf{P}_{2} \mathbf{O}_{5}$ & $\mathbf{A l}_{2} \mathbf{O}_{3}$ & $\mathrm{TiO}_{2}$ & $\mathrm{FeO}_{\mathrm{T}}$ & MgO & $\mathrm{CaO}$ & $\mathrm{Cr}_{2} \mathrm{O}_{3}$ & Total & $\begin{array}{l}\text { Circle- } \\
\text { label* }\end{array}$ & $\begin{array}{l}\text { Revised } \\
\text { mineral }\end{array}$ \\
\hline 9 & 39.715 & 0.000 & 0.028 & 0.006 & 0.000 & 24.734 & 0.017 & 12.591 & 0.906 & 24.039 & 0.000 & 102.036 & 2-mica9 & Mica \\
\hline 10 & 0.026 & 0.000 & 0.342 & 0.000 & 0.000 & 11.950 & 0.274 & 28.720 & 11.977 & 0.006 & 52.258 & 105.553 & 2-oxide10 & Cromite \\
\hline 11 & 53.220 & 0.008 & 0.250 & 0.339 & 0.012 & 0.773 & 0.001 & 8.127 & 13.406 & 23.274 & 0.000 & 99.410 & 4-px1 & Augite-1 \\
\hline 12 & 52.357 & 0.006 & 0.219 & 0.153 & 0.013 & 3.436 & 0.239 & 7.274 & 17.400 & 18.836 & 0.000 & 99.933 & 4-px2 & Augite- 2 \\
\hline 13 & 52.280 & 0.000 & 0.164 & 0.168 & 0.017 & 2.545 & 0.164 & 5.192 & 17.456 & 20.183 & 0.000 & 98.169 & 4-px3 & Augite-2 \\
\hline 14 & 52.653 & 0.004 & 0.134 & 0.183 & 0.015 & 2.162 & 0.131 & 4.985 & 17.891 & 19.948 & 0.000 & 98.106 & 4-px4 & Augite- 2 \\
\hline 15 & 52.654 & 0.004 & 0.165 & 0.175 & 0.017 & 2.169 & 0.113 & 6.081 & 19.449 & 17.694 & 0.000 & 98.521 & 4-px5 & Augite- 2 \\
\hline 16 & 53.890 & 0.009 & 0.227 & 0.199 & 0.014 & 0.706 & 0.062 & 8.031 & 14.369 & 22.570 & 0.000 & 100.077 & 4-px6 & Augite-1 \\
\hline 18 & 52.942 & 0.007 & 0.770 & 0.341 & 0.011 & 1.069 & 0.034 & 10.933 & 11.851 & 23.421 & 0.000 & 101.379 & 4-px7 & Augite-1 \\
\hline 19 & 53.076 & 0.000 & 0.519 & 0.140 & 0.000 & 2.342 & 0.128 & 5.252 & 17.468 & 19.891 & 0.000 & 98.816 & 4-px8 & Augite- 2 \\
\hline 21 & 97.873 & 0.023 & 0.050 & 1.513 & 0.013 & 3.058 & 0.012 & 0.305 & 0.000 & 0.421 & 0.000 & 103.268 & 4-fsp1 & Qtz \\
\hline 22 & 55.492 & 0.075 & 0.026 & 4.356 & 0.021 & 29.058 & 0.023 & 1.027 & 0.075 & 12.241 & 0.000 & 102.394 & 4-fsp2 & Ca-fsp \\
\hline 23 & 56.082 & 0.060 & 0.043 & 4.339 & 0.029 & 28.951 & 0.035 & 0.721 & 0.069 & 12.210 & 0.000 & 102.539 & $4-\mathrm{fsp} 3$ & Ca-fsp \\
\hline 24 & 56.527 & 0.052 & 0.000 & 4.381 & 0.019 & 28.828 & 0.033 & 0.745 & 0.085 & 12.284 & 0.000 & 102.954 & 4-fsp4 & Ca-fsp \\
\hline 25 & 55.704 & 0.060 & 0.028 & 4.485 & 0.024 & 28.743 & 0.000 & 0.835 & 0.091 & 12.080 & 0.000 & 102.050 & 4-fsp5 & Ca-fsp \\
\hline 26 & 52.454 & 0.021 & 0.000 & 2.871 & 0.006 & 31.647 & 0.008 & 1.048 & 0.149 & 15.026 & 0.000 & 103.230 & 4-fsp6 & Ca-fsp \\
\hline 27 & 54.892 & 0.054 & 0.000 & 3.696 & 0.028 & 29.883 & 0.044 & 0.816 & 0.205 & 13.309 & 0.000 & 102.927 & 4-fsp7 & Ca-fsp \\
\hline 28 & 53.738 & 0.048 & 0.039 & 3.633 & 0.015 & 30.125 & 0.002 & 1.306 & 0.155 & 13.940 & 0.000 & 103.001 & 4-fsp8 & Ca-fsp \\
\hline 29 & 51.767 & 0.034 & 0.000 & 3.400 & 0.010 & 30.310 & 0.040 & 1.036 & 0.143 & 14.446 & 0.000 & 101.186 & 4-fsp9 & Ca-fsp \\
\hline 33 & 52.912 & 0.000 & 0.651 & 0.237 & 0.025 & 0.796 & 0.051 & 9.850 & 12.976 & 23.172 & 0.000 & 100.670 & 6-px1 & Augite-1 \\
\hline 34 & 52.480 & 0.000 & 0.668 & 0.227 & 0.021 & 1.309 & 0.136 & 10.763 & 12.351 & 22.831 & 0.000 & 100.786 & $6-p \times 2$ & Augite-1 \\
\hline 35 & 53.096 & 0.011 & 0.752 & 0.238 & 0.019 & 0.615 & 0.000 & 10.869 & 12.728 & 22.262 & 0.000 & 100.590 & 6-px3 & Augite-1 \\
\hline 36 & 50.616 & 0.004 & 0.734 & 0.264 & 0.012 & 2.750 & 0.287 & 12.632 & 12.293 & 21.183 & 0.000 & 100.775 & 6-px4 & Augite-1 \\
\hline 37 & 49.798 & 0.033 & 1.137 & 0.293 & 0.007 & 2.125 & 0.358 & 15.575 & 11.237 & 19.886 & 0.000 & 100.449 & $6-p \times 5$ & Augite-1 \\
\hline 38 & 52.009 & 0.003 & 1.080 & 0.311 & 0.017 & 1.065 & 0.084 & 13.187 & 11.054 & 22.512 & 0.000 & 101.322 & $6-p \times 6$ & Augite-1 \\
\hline
\end{tabular}




\begin{tabular}{|c|c|c|c|c|c|c|c|c|c|c|c|c|c|c|}
\hline \multicolumn{15}{|c|}{ RD64-J49 bronzite andesite (con't) } \\
\hline No. & $\mathrm{SiO}_{2}$ & $\mathbf{K}_{2} \mathbf{O}$ & MnO & $\mathrm{Na}_{2} \mathrm{O}$ & $\mathbf{P}_{2} \mathbf{O}_{5}$ & $\mathbf{A l}_{2} \mathbf{O}_{3}$ & $\mathrm{TiO}_{2}$ & $\mathrm{FeO}_{\mathrm{T}}$ & MgO & $\mathrm{CaO}$ & $\mathrm{Cr}_{2} \mathrm{O}_{3}$ & Total & $\begin{array}{l}\text { Circle- } \\
\text { label* }\end{array}$ & $\begin{array}{l}\text { Revised } \\
\text { mineral }\end{array}$ \\
\hline 42 & 50.971 & 0.000 & 0.797 & 0.246 & 0.031 & 2.178 & 0.349 & 13.466 & 12.290 & 20.643 & 0.000 & 100.971 & 6-px7 & Augite-1 \\
\hline 43 & 52.345 & 0.033 & 1.123 & 0.368 & 0.004 & 1.437 & 0.066 & 12.074 & 12.222 & 20.163 & 0.000 & 99.835 & 6-px8 & Augite-1 \\
\hline 44 & 52.011 & 0.000 & 0.955 & 0.264 & 0.012 & 1.209 & 0.158 & 13.161 & 10.970 & 22.323 & 0.000 & 101.063 & 6-px9 & Augite-1 \\
\hline 45 & 51.619 & 0.015 & 0.738 & 0.246 & 0.014 & 1.539 & 0.209 & 11.491 & 12.477 & 22.288 & 0.000 & 100.636 & 6-px10 & Augite-1 \\
\hline 46 & 52.214 & 0.009 & 0.778 & 0.261 & 0.007 & 1.129 & 0.073 & 11.277 & 12.422 & 22.506 & 0.000 & 100.676 & 6-px11 & Augite-1 \\
\hline 47 & 50.865 & 0.000 & 0.833 & 0.286 & 0.008 & 2.092 & 0.233 & 11.973 & 12.033 & 21.395 & 0.000 & 99.718 & 6-px12 & Augite-1 \\
\hline 48 & 53.493 & 0.016 & 0.717 & 0.524 & 0.011 & 1.481 & 0.034 & 11.258 & 12.269 & 21.810 & 0.000 & 101.613 & 6-px13 & Augite-1 \\
\hline 49 & 48.711 & 0.001 & 0.799 & 0.273 & 0.012 & 3.798 & 0.581 & 14.565 & 11.064 & 20.317 & 0.000 & 100.121 & 6-px14 & Augite-1 \\
\hline 50 & 52.831 & 0.043 & 0.022 & 4.000 & 0.017 & 29.064 & 0.021 & 1.250 & 0.146 & 13.294 & 0.000 & 100.688 & 6-fsp1 & Ca-fsp \\
\hline 51 & 52.252 & 0.044 & 0.033 & 3.796 & 0.009 & 28.881 & 0.043 & 1.099 & 0.169 & 13.185 & 0.000 & 99.511 & 6-fsp2 & Ca-fsp \\
\hline 52 & 51.995 & 0.031 & 0.000 & 3.958 & 0.017 & 29.436 & 0.029 & 1.075 & 0.165 & 13.484 & 0.000 & 100.190 & 6-fsp3 & Ca-fsp \\
\hline 53 & 52.777 & 0.047 & 0.000 & 4.196 & 0.025 & 29.303 & 0.026 & 0.801 & 0.106 & 12.867 & 0.000 & 100.148 & 6-fsp4 & Ca-fsp \\
\hline 54 & 52.844 & 0.032 & 0.040 & 4.112 & 0.013 & 29.051 & 0.020 & 1.026 & 0.168 & 13.184 & 0.000 & 100.490 & 6-fsp5 & Ca-fsp \\
\hline 56 & 53.873 & 0.000 & 0.562 & 0.164 & 0.012 & 1.291 & 0.081 & 5.465 & 19.646 & 18.073 & 0.000 & 99.167 & 8-px1 & Augite-2 \\
\hline 57 & 52.823 & 0.000 & 0.409 & 0.166 & 0.014 & 1.912 & 0.060 & 5.344 & 18.509 & 18.934 & 0.000 & 98.171 & 8-px2 & Augite-2 \\
\hline 58 & 54.071 & 0.000 & 0.443 & 0.104 & 0.004 & 1.153 & 0.085 & 5.699 & 19.516 & 18.649 & 0.000 & 99.724 & 8-px3 & Augite-2 \\
\hline 59 & 51.757 & 0.000 & 0.496 & 0.224 & 0.013 & 3.820 & 0.350 & 8.271 & 16.332 & 19.635 & 0.000 & 100.898 & 8-px4 & Augite-2 \\
\hline 60 & 52.037 & 0.000 & 0.513 & 0.045 & 0.010 & 3.149 & 0.224 & 8.089 & 17.935 & 18.465 & 0.000 & 100.467 & 8-px5 & Augite-2 \\
\hline 61 & 52.376 & 0.000 & 0.382 & 0.179 & 0.015 & 3.040 & 0.259 & 7.065 & 17.083 & 20.005 & 0.000 & 100.404 & 8-px6 & Augite-2 \\
\hline 62 & 52.761 & 0.005 & 0.354 & 0.242 & 0.019 & 2.417 & 0.204 & 6.619 & 17.390 & 20.050 & 0.000 & 100.061 & 8-px7 & Augite-2 \\
\hline 63 & 53.866 & 0.000 & 0.498 & 0.111 & 0.012 & 1.354 & 0.048 & 5.840 & 19.087 & 18.821 & 0.000 & 99.637 & 8-px8 & Augite-2 \\
\hline 64 & 51.262 & 0.035 & 0.000 & 3.364 & 0.009 & 29.839 & 0.000 & 1.129 & 0.160 & 13.874 & 0.000 & 99.672 & 8-fsp1 & Ca-fsp \\
\hline 65 & 50.112 & 0.018 & 0.019 & 2.751 & 0.007 & 31.112 & 0.045 & 1.132 & 0.238 & 14.650 & 0.000 & 100.084 & 8 -fsp2 & Ca-fsp \\
\hline 66 & 52.228 & 0.042 & 0.159 & 3.999 & 0.013 & 29.564 & 0.047 & 1.267 & 0.108 & 13.149 & 0.000 & 100.576 & 8-fsp3 & Ca-fsp \\
\hline
\end{tabular}


A5.5. RD63-J07 - oxides

\begin{tabular}{|c|c|c|c|c|c|c|c|c|c|c|c|}
\hline No. & $\mathrm{SiO}_{2}$ & MnO & $\mathbf{V}_{2} \mathbf{O}_{3}$ & MgO & $\mathrm{FeO}_{\mathrm{T}}$ & $\mathbf{A l}_{2} \mathbf{O}_{3}$ & $\mathrm{TiO}_{2}$ & $\mathrm{Cr}_{2} \mathrm{O}_{3}$ & $\mathrm{CaO}$ & Total & Label in picture \\
\hline 1 & 0.053 & 0.000 & 0.867 & 0.006 & 94.563 & 0.147 & 0.148 & 2.975 & 0.000 & 98.759 & Magnetite- $1 \mathrm{~b}$ \\
\hline 2 & 0.000 & 0.000 & 0.023 & 0.000 & 99.438 & 0.072 & 0.027 & 0.037 & 0.000 & 99.597 & Std-Hematite \\
\hline 3 & 0.003 & 0.000 & 0.089 & 0.078 & 99.819 & 0.071 & 0.078 & 0.089 & 0.000 & 100.227 & Std-Magnetite \\
\hline 4 & 0.000 & 0.905 & 0.000 & 0.000 & 0.000 & 0.003 & 0.000 & 101.049 & 0.000 & 101.957 & Std-Chromium oxide \\
\hline 5 & 0.044 & 0.000 & 1.400 & 0.014 & 95.014 & 0.083 & 0.676 & 2.954 & 0.000 & 100.185 & Magnetite-1a \\
\hline 6 & 0.309 & 0.000 & 0.337 & 0.115 & 96.754 & 0.053 & 0.007 & 0.263 & 0.000 & 97.838 & Magnetite-2 \\
\hline 7 & 0.260 & 0.000 & 0.000 & 0.031 & 98.456 & 0.072 & 0.014 & 0.000 & 0.070 & 98.903 & Magnetite-3a \\
\hline 8 & 0.307 & 0.000 & 0.000 & 0.015 & 98.080 & 0.041 & 0.000 & 0.052 & 0.115 & 98.610 & Magnetite-3b \\
\hline 9 & 0.020 & 0.000 & 0.122 & 0.011 & 98.407 & 0.000 & 0.014 & 0.068 & 0.134 & 98.776 & Magnetite-4 \\
\hline 10 & 0.068 & 0.000 & 0.112 & 0.000 & 97.954 & 0.003 & 0.032 & 0.052 & 0.299 & 98.520 & Magnetite-5 \\
\hline 11 & 0.080 & 0.000 & 0.211 & 0.008 & 96.820 & 0.000 & 0.000 & 0.016 & 0.309 & 97.444 & Magnetite- 6 \\
\hline 12 & 0.022 & 0.000 & 0.571 & 0.000 & 94.657 & 0.054 & 0.043 & 2.687 & 0.036 & 98.070 & Magnetite-7a \\
\hline 13 & 0.069 & 0.000 & 0.549 & 0.008 & 95.611 & 0.077 & 0.223 & 2.500 & 0.000 & 99.037 & Magnetite- $7 \mathrm{~b}$ \\
\hline 14 & 0.061 & 0.000 & 1.471 & 0.008 & 95.484 & 0.090 & 0.167 & 2.682 & 0.034 & 99.997 & Magnetite-8a \\
\hline 15 & 0.059 & 0.000 & 0.695 & 0.000 & 96.318 & 0.097 & 0.054 & 2.586 & 0.041 & 99.850 & Magnetite- $8 \mathrm{~b}$ \\
\hline 16 & 0.052 & 0.000 & 0.204 & 0.002 & 95.159 & 0.076 & 0.001 & 3.840 & 0.067 & 99.401 & Magnetite-9a \\
\hline 17 & 0.090 & 0.000 & 0.122 & 0.018 & 96.506 & 0.099 & 0.004 & 3.649 & 0.157 & 100.645 & Magnetite-9b \\
\hline
\end{tabular}


A5.6. RD63-J15 - oxides

\begin{tabular}{|c|c|c|c|c|c|c|c|c|c|c|c|}
\hline No. & $\mathrm{SiO}_{2}$ & MnO & $\mathbf{V}_{2} \mathbf{O}_{3}$ & MgO & $\mathrm{FeO}_{\mathrm{T}}$ & $\mathbf{A l}_{2} \mathbf{O}_{3}$ & $\mathrm{TiO}_{2}$ & $\mathrm{Cr}_{2} \mathrm{O}_{3}$ & $\mathrm{CaO}$ & Total & Label in picture \\
\hline 1 & 0.000 & 1.085 & 0.000 & 0.009 & 0.000 & 0.025 & 0.000 & 99.318 & 0.000 & 100.437 & Std-Chromium oxide \\
\hline 2 & 0.034 & 0.000 & 0.179 & 0.118 & 99.776 & 0.068 & 0.055 & 0.000 & 0.004 & 100.234 & Std-Magnetite2 \\
\hline 3 & 0.009 & 0.000 & 0.000 & 0.000 & 96.276 & 0.000 & 0.000 & 0.000 & 0.004 & 96.289 & Std-Hematite \\
\hline 4 & 50.340 & 0.000 & 0.018 & 0.080 & 0.473 & 27.780 & 0.051 & 0.044 & 11.230 & 90.016 & St-PlagAn65 \\
\hline 5 & 35.899 & 0.136 & 0.186 & 17.776 & 12.776 & 14.898 & 1.386 & 0.042 & 0.039 & 83.138 & Std-Kaersutite2 \\
\hline 6 & 47.520 & 0.222 & 0.223 & 6.802 & 11.428 & 13.041 & 2.370 & 0.050 & 10.173 & 91.829 & Std-BHVO-1 \\
\hline 7 & 0.070 & 0.000 & 0.118 & 0.001 & 97.461 & 0.022 & 0.051 & 0.063 & 0.018 & 97.804 & Magnetite-1a \\
\hline 8 & 0.492 & 0.000 & 0.163 & 0.001 & 97.770 & 0.072 & 0.532 & 0.032 & 0.493 & 99.555 & Magnetite-1b \\
\hline 9 & 0.054 & 0.000 & 0.137 & 0.000 & 98.697 & 0.068 & 0.090 & 0.058 & 0.014 & 99.118 & Magnetite-2a \\
\hline 10 & 0.196 & 0.000 & 0.063 & 0.007 & 99.391 & 0.023 & 0.057 & 0.047 & 0.015 & 99.799 & Magnetite-2b \\
\hline 11 & 2.462 & 0.000 & 0.427 & 0.023 & 92.718 & 0.171 & 3.011 & 0.061 & 1.995 & 100.868 & Magnetite-3 \\
\hline 12 & 0.170 & 0.000 & 0.181 & 0.000 & 98.805 & 0.072 & 0.060 & 0.031 & 0.042 & 99.361 & Magnetite-4 \\
\hline 13 & 0.112 & 0.000 & 0.066 & 0.000 & 97.209 & 0.011 & 0.199 & 0.000 & 0.102 & 97.699 & Magnetite-5 \\
\hline 14 & 0.281 & 0.000 & 0.039 & 0.000 & 98.234 & 0.028 & 0.027 & 0.026 & 0.000 & 98.635 & Magnetite- 6 \\
\hline 15 & 0.131 & 0.000 & 0.114 & 0.000 & 99.257 & 0.078 & 0.115 & 0.000 & 0.026 & 99.721 & Magnetite-7 \\
\hline 16 & 0.047 & 0.000 & 0.244 & 0.000 & 97.461 & 0.060 & 0.908 & 0.000 & 0.004 & 98.724 & Magnetite- 8 \\
\hline 17 & 0.149 & 0.000 & 0.162 & 0.000 & 97.818 & 0.050 & 0.037 & 0.047 & 0.006 & 98.269 & Magnetite-9 \\
\hline 18 & 0.629 & 0.000 & 0.104 & 0.039 & 96.573 & 0.075 & 0.093 & 0.021 & 0.021 & 97.555 & Magnetite-10 \\
\hline 19 & 0.117 & 0.000 & 0.123 & 0.024 & 97.836 & 0.128 & 0.224 & 0.026 & 0.069 & 98.547 & Magnetite-11a \\
\hline 20 & 0.126 & 0.000 & 0.094 & 0.004 & 97.676 & 0.116 & 0.028 & 0.000 & 0.011 & 98.055 & Magnetite-11b \\
\hline 21 & 0.130 & 0.000 & 0.148 & 0.000 & 97.170 & 0.085 & 0.036 & 0.000 & 0.205 & 97.774 & Magnetite-12 \\
\hline 22 & 0.086 & 0.000 & 0.124 & 0.000 & 100.211 & 0.041 & 0.079 & 0.037 & 0.193 & 100.771 & Std-Hematite-12 \\
\hline 23 & 0.245 & 0.000 & 0.363 & 0.056 & 98.487 & 0.204 & 1.912 & 0.016 & 0.028 & 101.311 & Std-Hematite-11 \\
\hline 24 & 0.179 & 0.000 & 0.147 & 0.097 & 100.748 & 0.195 & 0.179 & 0.016 & 0.012 & 101.573 & Std-Hematite-11b \\
\hline
\end{tabular}




\begin{tabular}{|c|c|c|c|c|c|c|c|c|c|c|c|}
\hline \multicolumn{12}{|c|}{ RD63-J15 - oxides (con't) } \\
\hline No. & $\mathrm{SiO}_{2}$ & MnO & $\mathbf{V}_{2} \mathbf{O}_{3}$ & MgO & $\mathrm{FeO}_{\mathrm{T}}$ & $\mathbf{A l}_{2} \mathbf{O}_{3}$ & $\mathrm{TiO}_{2}$ & $\mathrm{Cr}_{2} \mathrm{O}_{3}$ & $\mathrm{CaO}$ & Total & Label in picture \\
\hline 25 & 0.127 & 0.000 & 0.149 & 0.032 & 99.949 & 0.025 & 0.117 & 0.026 & 0.085 & 100.510 & Magn-circle3-1 \\
\hline 26 & 0.069 & 0.000 & 0.160 & 0.000 & 98.095 & 0.047 & 0.095 & 0.010 & 0.095 & 98.571 & Magn-circle3-2 \\
\hline 27 & 2.947 & 0.000 & 0.036 & 0.008 & 92.413 & 1.204 & 0.081 & 0.069 & 0.396 & 97.154 & Magn-circle3-3 \\
\hline 28 & 0.056 & 0.000 & 0.182 & 0.000 & 98.102 & 0.106 & 0.475 & 0.000 & 0.000 & 98.921 & Magn-circle3-4a \\
\hline 29 & 0.086 & 0.000 & 0.130 & 0.000 & 98.837 & 0.124 & 0.143 & 0.042 & 0.018 & 99.380 & Magn-circle3-4b \\
\hline 30 & 0.018 & 0.000 & 0.151 & 0.001 & 98.533 & 0.096 & 0.063 & 0.000 & 0.034 & 98.896 & Magn-circle3-5 \\
\hline 31 & 27.732 & 0.000 & 0.000 & 0.119 & 53.496 & 14.550 & 0.000 & 0.000 & 4.623 & 100.520 & Magn-circle3-6 \\
\hline 32 & 0.049 & 0.000 & 0.098 & 0.000 & 98.554 & 0.051 & 0.020 & 0.000 & 0.000 & 98.772 & Magn-circle3-7a \\
\hline 33 & 0.169 & 0.000 & 0.199 & 0.000 & 97.487 & 0.022 & 0.241 & 0.000 & 0.124 & 98.242 & Magn-circle3-7b \\
\hline 34 & 0.145 & 0.000 & 0.168 & 0.000 & 98.398 & 0.103 & 0.110 & 0.000 & 0.000 & 98.924 & Magn-circle3-8a \\
\hline 35 & 0.083 & 0.000 & 0.166 & 0.001 & 98.849 & 0.050 & 0.056 & 0.000 & 0.084 & 99.289 & Magn-circle3-8b \\
\hline 36 & 0.122 & 0.000 & 0.146 & 0.000 & 96.885 & 0.009 & 0.070 & 0.000 & 0.084 & 97.316 & Magn-circle3-9 \\
\hline 37 & 0.280 & 0.000 & 0.048 & 0.019 & 95.539 & 0.062 & 0.000 & 0.000 & 0.093 & 96.041 & Magn-circle3-10 \\
\hline 38 & 0.084 & 0.000 & 0.181 & 0.000 & 98.297 & 0.032 & 0.096 & 0.010 & 0.023 & 98.723 & Magn-circle3-11 \\
\hline 39 & 0.085 & 0.000 & 0.171 & 0.000 & 102.240 & 0.056 & 0.117 & 0.010 & 0.014 & 102.693 & Std-Hematite-circle3-7 \\
\hline 40 & 0.000 & 0.676 & 0.000 & 0.014 & 0.007 & 0.039 & 0.000 & 100.873 & 0.015 & 101.624 & Std-Chromium oxide \\
\hline 41 & 0.032 & 0.000 & 0.152 & 0.095 & 97.697 & 0.052 & 0.079 & 0.079 & 0.006 & 98.192 & Std-Magnetite2 \\
\hline 42 & 50.183 & 0.000 & 0.010 & 0.077 & 0.426 & 27.885 & 0.083 & 0.000 & 11.027 & 89.691 & Std-PlagAn65 \\
\hline 43 & 36.102 & 0.134 & 0.175 & 16.786 & 12.653 & 15.130 & 1.504 & 0.133 & 0.051 & 82.668 & Std-Kaersutite2 \\
\hline 44 & 47.654 & 0.254 & 0.316 & 6.435 & 11.673 & 12.914 & 2.394 & 0.107 & 10.273 & 92.020 & Std-BHVO-1 \\
\hline
\end{tabular}


A5.7. RD63-J40 - oxides

\begin{tabular}{|c|c|c|c|c|c|c|c|c|c|c|c|}
\hline No. & $\mathrm{SiO}_{2}$ & MnO & $\mathrm{V}_{2} \mathrm{O}_{3}$ & MgO & $\mathrm{FeO}_{\mathrm{T}}$ & $\mathbf{A l}_{2} \mathbf{O}_{3}$ & $\mathrm{TiO}_{2}$ & $\mathrm{Cr}_{2} \mathrm{O}_{3}$ & $\mathrm{CaO}$ & Total & Label in picture \\
\hline 1 & 0.058 & 0.000 & 0.065 & 0.000 & 98.578 & 0.032 & 0.018 & 0.000 & 0.000 & 98.751 & circle2-oxide1 \\
\hline 2 & 0.150 & 0.000 & 0.087 & 0.000 & 96.860 & 0.000 & 0.012 & 0.000 & 0.031 & 97.140 & circle2-oxide2 \\
\hline 3 & 0.210 & 0.000 & 0.112 & 0.000 & 99.549 & 0.039 & 0.003 & 0.000 & 0.024 & 99.937 & circle2-oxide3 \\
\hline 4 & 0.190 & 0.000 & 0.087 & 0.000 & 99.759 & 0.003 & 0.000 & 0.000 & 0.020 & 100.059 & circle2-oxide4 \\
\hline 5 & 0.123 & 0.000 & 0.134 & 0.013 & 101.074 & 0.011 & 0.109 & 0.000 & 0.029 & 101.493 & circle2-oxide5 \\
\hline 6 & 0.139 & 0.000 & 0.100 & 0.000 & 98.346 & 0.015 & 0.114 & 0.000 & 0.004 & 98.718 & circle2-oxide6 \\
\hline 8 & 0.155 & 0.000 & 0.119 & 0.004 & 96.606 & 0.035 & 0.008 & 0.000 & 0.082 & 97.009 & circle2-oxide8 \\
\hline 9 & 0.177 & 1.020 & 0.426 & 0.000 & 96.516 & 0.032 & 2.779 & 0.016 & 0.000 & 100.966 & circle2-oxide9 \\
\hline 10 & 0.215 & 0.000 & 0.150 & 0.000 & 98.685 & 0.060 & 0.000 & 0.000 & 0.046 & 99.156 & Std-oxide-hematite2 \\
\hline 11 & 0.090 & 0.176 & 0.189 & 0.000 & 101.053 & 0.034 & 0.532 & 0.026 & 0.014 & 102.114 & Std-oxide-hematite1 \\
\hline 12 & 0.092 & 0.000 & 0.084 & 0.000 & 98.263 & 0.009 & 0.054 & 0.005 & 0.028 & 98.535 & Std-oxide5-magnetite \\
\hline 13 & 0.174 & 0.000 & 0.080 & 0.000 & 100.300 & 0.034 & 0.000 & 0.000 & 0.038 & 100.626 & Std-oxide8-hematite \\
\hline 15 & 2.533 & 0.019 & 0.018 & 1.060 & 79.988 & 0.114 & 0.001 & 0.000 & 0.283 & 84.016 & circle5-oxide1b \\
\hline 16 & 0.296 & 0.000 & 0.107 & 0.000 & 98.244 & 0.000 & 0.133 & 0.068 & 0.034 & 98.882 & circle5-oxide2 \\
\hline 17 & 0.145 & 0.000 & 0.050 & 0.000 & 98.728 & 0.034 & 0.000 & 0.000 & 0.028 & 98.985 & circle5-oxide3 \\
\hline 18 & 0.254 & 0.000 & 0.005 & 0.000 & 98.805 & 0.051 & 0.000 & 0.000 & 0.034 & 99.149 & circle5-oxide4 \\
\hline 19 & 0.104 & 9.970 & 5.991 & 0.000 & 44.537 & 0.000 & 44.298 & 0.000 & 0.075 & 104.975 & circle5-oxide5 \\
\hline 20 & 1.115 & 0.000 & 0.041 & 0.110 & 96.247 & 0.128 & 0.003 & 0.000 & 0.077 & 97.721 & circle5-oxide6 \\
\hline 21 & 0.000 & 0.540 & 0.007 & 0.007 & 0.000 & 0.000 & 0.000 & 102.568 & 0.000 & 103.122 & Std-Chromium Oxide \\
\hline 22 & 0.018 & 0.000 & 0.114 & 0.000 & 99.730 & 0.000 & 0.066 & 0.037 & 0.000 & 99.965 & Std-Magnetite2 \\
\hline 23 & 50.349 & 0.000 & 0.000 & 0.078 & 0.471 & 27.465 & 0.062 & 0.052 & 11.216 & 89.693 & Std-PlagAn65 \\
\hline 24 & 36.210 & 0.136 & 0.158 & 17.695 & 10.359 & 14.300 & 1.193 & 0.092 & 0.171 & 80.314 & Std-Kaersutite2 \\
\hline 25 & 47.747 & 0.217 & 0.296 & 6.913 & 11.433 & 12.506 & 2.341 & 0.064 & 10.217 & 91.734 & Std-BHVO-1 \\
\hline 26 & 0.000 & 0.000 & 0.005 & 0.000 & 99.449 & 0.000 & 0.015 & 0.000 & 0.016 & 99.485 & Std-Hematite \\
\hline
\end{tabular}


A5.8. RD64-J49 - oxides

\begin{tabular}{|c|c|c|c|c|c|c|c|c|c|c|c|}
\hline No. & $\mathrm{SiO}_{2}$ & MnO & $\mathbf{V}_{2} \mathbf{O}_{3}$ & MgO & $\mathrm{FeO}_{\mathrm{T}}$ & $\mathbf{A l}_{2} \mathbf{O}_{3}$ & $\mathrm{TiO}_{2}$ & $\mathrm{Cr}_{2} \mathrm{O}_{3}$ & $\mathrm{CaO}$ & Total & Label in picture \\
\hline 1 & 0.013 & 0.000 & 0.024 & 0.000 & 99.190 & 0.004 & 0.000 & 0.000 & 0.009 & 99.240 & Std-Hematite \\
\hline 2 & 0.024 & 0.898 & 0.000 & 0.012 & 0.000 & 0.000 & 0.000 & 100.077 & 0.005 & 101.016 & Std-Chromium oxide \\
\hline 3 & 50.512 & 0.000 & 0.017 & 0.099 & 0.448 & 27.334 & 0.079 & 0.000 & 11.260 & 89.749 & Std-PlagAn65 \\
\hline 4 & 36.096 & 0.153 & 0.176 & 17.463 & 10.868 & 14.399 & 1.064 & 0.155 & 0.216 & 80.590 & Std-Kaersutite2 \\
\hline 5 & 46.914 & 0.233 & 0.263 & 6.853 & 12.030 & 13.031 & 2.373 & 0.064 & 10.393 & 92.154 & Std-BHVO-1 \\
\hline 6 & 0.005 & 0.000 & 0.122 & 0.051 & 99.520 & 0.070 & 0.036 & 0.037 & 0.000 & 99.841 & Std-Magnetite2 \\
\hline 7 & 0.009 & 0.895 & 0.110 & 13.553 & 20.264 & 11.529 & 0.154 & 53.748 & 0.044 & 100.306 & circle2-oxide1a \\
\hline 8 & 0.093 & 0.922 & 0.090 & 13.827 & 20.049 & 11.732 & 0.159 & 55.921 & 0.028 & 102.821 & circle2-oxide1b \\
\hline 9 & 0.061 & 0.883 & 0.016 & 13.213 & 21.079 & 11.571 & 0.167 & 54.582 & 0.126 & 101.698 & circle2-oxide2 \\
\hline 10 & 0.057 & 0.793 & 0.086 & 13.651 & 19.908 & 11.914 & 0.177 & 54.547 & 0.118 & 101.251 & circle2-oxide3a \\
\hline 11 & 0.100 & 0.835 & 0.066 & 13.735 & 19.849 & 11.753 & 0.136 & 53.752 & 0.078 & 100.304 & circle2-oxide $3 b$ \\
\hline 12 & 0.051 & 0.884 & 0.125 & 11.867 & 22.442 & 11.970 & 0.178 & 54.241 & 0.051 & 101.809 & circle2-oxide4 \\
\hline 13 & 0.059 & 0.861 & 0.029 & 11.370 & 24.462 & 11.619 & 0.170 & 53.550 & 0.074 & 102.194 & circle2-oxide5 \\
\hline 14 & 0.067 & 0.861 & 0.122 & 11.566 & 25.785 & 11.599 & 0.232 & 52.500 & 0.096 & 102.828 & Near circle5-oxide1 \\
\hline 15 & 0.063 & 0.877 & 0.171 & 11.544 & 25.850 & 11.609 & 0.251 & 52.115 & 0.043 & 102.523 & Near circle5-oxide2 \\
\hline 16 & 0.033 & 0.727 & 0.099 & 11.832 & 23.570 & 11.939 & 0.271 & 53.497 & 0.039 & 102.007 & Near circle5-oxide3 \\
\hline 17 & 0.018 & 0.840 & 0.105 & 11.571 & 25.040 & 11.543 & 0.205 & 53.443 & 0.014 & 102.779 & Near circle5-oxide4a \\
\hline 18 & 0.050 & 0.892 & 0.077 & 11.512 & 23.897 & 11.062 & 0.180 & 53.191 & 0.001 & 100.862 & Near circle5-oxide $4 b$ \\
\hline 19 & 0.103 & 0.807 & 0.126 & 11.750 & 24.046 & 11.215 & 0.206 & 53.159 & 0.001 & 101.413 & Near circle5-oxide5 \\
\hline 20 & 0.060 & 0.739 & 0.109 & 11.800 & 23.227 & 11.325 & 0.211 & 48.545 & 0.009 & 96.025 & Near circle5-oxide6 \\
\hline 21 & 0.095 & 0.926 & 0.097 & 11.188 & 25.083 & 11.581 & 0.245 & 53.357 & 0.035 & 102.607 & Near circle5-oxide 7 \\
\hline 22 & 0.000 & 0.000 & 0.035 & 0.000 & 100.752 & 0.030 & 0.010 & 0.042 & 0.000 & 100.869 & Std-Hematite \\
\hline 23 & 0.028 & 0.821 & 0.000 & 0.000 & 0.014 & 0.000 & 0.000 & 102.367 & 0.004 & 103.234 & Std-Chromium oxide \\
\hline 24 & 50.787 & 0.036 & 0.001 & 0.059 & 0.447 & 27.726 & 0.072 & 0.000 & 11.090 & 90.218 & Std-PlagAn65 \\
\hline 25 & 37.242 & 0.084 & 0.082 & 18.319 & 10.872 & 15.224 & 1.103 & 0.120 & 0.314 & 83.360 & Std-Kaersutite2 \\
\hline 26 & 47.884 & 0.254 & 0.273 & 6.839 & 12.021 & 13.210 & 2.303 & 0.079 & 10.296 & 93.159 & Std-BHVO-1 \\
\hline 27 & 0.026 & 0.000 & 0.097 & 0.059 & 100.945 & 0.000 & 0.045 & 0.115 & 0.000 & 101.287 & Std-Magnetite2 \\
\hline
\end{tabular}


A5.9. EPMA backscatter images showing point labels and locations

\section{A5.9.1. RD63-J07}

Circle 3, pts no. 35-42

Circle 3, pts no. 43-48
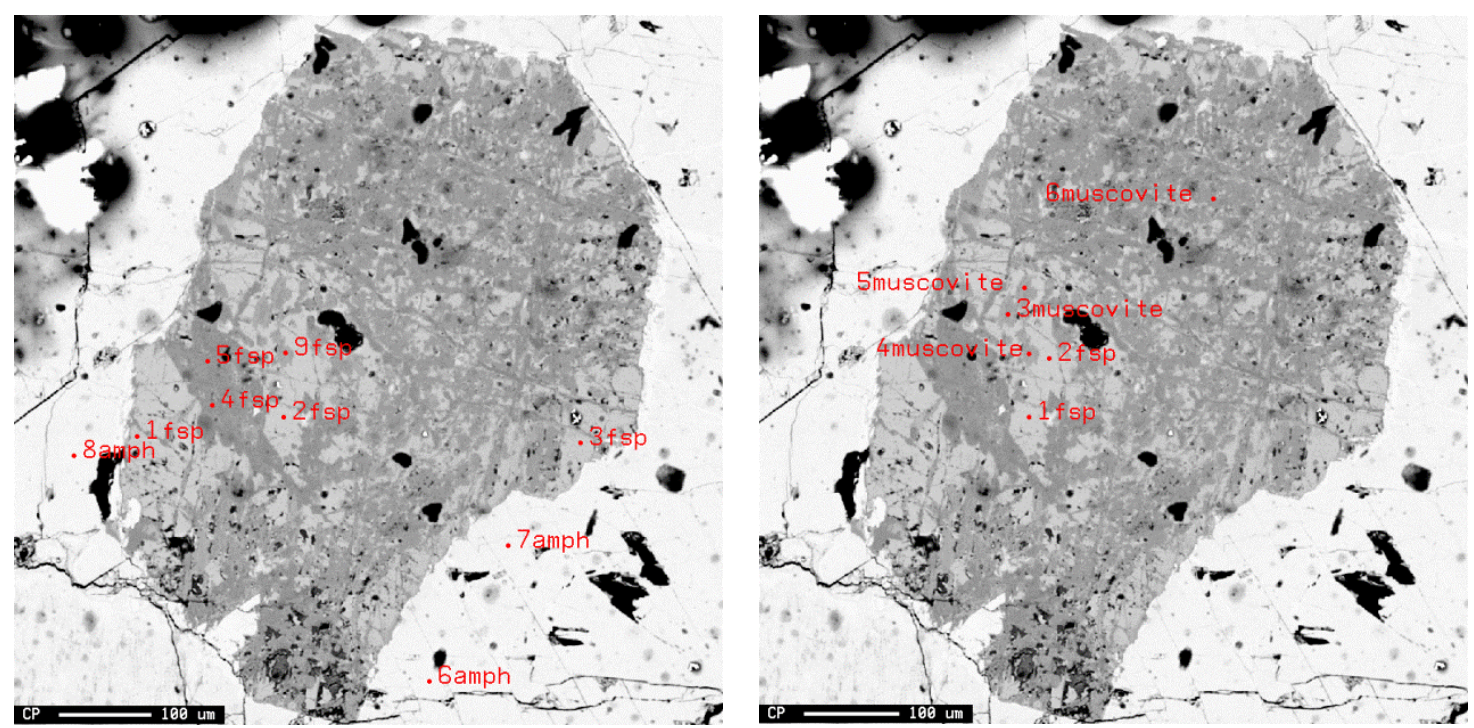

Circle 4, pts no. 1-9

Circle 4, pts no. 16-22
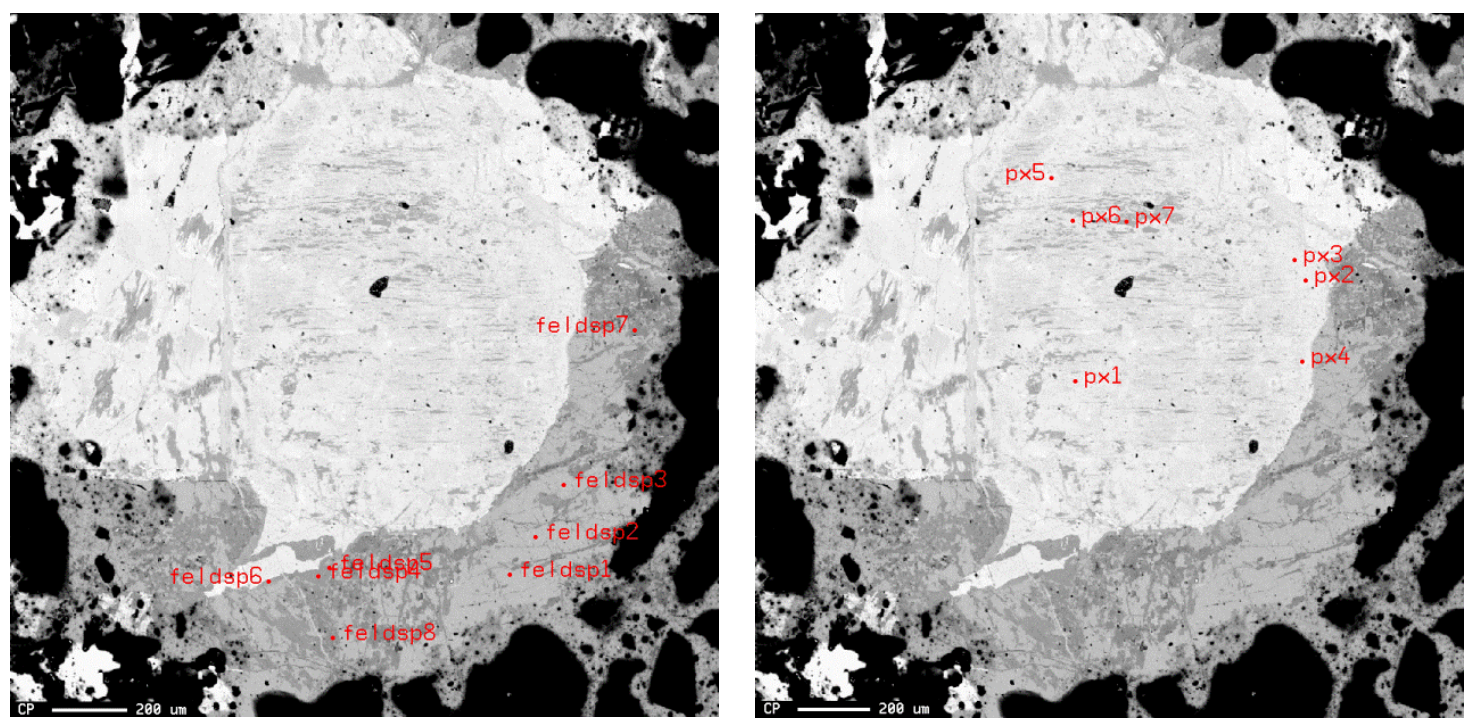
Oxide pts 12-17

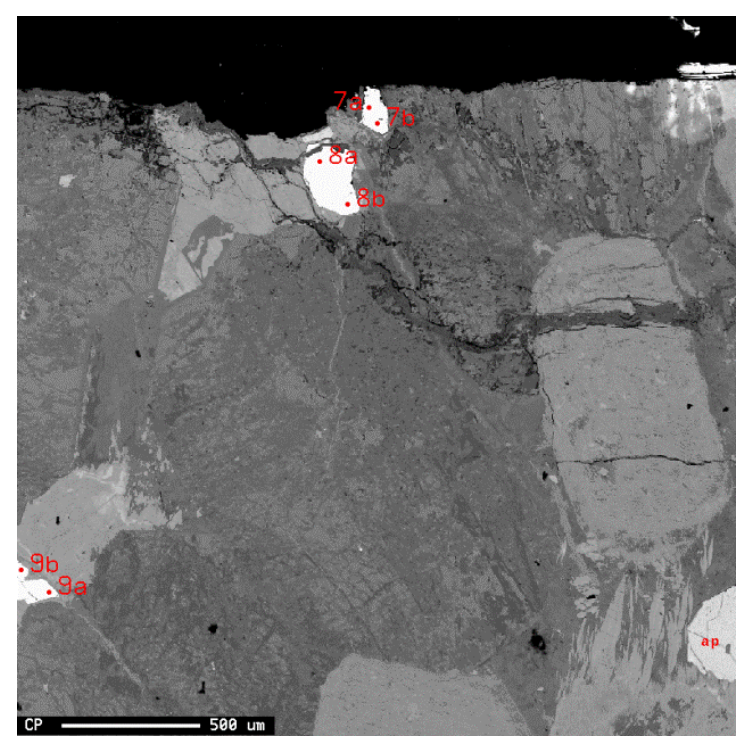

Oxide pts 7-8

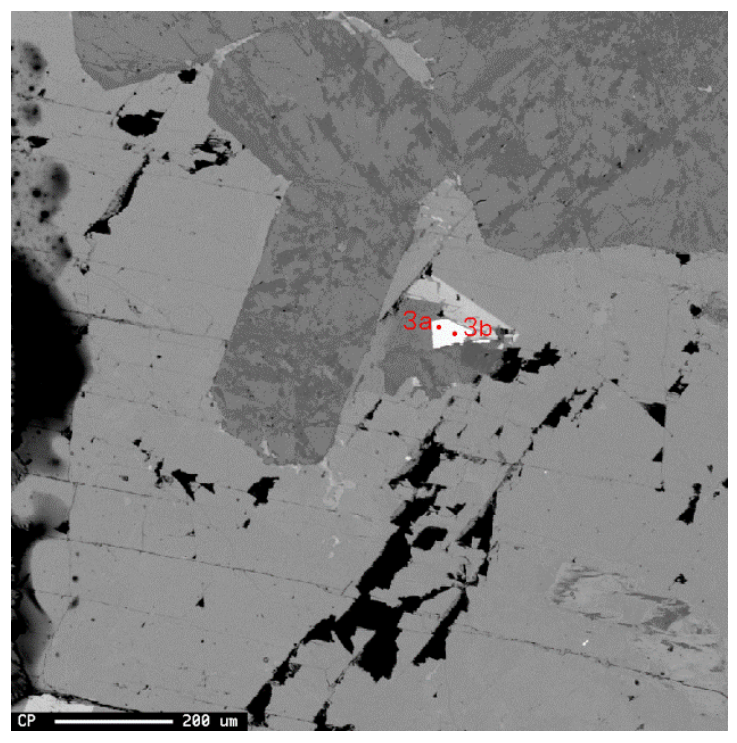

Oxide pts 1-6

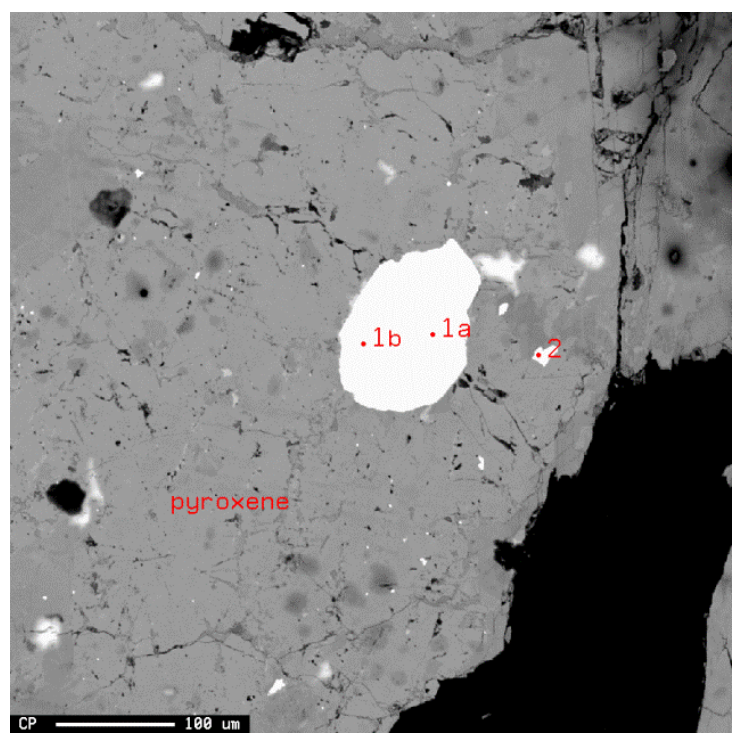

Oxide 9-11

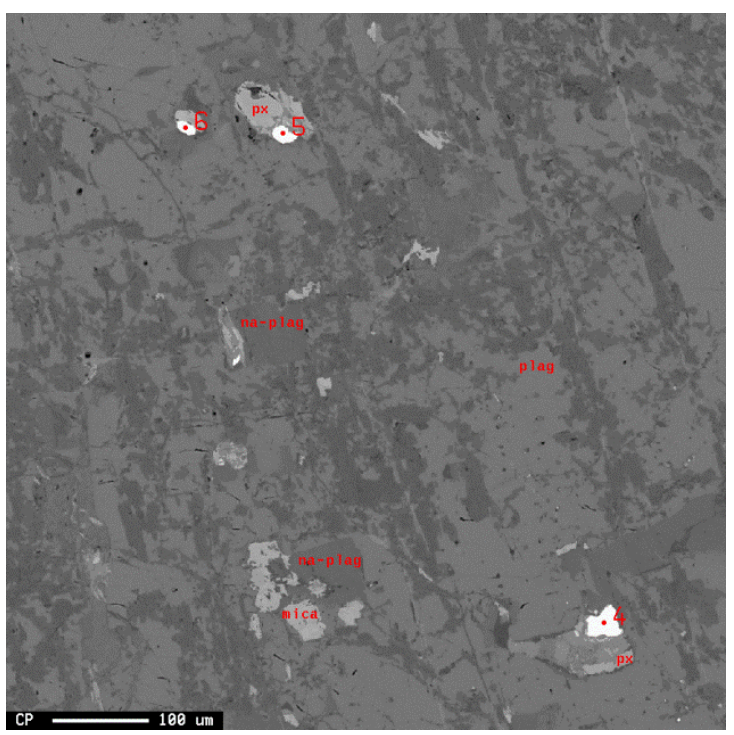


Zircon grain in RD63-J07, gabbro

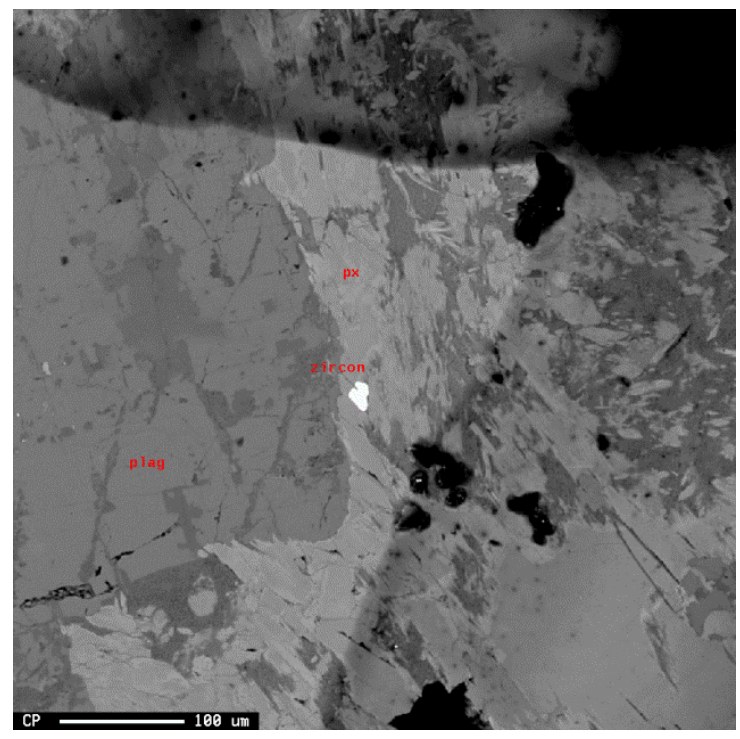

\section{A5.9.2. RD63-J15}

Circle 4 pts no. 1-9

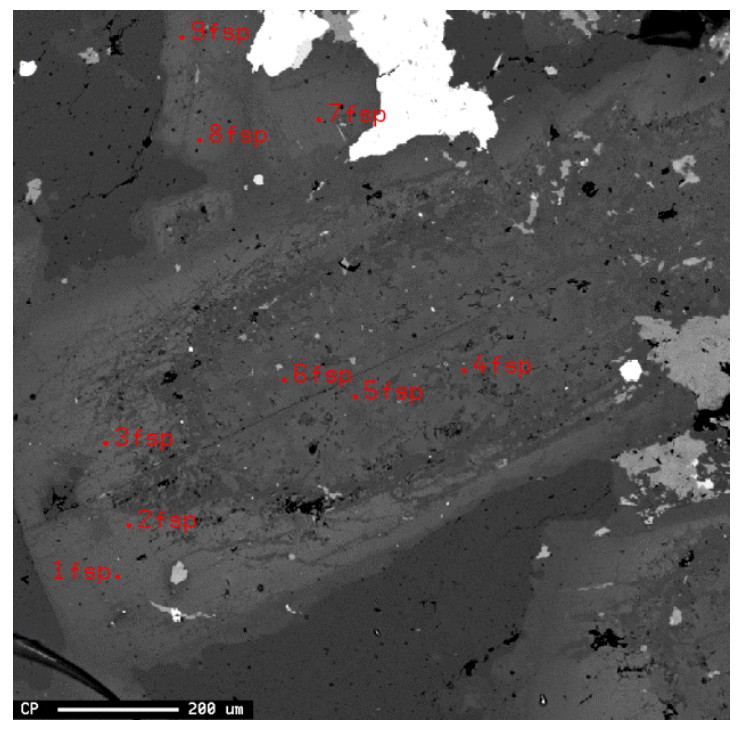

Circle 2, pts no. 10-27

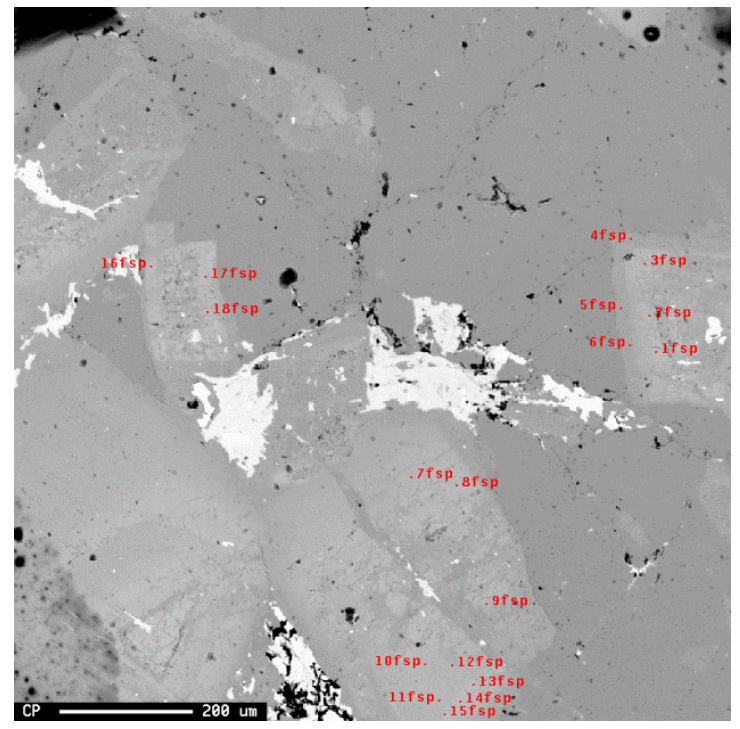


Oxide pts no. 7-18

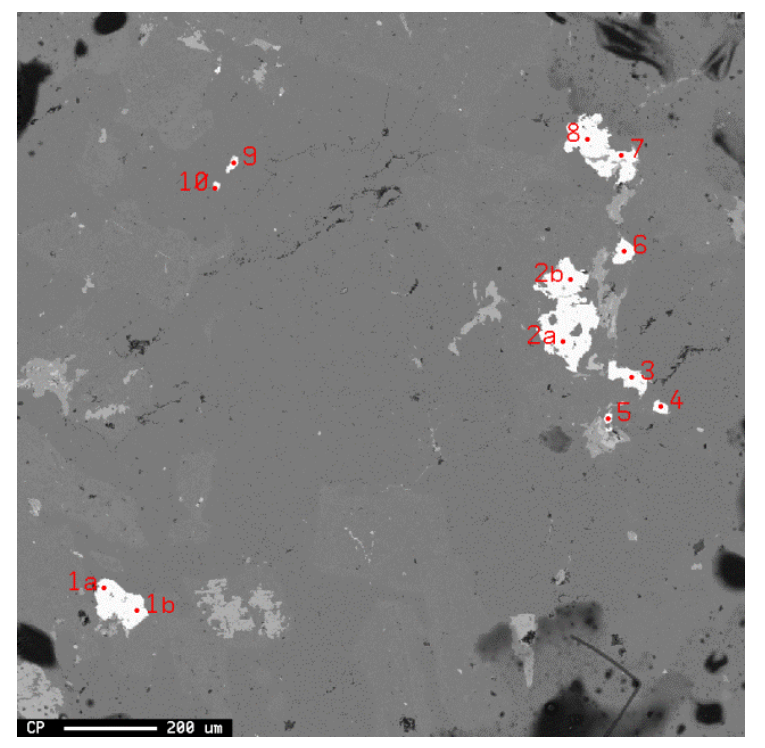

Oxide pts no 25-38

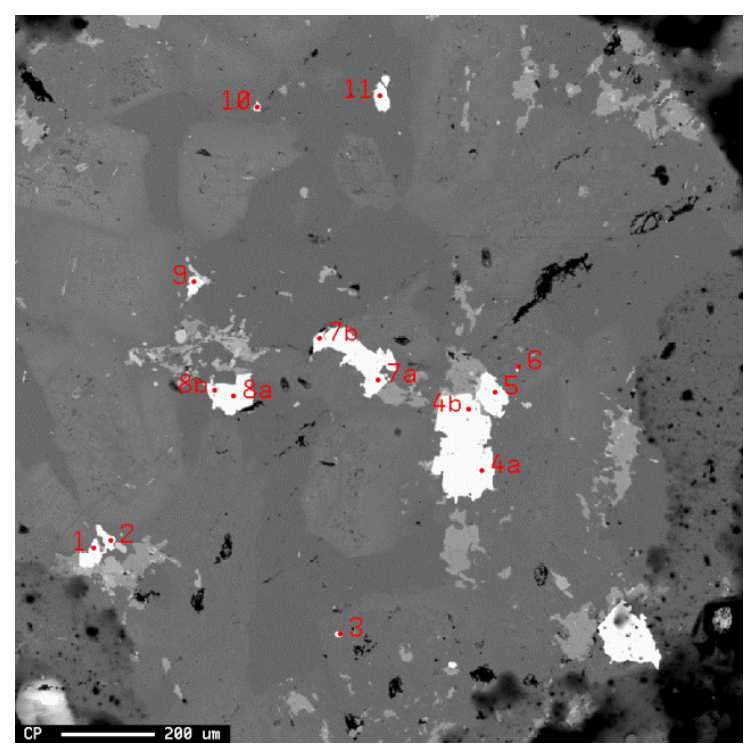

Oxide pts no.19-21

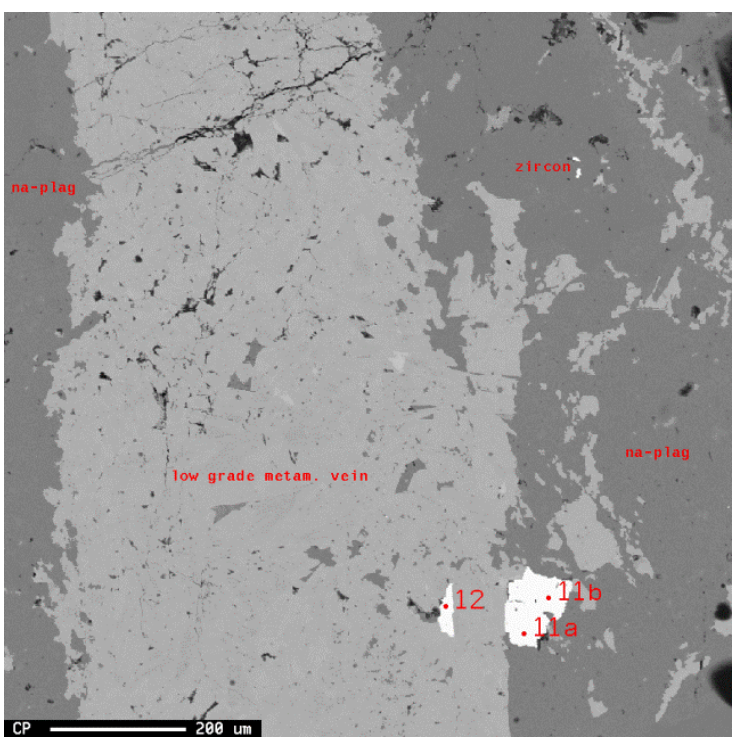


A5.9.3. RD63-J40

Circle 3, pts no. 1-11

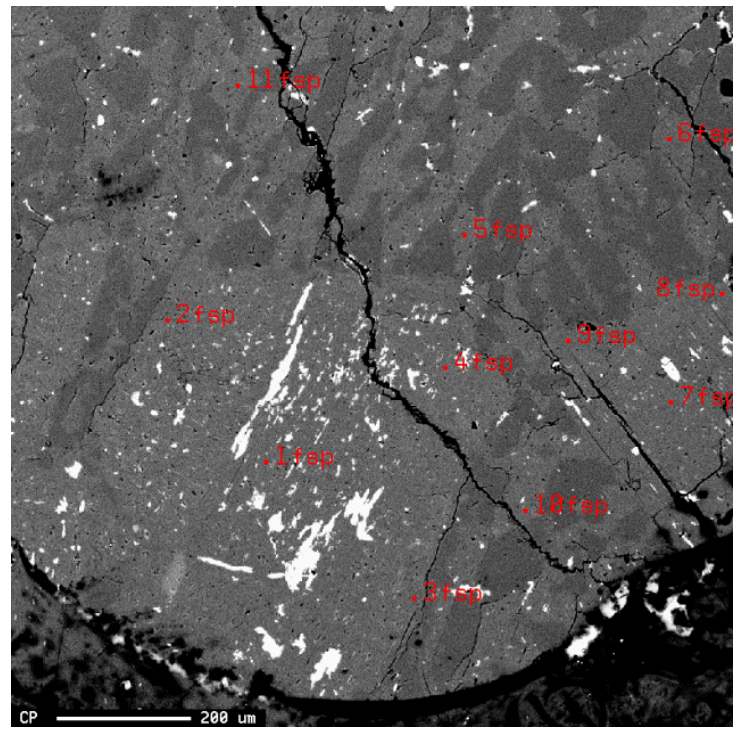

Circle, oxides, pts no.14-20

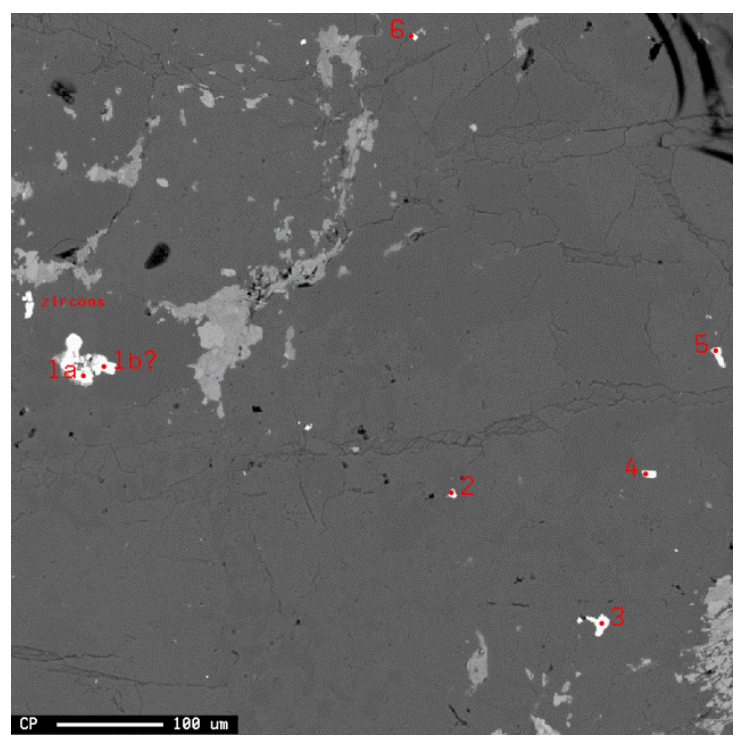

Circle 2, oxides, pts no. 1-9

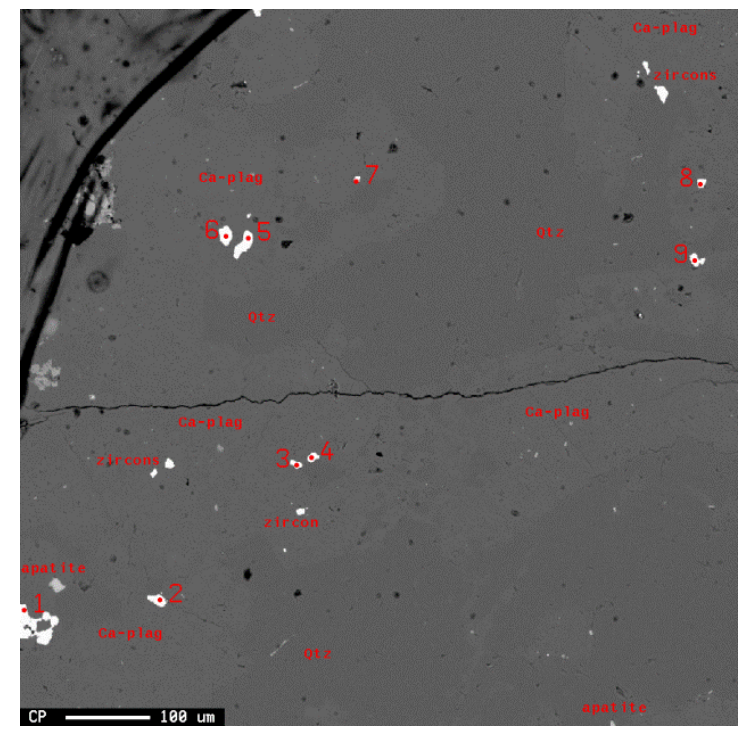


A5.9.4. RD64-J49

Circle 2, pts no. 1-7

Circle 4, pts no. 11-29
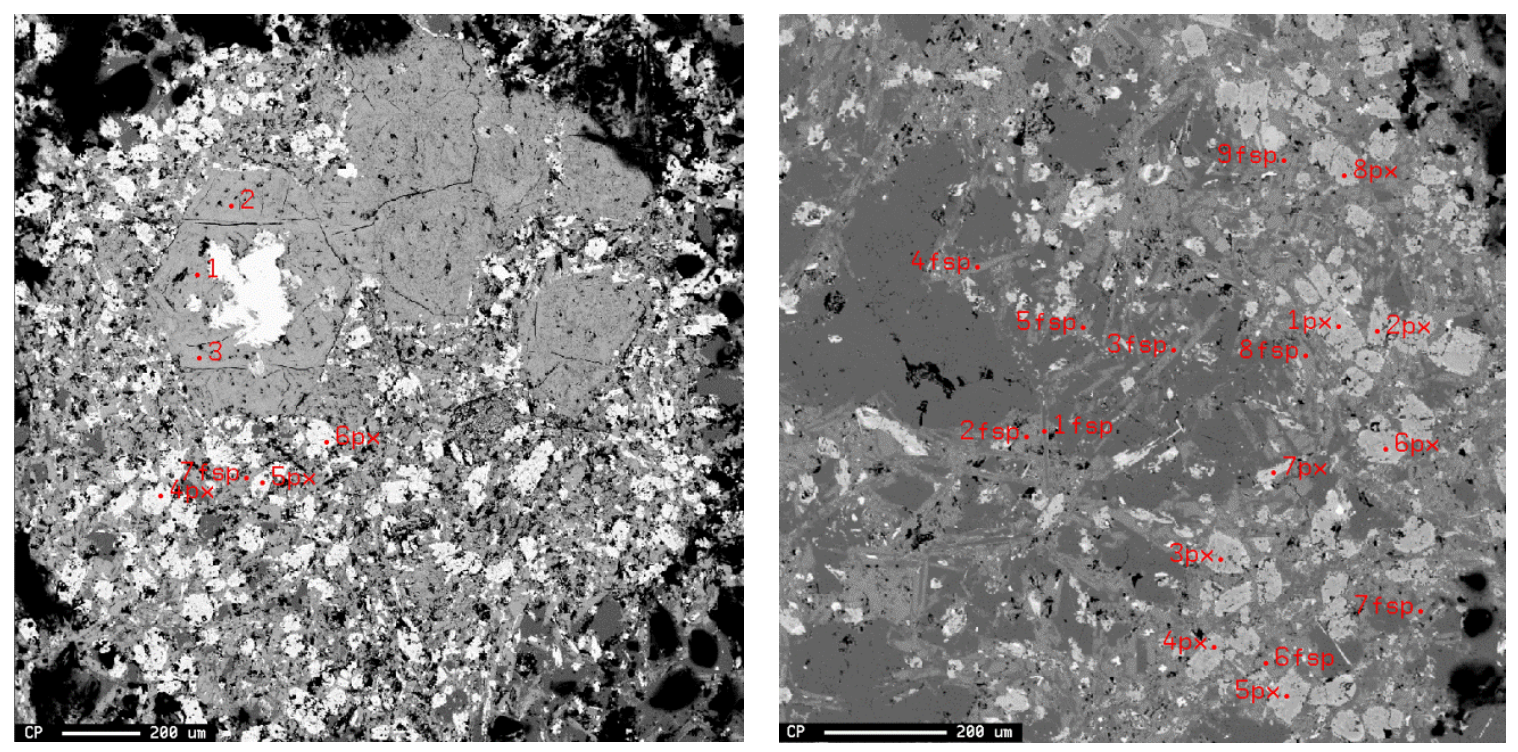

Circle 6, pts no. 33-49

Circle 8, pts. 56-66
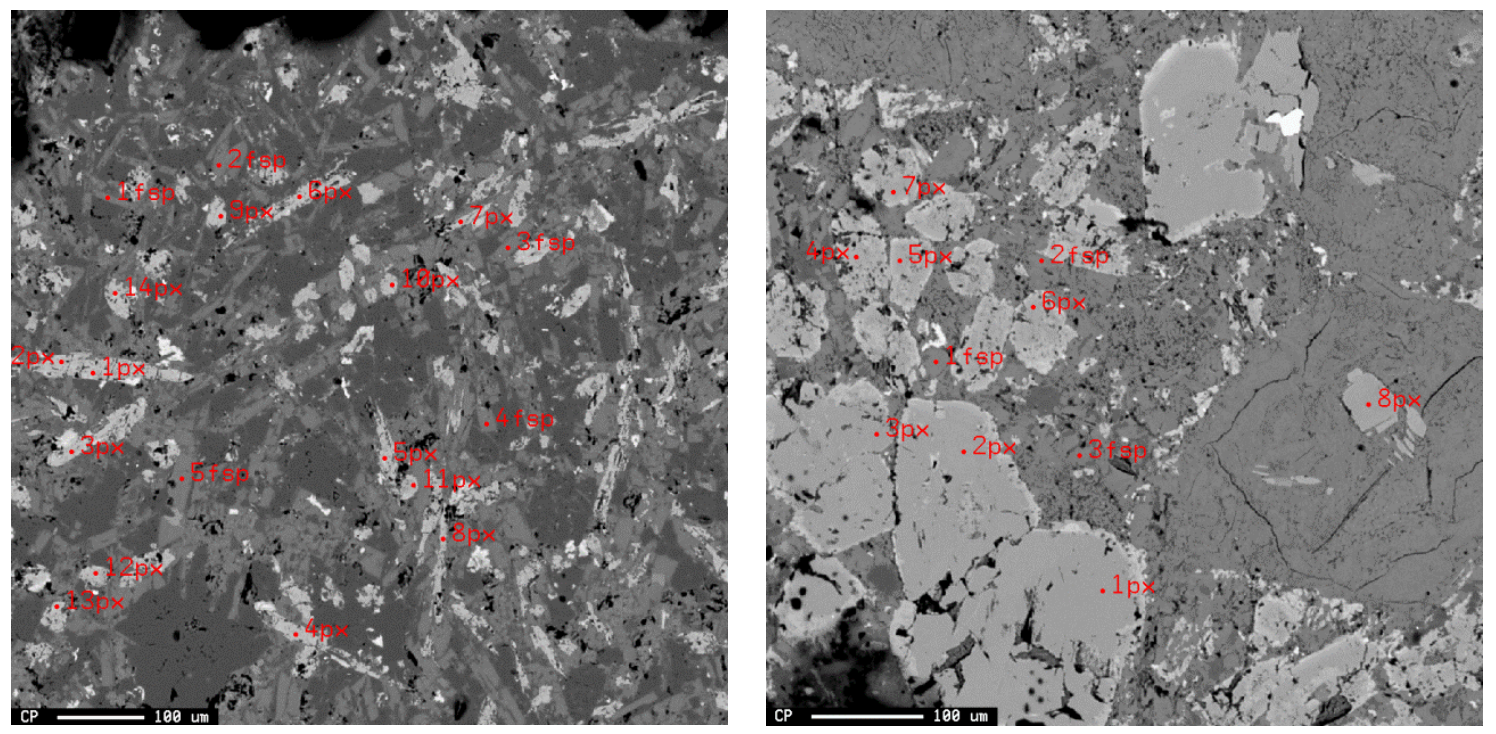
Circle 2, oxide pts no. 7-13

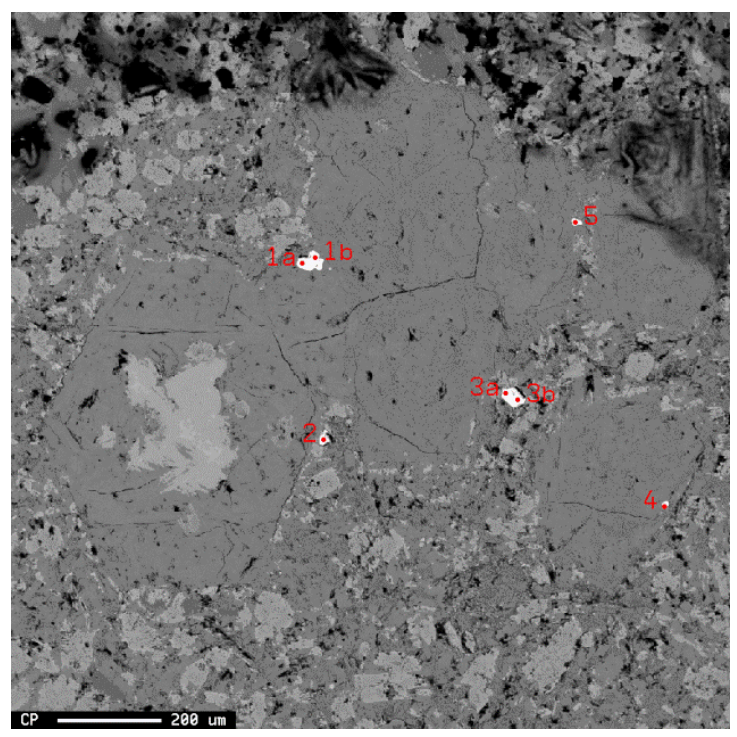

Circle 5, oxide pts no. 14-21

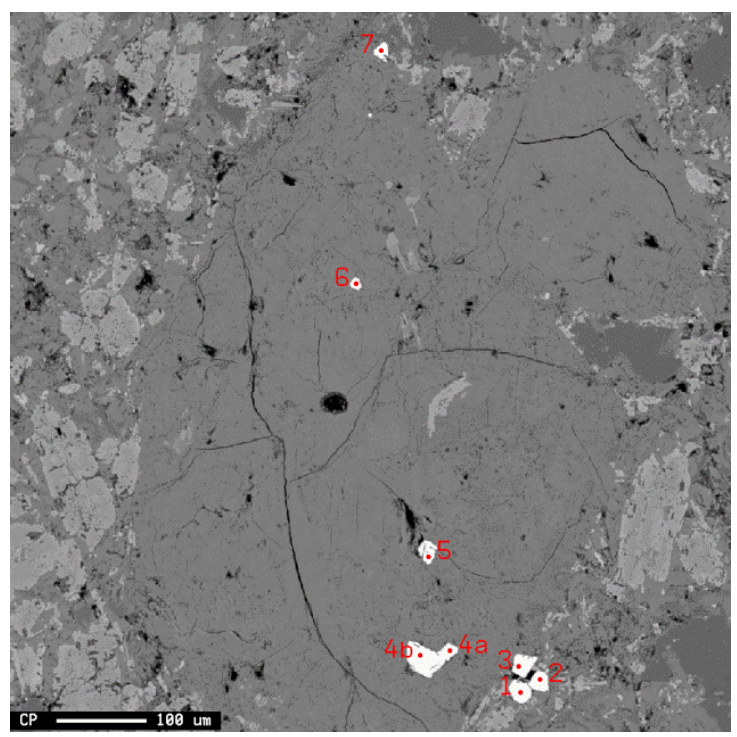




\section{APPENDIX 6}

A6. Example page of Microsoft Excel spreadsheet calculations for REE modeling. Equations used to calculate $\mathrm{D}$ and $\mathrm{C}_{\mathrm{S}}$ are embedded in the cells, and are given in the text (Chapter 4).

\begin{tabular}{|c|c|c|c|c|c|c|c|c|c|c|c|c|c|}
\hline & & La & $\mathrm{Ce}$ & Nd & $\mathbf{Z r}$ & Hf & Sm & $\mathbf{E u}$ & Gd & $\mathbf{T b}$ & Dy & $\mathbf{Y b}$ & Lu \\
\hline$C_{0}=$ & MORB & 4.13 & 11.46 & 9.3 & 104.24 & 2.974 & 3.752 & 1.13 & 4.04 & 0.68 & 4.7 & 2.72 & 0.41 \\
\hline
\end{tabular}

\begin{tabular}{|c|c|c|c|c|c|c|c|c|c|c|c|c|}
\hline & & & & & & & & & & & & \\
\hline Mineral & La & Ce & Nd & $\mathbf{Z r}$ & Hf & Sm & Eu & Gd & Tb & Dy & $\mathbf{Y b}$ & Lu \\
\hline Olivine & 0.008 & 0.0076 & 0.0061 & 0.0047 & 0.0038 & 0.0049 & 0.0052 & 0.0053 & 0.0051 & 0.0095 & 0.0468 & 0.009 \\
\hline Cpx & 0.0515 & 0.108 & 0.277 & 0.195 & 0.223 & 0.462 & 0.458 & 0.5954 & 0.61 & 0.711 & 0.633 & 0.623 \\
\hline Opx & 0.0008 & 0.0016 & 0.0056 & 0.032 & 0.06 & 0.015 & 0.03 & 0.034 & 0.054 & 0.077 & 0.22 & 0.22 \\
\hline Amph & 0.17 & 0.26 & 0.44 & 0.35 & 0.50 & 0.76 & 0.88 & 0.86 & 0.83 & 0.78 & 0.59 & 0.51 \\
\hline Plag & 0.0348 & 0.0278 & 0.0179 & 0.0094 & 0.0092 & 0.0132 & 0.0221 & 0.0125 & 0.06 & 0.0112 & 0.0155 & 0.012 \\
\hline Magnetite & 0.015 & 0.016 & 0.026 & 0.71 & 0.16 & 0.024 & 0.025 & 0.018 & 0.019 & 0.3 & 0.018 & 0.023 \\
\hline
\end{tabular}

Calc D

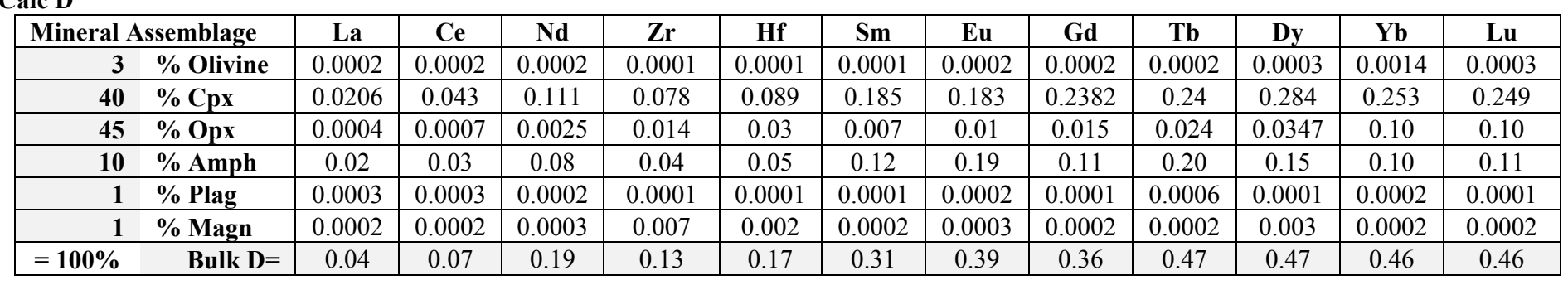

Calc $\mathrm{C}_{\mathrm{S}}=$

\begin{tabular}{|c|c|c|c|c|c|c|c|c|c|c|c|c|}
\hline $\mathbf{F}$ & La & Ce & Nd & Zr & Hf & Sm & Eu & Gd & Tb & Dy & Yb & Lu \\
\hline $\mathbf{0 . 0 5}$ & 73.78 & 183.31 & 104.98 & 1392.42 & 35.96 & 29.64 & 7.08 & 27.32 & 3.33 & 22.69 & 13.84 & 2.07 \\
\hline $\mathbf{0 . 1}$ & 37.87 & 96.52 & 59.92 & 764.36 & 20.20 & 18.37 & 4.63 & 17.56 & 2.31 & 15.76 & 9.50 & 1.43 \\
\hline $\mathbf{0 . 2}$ & 19.43 & 50.82 & 34.20 & 419.59 & 11.35 & 11.39 & 3.03 & 11.28 & 1.60 & 10.95 & 6.52 & 0.98 \\
\hline $\mathbf{0 . 3 5}$ & 11.34 & 30.28 & 21.74 & 258.55 & 7.12 & 7.74 & 2.15 & 7.89 & 1.19 & 8.16 & 4.81 & 0.72 \\
\hline $\mathbf{0 . 4}$ & 9.97 & 26.76 & 19.52 & 230.33 & 6.37 & 7.06 & 1.98 & 7.25 & 1.11 & 7.61 & 4.47 & 0.67 \\
\hline $\mathbf{0 . 6}$ & 6.75 & 18.39 & 14.06 & 162.18 & 4.55 & 5.34 & 1.55 & 5.60 & 0.89 & 6.15 & 3.59 & 0.54 \\
\hline $\mathbf{0 . 8}$ & 5.12 & 14.09 & 11.14 & 126.44 & 3.58 & 4.38 & 1.30 & 4.66 & 0.77 & 5.28 & 3.07 & 0.46 \\
\hline $\mathbf{1 . 0}$ & 4.13 & 11.46 & 9.30 & 104.24 & 2.97 & 3.75 & 1.13 & 4.04 & 0.68 & 4.70 & 2.72 & 0.41 \\
\hline
\end{tabular}


VITA

\section{JULIE ANN JOHNSON}

Born, Pittsburgh, Pennsylvania

1999-2003

B.S., Geoscience

Pennsylvania State University

State College, Pennsylvania

2003

$2^{\text {nd }}$ Place Geoscience Undergraduate Thesis in 2003

Department of Geoscience

Pennsylvania State University

State College, PA

2003-2006

Project Geologist

Griggs-Lang Consulting Geologists, Inc.

Troy, New York

$2009-2013$

Doctoral Candidate

Florida International University

Miami, Florida

$2009-2013$

Teaching Assistant

Florida International University

Miami, Florida

2013

April 2014

April 2014

Graduate Symposium Best Ph.D. Geosciences Presentation Department of Earth and Environment

Florida International University

Miami, Florida

2014 Ph.D. Geosciences recipient of the Award for Academic Excellence

Given by the College of Arts and Sciences

Florida International University

Miami, Florida

Best Geoscience Dissertation in 2013-2014

Department of Earth and Environment

Florida International University

Miami, Florida 


\section{PUBLICATIONS AND PRESENTATIONS}

Investigation of Temperature- and Pressure-dependence, and the Illitization of Smectite (2007) Earth Science Department Graduate Seminar, Florida International University, Miami, Florida, April 12, 2007.

Ohara, Y., Reagan, M., Bloomer, S., Fryer, P., Fuji, A., Hickey-Vargas, R., Imoto, H., Ishii, T., Ishizuka, O., Johnson, J., Michibayashi, K., Ribiero, J., Stern, R.J., Uehara, S. (2008) Studies of the Southern Izu-Bonin-Mariana (IBM) Forearc using Shinkai 6500: Watery Glimpses of an In Situ Forearc Ophiolite. Eos Transasctions AGU, 90(52), Poster V33A-2194, AGU annual Fall meeting, San Francisco, CA, December 14-18, 2008.

Geochronological and Geochemical Studies of Intrusive Igneous Rocks in the Southern Mariana Trench and Implications for Subduction-related Arc Development. (2009) Earth and Environment Department Seminar, Florida International University, April 16, 2009.

Johnson, J.A., Hickey-Vargas, R., Fryer, P. (2009) Studies of the Southern Mariana Trench and Recovery of Arc Crust. Program with Abstracts, INVEST technical workshop, Bremen, Germany, September 23-25, 2009.

Johnson, J.A., Hickey-Vargas, R., Fryer, P. (2009) Intrusive Rocks from the Southern Mariana Trench: Comparison with Volcanic Sequences of the Early Izu Bonin Mariana Arc. Eos Transactions AGU, 90(52), Poster T21A-1773, AGU Fall annual meeting, San Francisco, CA, December 14-18, 2009.

Johnson, J.A., Hickey-Vargas, R., Fryer, P. (2010) Middle Crustal Rocks from the Southern Mariana Trench - Relationship to Boninite and Tholeiitic Magma. Poster V33B-2370 presented at 2010 Fall Meeting, AGU, San Francisco, Calif., 13-17 Dec.

Mid-crustal rocks from the southern Mariana Trench: relationship to early volcanic sequences during subduction initiation. (2012) Verbal presentation at Department of Earth and Environment Graduate Symposium, Florida International University, Miami, Florida, April 11th, 2012.

Boninite-plutonics in the Mariana Trench: looking for equivalents in ophiolites. (2013) Verbal presentation at Department of Earth and Environment Graduate Symposium, Florida International University, Miami, Florida, February 15th, 2013.

Johnson, J. A., R. Hickey-Vargas, P. Fryer, V. Salters, and M. K. Reagan (2014), Geochemical and isotopic study of a plutonic suite and related early volcanic sequences in the southern Mariana forearc, Geochem. Geophys. Geosyst., 15, doi:10.1002/ $2013 \mathrm{GC} 005053$. 